\title{
THE ECONOMICS OF THE NUCLEAR FUEL CYCLE
}

Nuclear Energy Agency

Organisation for Economic Co-operation and Development 


\section{ORGANISATION FOR ECONOMIC CO-OPERATION AND DEVELOPMENT}

Pursuant to Article 1 of the Convention signed in Paris on 14th December 1960, and which came into force on 30th September 1961, the Organisation for Economic Co-operation and Development (OECD) shall promote policies designed:

- to achieve the highest sustainable economic growth and employment and a rising standard of living in Member countries, while maintaining financial stability, and thus to contribute to the development of the world economy;

- to contribute to sound economic expansion in Member as well as non-member countries in the process of economic development; and

- $\quad$ to contribute to the expansion of world trade on a multilateral, non-discriminatory basis in accordance with international obligations.

The original Member countries of the OECD are Austria, Belgium, Canada, Denmark, France, Germany, Greece, Iceland, Ireland, Italy, Luxembourg, the Netherlands, Norway, Portugal, Spain, Sweden, Switzerland, Turkey, the United Kingdom and the United States. The following countries became Members subsequently through accession at the dates indicated hereafter: Japan (28th April 1964), Finland (28th January 1969), Australia (7th June 1971), New Zealand (29th May 1973), Mexico (18th May 1994), the Czech Republic (21st December 1995), Hungary (7th May 1996), Poland (22nd November 1996) and the Republic of Korea (12th December 1996). The Commission of the European Communities takes part in the work of the OECD (Article 13 of the OECD Convention).

\section{NUCLEAR ENERGY AGENCY}

The OECD Nuclear Energy Agency (NEA) was established on 1st February 1958 under the name of the OEEC European Nuclear Energy Agency. It received its present designation on 20th April 1972, when Japan became its first non-European full Member. NEA membership today consists of 27 OECD Member countries: Australia, Austria, Belgium, Canada, Czech Republic, Denmark, Finland, France, Germany, Greece, Hungary, Iceland, Ireland, Italy, Japan, Luxembourg, Mexico, the Netherlands, Norway, Portugal, Republic of Korea, Spain, Sweden, Switzerland, Turkey, the United Kingdom and the United States. The Commission of the European Communities also takes part in the work of the Agency.

The mission of the NEA is:

- $\quad$ to assist its Member countries in maintaining and further developing, through international co-operation, the scientific, technological and legal bases required for a safe, environmentally friendly and economical use of nuclear energy for peaceful purposes, as well as

- to provide authoritative assessments and to forge common understandings on key issues, as input to government decisions on nuclear energy policy and to broader OECD policy analyses in areas such as energy and sustainable development.

Specific areas of competence of the NEA include safety and regulation of nuclear activities, radioactive waste management, radiological protection, nuclear science, economic and technical analyses of the nuclear fuel cycle, nuclear law and liability, and public information. The NEA Data Bank provides nuclear data and computer program services for participating countries.

In these and related tasks, the NEA works in close collaboration with the International Atomic Energy Agency in Vienna, with which it has a Co-operation Agreement, as well as with other international organisations in the nuclear field.

\section{(C) OECD 1994}

Permission to reproduce a portion of this work for non-commercial purposes or classroom use should be obtained through the Centre français d'exploitation du droit de copie (CCF), 20, rue des Grands-Augustins, 75006 Paris, France, Tel. (33-1) 44074770 , Fax (33-1) 46 34 67 19, for every country except the United States. In the United States permission should be obtained through the Copyright Clearance Center, Customer Service, (508)750-8400, 222 Rosewood Drive, Danvers, MA 01923, USA, or CCC Online: http://www.copyright.com/. All other applications for permission to reproduce or translate all or part of this book should be made to OECD Publications, 2, rue André-Pascal, 75775 Paris Cedex 16, France. 


\section{FOREWORD}

This subject was first studied by the NEA in 1983. Since then there have been significant developments in relevant technologies and associated costs. The NEA's Committee for Technical and Economic Studies on Nuclear Development and the Fuel Cycle (NDC) therefore believed it worthwhile to convene an ad hoc expert group to re-appraise this topic.

Experts from fourteen OECD countries and four international organisations participated in the working group; a full list is provided in Annex 12. This report has been prepared by the members of the expert group and is published under the responsibility of the Secretary-General of the OECD. It does not, however, necessarily represent the views of participating countries or international organisations.

\section{ACKNOWLEDGEMENTS}

The help provided by Messrs. K. Aratani, H. Mori and K. Ono of the Power Reactor and Nuclear Fuel Development Corporation (PNC), Japan, in performing calculations for this study is gratefully acknowledged. Thanks are also due to Miss T. Brydon of Nuclear Electric, United Kingdom, for valuable assistance in preparing material for the report. 



\section{CONTENTS}

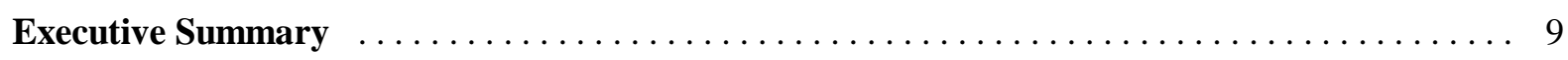

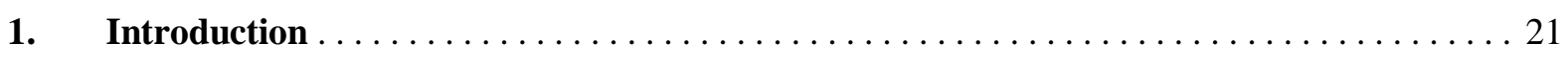

2. Methodology and common assumptions $\ldots \ldots \ldots \ldots \ldots \ldots \ldots \ldots \ldots \ldots \ldots \ldots$

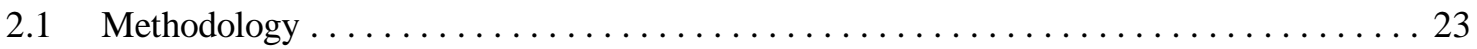

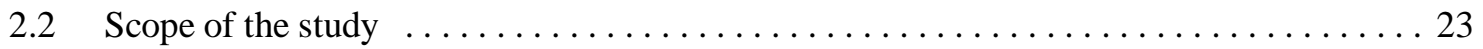

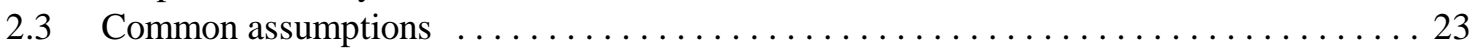

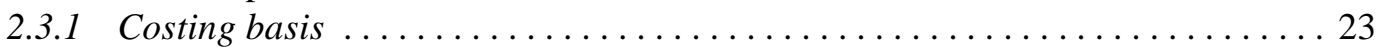

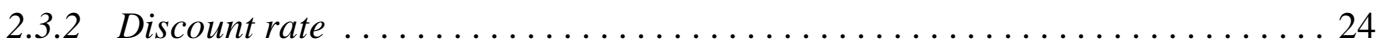

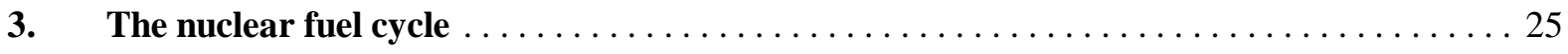

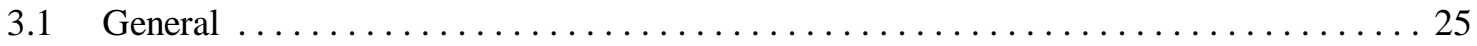

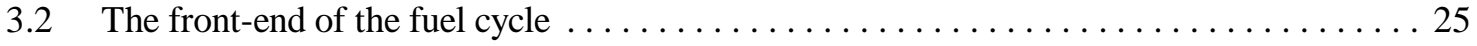

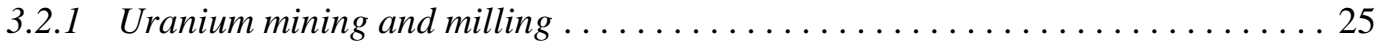

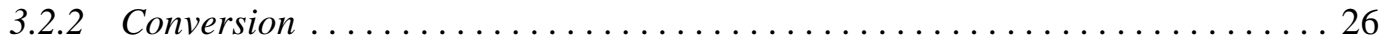

3.2.3 Enrichment ................................... 26

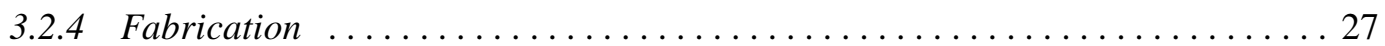

3.2.5 Wastes arising in the front-end of the fuel cycle $\ldots \ldots \ldots \ldots \ldots \ldots \ldots 27$

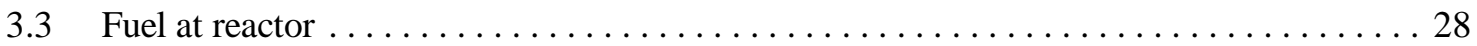

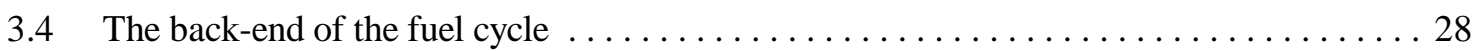

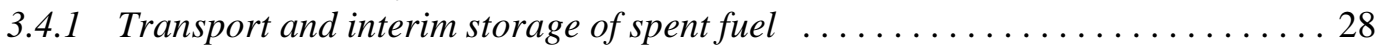

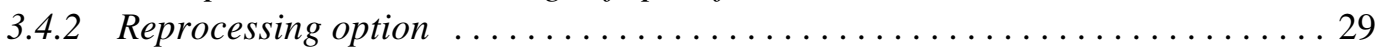

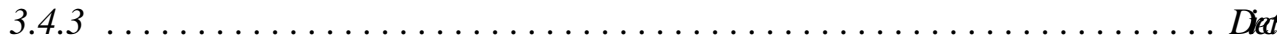

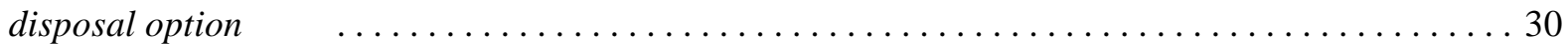

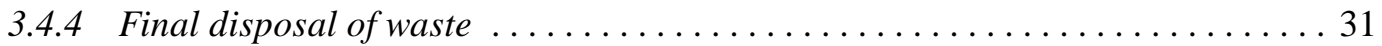

3.4 .5

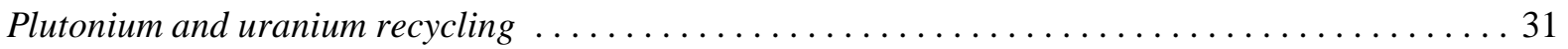

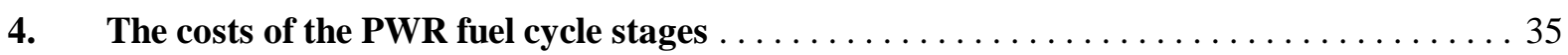

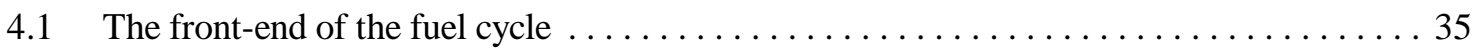

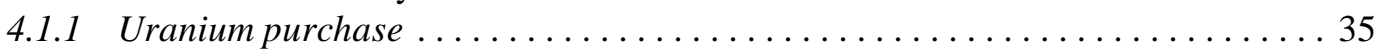

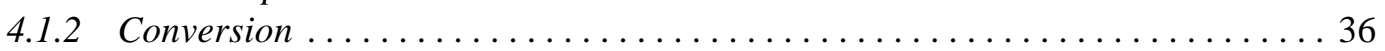

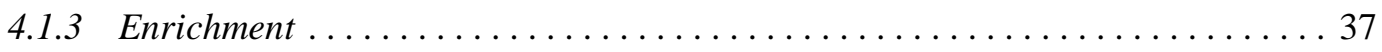

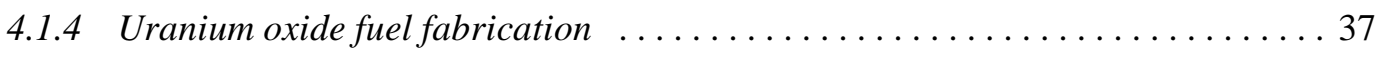




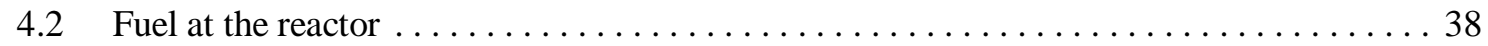

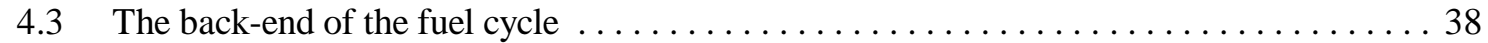

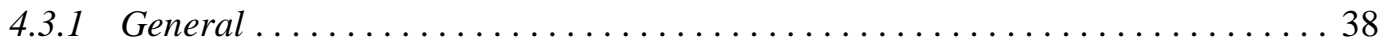

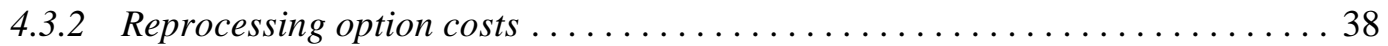

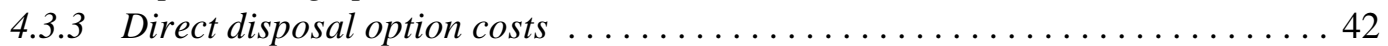

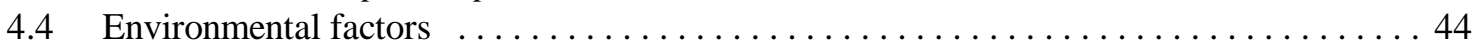

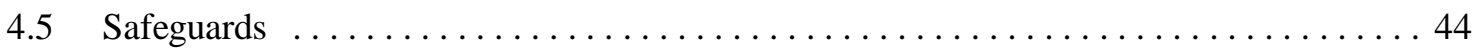

5. The calculation of total fuel costs for $P W R \ldots \ldots \ldots \ldots \ldots \ldots \ldots \ldots \ldots \ldots$

5.1 Principles of assembling stage costs into overall

fuel cost . . . . . . . . . . . . . . . . . . . . . . . . . . 47

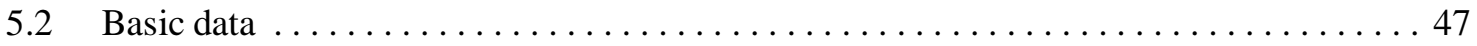

5.2.1 Choice of reactor parameters and base date . . . . . . . . . . . . . . . 47

5.2 .2 Tails assay for enrichment ........................... 48

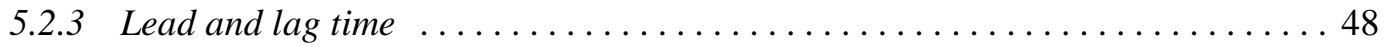

5.2 .4 Loss factor .................................... 48

5.2 .5 Unit price assumptions ............................ 48

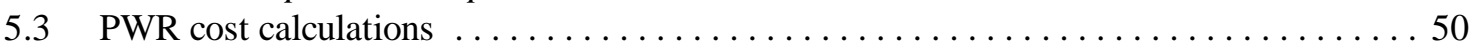

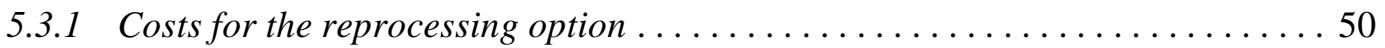

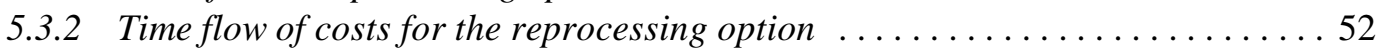

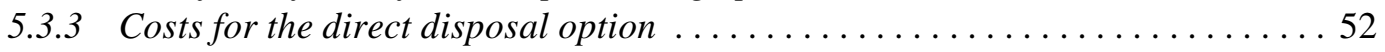

5.3 .4 Time flow of costs for the direct disposal option ................ 52

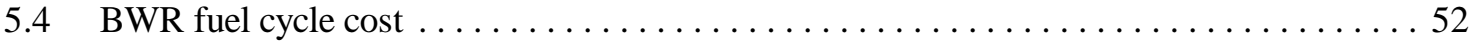

6. Sensitivity analyses for $P W R$ fuel $\operatorname{costs} \ldots \ldots \ldots \ldots \ldots \ldots \ldots \ldots \ldots \ldots \ldots \ldots$

6.1 General ........................................... 59

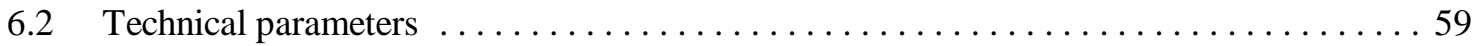

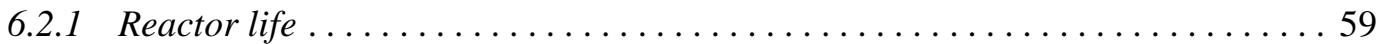

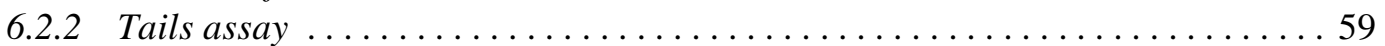

6.2 .3 Burn-up ......................................... 59

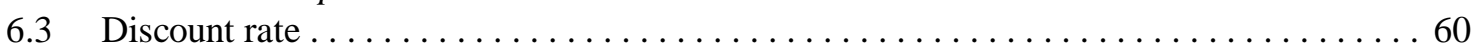

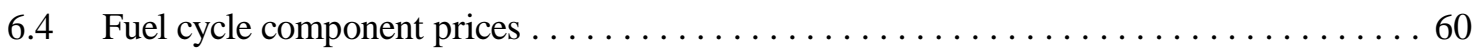

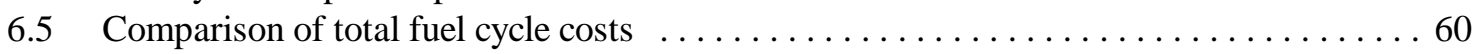

6.6 Likely range of total fuel cycle costs $\ldots \ldots \ldots \ldots \ldots \ldots \ldots \ldots \ldots \ldots \ldots \ldots \ldots \ldots \ldots \ldots \ldots \ldots$

\section{Comparison between the results of the present}

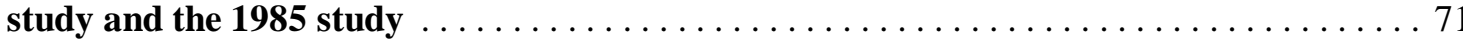

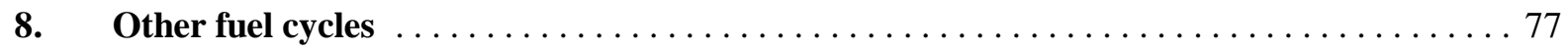

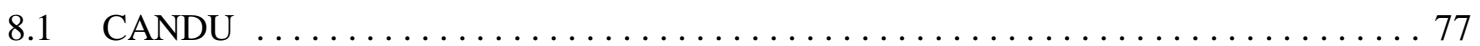

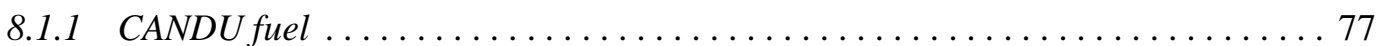

8.1 .2 Basic assumptions . . . . . . . . . . . . . . . . . . . . . . 77

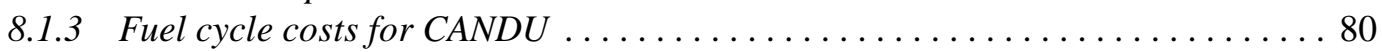




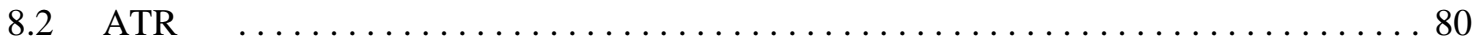

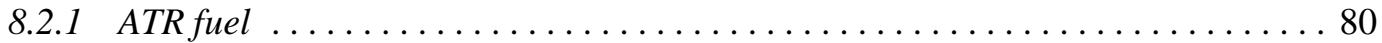

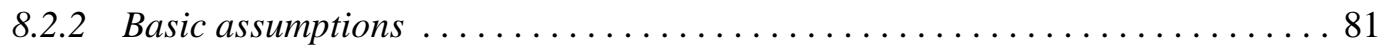

$8.2 .3 \quad$ Fuel cycle costs for ATR $\ldots \ldots \ldots \ldots \ldots \ldots \ldots \ldots \ldots \ldots \ldots \ldots \ldots \ldots \ldots$

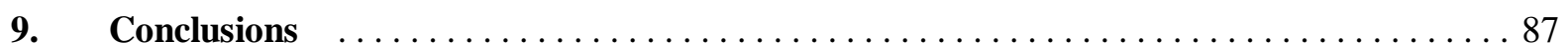

10. $\quad$ References $\ldots \ldots \ldots \ldots \ldots \ldots \ldots \ldots \ldots \ldots \ldots \ldots \ldots \ldots \ldots \ldots$
ANNEXES
1. Method of calculating a levelised price and a fuel cycle cost $\ldots \ldots \ldots \ldots \ldots \ldots \ldots \ldots 9$
2. Comparison between investment appraisal and financial appraisal . . . . . . . . . . . 99

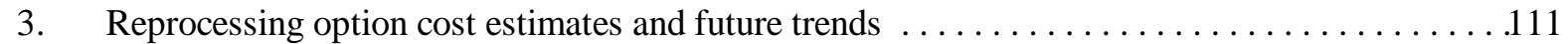
4. Direct disposal option cost estimates and future trends:
Sweden $($ reference $)$. . . . . . . . . . . . . . . . . . . . . . . . . . . . . . . . . . . . 123

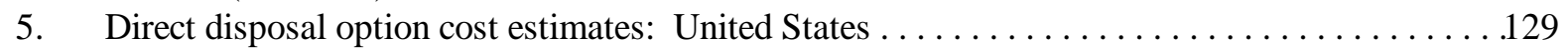

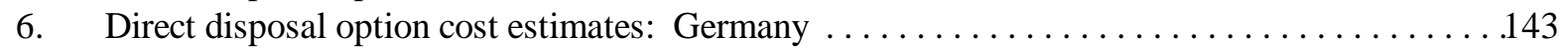

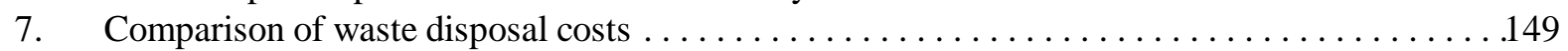

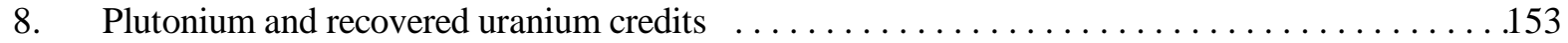

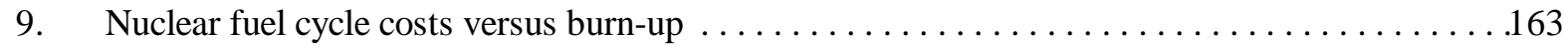

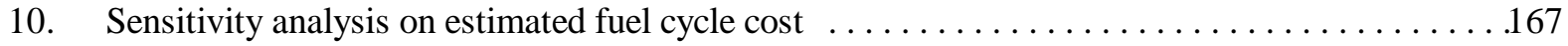

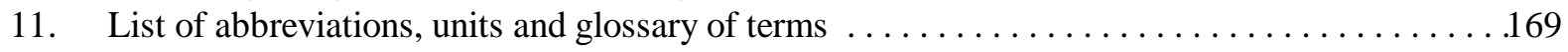
12. List of members of the expert group and the

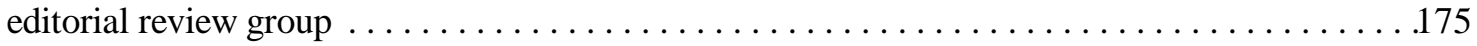





\section{EXECUTIVE SUMMARY}

\section{OVERVIEW}

The results of this study show that a 40 per cent real terms reduction has occurred in projected fuel cycle costs for a large PWR since the previous OECD/NEA study undertaken in the early 1980s. This reduction is due to major reductions in the projected prices for the uranium and enrichment components and reductions in the prices for back-end services. Improved fuel and reactor performance contribute further to the reduction.

The results indicate that there is a small cost difference between the prompt reprocessing option compared with the long-term storage and direct disposal option. Based on best estimate data, the reference cases show a difference of approximately 10 per cent of the total nuclear fuel cycle cost, the cost of the direct disposal option being lower. In light of the underlying cost uncertainties, this small cost difference between the reprocessing and direct disposal options is considered to be insignificant, and in any event, represents a negligible difference in overall generating cost terms. It is likely that considerations of national energy strategy including reactor type, environmental impact, balance of payments and public acceptability will play a more important role in deciding a fuel cycle policy than the small economic difference identified.

A contemporary OECD/NEA study on the projected costs of generating electricity shows that for nuclear stations the proportion of the total generating cost taken up by the fuel component is, typically, 15-25 per cent at 5 per cent real discount rate. This is in contrast to fossil-fuelled generation where coal represents, typically, 40-60 per cent of the total cost and, typically, 70-80 per cent in the case of gas. Clearly, nuclear generation costs are far less sensitive to fuel price volatility compared with the fossil-fuelled alternatives.

\section{Introduction}

In early 1991, an expert group, with a membership drawn from fourteen countries and four international organisations, was formed to examine the economics of the fuel cycle with particular reference to a power station comprising a pressurised water reactor (PWR) commissioning in the year 2000. The expert group finalised its report at the end of 1993.

\section{Study objective}

The task of the expert group was to update the OECD/NEA 1983/84 study which was published in 1985. That study defined the levelised lifetime fuel cycle cost using internationally accepted investment appraisal methodology. Costs were derived for fuel cycles based on reprocessing and on long-term spent fuel storage followed by direct disposal. 
The current study repeats that approach. Use of a 5 per cent reference case discount rate is still considered appropriate in reflecting the consensus of national practices. It also enables direct comparison to be made with previous results. Variations due to the use of different discount rates are also given.

\section{Power station parameters}

The reference reactor for the study is a French N4 type with a thermal output of 4020 MW giving an electrical output of $1390 \mathrm{MW}$. The power station is assumed to operate for 30 years with a levelised load factor of 75 per cent. The fuel costs were calculated for a four batch fuel cycle with annual refuels, the fuel being discharged at an average burn-up of $42.5 \mathrm{GWd} / \mathrm{tU}$.

Experience shows that similar fuel cycle costs will be associated with a boiling water reactor (BWR) of similar size, commissioning and operating over comparable timescales. Fuel costs for the Canadian CANDU reactor and the Japanese ATR were also considered; they are reported in Chapter 8 but are not included in this summary.

\section{Fuel cycle cost}

\subsection{General}

The operations associated with the nuclear fuel cycle and the management of the corresponding waste typically extend over a period of between 50 to 100 years, from mining the uranium ore to finally disposing of the high level waste. The entire fuel cycle and its components are shown in Figure S.1. The overall fuel cycle cost comprises the aggregation of a series of prices for each of the fuel cycle components. Thus, it may be seen that the resulting fuel cycle cost covers all expenditure and liabilities in a comprehensive manner.

\subsection{Front-end components and prices}

The front-end of the fuel cycle consists of four stages: uranium purchase; conversion to uranium hexafluoride; enrichment; and fabrication. Relative to the date the fuel is loaded into the reactor, the lead time assumed for these components is $24,18,12$ and 6 months, respectively.

A projection of prices for each of these components was derived from a survey of each expert group member's perception of future world market prices for term contracts. The study typically took the central value of the range that resulted from individual member inputs. All inputs were given in constant 1991 money value. The resulting values which were then used to calculate the reference fuel cycle cost are shown in Table S.1. 
Table S.1. Front-end component unit prices

(Reference case)

\begin{tabular}{||l|c||}
\hline Component & Price \\
\hline Uranium purchase & $\$ 50 / \mathrm{kg} \mathrm{U}$ (in 1990) \\
& $\left(\$ 19.2 / \mathrm{lb} \mathrm{U}_{3} 0_{8}\right)$ \\
& increasing at $1.2 \%$ p.a. \\
& in real terms \\
Conversion & $\$ 8 / \mathrm{kg} \mathrm{U}$ \\
Enrichment & $\$ 110 / \mathrm{SWU}$ \\
Fabrication & $\$ 275 / \mathrm{kg} \mathrm{U}$ \\
\hline
\end{tabular}

\subsection{Back-end components and prices}

Two back-end options were considered in the study. The first was based on prompt reprocessing of the spent fuel and the recycle of recovered uranium and plutonium. The basic cost estimates used were supplied by BNFL who, in conjunction with COGEMA, indicated future expected trends. These estimates assumed that the fuel would be reprocessed in a newly constructed plant. In costing this plant, the experience gained from the design, construction and operation of the latest reprocessing plants of THORP at Sellafield, and UP3 at La Hague, has been taken into consideration.

The second option was based on long term storage followed by direct disposal. Cost estimates developed by the SKB company in Sweden were used as the reference case.

The timing of spent fuel deliveries from the power station and all subsequent processes for both options are shown in Figure S.2. Unit prices at the time of delivery were derived using cost estimates and the reference 5 per cent p.a. discount rate.

To enable a proper comparison of the costs of the reprocessing and direct disposal options, the associated prices were derived in a comparable way using the ECU monetary unit and the assumption that the service provider obtains a 5 per cent real rate of return on capital employed.

The resulting reference 5 per cent levelised unit prices at the time of delivery derived for the two options are shown in Table S.2.

\section{Reprocessing option}

Reprocessing is available on a competitive world market; the main suppliers being European based. For this reason back-end prices were given in ECU. A long-term exchange rate of $1 \mathrm{ECU}=1 \mathrm{US}$ dollar was assumed. Reprocessing requires the use of large chemical plants with relatively large throughputs. Such plants are able to deal with the spent fuel from a large number of reactors, typically, 20-30 PWRs of the size considered in the study. Using cost estimates, unit prices were derived for reprocessing (which encompassed the associated spent fuel receipt, the waste conditioning/storage services and low and intermediate level waste disposal) and for the disposal of the vitrified high level waste (VHLW). 


\section{Direct disposal option}

Direct disposal services are not currently available on the world market; each individual country pursues its own approach. This is influenced by the final stage, the disposal of the conditioned spent fuel.

Using cost estimates supplied by SKB, unit prices were derived for the transport and storage and for the encapsulation and disposal stages of the direct disposal option.

Table S.2. Back-end service unit prices

(Reference case)

\begin{tabular}{|c|c|}
\hline Service & Price \\
\hline Option: Reprocessing & \\
\hline Transport (within European area) & ECU 50/kg U \\
\hline Reprocessing (includes all & \\
\hline processes except VHLW disposal) & ECU 720/kg U \\
\hline VHLW disposal & ECU 90/kg U \\
\hline Option: Direct disposal & \\
\hline Transport/Storage & ECU $230 / \mathrm{kg} \mathrm{U}$ \\
\hline Encapsulation/Disposal & ECU $610 / \mathrm{kg} \mathrm{U}$ \\
\hline
\end{tabular}

$\begin{aligned} \text { Notes: } & -\mathrm{kg} \mathrm{U} \text { refers to the mass of uranium in the fuel prior to irradiation. } \\ & -\quad \text { The above prices reflect discounting to appropriate delivery timing and as such } \\ & \text { they are not directly additive. }\end{aligned}$

\subsection{Environmental factors}

Fuel cycle costs take full account of the investment and operating experience in meeting the strict regulatory requirements for environmental protection and public safety. They cover all expected costs over the 50 to 100 year period of the entire nuclear fuel cycle. Other non-nuclear forms of electricity generation have their own environmental impact which is the subject of studies being undertaken elsewhere.

\section{Methodology}

The investment appraisal method of deriving the lifetime levelised fuel cost requires the examination of the entire fuel cycle cash outflow based on component prices. The cash outflows are discounted to a base date using the selected discount rate which was set for the reference case at 5 per cent per annum (real). The levelised fuel cycle cost is derived in mills $/ \mathrm{kWh}$ terms by equating the net present value of the entire fuel cycle cost and the net present value of the total electrical output over the station lifetime, where both have been discounted to the same date. 


\section{Sensitivity analysis}

\subsection{Front-end}

A sensitivity analysis has been carried out with respect to lead times and unit prices. For lead times, an upper bound sensitivity was made by approximately doubling the reference lead times for uranium purchase, conversion, enrichment and fabrication. The sensitivity range for front-end service prices generally reflects the upper and lower bound values seen in the spread of perceptions given by members for future world market prices. The values used are shown in Table S.3.

Table S.3. Front-end component unit prices

(Sensitivity range)

\begin{tabular}{||l|c||}
\hline Component & Price sensitivity range \\
\hline Uranium purchase & $\$ 40-\$ 90 / \mathrm{kg} \mathrm{U}$ \\
& escalation $0 \% \mathrm{p} . \mathrm{a}$. \\
Conversion & $\$ 6-\$ 11 / \mathrm{kg} \mathrm{U}$ \\
Enrichment & $\$ 80-\$ 130 / \mathrm{SWU}$ \\
Fabrication & $\$ 200-\$ 350 / \mathrm{kg} \mathrm{U}$ \\
\hline
\end{tabular}

\subsection{Back-end}

\section{Reprocessing option}

The reference price relates to a new, as yet unbuilt plant, and so contains a degree of uncertainty. The capital estimates used are based on outturn costs related to design and construction knowledge gained through the THORP project. The prospect exists, however, that technology and design improvements will result from THORP and UP3 operation such that new plants will benefit and their costs will be reduced. The downside range in price that has been used for the sensitivity study takes this into account as well as anticipated process improvements leading to much reduced waste volumes. It does not cover major step changes in technology.

Based on the above factors, the reprocessing price range used for sensitivity purposes is ECU 540 to ECU 720 per $\mathrm{kg} \mathrm{U}$ as shown in Table S.4, i.e. a downside sensitivity of 25 per cent. The reference value of ECU 720 per $\mathrm{kg} \mathrm{U}$ is comparable to the post-baseload price currently on offer from BNFL and COGEMA.

The costs in the reprocessing option are partly offset by credits for the recycled uranium and plutonium; the derivation of these credits is explained in the main part of this report.

While reprocessing services are available on the world market, the disposal of the resulting wastes, particularly the vitrified high level waste (VHLW), will be the responsibility of the customers' country. A wide sensitivity range has been used for VHLW disposal. This reflects the different possible geologies involved, the different timescales envisaged and the different size of the national nuclear programmes giving rise to the high level wastes. The sensitivity range chosen is representative of the range of values provided by the individual countries involved in a separate OECD/NEA study on the cost of high-level waste disposal in geological repositories. Although the reference VHLW disposal price is at the lower bound of the range, 
this fuel cycle component makes a very small contribution to the overall, levelised fuel cost, and hence any distortion this introduces is negligibly small. A similar comment is applicable to the direct disposal option where the reference disposal price was towards the upper bound of the range.

\section{Direct disposal option}

The direct disposal option is country specific. The reference case uses the Swedish system that has been well developed by SKB who possess detailed costing information. The cost estimates include normal engineering and construction contingency allowances which can be seen as providing against upside risk. The costs for the reference case are based on the use of $100 \mathrm{~mm}$ thick solid copper canisters in which the fuel will be encapsulated and disposed. Alternative canister designs and process engineering improvements could lead to a 15 per cent reduction in the reference cost estimates.

However, noting that the direct disposal option is country specific, in coming to a view on the appropriate sensitivity range to be used, recognition was given to the results of cost estimates provided by Germany and the United States. This led to a much wider sensitivity range for the two main components of the option, as shown in Table S.4.

Table S.4. Back-end service unit prices

(Sensitivity range)

\begin{tabular}{|c|c|}
\hline Service & Price sensitivity range \\
\hline \multicolumn{2}{|l|}{ Option: Reprocessing } \\
\hline Transport (within European area) & ECU 20-ECU 80/kg U \\
\hline Reprocessing (includes all & \\
\hline processes except VHLW disposal) & ECU 540-ECU 720/kg U \\
\hline VHLW disposal & ECU 90-ECU 580/kg U \\
\hline \multicolumn{2}{|l|}{ Option: Direct disposal } \\
\hline Transport/Storage & ECU 60-ECU 290/kg U \\
\hline Encapsulation/Disposal & ECU 140-ECU 670/kg U \\
\hline
\end{tabular}

\subsection{Combination of sensitivities}

Sensitivity price ranges were derived for each fuel cycle component as shown above. In practice, the out-turn price for each component would be expected to lie within those ranges. Not all prices will be at the upside or downside extreme. Indeed, the nature of the fuel cycle allows management steps to be taken to ameliorate the effects of adverse price movements, for example, adjustment of tails assay to optimise the price of enriched uranium or increased fuel burn-up to reduce the costs of spent fuel management. 
A rectangular distribution of prices within each component range was assumed. A statistical analysis was used to combine a large number of samples. This resulted in fuel cycle cost ranges shown in the next section.

\section{Results}

Based on reference prices, the lifetime levelised fuel cycle cost for each option is:

- reprocessing option: $\quad 6.23 \mathrm{mills} / \mathrm{kWh}$;

- direct disposal option: $\quad 5.46 \mathrm{mills} / \mathrm{kWh}$.

Using the results of the above-mentioned statistical analysis and taking two standard deviations around the mean value, the following ranges are derived:

- reprocessing option:

5.17-7.06 mills/kWh;

- direct disposal option: $\quad 4.28-6.30 \mathrm{mills} / \mathrm{kWh}$.

Figures S.3 and S.4 show the sensitivity of the fuel cycle cost to changes in each component price over a wide range encompassing a doubling or halving of the reference prices used in the study. This will enable other values to be selected that the reader may consider more appropriate.

\section{Comparison with the 1985 NEA study}

Figures S.5 and S.6 show the results from the present study compared with those from the 1985 NEA study. A 40 per cent real term reduction in levelised fuel cycle cost has occurred. This is due to two main factors:

a) major reductions in the projected price for the uranium and enrichment components, and reductions in the price for back-end services; and

b) improved fuel and reactor performance.

\section{Conclusions}

A 40 per cent real term reduction in estimated lifetime levelised costs has occurred since the 1985 study. This reduction is due to improved fuel and reactor performance factors and reductions in the projected prices of certain fuel cycle components.

This study shows that the reference lifetime levelised fuel cycle cost for a large PWR power station commissioning around the turn of the century is expected to lie in the range 5.5 to $6.2 \mathrm{mills} / \mathrm{kWh}$ depending on the spent fuel management option used. It is considered unlikely that the fuel cycle cost will lie outside the range 4.3 to 7.1 mills $/ \mathrm{kWh}$. Similar fuel cycle costs would be expected for a comparable BWR power station. 
Figure S.1 The nuclear fuel cycle

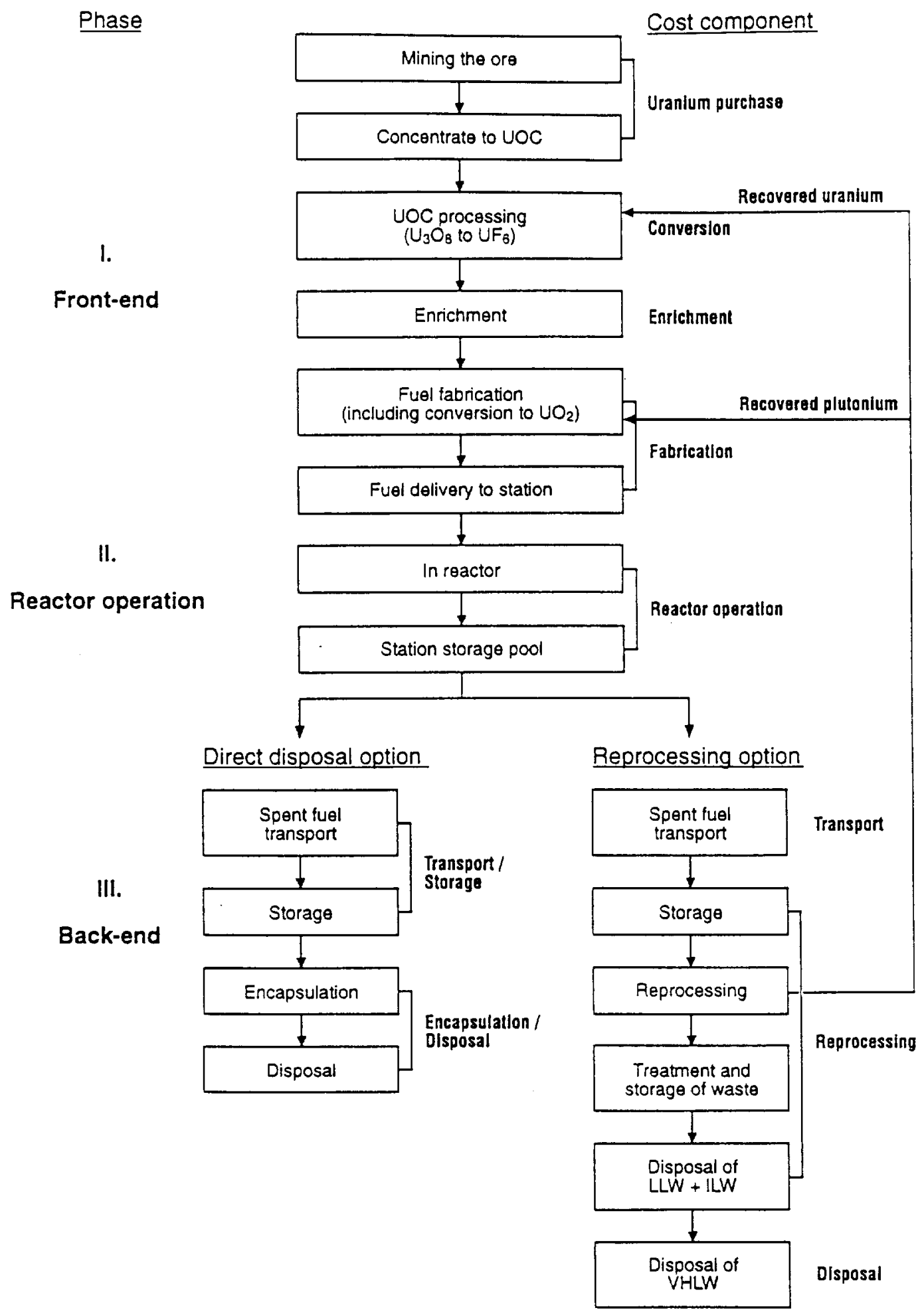


Figure S.2 Back-end options and operation timings

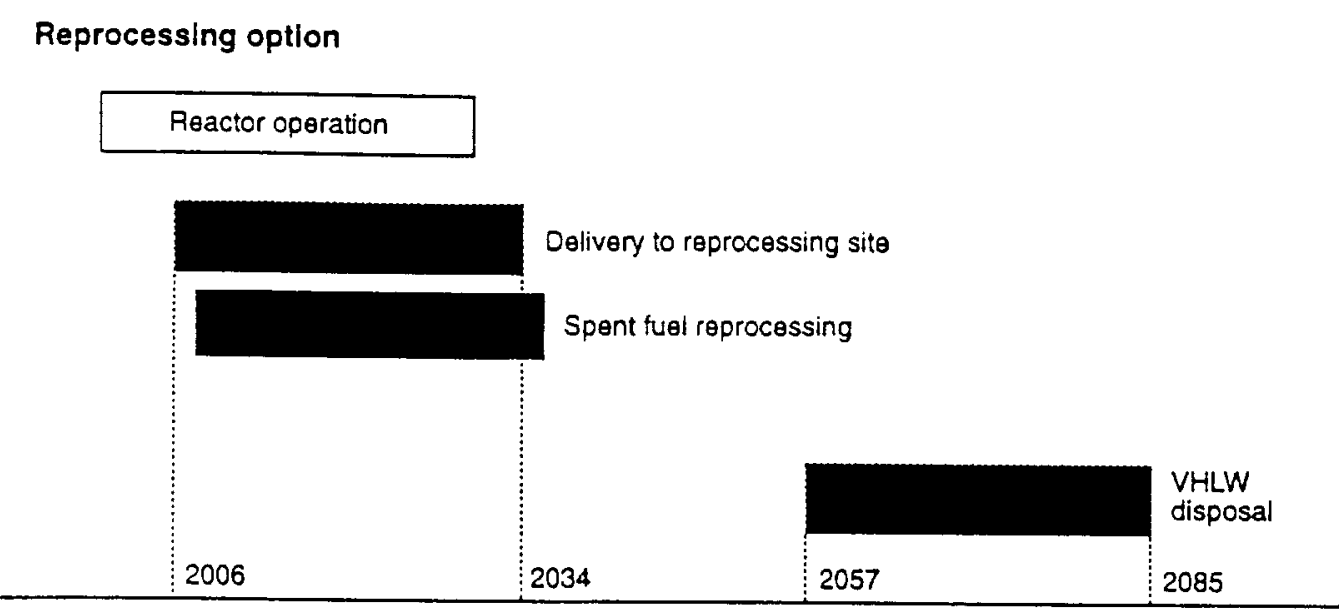

Direct disposal option

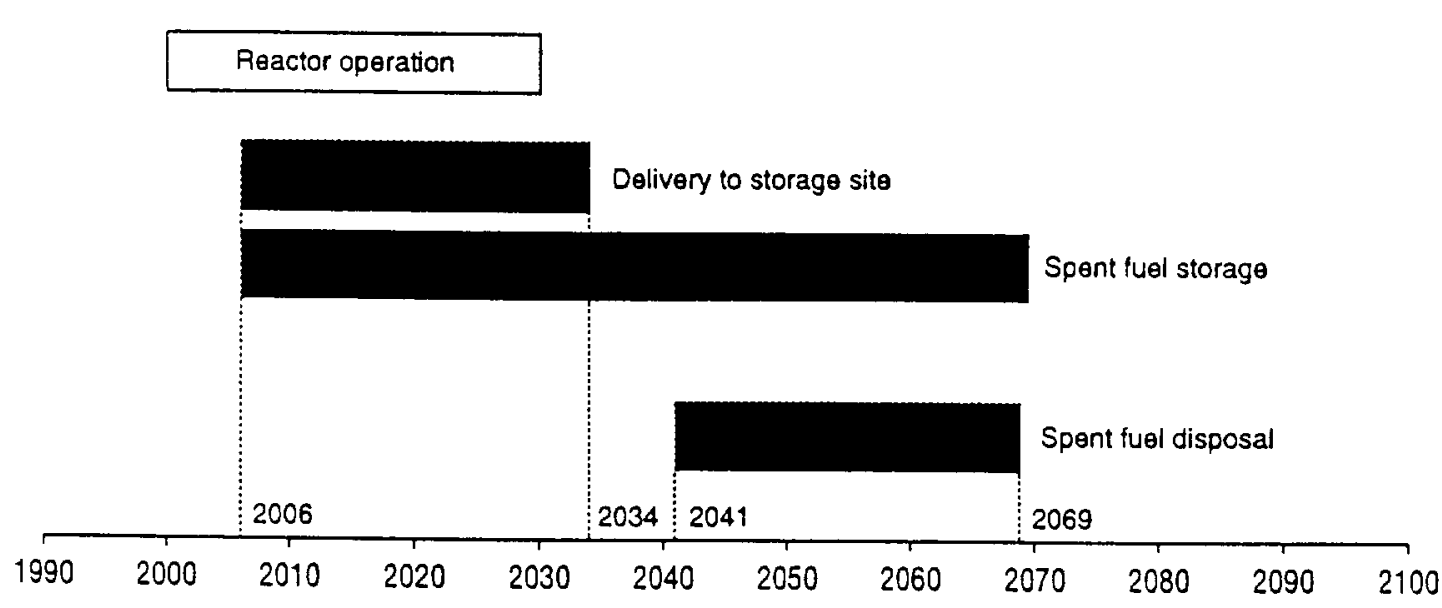


Figure S.3 Fuel cycle components - Sensitivity to price variations

(reprocessing option)

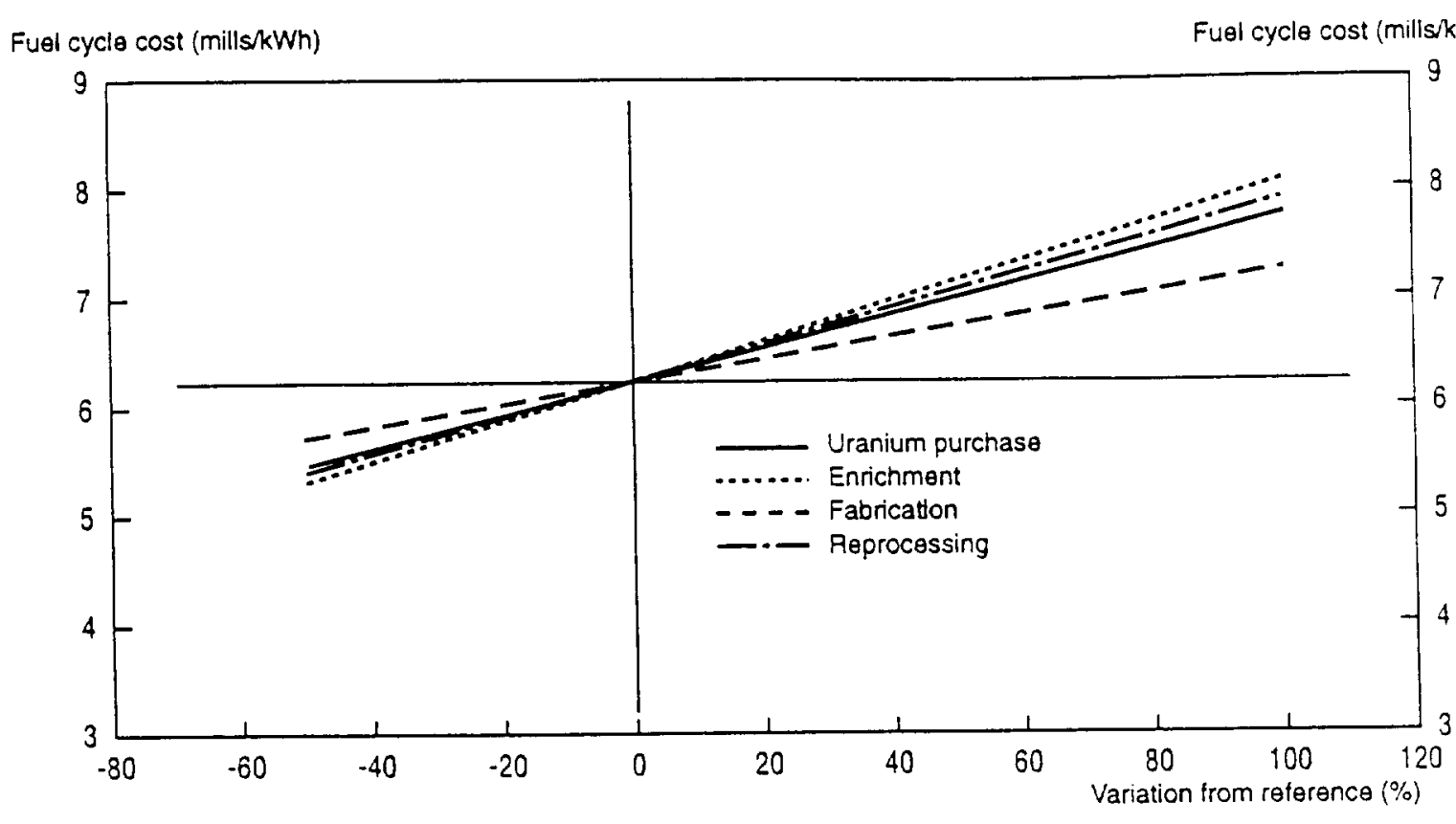

Figure S.4 Fuel cycle components - Sensitivity to price variations

(direct disposal option)

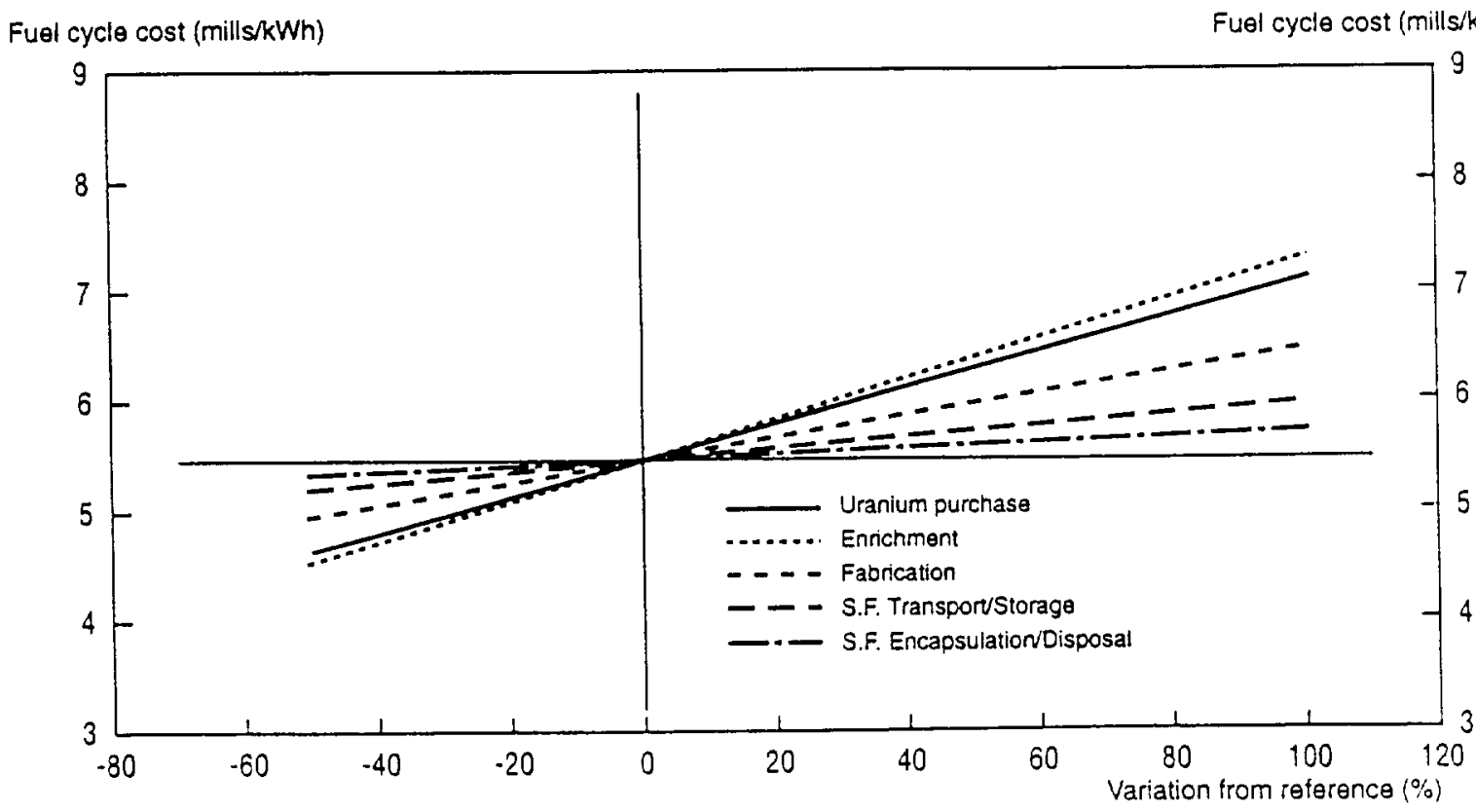


Figure S.5 Levelised lifetime PWR fuel cost

(reprocessing option)

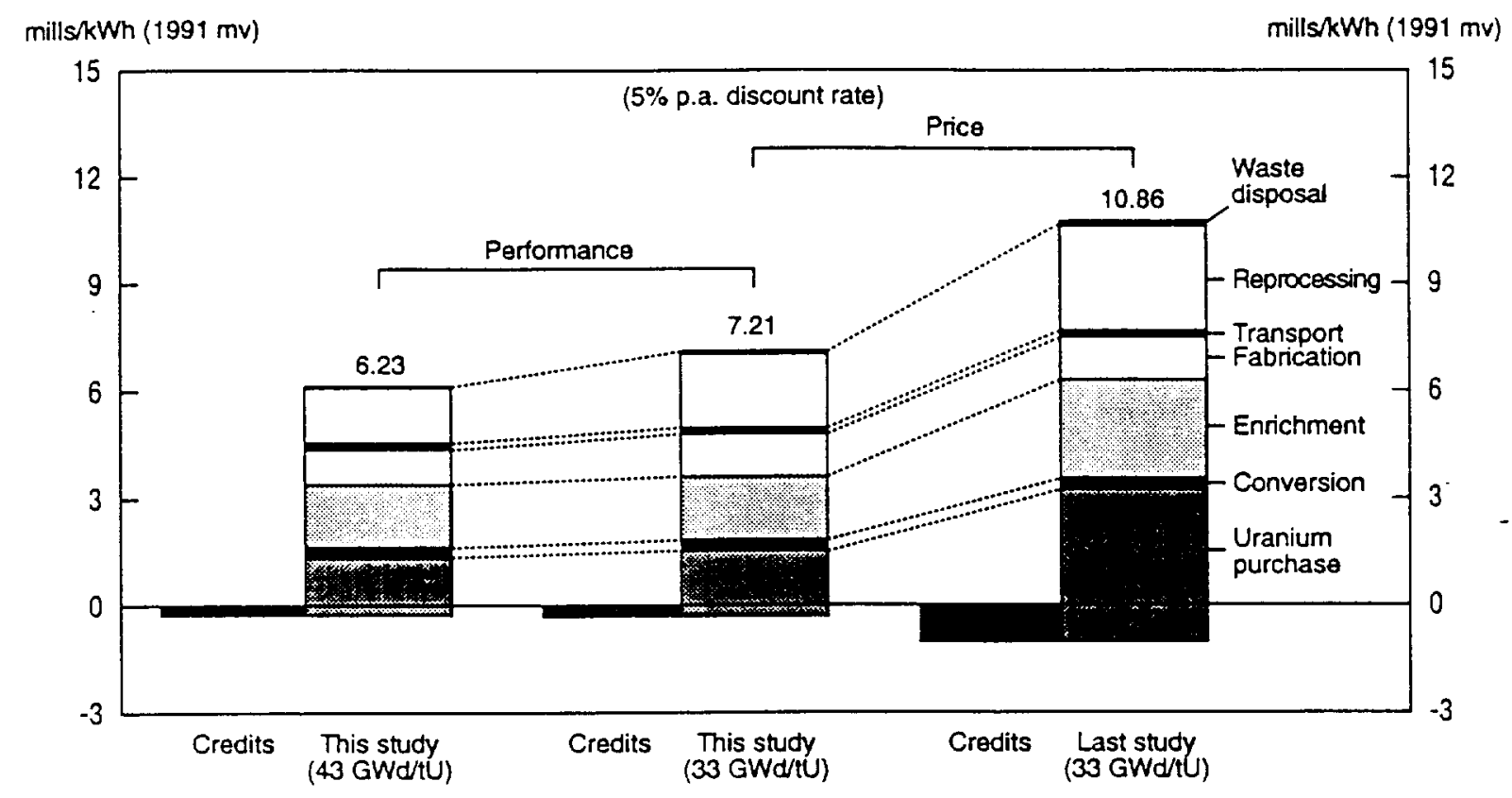

Figure S.6 Levelised lifetime PWR fuel cost

(direct disposal option)

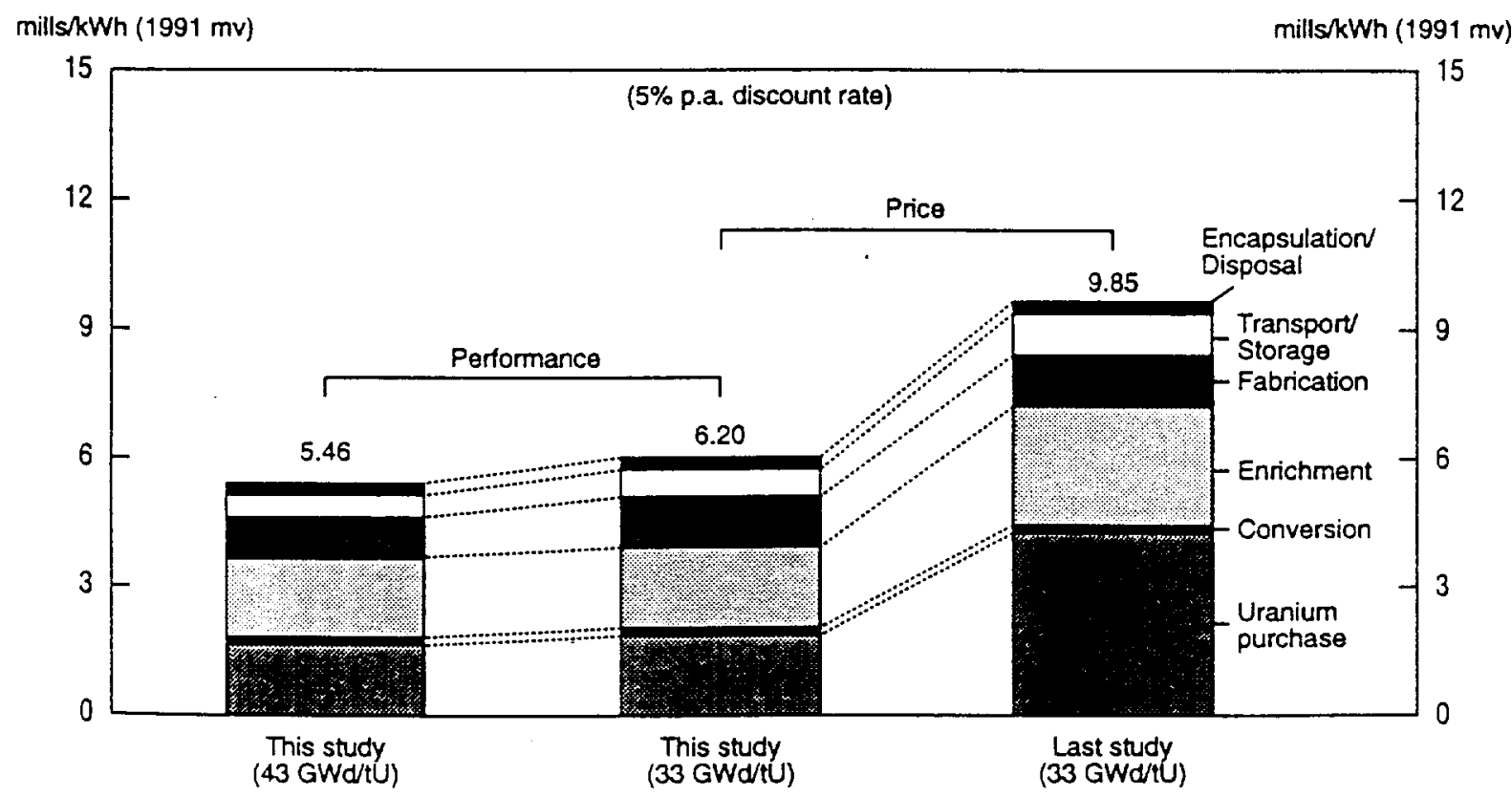





\section{INTRODUCTION}

In most OECD Member countries which are committed to nuclear power generation, the nuclear programmes are fairly stable resulting in nuclear electricity generation share figures of the order of 20 to 73 per cent. Construction of new power plants is currently infrequent and limited only to a small number of countries. This situation is not expected to change in the near future. However, the safety and operational record of the nuclear industry and current environmental and economic considerations underline the present and future importance of the nuclear power option. Nuclear fuel cycle choices and costs are, therefore, important in considering energy policies, fuel diversity, security of supply and the associated social and environmental impacts.

An OECD/NEA expert group, with a membership drawn from fourteen OECD countries, the CEC, the IAEA and the IEA, has examined in detail the projected costs of the various stages of the nuclear fuel cycle for pressurised water reactors, considering both the reprocessing and the direct disposal options.

The following countries were represented at the expert group meetings: Australia, Belgium, Canada, Finland, France, Germany, Italy, Japan, Netherlands, Spain, Sweden, Switzerland, United Kingdom and United States. The list of group members is given in Annex 12. The expert group was chaired by Mr. D. J. Groom.

The NEA has been carrying out a number of studies concerning the economics of nuclear power. Electricity generation cost studies ${ }^{(1,2,3,4)}$ were published in 1983, 1986, 1989 and 1993. Since quantities of plutonium, both in spent thermal reactor fuel and as separated material recovered by fuel reprocessing, have been increasing for the past 30 years and will continue to increase in the future, at least in the short-term, interest is being shown in the use of MOX fuel, which led to the publication of the 1989 NEA study: Plutonium Fuel - An Assessment ${ }^{(5)}$. The NEA has also recently published a report on the costs of disposal of high level waste into deep geological repositories ${ }^{(6)}$, the results of that report are compared with values used in this study.

The present study, which is an update of the 1985 OECD/NEA study on The Economics of the Nuclear Fuel Cycle $e^{(7)}$ presents in a clear and concise way estimates of the prices utilities expect to pay for the different components of the fuel cycle for a typical PWR coming into service at the turn of the century. Developments in the economics of the fuel cycle and improvements in plant technology and their role in reducing overall fuel costs are presented and discussed. It should be noted, however, that national fuel cycle strategies are not necessarily influenced solely by financial aspects; a number of other considerations such as national energy strategy including reactor type, environmental impact, balance of payments and public acceptability also play an important role in deciding a fuel cycle policy.

The nuclear fuel cycle can be divided into three stages: front-end, at-reactor and back-end. These, in turn, can be sub-divided into more specific components. The costs and current developments related to these components are presented, analysed and compared with those used in the 1985 study. 
Although a large, modern PWR has been taken as the reference plant for the study, the resulting fuel cycle costs are considered to be typical of those for a modern BWR. The fuel cycles and costs for the CANDU and ATR designs are also presented, although in less detail.

A competitive, diversified world market exists for uranium and front-end fuel cycle services. For the back-end, BNFL and COGEMA offer internationally commercial reprocessing services and some other countries have a limited, indigenous reprocessing capability. Nevertheless, a general feature of the back-end of the fuel cycle is that the onus is placed upon countries with nuclear power stations to provide disposal facilities for the resulting waste products, regardless of whether those products arise from reprocessing or from direct disposal of the spent fuel. In this study, the estimates of future reprocessing prices are in line with currently available contract prices, supported by cost data supplied by BNFL and future trend data from COGEMA. The estimates of direct disposal costs have been based primarily on data from Sweden with additional data from the United States and Germany to illustrate the effects of programme scale and timing. The use of mixed plutonium and uranium oxide fuel is discussed because of its importance in determining plutonium monetary values which may lead to plutonium credit in the reprocessing cycle. Similarly, the use of uranium fuel obtained by re-enrichment of the uranium recovered by reprocessing is also examined. 


\section{METHODOLOGY AND COMMON ASSUMPTIONS}

\subsection{Methodology}

The method adopted for calculating the fuel cycle costs in this study is the same, constant-money, levelised lifetime cost method which is fully described in the earlier NEA reports on generation and fuel cycle $\operatorname{costs}^{(1,2,3,4,5,7)}$ and is summarised in Annex 1.

The expert group gathered information on fuel cycle component prices, including expectations of future changes, and on other reactor and fuel cycle parameters, by means of a questionnaire which was circulated to the participating countries. The replies, supplemented by data from literature, were discussed and analysed by the group.

The fuel cycle costs calculated using this methodology will not necessarily appear consistent with figures presented in the financial accounts of utilities. However, the methodology used in this study will produce levelised economic resource costs which could be used to assist investment choices between generation or fuel cycle options. The distinction between "investment appraisal" and "financial appraisal" is discussed further in Annex 2.

\subsection{Scope of the study}

This study (like the 1985 study) focuses on the projected costs of the various stages of the fuel cycle for pressurised light water reactors (PWRs) commissioned in the year 2000 and considers both the direct disposal and the reprocessing options.

The monetary value attributed to the plutonium and uranium recovered from reprocessing is calculated in conformity with the method set out in the OECD/NEA report: Plutonium Fuel-An Assessment ${ }^{(5)}$. The fuel cycle for the mixed plutonium/uranium oxide (MOX) fuelled PWR has been examined only as far as necessary to set these values.

Briefer reviews of Canadian pressurised heavy water reactors (CANDU) and Japan's plutonium burning advanced thermal reactor (ATR) are also included.

\subsection{Common assumptions}

\subsubsection{Costing basis}

Countries provided price or cost estimates (early 1991 money value) either in US dollars (or in ECU) or in national currency with an appropriate exchange rate to allow conversion into US dollars. 
The basic data reflected prices of services or materials expected by the utilities for supply under term contracts. Front-end services and materials are usually given in US dollar prices; back-end (reprocessing) services are given in ECU to reflect the current European bias of the market.

In order to avoid long-term exchange rate uncertainties and for reasons of clarity, for the purposes of the study, the long-term exchange rate between US dollar and ECU is assumed to be one ECU per US dollar.

Price estimates for the various stages of the fuel cycle include costs for protecting the environment according to national and widely accepted international regulations and practices. Where appropriate all taxes in the producer country are included in the "market price" used.

\subsubsection{Discount rate}

In the 1985 study, a discount rate of 5 per cent p.a., in real terms, was adopted as the reference value; 0 and 10 per cent discount rates were assumed as parametric values. The expert group considered that the 5 per cent discount rate is still appropriate as the reference case. Based on country specific assumptions, a wider range of discount rates is used for parametric study purposes, namely: $0,2,8,10,12$ and 15 per cent. This enables the reader to select the value appropriate to individual country positions.

The significance of using a given discount rate in deriving a levelised price is explained in Annex 1; Annex 2 explains the significance from a financial appraisal point of view. In the recent past, given the economic situation in most OECD countries, the real interest rate has been over 5 per cent; over a long time span, however, this rate cannot be expected to be much different from the real growth of the economy in the OECD area, which is very likely to be less than 5 per cent. 


\section{THE NUCLEAR FUEL CYCLE}

\subsection{General}

The fuel cycle of a nuclear power plant can be divided into three main stages:

a) the so-called front-end which extends from the mining of uranium ore until the delivery of fabricated fuel elements to the reactor site;

b) fuel use in the reactor, where fission energy is employed to produce electricity, and temporary storage at the reactor site;

c) the so-called back-end, which starts with the shipping of spent fuel to away-from-reactor storage or to a reprocessing plant and ends with the final disposal of reprocessing VHLW or the encapsulated spent fuel itself.

Costs of the second stage, b), are not dealt with in this report, because they are conventionally covered under the capital or operating and maintenance costs of the nuclear power plant. For the analyses presented in this study, two PWR fuel cycle options are considered. The fuel cycle option in which the spent fuel from the reactor is reprocessed, to separate plutonium and remaining uranium from the wastes produced in the fission process, is identified as the reprocessing option. The second option, which is generally known as direct disposal, involves disposing of spent fuel following appropriate treatment after a period of, usually, long-term storage. Figures 3.1 and 3.2 illustrate the two fuel cycle options and also give an indication of the quantities of the material involved in the different stages, for each tonne of uranium fed into the study's reference reactor.

\subsection{The front-end of the fuel cycle}

\subsubsection{Uranium mining and milling}

Uranium is the fuel used in nearly all existing nuclear reactors. It is very widely distributed in the earth's crust and oceans, but can only be economically recovered where geological processes have locally increased its concentration. Almost all economically workable uranium-bearing ores have in the past typically contained less than 0.5 per cent of uranium, and in some cases ores were mined with grades as low as 400 parts per million. On the other hand, some uranium deposits exhibit uranium concentrations of several percent and the trend with new discoveries has been towards higher grades. The quantity, quality and geographical distribution of uranium resources are discussed in detail in regular OECD/NEA and IAEA publications ${ }^{(8)}$.

Uranium ore is mined either by conventional open-pit or underground mining methods and the uranium is extracted from the crushed ore in a processing plant (mill) using chemical methods appropriate to the specific mineral form. These usually extract some 85 to 95 per cent of the uranium present in the ore. The radioactivity of the separated uranium is very low. The radioactive daughter products are left with the mill tailings, stabilized and put back into the mine or otherwise disposed. 
In some cases it is possible to pass chemical solutions through the ore bodies and dissolve the uranium directly. This process is known as solution mining, or in-situ leaching. Uranium can also be recovered as a by-product of the extraction of other metals from their minerals, for example copper and gold, and as a by-product of phosphoric acid production from phosphate rocks. Solution mining has been increasingly used during recent times.

The uranium concentrate $\left(\mathrm{U}_{3} \mathrm{O}_{8}\right)$ produced in the ore processing plant is known as yellowcake and usually contains between 60 and 85 per cent uranium by weight. Depending on its quality, the concentrate is sometimes further purified in a refinery near the mine before being shipped in metal containers to a conversion plant.

\subsubsection{Conversion}

The high purity required for nuclear fuel is achieved by dissolving the uranium concentrate in nitric acid, filtering and treating the solution with chemical solvents. The resulting uranyl nitrate is more than 99.95 per cent pure.

The uranyl nitrate is reconverted to uranium oxide and this, in turn, is converted to readily volatile uranium hexafluoride $\left(\mathrm{UF}_{6}\right)$ which is used in the enrichment process. If enrichment is not required, for example for heavy water reactor fuel, then uranium dioxide $\left(\mathrm{UO}_{2}\right)$ is produced from the uranyl nitrate and shipped directly to a fuel fabrication plant.

\subsubsection{Enrichment}

Uranium occurring in nature consists largely of ${ }^{238} \mathrm{U}$ which acts predominantly as a neutron absorber. The fissile ${ }^{235} \mathrm{U}$, an isotope with a lighter atomic nucleus, occurs to the extent of only 0.71 per cent in natural uranium. Reactors such as the graphite moderated Magnox reactor and the heavy water cooled and moderated reactor (CANDU) are able to function with fuel containing only the naturally occurring proportion of ${ }^{235} \mathrm{U}$. Light water cooled and moderated reactors (LWR) as well as advanced gas-cooled reactors (AGR) contain a greater proportion of neutron absorbing materials and this has to be compensated for by increasing the concentration of the ${ }^{235} \mathrm{U}$ isotope in the fuel from 0.7 per cent to around 3 to 4 per cent.

Although the isotopes of a given element have identical chemical properties, the nuclei of their atoms have slightly different masses and these differences provide a means whereby a given element can be separated into portions containing different relative proportions of heavy and light isotopes. The process by which the concentration of the ${ }^{235} \mathrm{U}$ isotope is increased is known as enrichment.

The enrichment techniques generally involve separation in the gas phase hence the conversion to readily volatile uranium hexafluoride. This compound has the additional advantage that fluorine has only one isotope, so that molecular mass differences are entirely due to differences in the masses of the uranium atoms they contain.

Gaseous diffusion through porous membranes is the most widely used technique but a number of countries have installed gas centrifuges. An alternative process which may be used commercially in the future relies on separation in streams of gas flowing through specially-shaped nozzles.

Laser excitation techniques, in which advantage is taken of small differences in the light absorption characteristics of uranium atoms or their compounds, and enrichment through chemical processes, are being 
actively pursued in many laboratories. Laser enrichment and advanced gas centrifuge techniques are quite likely to be introduced within the timescale considered by this study. Their energy consumption is only a fraction of that required by the gaseous diffusion process.

After passing through the enrichment plant, the uranium hexafluoride has been separated into two fractions. The smaller of these is enriched in the ${ }^{235} \mathrm{U}$ isotope and is shipped to the fuel fabrication plant in metal cylinders with suitable precautions to guard against inadvertent criticality. The larger fraction (enrichment tails) is depleted in ${ }^{235} \mathrm{U}$ and is stored. It may be used in MOX fuel or in commercial breeder reactors in the future. Economic and technical changes may make the recovery of some of the residual 0.2 to 0.3 per cent ${ }^{235} \mathrm{U}$ contained in the tails worthwhile.

\subsubsection{Fabrication}

The enriched uranium hexafluoride is chemically converted to pure uranium dioxide powder which is then pressed into pellets and sintered in a furnace at high temperature to produce a dense ceramic fuel. The PWR fuel pellets are stacked together and then they are sealed in tubes of corrosion resistant zirconium alloy with a low neutron absorption. These loaded tubes, called fuel pins, are put together in a lattice of fixed geometry called a fuel assembly (289 pins per assembly for the study's reference reactor). A similar procedure is adopted for unenriched uranium oxide fuel for CANDU reactors and for the fuel for advanced gas-cooled reactors, although in the latter case stainless steel, which resists corrosion by the carbon dioxide reactor coolant, is used in place of zirconium alloy to contain the fuel pellets.

\subsubsection{Wastes arising in the front-end of the fuel cycle}

Uranium mining produces waste rock with a lower uranium content than that of the ore. Milling wastes include radium and other naturally occurring radioactive substances. These wastes are generally disposed of in engineered geological facilities which are covered on top and sealed underneath and on the sides in order to reduce radon emissions and the movement of ground water.

Wastes from the conversion process may contain uranium, acids and some organic chemicals. Some conversion facilities recycle such wastes to uranium mines in order to recover the uranium content while others directly dispose their waste.

Wastes arising from the uranium enrichment and fuel fabrication processes contain essentially small amounts of uranium and the associated naturally occurring radioactive elements.

Currently, the tails that result from the enrichment process (of fresh uranium or reprocessed uranium) are stored in the form of uranium hexafluoride, a high vapour pressure solid at ambient temperature. Later, these tails may be recycled in MOX fuel for thermal or fast reactors. Control and management of the fluorine gas and the $\mathrm{UF}_{6}$ tails poses a more difficult task than dealing with the radioactive waste products. To ensure even greater safety it is likely that $\mathrm{UF}_{6}$ tails will be converted to $\mathrm{U}_{3} \mathrm{O}_{8}$ powder form in future. 
During fuel fabrication, it is important to distinguish between scraps and wastes. Scraps are recycled through dry or wet routes (the latter allowing chemical purification). The volume of scraps usually represents a few per cent of the initial material. Wastes comprise contaminated materials; they arise in much greater volume but contain far lower quantities of initial materials than scraps and therefore are not recycled. In the case of $\mathrm{UO}_{2}$, the low radioactivity of the product allows a very simple management of both the scraps and the wastes.

Although uranium has a low radio-toxicity, the same is not true for plutonium. Thus, in the case of MOX fuel fabrication greater care has to be taken in the management of the wastes. The treatment of wastes in order to separate the plutonium and uranium, and the subsequent waste conditioning are fully mastered. A typical value for the quantity of plutonium finally present in wastes is 0.01 per cent of the initial plutonium.

\subsection{Fuel at reactor}

New fuel arriving at the reactor site is placed in a store designed to contain sufficient stock to cover the reactor operator's needs and to guard against any short term supply problems.

From the store, the fuel assemblies are transferred to the reactor and placed in the core where they remain for about three to five years, depending on the selected refuelling schedule. During this time, a proportion of the uranium atoms undergo fission to produce energy and fission products. In addition, plutonium is also produced from uranium atoms and is, in turn, partly fissioned ${ }^{(5)}$ in the reactor. As a consequence, the discharged fuel is highly radioactive and has to be heavily shielded. A typical PWR fuel assembly also generates, immediately after discharge, many hundreds of $\mathrm{kW}$ of heat from the radioactive decay of the fission products within the fuel. For these reasons it is normal practice to store the newly discharged PWR fuel assemblies in the reactor pool for at least a few years, to allow the radioactivity to decline naturally. Two meters of water above the fuel assemblies provides adequate protection against radiation; the water in the pool also acts as a good heat transfer medium.

In addition to the spent fuel, a reactor produces, during its normal operation, some liquid and solid wastes containing much lower levels of radioactivity. The costs of storing, treating and ultimately disposing of these wastes are relatively small and are regarded as operational costs rather than fuel cycle costs.

\subsection{The back-end of the fuel cycle}

\subsubsection{Transport and interim storage of spent fuel}

\subsubsection{Transport}

After a cooling period of a few years at the reactor site, the most highly radioactive fission products will have decayed and the rate of heat production from the spent fuel will have declined appreciably. Although the fuel assemblies are still highly radioactive and produce significant quantities of heat, safe transport of the spent fuel is now more readily accomplished. For transport the spent fuel is loaded into heavily shielded transport casks in which it is shipped to the interim storage facility or to the reprocessing plant. These transport casks, which provide cooling for the fuel elements and shielding for workers and the public against the emitted radiation, are designed to withstand transport crashes and fires so that the protection they afford would be maintained even in the event of a major accident.

\subsubsection{Interim storage}


The interim storage period is the time interval after the minimum cooling period following discharge from the reactor until reprocessing or spent fuel encapsulation prior to disposal. Interim storage of spent fuel could take place at the reactor site in cooling pools or in cask storage. In this case, storage costs are often an integral part of the power plant operating costs. Alternatively, it could take place at a separate interim storage site or in storage pools at the reprocessing site. In the latter case, interim storage costs are usually included in the reprocessing price.

A number of different approaches have been developed for interim storage in which the fuel assemblies, either intact or dismantled to reduce the volume they take up, are stored in cooling pools situated either on the reactor site or at separate sites. Additionally, dry stores have been developed in which the fuel assemblies, with or without pre-treatment and special packaging, can be safely held in either an air or inert gas atmosphere.

\subsubsection{Reprocessing option}

\subsubsection{Reprocessing}

Reprocessing involves dissolving the spent fuel to enable the re-usable plutonium and uranium content to be separated from the residual waste fission products and actinides. PWR spent fuel typically contains 1.15 per cent (by weight) plutonium, 94.3 per cent uranium and 4.55 per cent waste products. The separated uranium may then be re-enriched prior to re-use and the plutonium incorporated with MOX fuel. In this manner, about 30 per cent of the potential energy in the initial fuel can be re-utilised in thermal reactors and more if fast reactors were used.

Operations at the reprocessing plant are conducted remotely in facilities with adequate shielding to protect the workforce from the effects of radiation exposure. The fuel assemblies are chopped up and placed in nitric acid. This enables the fuel content, which dissolves in the acid, to be separated from the insoluble zirconium alloy or stainless steel cladding.

The solution of uranium, plutonium, other actinides and fission products is then chemically treated in a series of stages which are designed to produce solutions of plutonium nitrate and uranyl nitrate of high chemical purity. The waste products (other actinides, fission products and unwanted impurities) are stored as a highly radioactive solution in water cooled double-walled high integrity stainless steel tanks before further conditioning. The separate solutions of uranyl nitrate and plutonium nitrate are further processed. The uranium can be converted to uranium dioxide for storage or for the production of new fuel, by blending with fissile material or conversion to uranium hexafluoride for return to the enrichment plant. The plutonium nitrate is converted to plutonium dioxide for storage or for incorporation into mixed oxide fuels for thermal or fast reactors.

\subsubsection{Waste management}

Conditioning of the wastes produced by reprocessing is a well established operation that has been rigorously examined and approved by regulatory authorities in several countries. The removal of the plutonium and the uranium via reprocessing reduces the volume of high level waste, but leads to the production of low and intermediate level wastes (see below and Annex 3). Operating experience has been accompanied by a strong downward trend in the volume of wastes produced. In addition, there are important programmes in hand to further diminish these volumes. For instance, the volume of French wastes for deep 
disposal is expected to decrease from the current volume of 1400 1/tHM to a volume less than $4651 /$ tHM by around the year 2000 .

i) Process wastes

The process wastes are primarily fission products and actinides which represent about 99 per cent of the total radioactivity in spent fuel. These products have been vitrified on a commercial scale since 1978 . The volume of VHLW is only 115 1/tHM.

The second source of process wastes is hulls and end fittings. These wastes are embedded in cement and belong to the category of Intermediate Level Waste (ILW).

The operation of reprocessing plants results in the discharge to the environment, after appropriate treatment, of very low level airborne and liquid effluents arising from various process stages.

ii) Technological wastes

These are the wastes coming from the operation of the plant:

- used equipment and parts;

- degraded solvent;

- "trash bins" (gloves, etc.);

- metallic drums containing small contaminated parts.

They are either liquids or solids. Liquid wastes are concentrated and today embedded on line in bitumen (ILW) or are precipitated to form a solid waste. Solid wastes are either embedded in cement (ILW) or packaged in drums (LLW).

iii) Interim storage of wastes

In most countries, interim storage is also required for the wastes during the period between conditioning and final disposal. Specially constructed facilities already exist for this purpose.

\subsubsection{Direct disposal option}

\subsubsection{Encapsulation of spent fuel}

After removal from the reactor, the spent fuel will normally be stored in pools at the reactor site and then be transferred to an interim store.

Fuel assemblies may, after a period of cooling, which may be 30 to 50 years, be encapsulated directly or be disassembled using remote handling techniques so that the fuel pins can be packed together more closely prior to encapsulation. The encapsulation process involves placing the spent fuel in a canister of metal, such as copper, steel or titanium, or of ceramic material. After that the canister is tightened, e.g. by welding a lid. Intermediate storage and encapsulation results in $0.2 \mathrm{~m}^{3}$ of medium level waste per tonne of uranium. 
In both the reprocessing and the direct disposal options, disposal of the wastes arising at the front-end of the fuel cycle and from interim storage are included for costing purposes with the appropriate fuel cycle components.

\subsubsection{Reprocessing}

Following conditioning and, in most cases, interim storage for a number of decades to allow further reduction of radioactivity and heat generation, vitrified HLW, suitably encased, can be transported to and placed in a deep geological repository. Here, it can be held under supervision and, when considered appropriate, sealed off permanently. The glass matrix in which the highly radioactive wastes are incorporated, the method of encapsulation and the geological formation chosen to isolate the radioactivity from the biosphere, are carefully selected to ensure long term safety. disposal.

ILW fixed in a concrete or a bitumen matrix within a steel container can also be consigned to geological

Conditioned solid LLW is usually transported to shallow land burial sites or placed in geological repositories under carefully controlled and monitored conditions which seek to ensure that there is no risk of significant radiation exposure to any member of the general public. Very low level liquid wastes are discharged to the sea or to rivers. The level of liquid wastes discharged to the sea or rivers complies with stringently enforced regulations.

\subsubsection{Direct disposal}

Following encapsulation, the entire amount of spent fuel is treated as HLW and is disposed of in a range of ways paralleling those for the vitrified high level waste from reprocessing. In general this will involve placing the encapsulated fuel in deep geological repositories, possibly surrounded by a buffer material (e.g. bentonite) to prevent ground water coming into contact with the outer container forming the encapsulation.

\subsubsection{Plutonium and uranium recycling}

\subsubsection{Plutonium recycling}

Plutonium can be used in MOX fuel in thermal reactors, such as PWR or BWR, or in fast reactors. Other reactors, such as the ATR, can also use plutonium (see section 8.2). Fast reactors hold considerable promise for the next century and the use of MOX in PWRs and BWRs is currently well developed. The first MOX assembly was loaded in a PWR in Belgium for demonstration purposes almost 30 years ago. The present global production capacity for thermal reactor MOX fuel is about 70 tonnes p.a. with almost 350 tonnes p.a. forecasted for 2000. An international market for MOX fuel already exists, with countries such as France, Germany and Switzerland having experience with thermal MOX fuels, and other countries, such as Japan and Belgium, planning to load MOX in their reactors in the future. The use of MOX fuel leads to changes in reactor core properties; shut-down margins 
are reduced, compared to conventional fuel. In current LWRs, the largest licensed fraction of MOX fuel which may be loaded is approximately 50 per cent. In the future, however, it should be possible to design LWRs utilising up to 100 per cent MOX fuel.

The quantities of high neutron absorbing isotopes of plutonium increase with fuel burn-up. ${ }^{238} \mathrm{Pu}$ produces significant quantities of heat and neutrons and is one of the factors to be considered in the transport and storage of plutonium and mixed oxides. Countries that have chosen reprocessing manage the stocks and flows of plutonium while taking into account the above constraints.

Plutonium production ceases when fuel is removed from the reactor. Thereafter radioactive decay becomes the critical factor in plutonium recycle as it produces a decrease in the fissile isotope content and a build-up of gamma-emitting decay products which, progressively, make handling of $\mathrm{PuO}_{2}$ during $\mathrm{MOX}$ fuel fabrication increasingly difficult and more expensive.

The 1989 NEA Plutonium Study ${ }^{(5)}$ has recommended limits, based on practical experience, regarding suitable storage periods for materials containing plutonium recovered from LWR spent fuel. Maximum indicative storage periods for $\mathrm{PuO}_{2}$ powders, MOX fuel rods and fresh MOX fuel assemblies are 2 years, 10 to 13 years and 13 to 20 years, respectively. In general, a short time interval should occur between reprocessing and MOX fuel fabrication.

New plants, such as the German SIEMENS MOX plant in Hanau and the French MELOX plant, will be capable of dealing with much older plutonium powders (about 5 to 6 years after reprocessing) because of increased automation and better worker protection. If needed, it is possible to gain more flexibility by subjecting "old" plutonium to further chemical purification.

Second generation MOX plants (e.g. the Sellafield MOX plant) which will start operation later this decade, have been designed to handle even older plutonium powders from high burn-up fuels (10 years old plutonium from $60 \mathrm{GWd} / \mathrm{t}$ fuel).

\subsubsection{Uranium recycling}

The present economic situation of the uranium market limits the interest in uranium recycling. Nevertheless, some electric utilities (e.g. in France, Japan, Germany and Switzerland) show some interest in developing recycling programmes.

The technology for making reprocessed uranium fuel is well established so there should be no technical limits on these programmes. In addition, the coming into operation of AVLIS enrichment will provide a very efficient means for re-enrichment of reprocessed uranium. 
Figure 3.1 Material flow of the PWR reprocessing option

(the figure is an example and the numbers are approximate only)

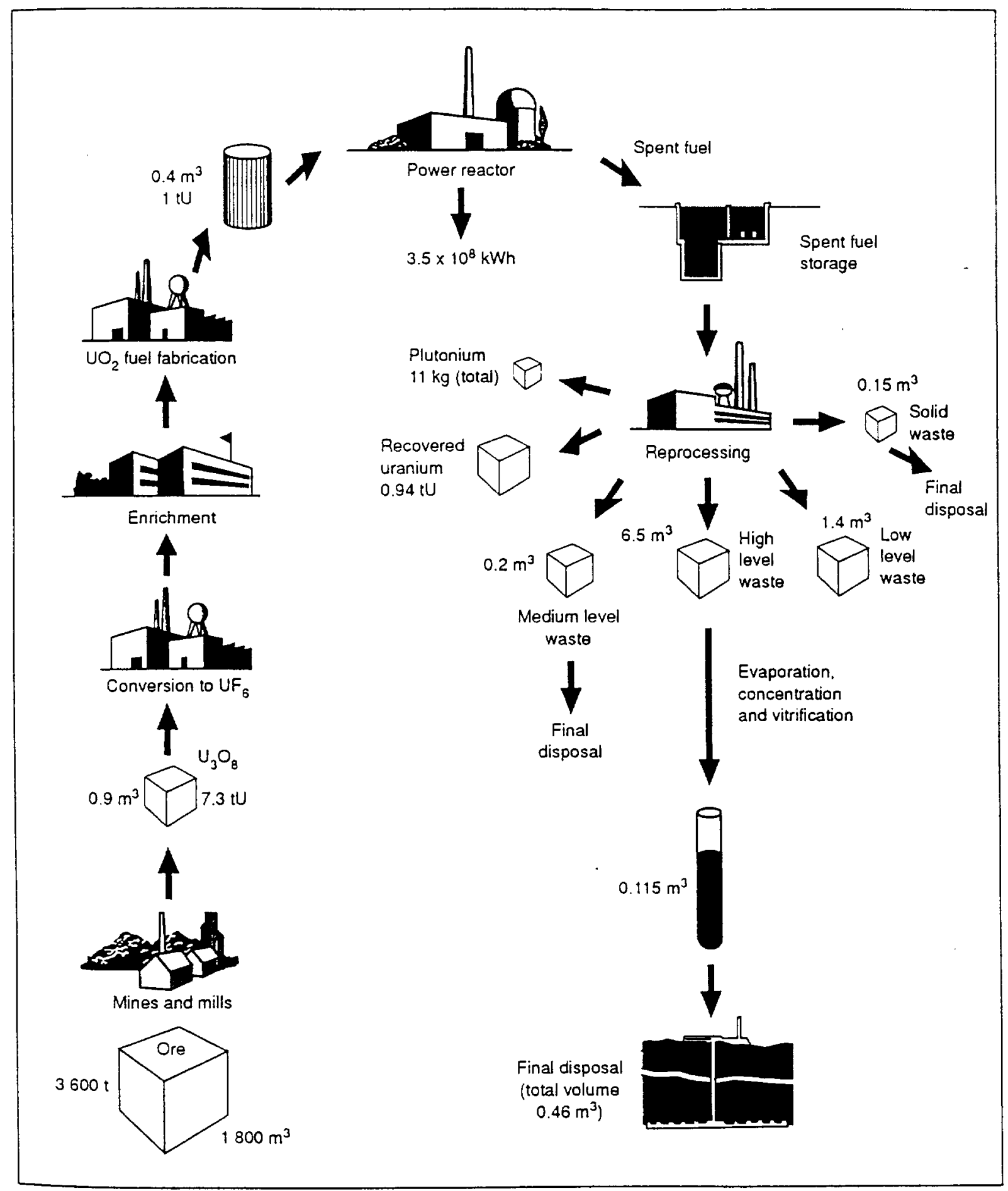

Recovered uranium and plutonium can be recycled. Source: COGEMA, HORIZON 2000 
Figure 3.2 Material flow of the PWR direct disposal option

(the figure is an example and the numbers are approximate only)

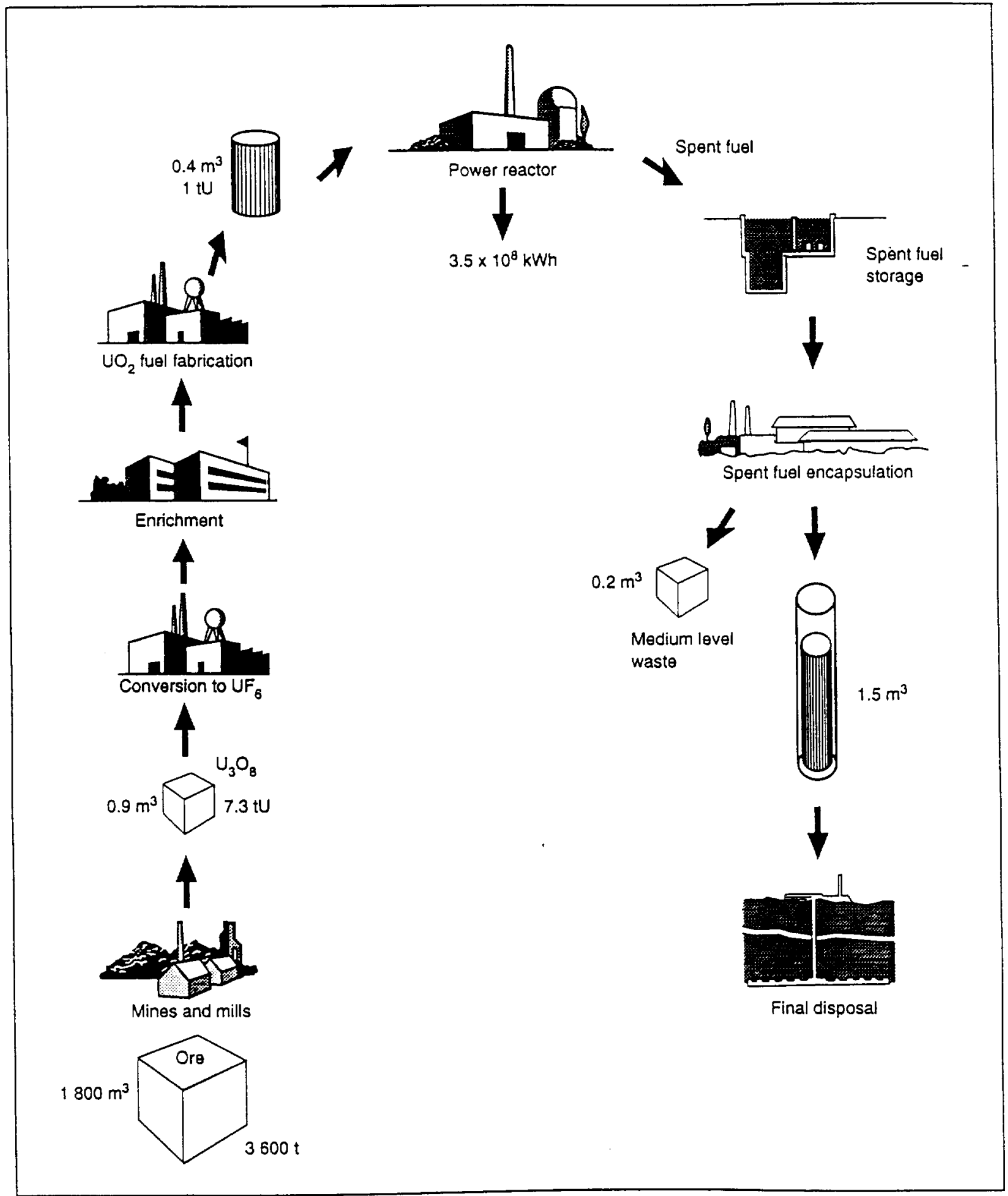

Source: COGEMA, HORIZON 2000 and information provided by SKB. 


\section{THE COSTS OF THE PWR FUEL CYCLE STAGES}

\subsection{The front-end of the fuel cycle}

\subsubsection{Uranium purchase}

For the range of uranium prices considered in the 1985 study, uranium purchase contributed between 30 and 50 per cent of the total cost of the PWR fuel cycle. This represented between 5 and 20 per cent of the total electricity generation cost. With current data, Tables 5.7 and 5.8 show that uranium purchase contributes about the same level as enrichment services, while fabrication costs have also become important. The demand for uranium is now more predictable than it used to be. A number of technological advances such as increased fuel burn-ups, advanced fuel designs, improved plant efficiency, and the use of MOX fuel and reprocessed uranium have led to reduced uranium requirements.

Since the publication of the previous study, uranium market developments have made the highest of the price projections look less likely today. Although the uranium market is currently characterised by large global inventories and low prices, the future is uncertain ${ }^{(8)}$. As consumption of natural uranium is currently higher than production, the situation beyond the year 2000 is likely to be different after excess inventories are consumed. Some of the factors that might influence the uranium market are:

\section{Demand side}

- New reactor orders have stagnated since the late 1970s; the world total reactor capacity is, therefore, now plateauing and the annual growth rate of nuclear electricity production has become slower than in the past 20 years.

- Reactor retirements are small, but growing; however, if life extensions are developed, most of the reactors operating at present will also be operating up to the year 2000; uncertainty exists on the future of several reactors in Eastern Europe.

- Fossil fuelled plants make a significant contribution to global warming ("greenhouse effect") and may need to be replaced in significant numbers by systems which release no "greenhouse" gases. Nuclear systems are one such source.

- The world population growth will lead to the growth of the global energy consumption, even if energy will be utilised in a more rational way; as fossil fuels will become more expensive, more nuclear generated energy may be required.

- The 1980s were characterised by increasing fuel efficiency which will ultimately lead to a 10 to 15 per cent reduction in uranium demand; in addition, reprocessing activities will gradually grow, leading to further reductions in uranium fuel requirements.

- The long-term demand (after 2015) is highly speculative; it depends on the nuclear performance record, environmental considerations and the development of new technologies. 
- Theoretically, global inventories from all sources are adequate to make up a production shortfall beyond 2000.

- A part of the military inventory will eventually find its way to the market despite the technical and institutional difficulties; this part is likely to be less than 10 per cent of the global consumption up to 2030 .

- Depleted enrichment tailings could be a significant source if new technology is developed.

- Significant undeveloped reserves are available at reasonable costs (less than $\$ 50$ per kg U).

- No significant availability problem before 2015 is foreseen, although there could be big swings about the trend line from year to year.

- New regulations on the environment, radiological protection and decommissioning may increase production costs and may lead to some mine closures.

\section{Long-term trend}

- Significant future uranium market price rises may be limited by technological improvements (e.g. breeders and reprocessing), fuel substitution (e.g. the thorium cycle), new and alternate technologies (fusion, solar, wind, biomass, geothermal, tidal, etc.) and, as experience with other metals indicates, the discovery of new uranium.

- Based on resource analysis, there will most probably be an upper limit of about $\$ 130$ per $\mathrm{kg} \mathrm{U}$ throughout the entire period to 2030; new uranium discoveries may reduce this limit.

The previous NEA fuel cycle study used $\$ 83.2$ per $\mathrm{kg} U$ escalating at 2 per cent per annum as the reference price and parametric evaluations were performed for an escalation rate of 0 and 4 per cent per annum. Ranges shown in the questionnaire replies vary between $\$ 40$ per kg U in 1990 to around $\$ 105$ per $\mathrm{kg} \mathrm{U}$ in 2030. It was agreed to use the price of $\$ 50$ per $\mathrm{kg} \mathrm{U}$ (1990 money value), rising in real terms at a rate of 1.2 per cent per annum (i.e. $\$ 90$ per $\mathrm{kg} \mathrm{U}$ in 2040), as the reference value, which is in line with the recommendation of the NEA Uranium Group and for the sensitivity analyses the prices of $\$ 40$ per $\mathrm{kg} U$ constant and $\$ 90$ per kg U constant for the lower and the upper bounds, respectively. Additionally, further sensitivity analyses involving -50 to +100 per cent price changes are presented.

It should be noted that the average price of other metals (e.g. copper) has remained constant, in real terms, for more than 50 years despite heavy fluctuations over a number of years.

\subsubsection{Conversion}

The prices for conversion of natural uranium oxide to uranium hexafluoride for enrichment lie in the range $\$ 6$ to $\$ 11$ per $\mathrm{kg} \mathrm{U}$ and there is no expectation of any significant increase in real terms in the future. A price of $\$ 8$ per $\mathrm{kg} U$ was adopted as the reference case; $\$ 6$ and $\$ 11$ per $\mathrm{kg} \mathrm{U}$ are the lower band and upper band values for sensitivity purposes.

The reference case in the 1985 study was $\$ 6$ per $\mathrm{kg} \mathrm{U}$, corresponding to $\$ 7.6$ per $\mathrm{kg}$ U in $1991 \mathrm{US} \$$. The 1989 plutonium study adopted $\$ 7$ per $\mathrm{kg} \mathrm{U}$ as an illustrative value, which is $\$ 8.2$ per $\mathrm{kg} \mathrm{U}$ in $1991 \mathrm{US} \$$. As regards the historical trend the conversion price is very stable. Conversion prices constitute only a few per cent of the total fuel cycle cost, therefore, their fluctuation would have insignificant effects on the cost of the overall fuel cycle.

\subsubsection{Enrichment}


Enrichment costs form a significant component of the total fuel cycle cost. In the 1985 study, enrichment costs contributed approximately one quarter of the total fuel cycle costs.

The gaseous diffusion and centrifuge processes are commercially well established. The introduction of new technologies, such as advanced centrifuge and laser enrichment, is expected to provide additional enrichment capability at prices substantially below those from existing plants due to lower energy requirements. Relevant research and development projects are carried out in France, Japan, the United Kingdom and the United States. The laser enrichment technology that is being developed in the United States (AVLIS) is projected to have a production cost for enriched uranium that is approximately one-half the cost of the existing gaseous diffusion plants.

Throughout the remainder of this century, and through the first decade of the 21 st century, plant capacity is expected to exceed the demand for uranium enrichment services. Excess capacity is due to the slower than originally planned expansion of nuclear power on a worldwide basis. There is an expectation that supplies of enriched uranium from the former USSR may increase. The price of enrichment services is expressed per separative work unit (SWU), the quantity of SWUs necessary to obtain a quantity of enriched uranium at the required enrichment level being given by a complex formula (see Annex 1). Current enrichment prices vary between $\$ 70$ and $\$ 160$ per SWU. Potential new enrichment technologies, such as AVLIS, could lead to significantly lower values. It is possible that enrichment prices could decrease by 2 per cent per annum in real terms. However in this study it has been assumed prudently that enrichment prices will remain constant in real terms.

The reference case adopted was $\$ 110$ per SWU with $\$ 80$ per SWU and $\$ 130$ per SWU being the lower and higher values for sensitivity calculations.

\subsubsection{Uranium oxide fuel fabrication}

There has always been high competition among fabrication services suppliers because the processes involved are well established, relatively straightforward and the market is over-supplied. Reported prices differ from country to country due, partly, to the existence of plants which have different sizes and ages, and, partly, due to the fluctuation of foreign currencies relative to the US dollar which forms a bench-mark for pricing purposes.

A few countries have reported high prices, but it is generally considered that prices for $43000 \mathrm{MWd} / \mathrm{t}$ fuel lie in the range $\$ 200$ to $\$ 400$ per $\mathrm{kg}$ U. For the purposes of this study $\$ 275$ per $\mathrm{kg} \mathrm{U}$ was adopted as the reference case and for the sensitivity analyses $\$ 200$ per $\mathrm{kg} \mathrm{U}$ and $\$ 350$ per $\mathrm{kg}$ U were used.

For comparison, in the 1985 study, the reference case was \$190 per kg U (\$242 per kg U in 1991 US\$) and for the 1989 plutonium study $\$ 200$ per $\mathrm{kg} \mathrm{U}$ ( $\$ 233$ per kg U in 1991 US\$). For both studies prices were for $33000 \mathrm{MWd} / \mathrm{t}$ fuels.

The price of fuel fabrication has remained stable over the past decade. During the same period, fuel assembly design and construction has become more sophisticated, thus enabling better fuel utilisation, burn-up extension and better operational behaviour. This has led to an improved fuel cycle 
economy. Higher fuel fabrication prices are to be expected for the even higher burn-ups that are anticipated in future. It was reported that the price for advanced fuel assemblies capable of a burn-up of $50000 \mathrm{MWd} / \mathrm{t}$ could reach approximately $\$ 400$ per $\mathrm{kg} \mathrm{U}$.

\subsection{Fuel at the reactor}

The costs of storage of new or irradiated fuel at the reactor site and costs associated with the management or disposal of low level liquid and solid wastes produced during the reactor operations are not included in the costs of the fuel cycle.

\subsection{The back-end of the fuel cycle}

\subsubsection{General}

All back-end prices are levelised to the point of delivery to the respective plants for both the reprocessing and direct disposal options.

A levelised price is calculated in the same way as the total levelised fuel cost, i.e. by setting the net present values of the plant income (based on tonnes of uranium throughput) and cost profiles equal (see Annex 1). This ensures the correct price is charged for each tonne delivered to the plant, enabling the plant operator to meet all costs and also show a return on the capital employed. The discount rate used to obtain the levelised price reflects the rate of return that the plant operator requires on the capital employed (see Annex 2).

Following discharge from the reactor, the spent fuel undergoes a period of storage in the reactor pool. This stage of the fuel cycle is common to both the reprocessing and direct disposal options.

To ease transport requirements, fuel is usually held in the reactor pool for at least a few years prior to transport to allow significant reduction in heat output to occur. In this study a five years in reactor pool storage period is assumed for either option (the final core is assumed to be stored for only four years). The costs for this storage period are covered by the normal operating costs of the power station and they have not been included as a specific fuel cycle cost.

\subsubsection{Reprocessing option costs}

\subsubsection{Transport of spent fuel}

Based on the figures provided in the questionnaire responses a fixed price of $\$ 50$ per $\mathrm{kg} \mathrm{U}$ has been used as the reference price. This assumes relatively short transportation distances within the European area; it would not cover long distance sea transport such as Japan to Europe. For sensitivity purposes a range of $\$ 20$ to $\$ 80$ per kg U was used.

\subsubsection{Interim storage of spent fuel}

On receipt at the reprocessing site, spent fuel is subject to a further period of, usually, short storage. The length of this period can vary over a wide range of a few months to several years according to customers' 
requirements and plant availability. In this study it is assumed that spent fuel is stored at the reprocessing site for one year prior to reprocessing. The cost of this storage is included in the reprocessing price.

\subsubsection{Reprocessing}

Spent fuel reprocessing is offered commercially on an international basis by France and the United Kingdom. Japan is actively developing plans to build a commercial reprocessing plant.

The basic cost estimates used in this study were provided by British Nuclear Fuels plc (BNFL) and possible trends relating to future costs have been contributed by COGEMA.

Reprocessing plant cost estimates have been provided for a hypothetical modern reprocessing plant which is built and operated to coincide with the requirements of the study's reference PWR (see Annex 3). Experience gained from the design, construction and operation of the latest reprocessing plants, THORP at Sellafield and UP3 at La Hague has been taken into consideration in deriving the cost estimates for the hypothetical plant and for sensitivity analysis purposes.

Reprocessing permits the use of the recovered uranium and plutonium instead of burying it as waste, as exemplified by the direct disposal option. It is assumed that the fuel is stored one year at the reprocessing site prior to the reprocessing operations. High level waste (HLW) is assumed to be vitrified within a few years of production and the vitrified waste (VHLW) stored at the reprocessing site for 50 years prior to final disposal. LLW is assumed to be disposed shortly after production in common with current practice. ILW is assumed to be fixed in a cement matrix in metal containers and, after short interim storage, disposed in a deep geological repository. Account has been taken of the current operational experience with the Sellafield vitrification and waste conditioning plants.

The reference 5 per cent levelised unit price at time of delivery to the plant, covering all back-end costs after fuel delivery up to but not including final disposal of VHLW, is ECU 720 per $\mathrm{kg} \mathrm{U}$ (this price is comparable to the post-baseload price currently on offer from BNFL and COGEMA). This price is based on the weight of fuel input to the reactor and not the weight of uranium and plutonium in spent fuel discharged from the reactor as in the 1985 study. This price includes research and development costs. Unlike the 1985 study, where the sensitivity analysis took into account possible increases as well as decreases in the reference

price, the present study considers only a possible 25 per cent reduction. The argument supporting such a reduction is set out in Annex 3.

\subsubsection{Waste disposal}

The cost of disposing of low and intermediate level wastes forms a relatively small part of the price charged for reprocessing.

Cost estimates for the disposal of VHLW based on a hypothetical repository dedicated to the reprocessing plant using the latest UK perception regarding design and timing are detailed in Annex 3. These costs have been scaled from actual UK design studies using the appropriate quantity of VHLW assumed in the reference case. Noting the long timescales involved there is inevitably greater uncertainty in repository cost estimates compared with those for reprocessing plants. A reference 5 per 
cent levelised price of ECU 90 per $\mathrm{kg} \mathrm{U}$ was used with an upper bound sensitivity price of ECU 580 per $\mathrm{kg} \mathrm{U}$ [this price was derived using cost information from the OECD/NEA waste disposal costing study ${ }^{(6)}$ ].

\subsubsection{Recovered uranium and plutonium credit}

The monetary value of the credit of recovered uranium and plutonium contained in the spent fuel from the reference PWR assumes:

i) that the recovered material is recycled as soon as it is available in a reactor similar to the reference PWR and with the same design burn-up as the reference fuel; and

ii) that only one stage of recycling takes place.

As shown in Annex 8, a single recycle of the recovered material would allow approximately a 15 to 20 per cent core loading of MOX and approximately a 20 to 25 per cent reduction in natural uranium requirements. Together, these would reduce the reference fuel cycle cost by about 4 per cent (see Table 5.7).

Current PWR designs can be licensed to operate with up to a 50 per cent MOX core load, the balance in theory could comprise enriched $\mathrm{UO}_{2}$ fuel from recovered uranium recycle. Thus, if the recovered plutonium and uranium were preferentially used in a limited number of PWRs, greater reductions in fuel cycle cost for these PWRs could be achieved.

The plutonium credits considered above assume that the plutonium is recycled once as MOX fuel in the reference PWR after only limited storage following its recovery from reprocessing. To the extent that recycle is delayed, additional costs could accrue through the need for additional storage and possibly a need for further processing to remove in-grown americium to meet the specification for MOX fabrication plants. Any need to transport plutonium prior to fabrication would also lead to higher costs. All of these aspects are considered in sections 4.3.2.6 et seq. hereafter.

The additional costs associated with the extended storage and purification of plutonium would tend to erode the credits identified in Annex 8. It is expected that on the time horizon of the current study, MOX fabrication plants will be available to accept the plutonium arisings from the assumed future reprocessing operations without further purification, even in the case of extended storage.

\subsubsection{Plutonium storage}

Published costs of plutonium storage vary widely owing to differences in the size of stores and the economic and financial differences which exist between countries. They are usually taken to be in the region of $\$ 1$ to $\$ 2$ per gram of total plutonium [Pu(t)] per year. Both BNFL and COGEMA include the cost of shortterm storage as a minor component of the overall reprocessing price but some countries requiring longer-term storage are incurring additional prices of this order. 


\subsubsection{Plutonium purification}

Long-stored plutonium may need to be purified, by the removal of in-grown americium before it can be recycled. The extent to which this will be necessary will depend upon the source of the plutonium, its period of storage and the design of the MOX fuel fabrication plant. The cost may vary ${ }^{(5)}$ between $\$ 10$ and $\$ 28$ per gram $\mathrm{Pu}(\mathrm{t})$; a price of $\$ 18$ per gram $\mathrm{Pu}(\mathrm{t})$ would be appropriate for plants treating about two tonnes $\mathrm{Pu}(\mathrm{t}) \mathrm{per}$ annum. This figure relates to americium removal from plutonium oxide; it would be less if the plutonium could be stored as a nitrate solution.

\subsubsection{Plutonium transport}

If plutonium transport is needed, the price is far higher per $\mathrm{kg}$ than that of spent fuel due to the more onerous criticality and physical security requirements. Indicative figures of around $\$ 500$ to $\$ 900 \mathrm{per} \mathrm{kg}$, which will vary with the mode of transport (air, land or sea), have been published ${ }^{(5)}$. Plutonium transport costs within a single site would be trivial by comparison.

\subsubsection{Plutonium recycling}

The recycling of plutonium in PWRs requires the mixing of plutonium and uranium oxides and their fabrication into MOX fuel in plants specially designed for that purpose. A comprehensive study ${ }^{(5)}$ deals with plutonium recycling in greater detail. It also addresses the technicalities associated with multiple recycling.

MOX fuel fabrication costs are higher than those of enriched uranium oxide fuels. This is due to the higher investment cost of a MOX plant and to the latter's modular nature which does not confer the same advantages of scale that apply to a uranium plant. As the use of MOX fuel increases and the new MOX fabrication plants reach higher commercial throughputs, the present MOX fabrication prices will fall. The industry expects that, on current plans, the MOX fabrication price will have fallen to about three times that for uranium fuel by 2010. However, the reference case in the 1989 NEA plutonium study assumed that by the late 1990s, MOX fabrication prices would be four times those for enriched uranium fuel. For the purpose of the present study it was agreed that the reference case would prudently use a ratio of four over the entire reactor lifetime. Thus, the reference price was set at $\$ 1100$ per $\mathrm{kg} \mathrm{HM}$ with a corresponding range for sensitivity analyses of $\$ 800$ to $\$ 1400$ per $\mathrm{kg} \mathrm{HM}$. This range corresponds to the use of fabrication price ratios of three and five, respectively. It also corresponds to the use of the low and high uranium fuel fabrication prices with the reference MOX fabrication factor of four. The values used in the study are considered to be very robust.

\subsubsection{Uranium recycling}

The present economic situation of the uranium market limits the interest in uranium recycling. Nevertheless, some electric utilities (e.g. in France, Japan, Switzerland and Germany) show some interest in developing recycling programmes.

The technology for making reprocessed uranium fuel is well established so there should be no technical limits on these programmes. In addition, the development of laser enrichment will provide an efficient way of re-enriching reprocessed uranium. 
The calculations in Annex 8 of the value of reprocessed uranium are based on the N4 reactor type fuel cycle, a reprocessing facility producing $\mathrm{UO}_{3}$ as the end product and conversion of reprocessed uranium in large facilities where the cost of conversion will not be more expensive than the cost of conversion of natural uranium.

The value of the uranium credit on the above assumptions is 0.18 mills $/ \mathrm{kWh}$ or approximately 3 per cent of the fuel cycle cost. The future trend towards higher burn-up together with improved utilisation of the

${ }^{235} \mathrm{U}$ content of the fuel through the use of gadolinia poisons could result in the spent fuel containing less ${ }^{235} \mathrm{U}$ and more ${ }^{236} \mathrm{U}$ compared with the reference case. In addition, if the conversion of the reprocessed uranium were to attract a price premium compared with conversion of natural uranium, then the uranium credit could be significantly reduced and possibly extinguished altogether.

\subsubsection{Direct disposal option costs}

Consistent with the reprocessing case, cost estimates have been provided for storage, encapsulation and disposal plants based on the well developed strategy currently being followed in Sweden (see Annex 4). For costing purposes in this study, the relative timings in the Swedish case were maintained but the start of the interim storage operation was adjusted to coincide with the needs of the hypothetical PWR under study. This is shown in Figure 5.6.

\subsubsection{Transport of spent fuel}

Based on the Swedish approach, the reference case assumes significant sea transport using a specially designed vessel (M.V. Sigyn) and supporting transport vehicles (see Annex 4). It is judged that inter-European rail costs would be comparable or lower than the reference case. The costs for spent fuel transport are included in the calculation of the levelised storage price to be charged on delivery of the fuel to the interim storage facility.

\subsubsection{Interim storage of spent fuel}

Relatively long interim storage times are a major feature of the direct disposal option. In the Swedish example, on which the reference case is based, a period of 35 years further storage is involved; the spent fuel being stored underwater at a central facility (CLAB).

To enable direct disposal costs used in the reference case to be directly compared with alternative country options (direct disposal and reprocessing), a 5 per cent levelised price that would be paid on delivery of the fuel to the plant was derived. The reference 5 per cent levelised transport and storage price to be charged on delivery to the storage site is ECU 230 per kg U (see Annex 4).

\subsubsection{Spent fuel encapsulation and final disposal}

After 35 years at the interim storage facility, the spent fuel is assumed to be transported to the final disposal site where it is encapsulated just prior to emplacement in a deep, hard-rock geology. The 5 per cent reference levelised price for encapsulation and disposal that is to be charged on delivery to the repository is ECU 610 per kg U. 
It should be noted that the SKB cost estimates used to derive this levelised price include a contingency of 27 per cent to reflect the uncertainty associated with the current state of the cost estimates for the encapsulation plant.

\subsubsection{Comparison with other countries' plans}

Unlike reprocessing which is available on the world market, the direct disposal option for spent fuel involves country-specific facilities for the entire back-end of the fuel cycle.

The reference case has been based on the Swedish example, the detailed costings of which are shown in Annex 4. Germany and the United States are also developing the direct disposal option. The state of development and the relative timing of the transport/storage and encapsulation/disposal operations are different to the Swedish example on which the reference case is based. This is shown diagramatically in Figure 4.1.

In the German example, intervenor action has introduced a delay between the actual construction (capital spend) phase and operation of the storage facility. The levelised prices shown take into account the capital and decommissioning costs although their timescales are not shown in Figure 4.1.

The method used in this study is to derive unit prices, levelised to the time of delivery, for the transport/storage and encapsulation/disposal operations. These levelised prices are shown in Figure 4.1 and are tabulated in Table 4.1. This method allows those prices to be applied to the delivery timings assumed for the hypothetical PWR whose fuel cycle cost is being calculated.

Table 4.1. Comparison of country-specific direct disposal costing data

\begin{tabular}{||l|c|c|c|c||}
\hline \multirow{3}{*}{ Country } & \multicolumn{2}{|c|}{ Undiscounted Costs (ECU/kg U) } & \multicolumn{2}{c|}{ Levelised Price, 5\% (ECU/kg U) } \\
\cline { 2 - 5 } & $\begin{array}{c}\text { Transport/ } \\
\text { Storage }\end{array}$ & $\begin{array}{c}\text { Encapsulation/ } \\
\text { Disposal }\end{array}$ & $\begin{array}{c}\text { Transport/ } \\
\text { Storage }\end{array}$ & $\begin{array}{c}\text { Encapsulation/ } \\
\text { Disposal }\end{array}$ \\
\hline Sweden & 210 & 360 & 230 & 610 \\
Germany $^{(\mathrm{a})}$ & 290 & 500 & 290 & 670 \\
US $^{(\mathrm{b})}$ & 40 & 120 & 60 & 140 \\
\hline
\end{tabular}

a. In the German case, the levelised price has been derived using a 4.3 per cent per year (real) rate of return. However, because of the timing of events, this introduces a negligibly small error and the values are a good approximation to the 5 per cent levelised price.

b. In the US case, the storage price is calculated for a quantity of approximately $87000 \mathrm{tU}$ of spent fuel alone, whereas the disposal price is calculated for this quantity of spent fuel and about $9000 \mathrm{tU}$ of equivalent defence programme wastes, i.e. a total of approximately $96000 \mathrm{tU}$.

In the Swedish case the disposal repository is being engineered to take only encapsulated spent fuel. In the US and German cases the repository will be designed to accept both conditioned HLW from reprocessing and encapsulated spent fuel. In the US case, spent fuel comprises over 90 per cent of the waste, whereas in the German case it is assumed to represent about 30 per cent. The ability of the repository to take both types of high level waste makes it difficult to identify costs solely attributable to the spent fuel 
component. However, since the US and German cases are being used only to set boundary values for sensitivity purposes, this is not considered to be of major importance.

The SKB data are related to facilities for a total of $8000 \mathrm{tU}$ of spent fuel. The US data are related to $87000 \mathrm{tU}$ of spent fuel plus defence programme wastes equivalent to $9000 \mathrm{tU}$, and the German example relates to $35000 \mathrm{tU}$ of spent fuel (70 per cent as VHLW and 30 per cent as encapsulated spent fuel). This quantity is higher than that currently assumed by the German utilities in setting financial provisions to cover disposal liabilities. Because of burn-up increases, the German utilities assume a lower quantity for disposal and hence use a prudently higher unit disposal price.

The Swedish and US cost estimates in the above table relate to plant costs and do not include supporting research and development costs. These could act to increase costs by about 20 per cent in the Swedish case to as much as doubling the cost in the US case. In the German case, supporting research and development has been included but as it sets the upper bound to the sensitivity range no attempt has been made to separate it out.

The back-end cost of the direct disposal option will be heavily influenced by country-specific regulatory and licensing requirements, by programme timing and by the engineering and design approach and nature of the geology into which disposal is made.

It is to be noted that the reference case (based on the Swedish experience) lies within the range shown. For sensitivity calculations the values for the German and the US cases have been taken to set the upper and lower bounds, respectively, for the range of encapsulated spent fuel disposal prices used in this study. In all instances, the relative timings set by the Swedish reference case have been consistently applied.

\subsection{Environmental factors}

The operation of nuclear power stations and associated nuclear fuel cycle service plants is carried out under strict regulatory requirements for environmental protection and public safety. These requirements cover all aspects of the fuel cycle including operation and decommissioning and cover transport of radioactive materials. Additionally, the aerial and liquid discharges from the sites containing fuel plants are subject to authorisations and monitoring whilst solid wastes must conform to specifications to meet regulatory requirements for transport, storage and ultimate disposal. The costs that have been used in this study take full account of the investment and operating experience that has been found to be necessary in meeting these comprehensive requirements.

It would be appropriate in all comparisons of costs with those of non-nuclear fuel cycles to acknowledge the comprehensive nature of the nuclear costs.

\subsection{Safeguards}

In the 1985 study, costs for implementing safeguards procedures were included in the cost of each component of the fuel cycle. 
Safeguards procedures both for the front-end and for the reprocessing facilities in the back-end of the fuel cycle are well established and more efficient methods are currently being pursued. Safeguards procedures for the disposal of radioactive wastes have not yet been properly established; additional costs for the implementation of safeguards are expected for the direct disposal of spent fuel.

Costs for safeguards are negligibly small in comparison to the other cost components of the fuel cycle. 


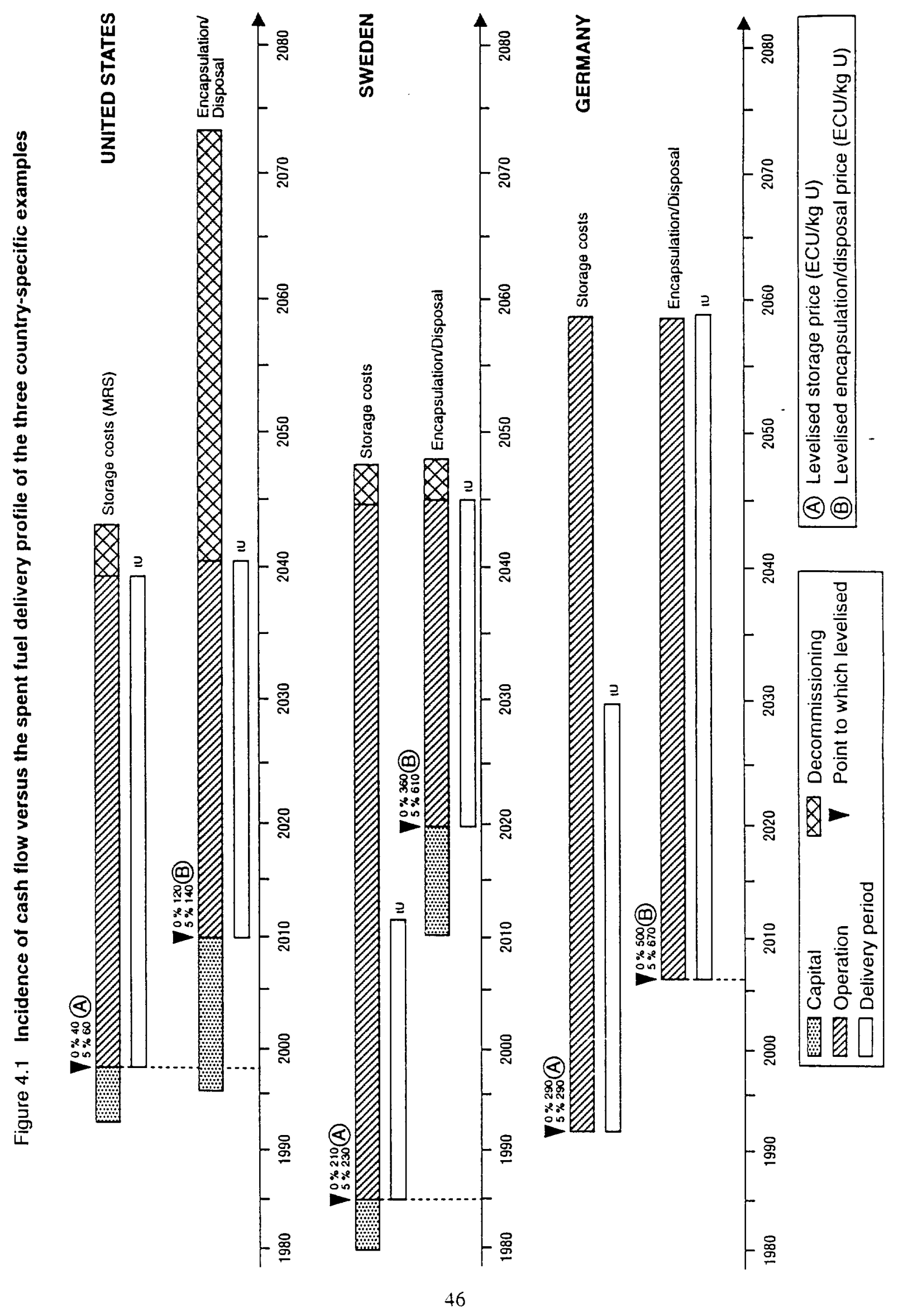




\section{THE CALCULATION OF TOTAL FUEL COSTS FOR PWR}

\subsection{Principles of assembling stage costs into overall fuel cost}

The unit costs for the different stages of the fuel cycle are discounted to a selected base date and added together in order to arrive at a total fuel cost in present value terms. In order to obtain the levelised fuel cycle cost, net present values (npv's) are taken of the cost profile and the income profile (based on generation) to the commissioning date of the reactor. Setting the two npv's equal allows the levelised fuel cost to be calculated (see Annex 1).

\subsection{Basic data}

\subsubsection{Choice of reactor parameters and base date}

In addition to the fuel cycle cost data which are presented in Table 5.5, the basic assumptions adopted are given in Tables 5.1, 5.2, 5.3 and 5.4. The reference reactor is a $1390 \mathrm{MWe}$ PWR which is assumed to be commissioned in the year 2000. The load factor adopted is 75 per cent and the plant lifetime is 30 years with 25 and 40 years values for sensitivity analyses. The fuel mass balance for the reference reactor which is based on a fuel burn-up level of $42500 \mathrm{MWd} / \mathrm{t}$ is shown in Table 5.6.

Table 5.1. Reactor and fuel data

\begin{tabular}{|c|c|c|}
\hline Item & Reference & Sensitivity range \\
\hline Reactor type & PWR (French N4) & \\
\hline Thermal output & $4020 \mathrm{MWt}$ & \\
\hline Electric output & $1390 \mathrm{MWe}$ & \\
\hline Load factor $^{(a)}$ & $75 \%$ & \\
\hline Commissioning year & 2000 & \\
\hline Plant lifetime & 30 years & $25-40$ years \\
\hline Fuel burn-up ${ }^{(b)}$ & $42500 \mathrm{MWd} / \mathrm{t}$ & \\
\hline Fuel mass balance & (see Table 5.6) & \\
\hline
\end{tabular}

a. Discounted average

b. At equilibrium 
Table 5.2. Cost data

\begin{tabular}{||l|c||}
\hline Item & Reference \\
\hline Base date of monetary unit & Early 1991 \\
Monetary unit & $\begin{array}{l}\text { Front-end: US\$ } \\
\text { Back-end: ECU }\end{array}$ \\
$\begin{array}{l}\text { Assumed exchange rate } \\
\text { (long term) }\end{array}$ & US\$1 = ECU 1 \\
\hline
\end{tabular}

Note: Unit prices for each component are given in Table 5.5.

\subsubsection{Tails assay for enrichment}

The tails assay, i.e. the concentration of ${ }^{235} \mathrm{U}$ in the depleted uranium stream, is assumed to be 0.25 per cent, with 0.2 and 0.3 per cent being taken as variants for sensitivity calculations.

\subsubsection{Lead and lag time}

Lead time is the term referring to the date at which materials are obtained, services are performed and payments for front-end components occur, prior to the date of loading fuel into the reactor. Lag time is the date at which a payment for the back-end occurs, after the fuel discharge date. The full range of the selected reference and parametric lead and lag times for the various stages of the fuel cycle is shown in Table 5.3.

\subsubsection{Loss factor}

For costing purposes, the material losses in the different stages of the fuel cycle have been assumed to be 0.5 per cent for conversion, 1.0 per cent for fabrication and 2.0 per cent for reprocessing while no allowances have been assumed for losses in the other processes.

The actual losses which occur in practice are below these assumed values.

\subsubsection{Unit price assumptions}

The unit price assumptions for the component stages of the fuel cycle, which were presented in Chapter 4, are summarised in Table 5.5. The constant monetary units are the US dollar and the ECU, 1991 money values, for the front-end and the back-end of the fuel cycle, respectively. 
Table 5.3. Fuel cycle data

\begin{tabular}{|c|c|c|}
\hline Item & Reference & Sensitivity range \\
\hline $\begin{array}{l}\text { Tails assay for enrichment } \\
\text { Lead time (relative to fuel } \\
\text { loading date) for: } \\
\text { - uranium purchase } \\
\text { - conversion } \\
\text { - enrichment } \\
\text { - fabrication } \\
\text { Lag time (relative to spent } \\
\text { fuel discharge date) for: } \\
\text { - spent fuel transport } \\
\text { - reprocessing option }{ }^{(b)} \\
\text { - reprocessing } \\
\text { - VHLW disposal } \\
\text { - direct disposal option }{ }^{(c)} \\
\text { - interim storage } \\
\text { - spent fuel encapsulation } \\
\text { \& disposal } \\
\\
\text { Loss factor for: } \\
\text { - conversion } \\
\text { - fabrication } \\
\text { - reprocessing } \\
\text { - others }\end{array}$ & $\begin{array}{c}24 \text { months }^{(\mathrm{a})} \\
18 \text { months }^{(\mathrm{a})} \\
12 \text { months }^{(\mathrm{a})} \\
6 \text { months }^{(\mathrm{a})} \\
\\
5 \text { years } \\
6 \text { years } \\
56 \text { years } \\
5 \text { years } \\
40 \text { years } \\
\\
0.5 \% \\
1.0 \% \\
2.0 \% \\
0 \%\end{array}$ & $\begin{array}{l}42 \text { months }^{(a)} \\
34 \text { months }^{(a)} \\
22 \text { months }^{(a)} \\
12 \text { months }^{(a)}\end{array}$ \\
\hline
\end{tabular}

a. For initial fuel, 6 months are added.

b. Including 5 years storage time at reactor.

c. Including 5 years storage at reactor followed by 35 years storage at interim storage facilities.

Table 5.4. Other data

\begin{tabular}{|c|c|c|}
\hline Item & Reference & Sensitivity range \\
\hline Discount rate & $5 \%$ & $\begin{array}{c}0 \%, 2 \%, 8 \%, 10 \%, \\
12 \% \& 15 \%\end{array}$ \\
\hline Uranium credit & $\begin{array}{l}70 \% \text { of the cost } \\
\text { of new uranium at the } \\
\text { same enrichment }\end{array}$ & \\
\hline Plutonium credit & $\$ 5 / \mathrm{g}$ Puf & \\
\hline
\end{tabular}


Table 5.5. PWR fuel cycle unit prices ${ }^{(a)}$

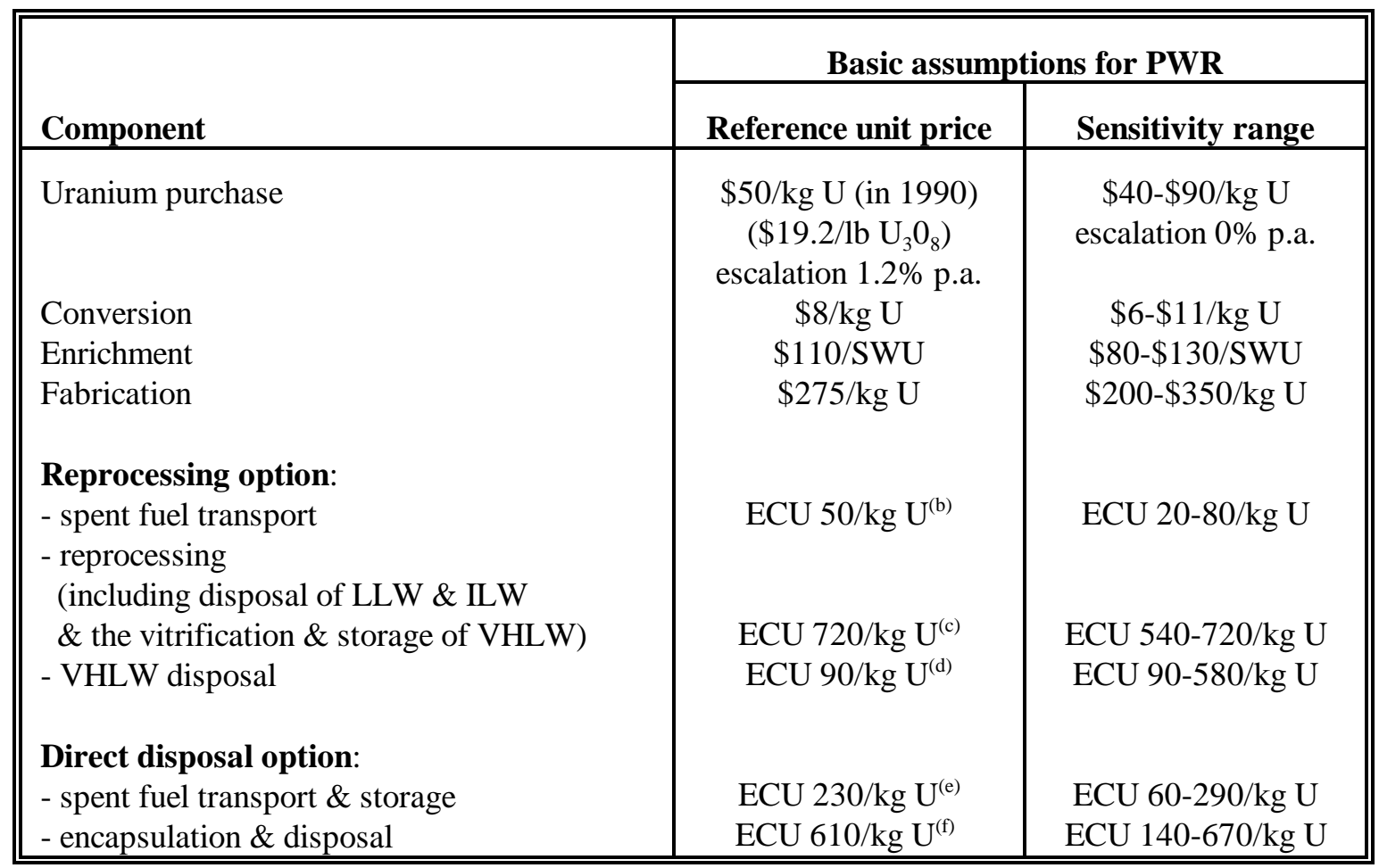

\footnotetext{
a. Early 1991 money value.

b. Transportation within the European area.

c. Payable on delivery to the reprocessing site.

d. Payable on delivery to the VHLW disposal site.

e. Payable on delivery to the interim storage site and includes the price of transport.

f. Payable on delivery to the encapsulation and disposal site.
}

\subsection{PWR cost calculations}

All the fuel cycle cost calculations for both the reference and sensitivity analyses for both the reprocessing and the direct disposal options were carried out by PNC (Power Reactor and Nuclear Fuel Development Corporation), Japan. All calculations were performed using the PNC computer code PNC-REFCO and are based on the methodology indicated in Annex 1.
5.3 .1
Cos $t$ s
for
the
reprocessing
option

The fuel cycle costs for the reprocessing scenario of the reference PWR were calculated using the reference assumptions and unit prices as shown in Tables 5.3 and 5.5, respectively. Sensitivity calculations were made to analyse the impact of the variations in both the basic assumptions and unit prices on the total fuel costs and these are shown in Chapter 6. 
Table 5.6. Material balance (PWR, 42500 MWd/t)

\begin{tabular}{|c|c|c|c|c|c|c|}
\hline $\begin{array}{c}\text { Time } \\
\text { (EFPY) }\end{array}$ & $\begin{array}{c}\text { Interval } \\
\text { between } \\
\text { reload } \\
(\mathrm{EFPY}) \\
\end{array}$ & $\begin{array}{c}\text { Total } \\
\text { uranium } \\
\text { (tonne) }\end{array}$ & $\begin{array}{l}{ }^{235} \mathrm{U} \\
(\%) \\
\end{array}$ & $\begin{array}{c}\text { Fissile } \\
\text { Pu } \\
(\mathbf{k g}) \\
\end{array}$ & $\begin{array}{c}\text { Total } \\
\text { Pu } \\
(\mathbf{k g}) \\
\end{array}$ & $\begin{array}{l}\text { Burn-up } \\
(\mathrm{MWd} / \mathrm{t})\end{array}$ \\
\hline \multicolumn{7}{|c|}{ 1. Non-equilibrium cycle charge data } \\
\hline $\begin{array}{c}0 \\
0 \\
0 \\
0 \\
0 \\
0 \\
1.046 \\
1.724 \\
2.442 \\
\end{array}$ & & $\begin{array}{r}28.00 \\
9.16 \\
18.85 \\
17.77 \\
10.23 \\
26.39 \\
28.00 \\
28.00 \\
28.00 \\
\end{array}$ & $\begin{array}{l}1.80 \\
1.80 \\
2.40 \\
2.40 \\
3.10 \\
3.10 \\
3.60 \\
3.60 \\
3.60 \\
\end{array}$ & & & \\
\hline \multicolumn{7}{|c|}{ 2. Equilibrium cycle charge data } \\
\hline 3.240 & 0.798 & 28.00 & 3.60 & & & \\
\hline \multicolumn{7}{|c|}{ 3. Non-equilibrium cycle discharge data } \\
\hline $\begin{array}{l}1.046 \\
1.724 \\
1.724 \\
2.442 \\
2.442 \\
3.240 \\
4.037 \\
4.835 \\
5.632 \\
\end{array}$ & & $\begin{array}{r}27.44 \\
8.82 \\
18.19 \\
17.01 \\
9.75 \\
26.50 \\
26.53 \\
26.47 \\
26.40 \\
\end{array}$ & $\begin{array}{l}0.84 \\
0.60 \\
0.78 \\
0.53 \\
0.85 \\
0.64 \\
0.94 \\
0.88 \\
0.81 \\
\end{array}$ & $\begin{array}{r}130.00 \\
54.40 \\
119.00 \\
119.46 \\
72.20 \\
208.00 \\
214.24 \\
216.32 \\
218.40 \\
\end{array}$ & $\begin{array}{r}172.64 \\
76.50 \\
164.50 \\
175.56 \\
102.60 \\
312.00 \\
309.40 \\
316.16 \\
322.92 \\
\end{array}$ & $\begin{array}{l}13900 \\
22000 \\
23000 \\
32000 \\
33000 \\
41000 \\
39000 \\
40600 \\
42500\end{array}$ \\
\hline \multicolumn{7}{|c|}{ 4. Equilibrium cycle discharge data } \\
\hline 6.430 & 0.798 & 26.40 & 0.81 & 218.40 & 322.92 & 42500 \\
\hline \multicolumn{7}{|c|}{ 5. Final core discharge data } \\
\hline & & $\begin{array}{l}26.40 \\
26.77 \\
27.20 \\
27.54\end{array}$ & $\begin{array}{l}0.81 \\
1.24 \\
1.80 \\
2.50\end{array}$ & $\begin{array}{l}218.40 \\
202.80 \\
166.40 \\
109.20\end{array}$ & $\begin{array}{l}322.92 \\
275.60 \\
212.16 \\
127.40\end{array}$ & $\begin{array}{l}42500 \\
31900 \\
21300 \\
10700\end{array}$ \\
\hline
\end{tabular}

Note: $\quad$ EFPY $=$ effective full-power year. 


\subsubsection{Time flow of costs for the reprocessing option}

The cash flow of payments for the entire fuel cycle based on the reference reprocessing option is shown in Figure 5.1. The payments for the various components of the fuel cycle are made at discrete points in time, corresponding to the refuelling interval plus or minus lead or lag times. The payments depend on the amount of material or service required and the unit price of each component. In this study the levelised prices for reprocessing and disposal of a batch of fuel are charged at the time of delivery of the fuel to the respective facility. The reprocessing price covers all services up to the time of final disposal, i.e. vitrification, ILW disposal and HLW storage. Both prices are levelised to ensure that the reprocessor can meet all costs and financial targets (see Annex 1). Figure 5.2 gives an example of the relative fuel cycle component costs and the time flow for a typical reprocessing fuel batch. Credits for plutonium and uranium are deducted from the cash flows.

From the above, the reference reactor, which is commissioned on the 1st January 2000, has a typical time flow of payments commencing in 1997 (with the purchase of uranium for the initial core) which extends out to 2085 when the final core is disposed (see Figure 5.3).

In order to obtain the levelised fuel cycle cost, net present values (npv's) are taken of the cost profile (Figure 5.3) and the income profile (based on generation) to the commissioning date of the reactor. Setting the two npv's equal allows the levelised fuel cost to be calculated (see Annex 1). The levelised fuel cost that results from the reprocessing cycle is $6.23 \mathrm{mills} / \mathrm{kWh}$. The contribution of each fuel cycle component for the initial core and refuels in the total fuel cycle cost is shown in Table 5.7.
5.3 .3
Costs
for
the
direct
dis pos a l
option

As with the reprocessing option detailed above, the costs for the direct disposal option were calculated using reference assumptions and unit prices shown in Tables 5.3 and 5.5, respectively. Timings of back-end services used those appropriate to Sweden (the reference case).

\subsubsection{Time flow of costs for the direct disposal option}

The cash flow of payments for the reference direct disposal option is shown in Figure 5.4. Due to the country specific nature of the reference case, timings of payments, as displayed in Figures 5.5 and 5.6, are different to those of the reprocessing scenario.

The levelised fuel cycle cost over the reactor life is $5.46 \mathrm{mills} / \mathrm{kWh}$ for the chosen reference case. The split of this cost into each fuel cycle component for both initial core and refuels is shown in Table 5.8.

\subsection{BWR fuel cycle cost}

Recent bid comparisons ${ }^{(9)}$ confirmed that the lifetime levelised fuel cost for a modern future BWR is about the same as that for a modern PWR, when the equilibrium burn-up value of the BWR fuel is approximately 90 per cent the burn-up value of the PWR fuel. This applies to the direct disposal fuel cycle. If the reprocessing fuel cycle option is considered, the BWR fuel cost would, due to the slightly lower burn-up, be marginally higher than the PWR fuel cost. While the share of the uranium cost is typically lower for modern BWR fuel, fabrication costs are higher than those of the PWR fuel. Individual plant and fuel design features are, however, more important in determining fuel cycle costs than is the reactor type. 
Table 5.7. Levelised PWR fuel cycle cost for the reprocessing option (Reference case)

\begin{tabular}{||l|c|c|c||}
\hline \multirow{2}{*}{ Component } & \multicolumn{3}{|c|}{ (mills/kWh) } \\
\cline { 2 - 4 } & Initial core & Reloads & Total \\
\hline Uranium & 0.17 & 1.47 & 1.64 \\
Conversion & 0.03 & 0.18 & 0.21 \\
Enrichment & 0.18 & 1.67 & 1.85 \\
Fuel fabrication & 0.19 & 0.81 & 1.00 \\
Subtotal for front-end & $\mathbf{0 . 5 7}$ & $\mathbf{4 . 1 3}$ & $\mathbf{4 . 7 0}$ \\
Transport of spent fuel & & & \\
Reprocessing \& vitrification & 0.02 & 0.09 & 0.11 \\
Waste disposal & 0.32 & 1.34 & 1.66 \\
Subtotal for back-end & 0.003 & 0.02 & 0.02 \\
Uranium credit & $\mathbf{0 . 3 4}$ & $\mathbf{1 . 4 5}$ & $\mathbf{1 . 7 9}$ \\
Plutonium credit & & & -0.18 \\
Subtotal for credit & -0.01 & -0.17 & -0.08 \\
Total cost & -0.01 & -0.07 & $\mathbf{- 0 . 2 6}$ \\
\hline \hline
\end{tabular}

Table 5.8. Levelised PWR fuel cycle cost for the direct disposal option (Reference case)

\begin{tabular}{||l|c|c|c||}
\hline \multirow{2}{*}{ Component } & \multicolumn{3}{|c||}{$(\mathrm{mills} / \mathrm{kWh})$} \\
\cline { 2 - 4 } & Initial core & Reloads & Total \\
\hline Uranium & 0.17 & 1.47 & 1.64 \\
Conversion & 0.03 & 0.18 & 0.21 \\
Enrichment & 0.18 & 1.67 & 1.85 \\
Fuel fabrication & 0.19 & 0.81 & 1.00 \\
Subtotal for front-end & $\mathbf{0 . 5 7}$ & $\mathbf{4 . 1 3}$ & $\mathbf{4 . 7 0}$ \\
Transport/Storage & & & \\
of spent fuel & 0.10 & 0.41 & 0.51 \\
Encapsulation/Disposal & & & 0.25 \\
of spent fuel & 0.05 & $\mathbf{0 . 6 1}$ & $\mathbf{0 . 7 6}$ \\
Subtotal for back-end & $\mathbf{0 . 1 5}$ & $\mathbf{4 . 7 4}$ & $\mathbf{5 . 4 6}$ \\
Total cost & $\mathbf{0 . 7 2}$ & & \\
\hline
\end{tabular}




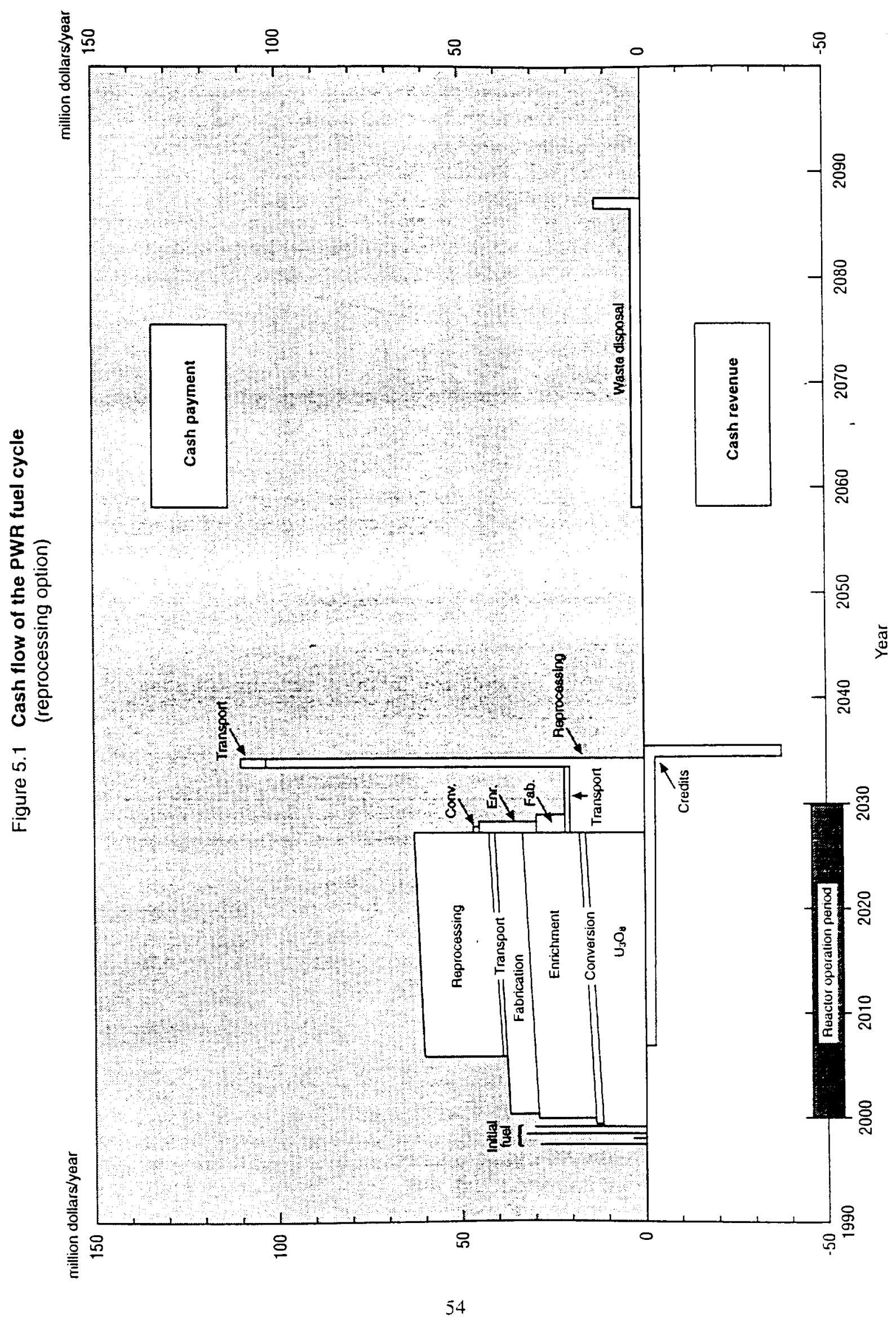




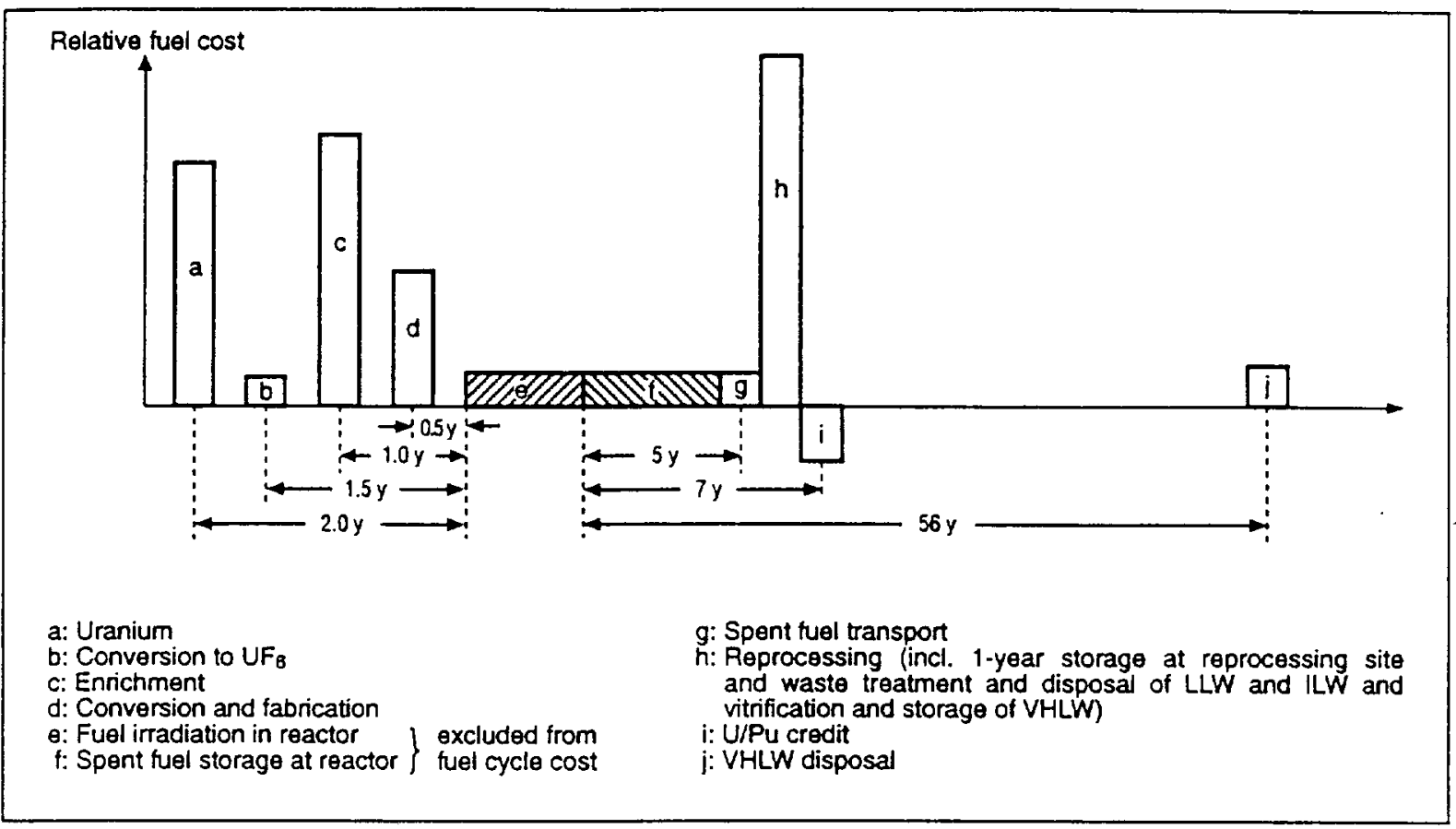

Figure 5.3 Scenario for back-end of PWR reprocessing option

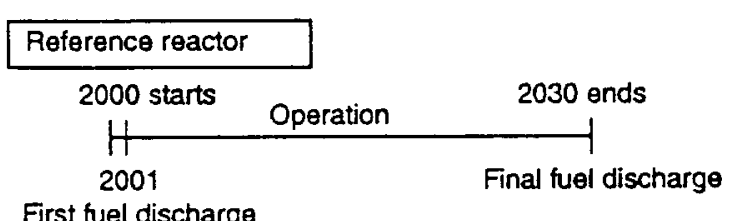

First fuel discharge
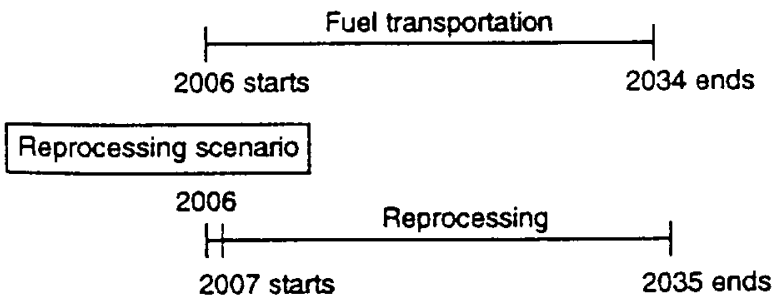

1-year buffer storage

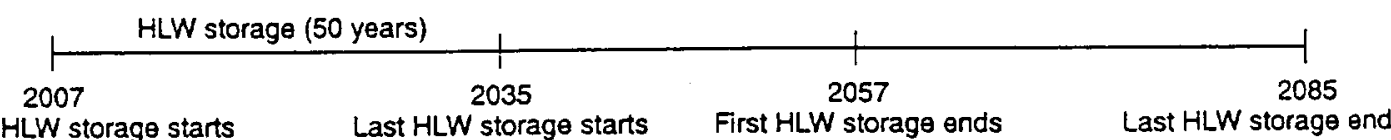

First HLW storage starts

Last HLW storage starts

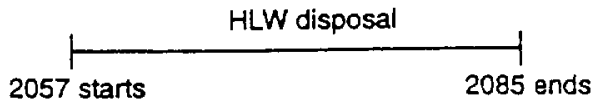




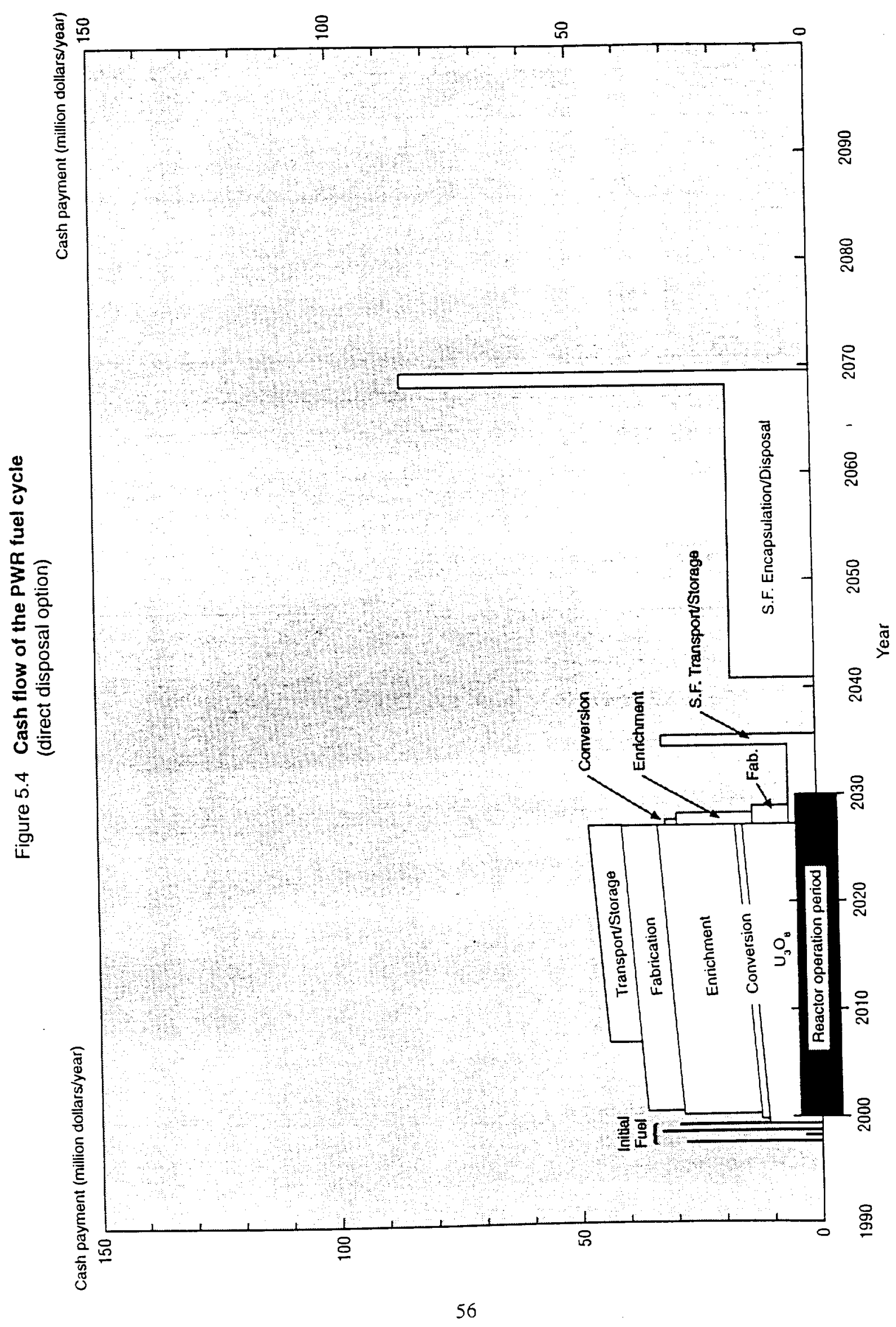


Figure 5.5 Time flow of nuclear fuel cycle cost

(PWR direct disposal option)

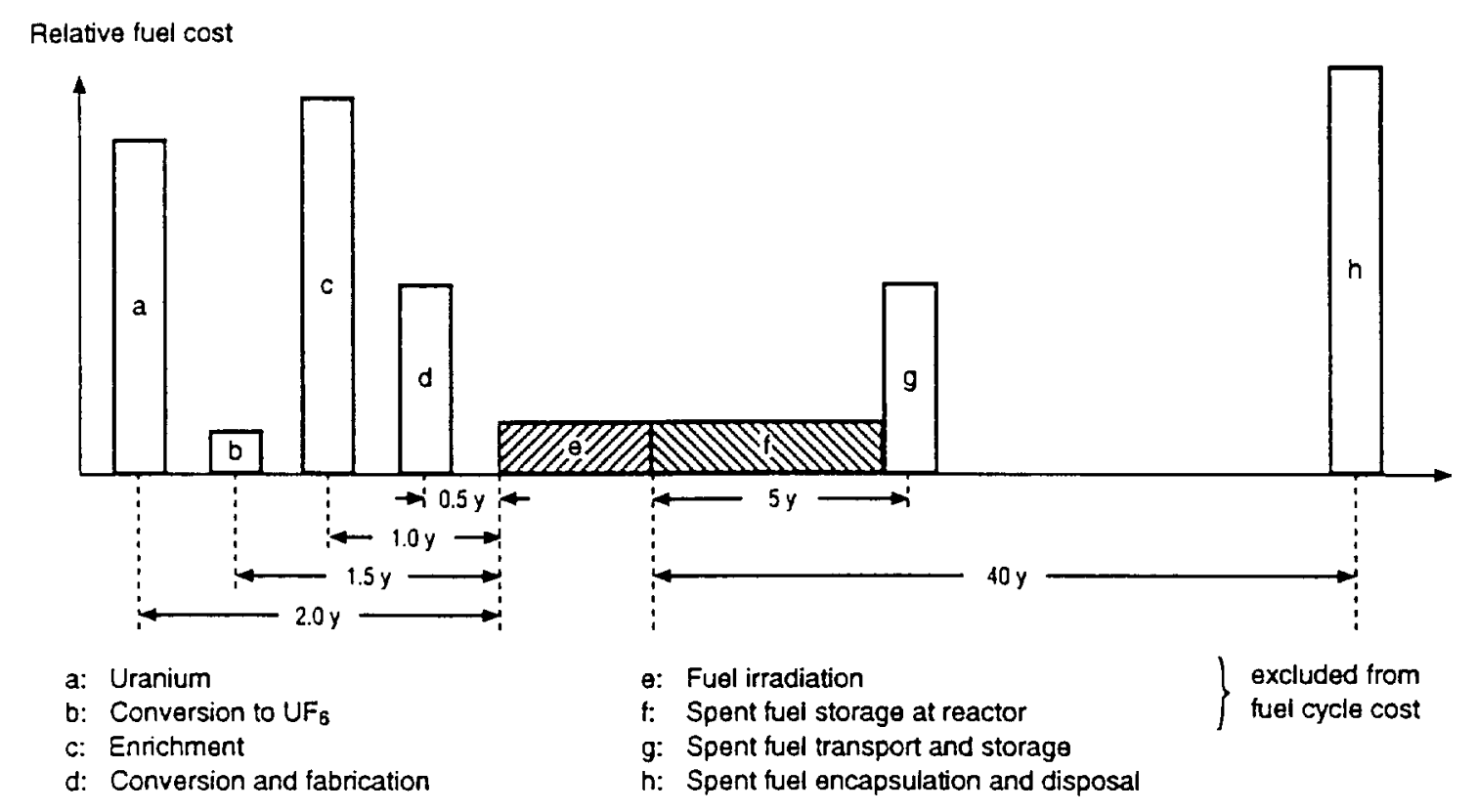

Figure 5.6 Scenario for back-end of PWR direct disposal option

Reference reactor

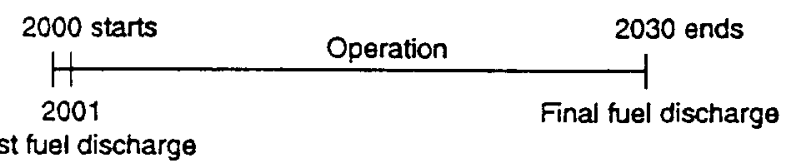

First fuel discharge

$\left.\right|_{2006 \text { starts }} ^{\text {Fuel transportation }}$

Direct disposal scenario
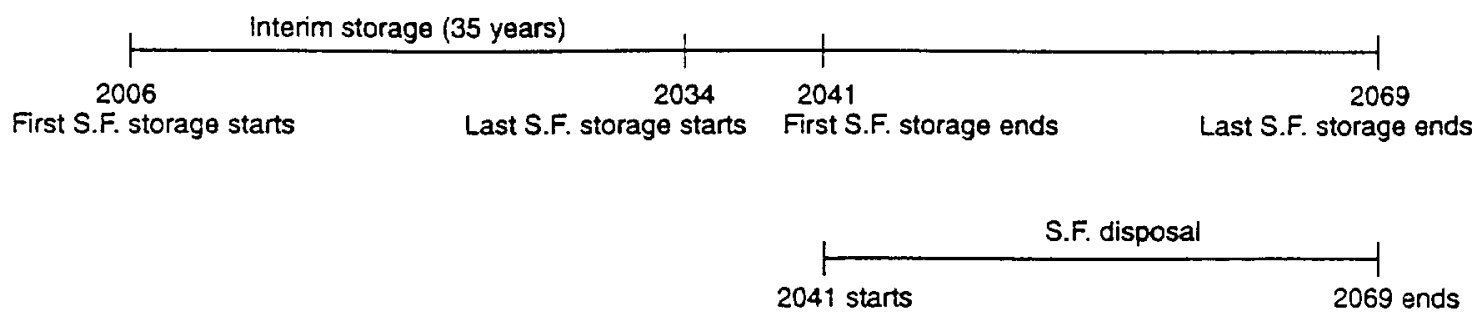


\section{SENSITIVITY ANALYSES FOR PWR FUEL COSTS}

\subsection{General}

Sensitivity calculations were made to analyse the impact on the total fuel cycle cost of variations in the technical parameters and in the unit prices for each fuel cycle component. The results of these sensitivity analyses are summarised in Figure 6.1 for the reprocessing option and Figure 6.2 for the direct disposal option.

\subsection{Technical parameters}

\subsubsection{Reactor life}

The reactor life is an important factor in the evaluation of total generation cost (mills $/ \mathrm{kWh}$ ) for a nuclear power station because it influences the total amount of electricity produced and hence the capital

contribution to the unit cost. The reference reactor lifetime is 30 years. In the sensitivity cases this value changed to 25 and 40 years.

Although important to the total generation cost, the lifetime assumption does not have a major influence on the total unit fuel cost because fuel usage is related directly to the amount of electricity generated.

\subsubsection{Tails assay}

The reference value of the tails assay was assumed to be 0.25 per cent ${ }^{235} \mathrm{U}$ in the uranium tails. Operation at 0.2 per cent tails assay increases the total fuel cost by about 1 to 2 per cent for the reprocessing and the direct disposal options, respectively. The fuel cost in the case of 0.3 per cent tails assay is almost the same as the cost for the 0.25 per cent tails assay.

\subsubsection{Burn-up}

Annex 9 discusses the sensitivity of fuel cycle costs to fuel discharge burn-up and the way it is influenced by the level of fuel cycle component prices and of the discount rate. It is shown that, for the reference data, the fuel cycle cost still decreases with fuel burn-up above the $42.5 \mathrm{GWd} / \mathrm{t}$ reference value. 


\subsection{Discount rate}

Figures 6.3 and 6.4 show the effects of the discount rate on the fuel cycle cost for the reprocessing and direct disposal options, respectively. For both options the front-end fuel costs are identical and increase with an increasing discount rate. This is due to the compounding effect that the lead times for the purchase of uranium and front-end fuel cycle services have on the levelised fuel cost.

The unit prices for back-end services that were used in the sensitivity analysis were obtained using a rate of return equal to the discount rate. This properly reflected the time value of money as seen by the utility and the service provider. Despite increasing back-end service prices with an increasing discount rate, the overall effect is for the back-end unit fuel cost to reduce and then level out in the reprocessing case; or to reduce to a minimum and then increase slightly in the direct disposal case. This is due to the electricity production occurring before the back-end payments are made.

As will be seen from Figures 6.3 and 6.4, the overall effect on the total levelised unit fuel cost is for minima to occur at the 2 and 5 per cent discount rates for the reprocessing and direct disposal options, respectively.

The effect of the discount rate on the individual components of the fuel cycle is shown in detail in Tables 6.1 and 6.2.

The effect of varying the discount rate in deriving the fuel cycle cost but holding the levelised price for the back-end components at a fixed value is shown in Annex 2.

\subsection{Fuel cycle component prices}

Figures 6.1 and 6.2 show that the total fuel cost is particularly sensitive to the uranium and enrichment price (more so for the latter than in the 1985 study). In the direct disposal option the back-end contributed 13.9 per cent of the total unit fuel cost, hence any alteration in the unit price for the back-end services has a minimal effect on the overall unit fuel cost. This is also true for the reprocessing option although the contribution the back-end component makes to the overall unit fuel cost is somewhat larger in this case.

\subsection{Comparison of total fuel cycle costs}

For the reference assumptions and unit prices, the difference between the two options is $0.77 \mathrm{mills} / \mathrm{kWh}$, which in absolute terms is slightly lower than that in the 1985 study. As there is no difference in the front-end costs for the two scenarios, the difference is due to the back-end costs, particularly the assumed timing of events and the magnitude of the recovered uranium and plutonium credit. The 12.4 per cent difference between the two fuel cycle options is considered to be insignificantly small in the light of the underlying cost uncertainties, and in any event, it represents a negligibly small difference in overall generating cost terms. 


\subsection{Likely range of total fuel cycle costs}

The reference fuel cycle cost together with higher and lower bounding values are shown in Figures 6.5 and 6.6. The higher and lower bounds show the extreme maximum and minimum range of nuclear fuel cycle costs. These extremes have been derived by the simple mathematical addition of each component fuel cost at its maximum or minimum. Each component cost is dependent on two types of parameters:

a) the price and price range for uranium and every fuel cycle service;

b) the technical assumptions on lead times, tails assay, reactor lifetime, etc.

In practice, not all parameters would simultaneously assume the high or low extremes, and the realistic uncertainty range is much narrower.

To derive this more realistic range, a statistical analysis has been performed. This analysis held all technical parameters fixed to the reference value and only considered price variations for the fuel cycle components of Table 5.5. It was assumed that each component price would lie within a rectangular distribution bounded by the ranges shown in Table 5.5 and that each component price was independent of the others. Using well established, standard statistical analysis techniques, the expected value and the variance for each fuel cycle component was calculated. These were then combined statistically to derive the overall fuel cycle cost range within the 95 per cent confidence interval. This is shown in Table 6.3 and as a vertical line in Figures 6.5 and 6.6. The range shown is approximately \pm 20 per cent around the reference fuel cycle cost for both the reprocessing and direct disposal options.

This analysis does not take into account the scope that exists in fuel cycle management to offset an increase in one component price by varying one of the technical parameters. For example, an increase in uranium price can be offset by reducing tails assay and using more enrichment services for a given quantity of fuel. The corollary of this is that an increase in enrichment price can be offset by increasing tails assay. The effect on fuel cycle costs of increases in the unit price for back-end services may be offset by increasing fuel burn-up. Through use of these measures there is confidence that fuel cycle costs can in practice be optimised to developing market conditions and held within the ranges indicated by the vertical lines in Figures 6.5 and 6.6. 
Table 6.1. Effect of discount rate on fuel cycle costs (reprocessing option) (mills/kWh)

\begin{tabular}{||l|c|c|c|c|c|c|c||}
\hline \multirow{2}{*}{ Fuel cycle component } & \multicolumn{7}{|c||}{ Discount rate (\%) } \\
\cline { 2 - 8 } & $\mathbf{0}$ & $\mathbf{2}$ & $\mathbf{5}$ & $\mathbf{8}$ & $\mathbf{1 0}$ & $\mathbf{1 2}$ & $\mathbf{1 5}$ \\
\hline Uranium & 1.45 & 1.52 & 1.64 & 1.78 & 1.89 & 2.00 & 2.19 \\
Conversion & 0.18 & 0.19 & 0.21 & 0.23 & 0.24 & 0.25 & 0.28 \\
Enrichment & 1.65 & 1.72 & 1.85 & 1.98 & 2.07 & 2.18 & 2.33 \\
Fuel fabrication & 0.87 & 0.92 & 1.00 & 1.09 & 1.16 & 1.23 & 1.34 \\
Subtotal for front-end & $\mathbf{4 . 1 5}$ & $\mathbf{4 . 3 5}$ & $\mathbf{4 . 7 0}$ & $\mathbf{5 . 0 8}$ & $\mathbf{5 . 3 6}$ & $\mathbf{5 . 6 6}$ & $\mathbf{6 . 1 4}$ \\
& & & & & & & \\
Transport of spent fuel & 0.16 & 0.14 & 0.11 & 0.10 & 0.09 & 0.08 & 0.07 \\
Reprocessing & 1.97 & 1.78 & 1.66 & 1.63 & 1.61 & 1.62 & 1.63 \\
Waste disposal & 0.18 & 0.07 & 0.02 & 0.004 & 0.002 & 0.001 & 0.00 \\
Subtotal for back-end & $\mathbf{2 . 3 1}$ & $\mathbf{1 . 9 9}$ & $\mathbf{1 . 7 9}$ & $\mathbf{1 . 7 3}$ & $\mathbf{1 . 7 0}$ & $\mathbf{1 . 7 0}$ & $\mathbf{1 . 7 0}$ \\
& & & & & & & \\
Uranium credit & -0.30 & -0.24 & -0.18 & -0.13 & -0.11 & -0.09 & -0.07 \\
Plutonium credit & -0.12 & -0.10 & -0.08 & -0.06 & -0.06 & -0.05 & -0.04 \\
Subtotal for credit & $\mathbf{- 0 . 4 2}$ & $\mathbf{- 0 . 3 4}$ & $\mathbf{- 0 . 2 6}$ & $\mathbf{- 0 . 1 9}$ & $\mathbf{- 0 . 1 7}$ & $\mathbf{- 0 . 1 4}$ & $\mathbf{- 0 . 1 1}$ \\
Total cost & & & & & & & \\
\hline \hline
\end{tabular}

Levelised unit prices (ECU/kg U) of reprocessing and disposal of vitrified waste for a range of discount rates

\begin{tabular}{||l|r|r|r|r|r|r|r||}
\hline & \multicolumn{7}{|c||}{ Discount rate (\%) } \\
\cline { 2 - 8 } & $\mathbf{0}$ & $\mathbf{2}$ & $\mathbf{5}$ & $\mathbf{8}$ & $\mathbf{1 0}$ & $\mathbf{1 2}$ & $\mathbf{1 5}$ \\
\cline { 2 - 8 } & 620 & 640 & 720 & 840 & 930 & 1040 & 1220 \\
Reprocessing & 60 & 70 & 90 & 120 & 140 & 170 \\
HLW disposal & 620 \\
\hline
\end{tabular}

Note: Data at the same discount rate were used in deriving the above back-end fuel cycle costs, i.e. a reprocessing price of ECU 720 per $\mathrm{kg} \mathrm{U}$ was used to obtain the final cycle cost at the 5 per cent discount rate and a reprocessing price of ECU 930 per $\mathrm{kg} \mathrm{U}$ was used for the fuel cycle cost at 10 per cent discount rate. The same convention was used for the waste disposal component. 
Table 6.2. Effect of discount rate on fuel cycle costs (direct disposal option) (mills/kWh)

\begin{tabular}{||l|c|c|c|c|c|c|c||}
\hline \multirow{2}{*}{ Fuel cycle component } & \multicolumn{7}{|c||}{ Discount rate (\%) } \\
\cline { 2 - 8 } & $\mathbf{0}$ & $\mathbf{2}$ & $\mathbf{5}$ & $\mathbf{8}$ & $\mathbf{1 0}$ & $\mathbf{1 2}$ & $\mathbf{1 5}$ \\
\hline Uranium & 1.45 & 1.52 & 1.64 & 1.78 & 1.89 & 2.00 & 2.19 \\
Conversion & 0.18 & 0.19 & 0.21 & 0.23 & 0.24 & 0.25 & 0.28 \\
Enrichment & 1.65 & 1.72 & 1.85 & 1.98 & 2.07 & 2.18 & 2.33 \\
Fuel fabrication & 0.87 & 0.92 & 1.00 & 1.09 & 1.16 & 1.23 & 1.34 \\
Subtotal for front-end & $\mathbf{4 . 1 5}$ & $\mathbf{4 . 3 5}$ & $\mathbf{4 . 7 0}$ & $\mathbf{5 . 0 8}$ & $\mathbf{5 . 3 6}$ & $\mathbf{5 . 6 6}$ & $\mathbf{6 . 1 4}$ \\
& & & & & & & \\
Transport/Storage & 0.67 & 0.55 & 0.51 & 0.55 & 0.58 & 0.62 & 0.66 \\
Encapsulation/Disposal & 1.14 & 0.60 & 0.25 & 0.11 & 0.07 & 0.04 & 0.02 \\
Subtotal for back-end & $\mathbf{1 . 8 1}$ & $\mathbf{1 . 1 5}$ & $\mathbf{0 . 7 6}$ & $\mathbf{0 . 6 6}$ & $\mathbf{0 . 6 5}$ & $\mathbf{0 . 6 6}$ & $\mathbf{0 . 6 8}$ \\
& & & & & & & \\
Total cost & $\mathbf{5 . 9 6}$ & $\mathbf{5 . 5 0}$ & $\mathbf{5 . 4 6}$ & $\mathbf{5 . 7 4}$ & $\mathbf{6 . 0 1}$ & $\mathbf{6 . 3 2}$ & $\mathbf{6 . 8 2}$ \\
\hline \hline
\end{tabular}

Back-end levelised unit prices (ECU/kg U) for the direct disposal option at various discount rates

\begin{tabular}{|c|c|c|c|c|c|c|c|}
\hline \multirow[b]{3}{*}{ Transport/Storage } & \multicolumn{7}{|c|}{ Discount rate $(\%)$} \\
\hline & $\mathbf{0}$ & 2 & 5 & 8 & 10 & 12 & 15 \\
\hline & 210 & 200 & 230 & 280 & 340 & 400 & 500 \\
\hline Encapsulation/Disposal & 360 & 430 & 610 & 870 & 1100 & 1390 & 1920 \\
\hline
\end{tabular}

Note: Data at the same discount rate were used in deriving the above back-end fuel cycle costs, i.e. a transport/storage price of ECU 230 per $\mathrm{kg} \mathrm{U}$ was used to obtain the final cycle cost at the 5 per cent discount rate and a transport/storage price of ECU 340 per $\mathrm{kg} \mathrm{U}$ was used for the fuel cycle cost at 10 per cent discount rate. The same convention was used for the waste encapsulation/disposal component. 
Table 6.3. Likely range of fuel cycle costs, overall and for separate uranium price profiles

(mills/kWh)

\begin{tabular}{||l|c|c||}
\hline & $\begin{array}{c}\text { Reprocessing } \\
\text { option }\end{array}$ & $\begin{array}{c}\text { Direct disposal } \\
\text { option }\end{array}$ \\
\cline { 2 - 3 } For all parameters & $5.17-7.06$ & $4.28-6.30$ \\
U price: \$50/kg U, escalation & & $4.54-5.88$ \\
$1.2 \%$ p.a. (reference) & $5.39-6.65$ & $3.93-5.26$ \\
U price: $\$ 40 / \mathrm{kg}$ U, escalation 0\% p.a. & $4.83-6.10$ & $5.25-6.58$ \\
\hline U price: $\$ 90 / \mathrm{kg} U$, escalation 0\% p.a. & $6.06-7.33$ & \\
\hline
\end{tabular}

Note: As described in section 6.5, the "likely range" is based on the two sigma limit (i.e. 95 per cent confidence interval) of the overall fuel cost distribution. 
Figure 6.1 Summary of sensitivity analysis for the reprocessing option

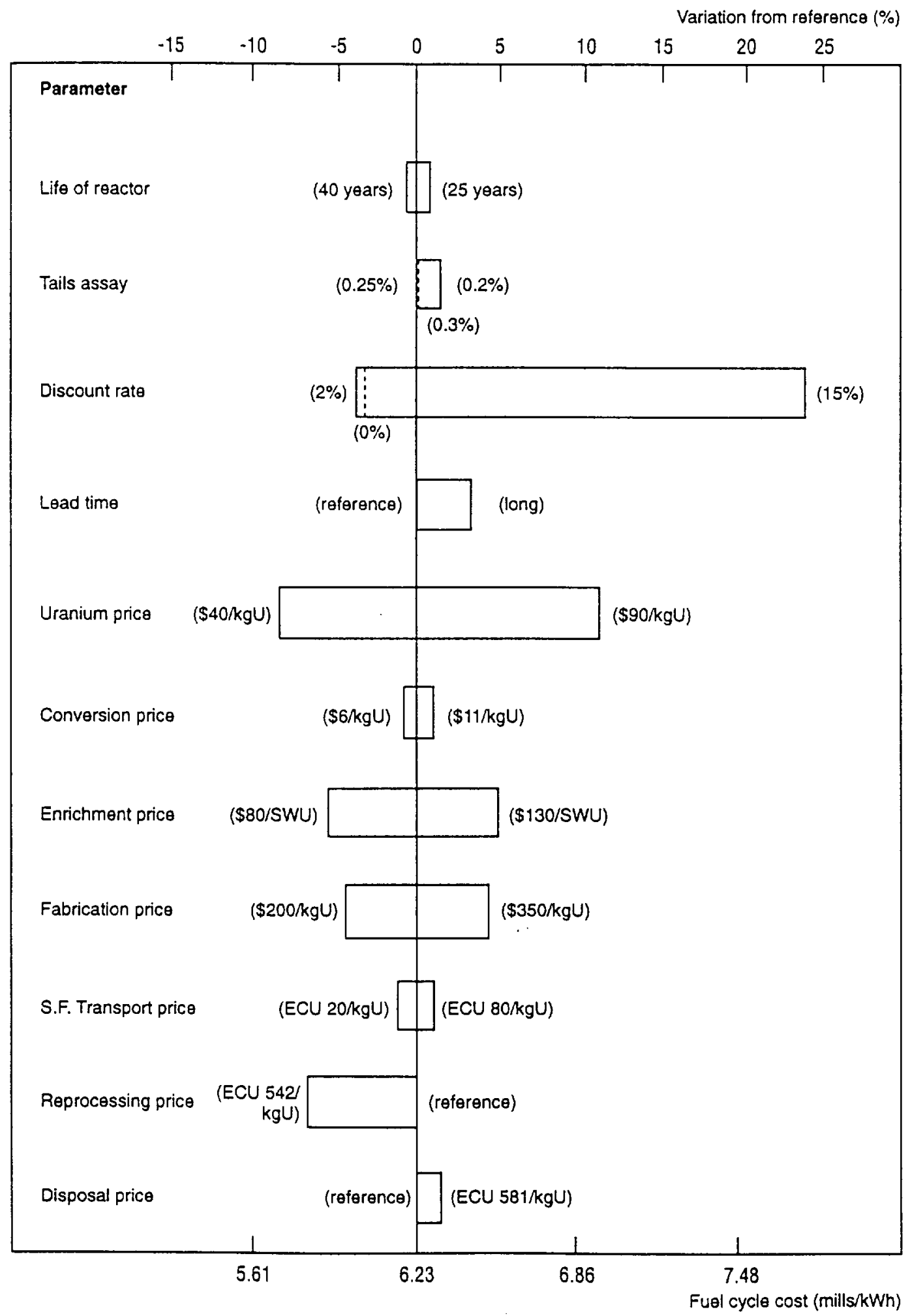


Figure 6.2 Summary of sensitivity analysis for the direct disposal option

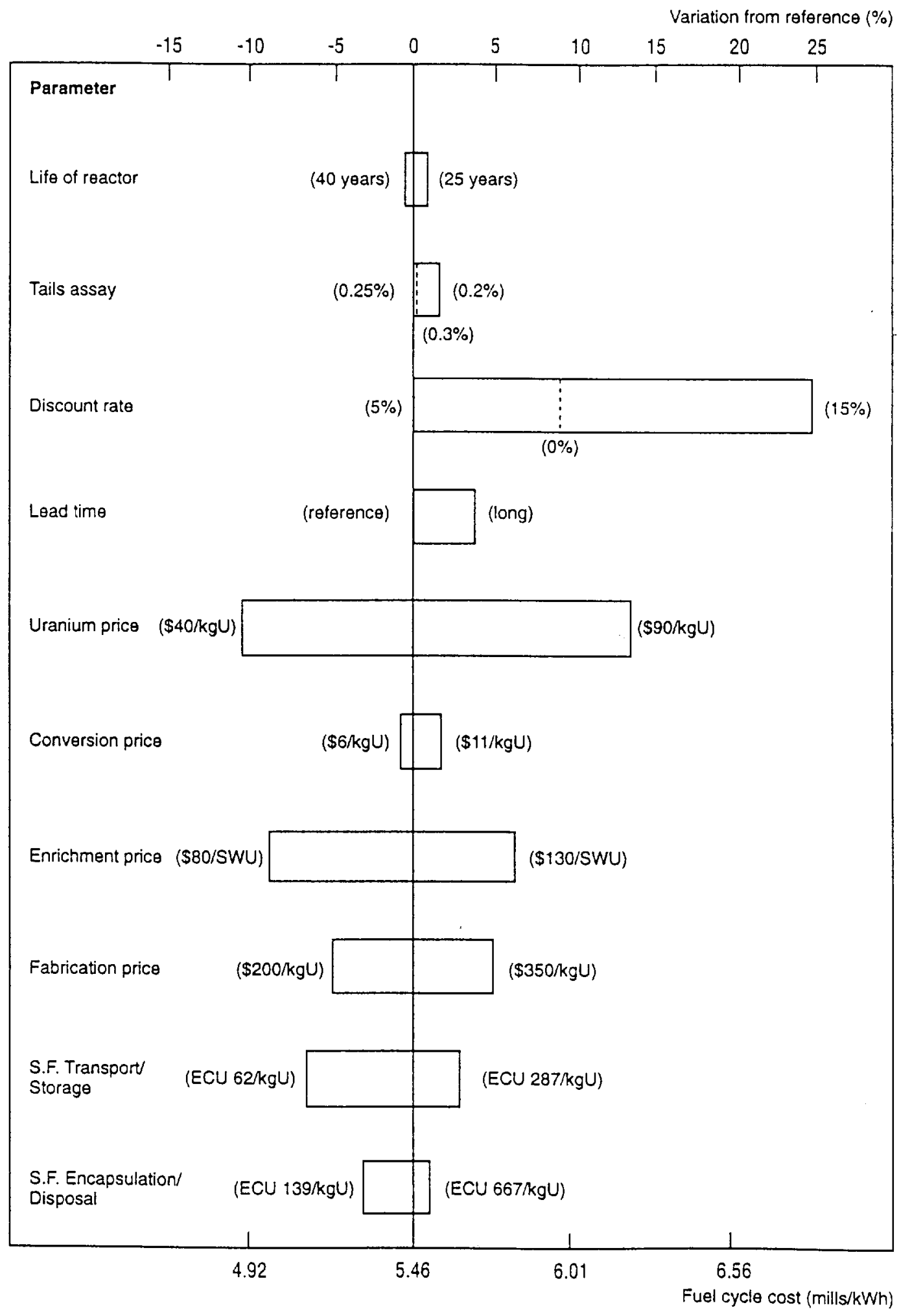


Figure 6.3 Effect of discount rate on fuel cycle costs

(reprocessing option)

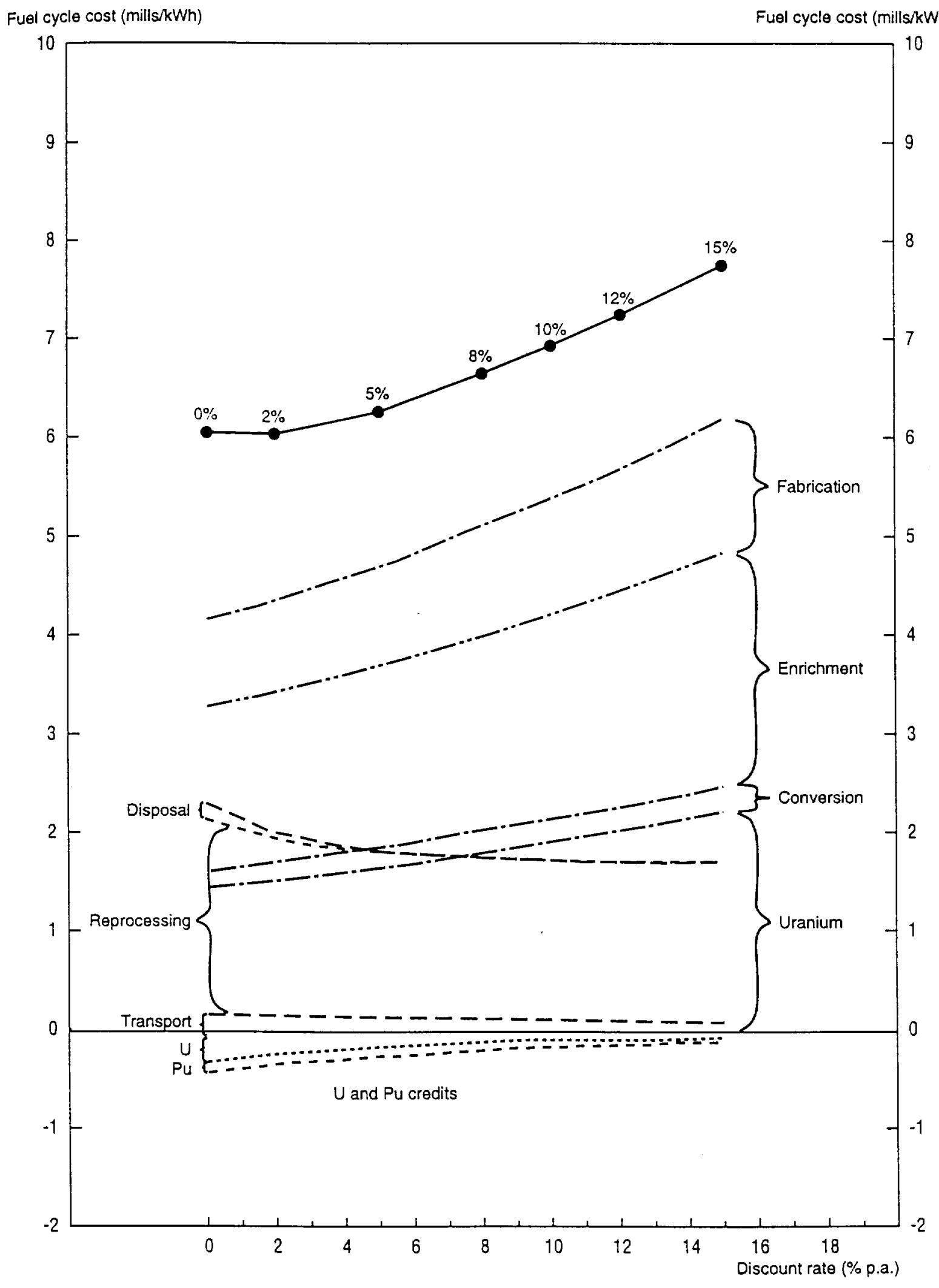


Figure 6.4 Effect of discount rate on fuel cycle costs (direct disposal option)

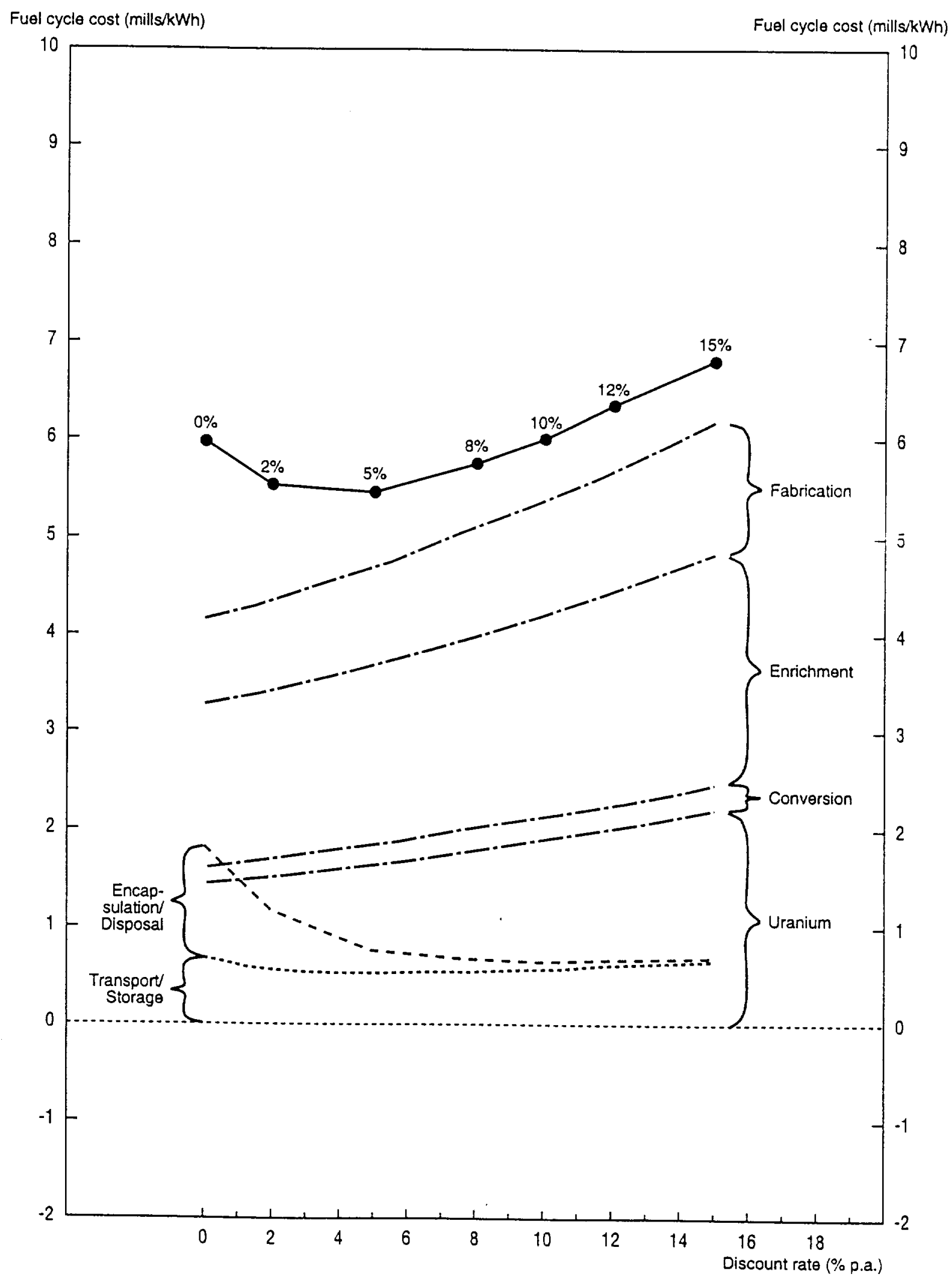


Figure 6.5 Maximum range of PWR fuel cycle cost

for the reprocessing option

\begin{tabular}{|c|c|c|}
\hline Parameter & Higher bound & Lower bound \\
\hline Life of reactor & 25 years & 40 years \\
Tails assay & $0.20 \%$ & $0.25 \%$ (reference) \\
Lead time & Longer lead times & Reference lead times \\
Unit costs & Higher variants & Lower variants \\
\hline
\end{tabular}

Fuel cycle cost (mills/kWh)

Fuel cycle cost (mills/kWh)

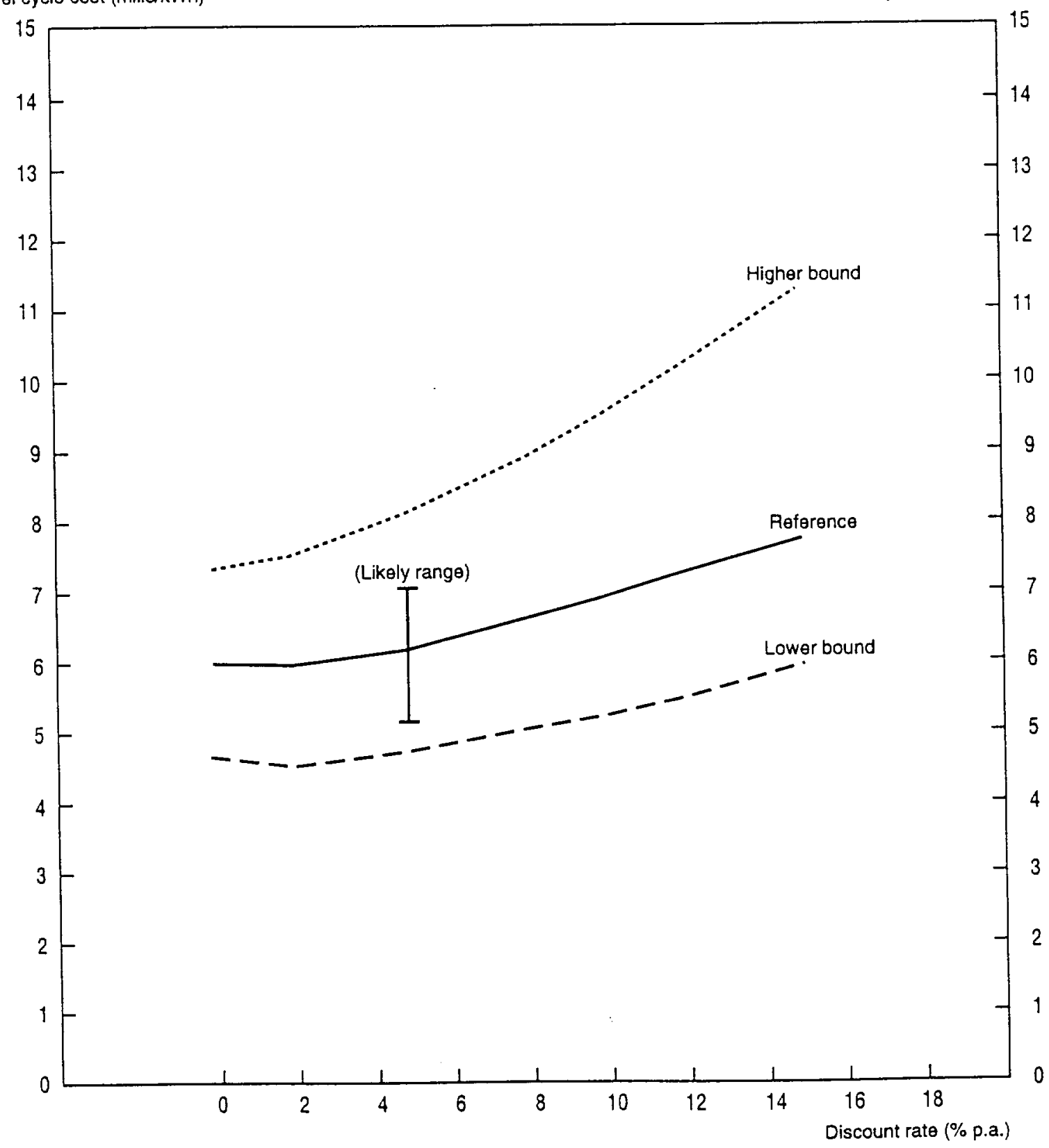


Figure 6.6 Maximum range of PWR fuel cycle cost for the direct disposal option

\begin{tabular}{|c|c|c|}
\hline Parameter & Higher bound & Lower bound \\
\hline Life of reactor & 25 years & 40 years \\
Tails assay & $0.20 \%$ & $0.25 \%$ (reference) \\
Lead time & Longer lead times & Reference lead times \\
Unit costs & Higher variants & Lower variants \\
\hline
\end{tabular}

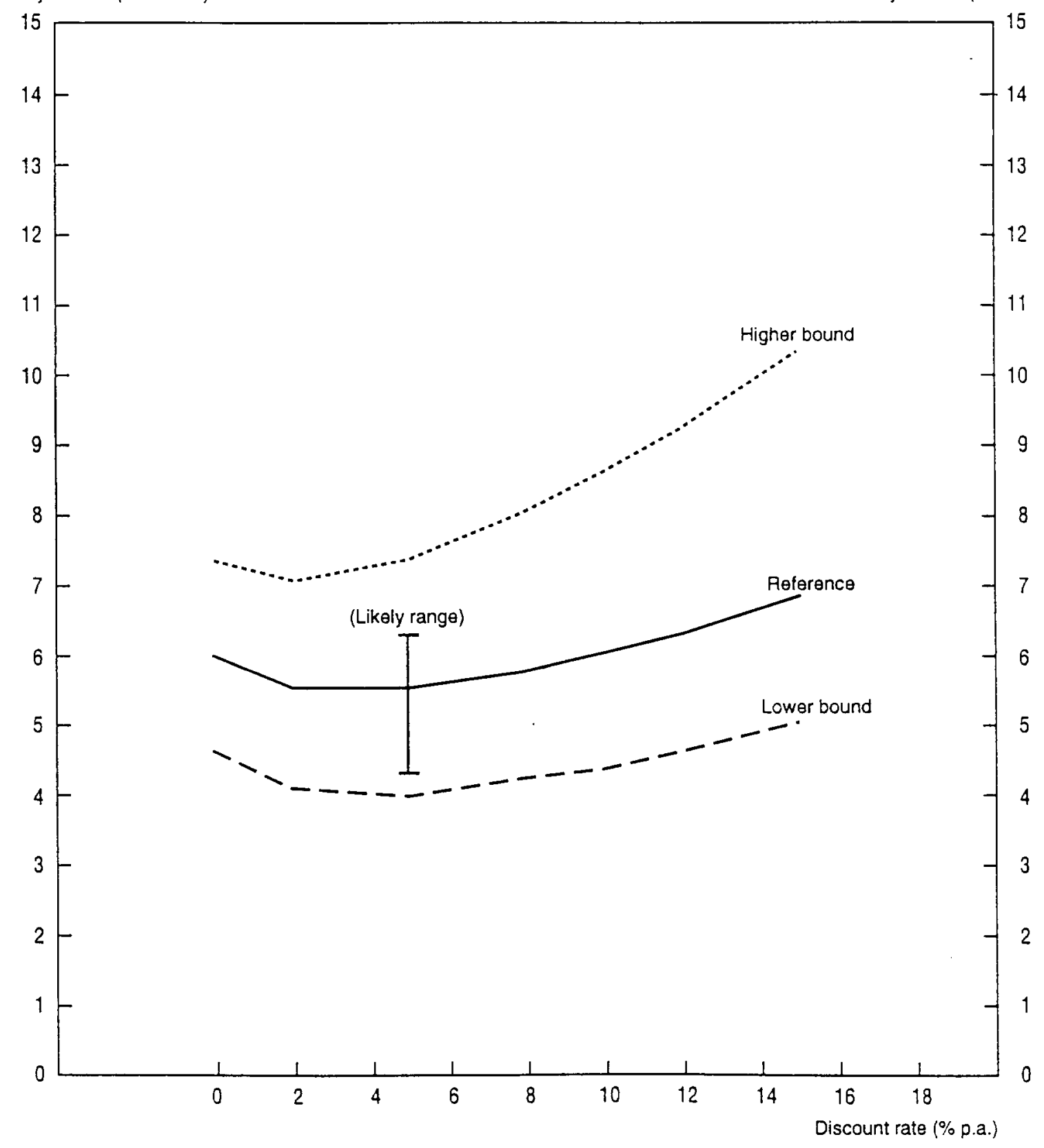




\section{COMPARISON BETWEEN THE RESULTS OF THE PRESENT STUDY AND THE 1985 STUDY}

The main purpose of the present study is to revise the 1985 NEA study on The Economics of the Nuclear Fuel Cycle ${ }^{(7)}$. The principal revisions concern the unit prices for the fuel cycle and the reactor core performance. The uranium purchase price which shared approximately 40 per cent of the total fuel cycle costs in the 1985 NEA study for both spent fuel disposal options is now much lower and stable for reasons of over-supply. Furthermore, the N4 reference French reactor is expected to have an improved core performance and a higher burn-up (42 $500 \mathrm{MWd} / \mathrm{t})$.

The results of the 1985 study cannot be compared directly with the results of the present study because of the differences in money values and core performances adopted. Therefore, two approaches are used to compare the results of these studies. Firstly, the January 1984 money value is converted to the January 1991 money value by using the GDP deflator to the US dollar and by recalculating the fuel cycle costs of the 1985 study utilising the converted unit prices. Secondly, the fuel cycle costs are calculated by using the 1985 study adopted reactor burn-up (33 $000 \mathrm{MWd} / \mathrm{t}$ ) and the unit prices of the present study.

The importance of the changes in unit prices can be estimated by comparing the results of the above mentioned approaches. This comparison is not, strictly speaking, accurate because of the adoption of the slightly different core performances assumed in the two studies, but is quite helpful in indicating the total cost changes. The effects of the reactor core performances can be seen by comparing the results of the present study to those of the above mentioned second approach.

Tables 7.1, 5.6 and 7.2 show the plant performance and fuel cycle data for the two studies while the various unit prices are displayed in Table 7.3. From these data it can be seen that the uranium purchase price which was used in the present study is drastically lower than that used in the 1985 study.

Figure 7.1 displays the comparison of the results of the two studies for the reprocessing option. It can be seen that the total fuel cycle costs are reduced from 10.86 to 6.23 mills $/ \mathrm{kWh}$. Nearly 80 per cent of this reduction is due to the differences in unit prices and, in particular, the much lower uranium purchase cost component (approximately 60 per cent). The rest of the reduction is due to the improved reactor performance.

Figure 7.2 shows the comparison of the results of the two studies for the direct disposal option. Total fuel cycle costs are reduced from 9.85 to $5.46 \mathrm{mills} / \mathrm{kWh}$. Nearly 85 per cent of this reduction is due to the reduction in unit prices and the rest is due to the improved reactor and fuel performance. 
Table 7.1. Basic assumptions used in PWR cycle cost calculations

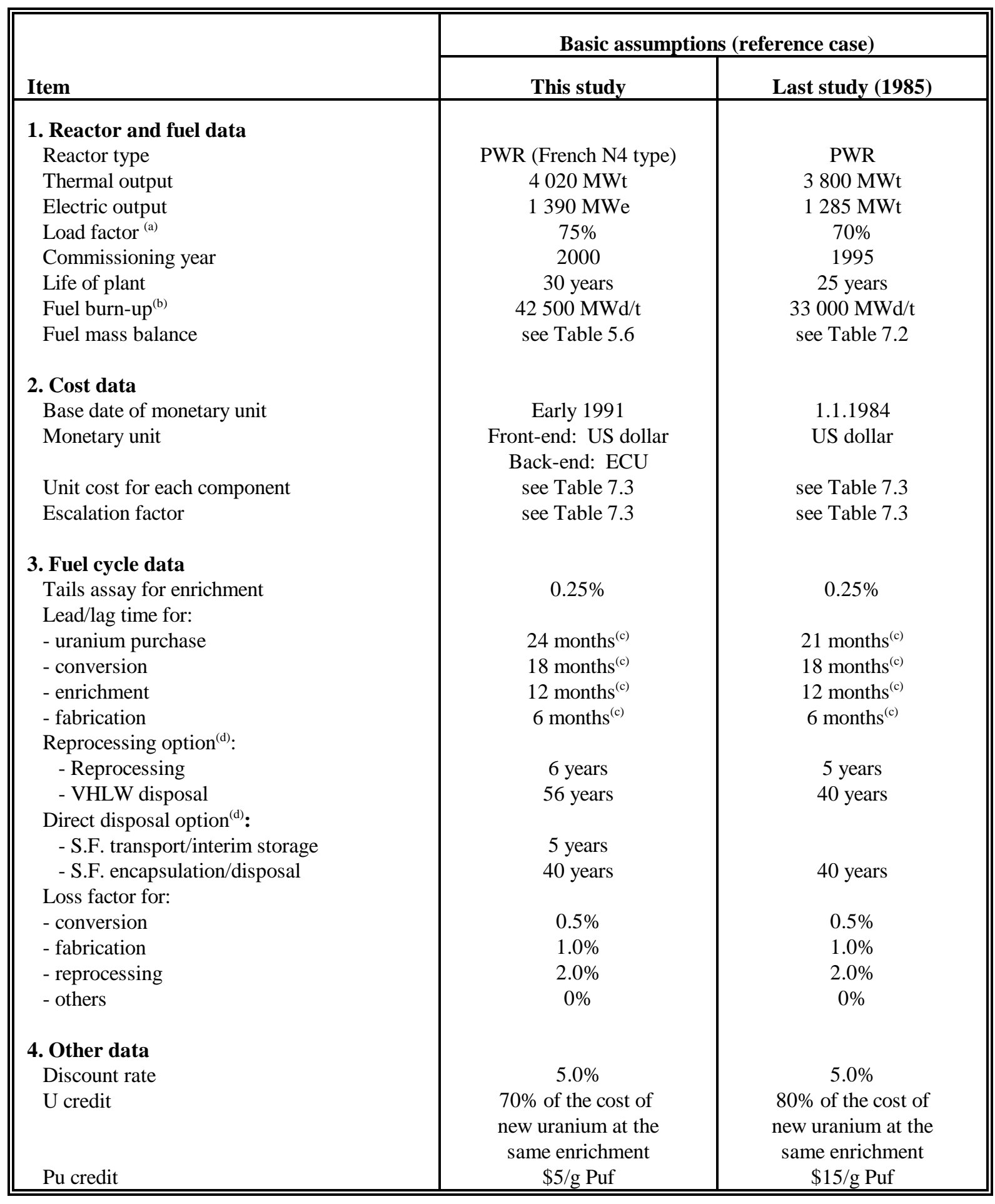

$\begin{array}{lll}\text { Notes: } & \text { a. } & \text { Discounted average. } \\ & \text { b. } & \text { At equilibrium. } \\ & \text { c. } & \text { For initial fuel } 6 \text { months are added. } \\ \text { d. } & \text { Including storage time at reactor. }\end{array}$


Table 7.2. Material balance (PWR, 33000 MWd/t)

\begin{tabular}{|c|c|c|c|c|c|c|}
\hline $\begin{array}{c}\text { Time } \\
\text { (EFPY) }\end{array}$ & $\begin{array}{c}\text { Interval between } \\
\text { reload } \\
(\text { EFPY) }\end{array}$ & $\begin{array}{c}\text { Total } \\
\text { uranium } \\
\text { (tonne) }\end{array}$ & $\begin{array}{c}\text { U-235 } \\
(\%)\end{array}$ & $\begin{array}{c}\text { Fissile } \\
\text { Pu } \\
(\mathbf{k g})\end{array}$ & $\begin{array}{c}\text { Total } \\
\text { Pu } \\
(\mathbf{k g})\end{array}$ & $\begin{array}{l}\text { Burn-up } \\
(\mathrm{MWd} / \mathrm{t})\end{array}$ \\
\hline \multicolumn{7}{|c|}{ 1. Non-equilibrium cycle charge data } \\
\hline $\begin{array}{l}0 \\
0 \\
0 \\
0.919 \\
1.687 \\
\end{array}$ & & $\begin{array}{l}35.00 \\
34.50 \\
34.50 \\
34.70 \\
34.70 \\
\end{array}$ & $\begin{array}{l}1.50 \\
2.40 \\
2.95 \\
3.10 \\
3.10 \\
\end{array}$ & & & \\
\hline \multicolumn{7}{|c|}{ 2. Equilibrium cycle charge data } \\
\hline 2.467 & 0.325 & 34.70 & 3.10 & & & \\
\hline \multicolumn{7}{|c|}{ 3. Non-equilibrium cycle discharge data } \\
\hline $\begin{array}{l}0.919 \\
1.687 \\
2.476 \\
3.292 \\
4.117 \\
\end{array}$ & & $\begin{array}{l}34.30 \\
33.50 \\
33.10 \\
33.30 \\
33.30 \\
\end{array}$ & $\begin{array}{l}0.64 \\
0.76 \\
0.80 \\
0.85 \\
0.85 \\
\end{array}$ & $\begin{array}{l}159.00 \\
201.00 \\
224.00 \\
232.00 \\
229.00 \\
\end{array}$ & $\begin{array}{l}217.00 \\
274.00 \\
305.00 \\
318.00 \\
314.00 \\
\end{array}$ & $\begin{array}{l}12035 \\
23860 \\
31750 \\
32000 \\
33000 \\
\end{array}$ \\
\hline \multicolumn{7}{|c|}{ 4. Equilibrium cycle discharge data } \\
\hline 4.942 & 0.825 & 33.30 & 0.85 & 229.00 & 314.00 & 33000 \\
\hline \multicolumn{7}{|c|}{ 5. Final core discharge data } \\
\hline & & $\begin{array}{l}33.30 \\
33.30 \\
33.40 \\
\end{array}$ & $\begin{array}{l}0.85 \\
1.60 \\
2.35 \\
\end{array}$ & $\begin{array}{l}229.00 \\
200.00 \\
171.00 \\
\end{array}$ & $\begin{array}{l}314.00 \\
272.00 \\
214.00 \\
\end{array}$ & $\begin{array}{l}33000 \\
21000 \\
11000 \\
\end{array}$ \\
\hline
\end{tabular}

Note: $\mathrm{EFPY}=$ effective full-power year 
Table 7.3. PWR fuel cycle unit prices

\begin{tabular}{|c|c|c|c|}
\hline \multirow[b]{2}{*}{ Component } & \multicolumn{3}{|c|}{ Basic assumptions for PWR (reference case) } \\
\hline & $\begin{array}{c}\text { This study } \\
\text { (early } 1991 \text { US\$) }\end{array}$ & $\begin{array}{c}\text { Last study } \\
\text { (US\$ at 1.1.84) }\end{array}$ & $\begin{array}{c}\begin{array}{c}\text { Last study } \\
\text { (early } 1991 \text { US\$) }\end{array} \\
\end{array}$ \\
\hline Uranium purchase & $\begin{array}{c}\$ 50 / \mathrm{kg} \mathrm{U}(\text { in } 1990) \\
\left(\$ 19.2 / \mathrm{lb} \mathrm{U}_{3} 0_{8}\right) \\
\text { Escalation } 1.2 \% \text { p.a. }\end{array}$ & $\begin{array}{c}\$ 83.2 / \mathrm{kg} \mathrm{U} \text { (in } 1984) \\
\quad\left(\$ 32 / \mathrm{lb} \mathrm{U}_{3} 0_{8}\right) \\
\text { Escalation } 2.0 \% \text { p.a. }\end{array}$ & $\begin{array}{l}\$ 105 / \mathrm{kg} \mathrm{U} \text { (in } 1991) \\
\quad\left(\$ 41 / \mathrm{lb} \mathrm{U}_{3} 0_{8}\right) \\
\text { Escalation } 2.0 \% \text { p.a. }\end{array}$ \\
\hline Conversion & $\$ 8 / \mathrm{kg} \mathrm{U}$ & $\$ 6 / \mathrm{kg} \mathrm{U}$ & $\$ 8 / \mathrm{kg} \mathrm{U}$ \\
\hline Enrichment & \$110/SWU & $\$ 130 /$ SWU & $\$ 165 /$ SWU \\
\hline Fabrication & $\$ 275 / \mathrm{kg} \mathrm{U}$ & $\$ 190 / \mathrm{kg} \mathrm{U}$ & $\$ 241 / \mathrm{kg} \mathrm{U}$ \\
\hline $\begin{array}{l}\text { Reprocessing option: } \\
\text { - spent fuel transport }{ }^{(b)} \\
\text { - spent fuel storage } \\
\text { - reprocessing } \\
\text { (incl. buffer st.): } \\
\text { vitrification } \\
\text { - waste disposal }\end{array}$ & $\begin{array}{l}\text { ECU 50/kg U } \\
\text { B } \\
\text { C ECU 720/kg U } \\
\text { D } \\
\text { ECU 90/kg U }\end{array}$ & $\begin{array}{c}\$ 40 / \mathrm{kg} \mathrm{HM} \\
\$(40+4 / \text { year }) / \mathrm{kg} \mathrm{HM} \\
\\
\$ 550 / \mathrm{kg} \mathrm{HM} \\
\$ 200 / \mathrm{kg} \mathrm{HM} \\
\$ 150 / \mathrm{kg} \mathrm{HM}\end{array}$ & $\begin{array}{c}\$ 51 / \mathrm{kg} \mathrm{HM} \\
\$(51+5 / \text { year }) / \mathrm{kg} \mathrm{HM} \\
\\
\$ 696 / \mathrm{kg} \mathrm{HM} \\
\$ 253 / \mathrm{kg} \mathrm{HM} \\
\$ 190 / \mathrm{kg} \mathrm{HM}\end{array}$ \\
\hline $\begin{array}{l}\text { Direct disposal option: } \\
\text { - spent fuel transport }{ }^{(\mathrm{b})} \\
\text { - spent fuel storage } \\
\text { - encapsulation } \\
\text { - disposal }\end{array}$ & $\begin{array}{l}\text { @ECU 230/kg U } \\
\text { @ECU 610/kg U }\end{array}$ & $\begin{array}{c}\$ 40 / \mathrm{kg} \mathrm{HM} \\
\$(40+4 / \text { year }) / \mathrm{kg} \mathrm{HM} \\
\$ 200 / \mathrm{kg} \mathrm{HM} \\
\$ 150 / \mathrm{kg} \mathrm{HM}\end{array}$ & $\begin{array}{c}\$ 51 / \mathrm{kg} \mathrm{HM} \\
\$(51+5 / \text { year }) / \mathrm{kg} \mathrm{HM} \\
\$ 253 / \mathrm{kg} \mathrm{HM} \\
\$ 190 / \mathrm{kg} \mathrm{HM}\end{array}$ \\
\hline
\end{tabular}

a. Prices have been revised by using a GDP deflator of 1.266.

b. Transportation within the European area. 


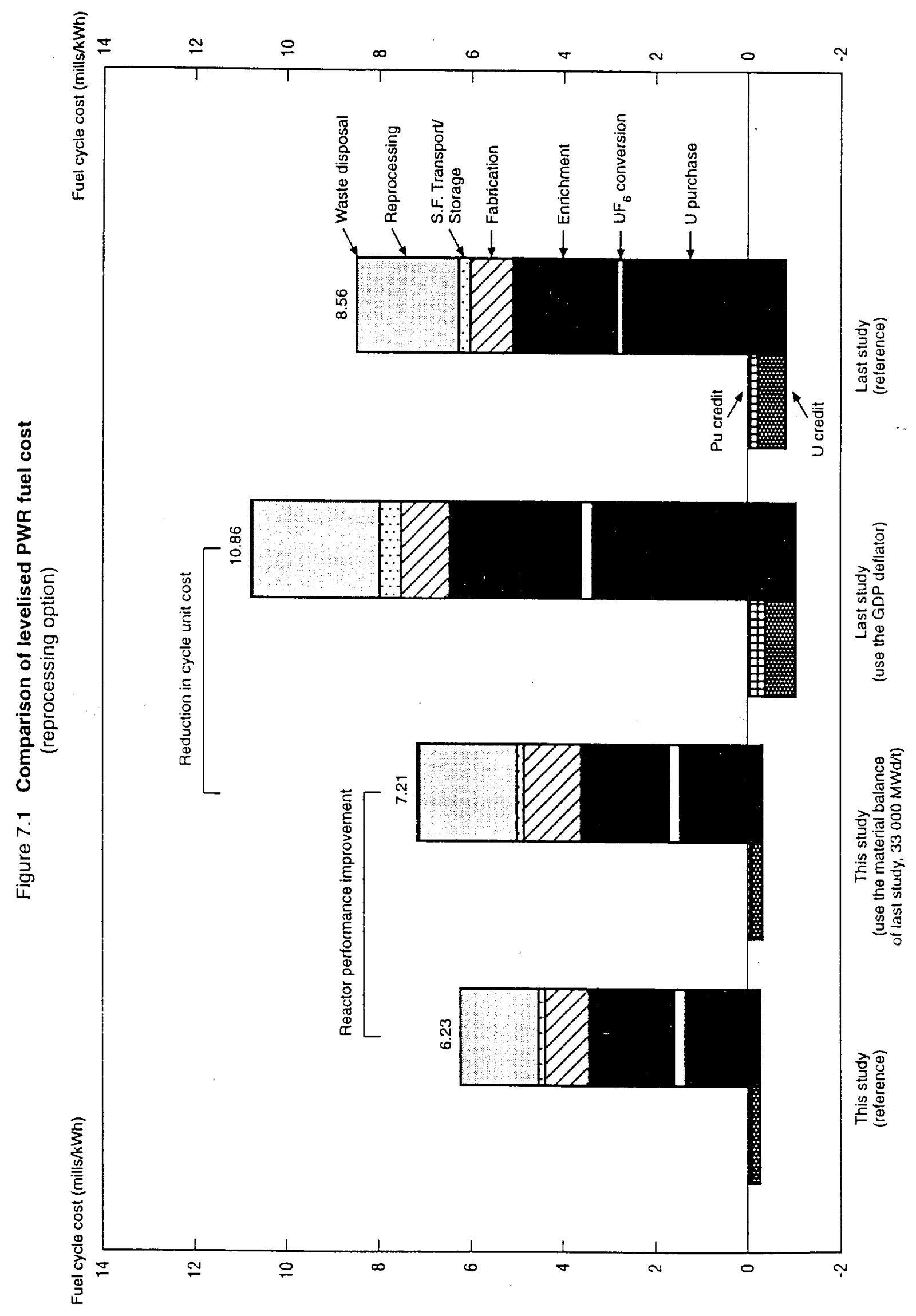




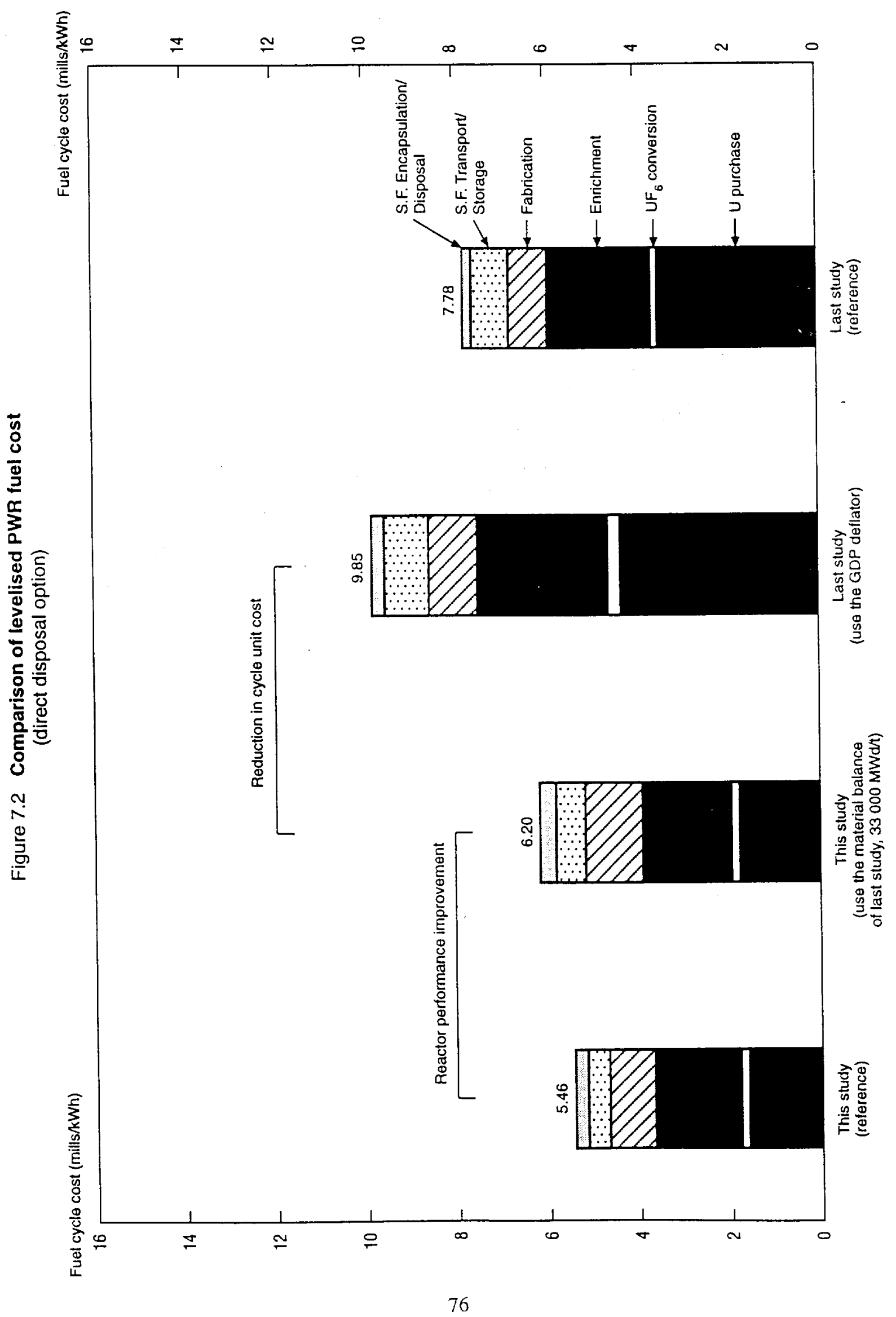




\section{OTHER FUEL CYCLES}

\subsection{CANDU}

\subsubsection{CANDU fuel}

The Canadian pressurised heavy water reactor (PHWR or CANDU) uses natural uranium fuel in the form of uranium oxide pellets sealed in thin zircalloy sheaths. The initial stages of the fuel cycle are similar to those for the PWR, as described elsewhere in this report. CANDU fuel does not require enrichment and the fuel assemblies are very simple, typically containing only 37 fuel elements, and much shorter than those used in the PWR.

The reactor design permits bi-directional on-load refuelling which can be performed on a "continuous" basis without the reactor being shut down. The PWR, in contrast, has to be shut down and the fuel replaced in a batchwise manner.

Because CANDU uses natural uranium, it does not produce any enrichment tails. Thus, although it has an apparently low average burn-up of about $8330 \mathrm{MWd} / \mathrm{t}$, CANDU fuel actually produces about 38 per cent more energy per tonne of uranium mined than enriched PWR fuel with an average burn-up of 42500 $\mathrm{MWd} / \mathrm{t}$. The discharged fuel contains less than the natural concentration of fissionable isotopes so that it can be handled without any need for consideration of criticality in the natural environment. The discharged fuel is stored for a planned period of 10 years at the reactor sites in water filled bays or dry storage containers. Canada has no plans to reprocess its spent fuel and procedures have been designed for the encapsulation and ultimate disposal of the fuel following the direct disposal approach as the LWRs. Figure 8.1 illustrates the material flow of the CANDU fuel cycle.

\subsubsection{Basic assumptions}

Table 8.1 shows the basic assumptions used in CANDU fuel cycle cost calculations.

The reference CANDU adopted for this study has a rated net output of $881 \mathrm{MWe}$, based on the Darlington A design, which can be constructed for commercial operation in the year 2000. For the purpose of this study, the reactor lifetime and load factor have been assumed to be 30 years and 75 per cent respectively, similar to the PWR, although Canadian experience indicates a lifetime capacity factor of above 80 per cent is likely and national assumptions use lifetimes of 30 to 40 years. The fuel mass balance for this reactor is shown in Table 8.2.

The price of uranium is assumed to be $\$ 65$ per $\mathrm{kg} \mathrm{U}$ (1991 US dollars). Other prices such as conversion, fabrication, transportation and spent fuel disposal are based on Canadian experience and estimates. Because no enrichment is required, the uranium dioxide $\left(\mathrm{UO}_{2}\right)$ produced from the uranyl 
Table 8.1. Basic assumptions used in CANDU fuel cycle cost calculations

\begin{tabular}{|c|c|}
\hline Item & Reference \\
\hline \multicolumn{2}{|l|}{ 1. Reactor and fuel data } \\
\hline Reactor type & PHWR \\
\hline Thermal output & $2779 \mathrm{MWt}$ \\
\hline Gross electrical output & $935 \mathrm{MWe}$ \\
\hline Net electrical output & $881 \mathrm{MWe}$ \\
\hline Load factor $^{(a)}$ & $75 \%$ \\
\hline Commissioning year & 2000 \\
\hline Life of plant & 30 years \\
\hline Fuel burn-up ${ }^{(\mathrm{b})}$ & $8330 \mathrm{MWd} / \mathrm{t}$ \\
\hline Fuel mass balance & see Table 8.2 \\
\hline \multicolumn{2}{|l|}{ 2. Cost data } \\
\hline Base date of monetary unit & Early 1991 \\
\hline Monetary unit & US dollar \\
\hline Unit price for each component & \\
\hline - natural uranium & $\$ 65 / \mathrm{kg} \mathrm{U}$ \\
\hline - conversion to $\mathrm{UO}_{2}$ & $\$ 8 / \mathrm{kg} \mathrm{U}$ \\
\hline - fabrication & $\$ 65 / \mathrm{kg} \mathrm{U}$ \\
\hline - transportation of spent fuel & $\$ 13 / \mathrm{kg} \mathrm{HM}$ \\
\hline - storage of spent fuel ${ }^{(\mathrm{c})}$ & - \\
\hline - disposal of spent fuel & $\$ 73 / \mathrm{kg} \mathrm{HM}$ \\
\hline \multicolumn{2}{|l|}{ 3. Fuel cycle data } \\
\hline \multicolumn{2}{|l|}{ Lead/lag time for } \\
\hline - uranium purchase & 17 months \\
\hline - conversion to $\mathrm{UO}_{2}$ & 13 months \\
\hline - fabrication & 10 months \\
\hline - disposal of spent fuel & 10 years \\
\hline \multicolumn{2}{|l|}{ Loss factor for } \\
\hline - conversion to $\mathrm{UO}_{2}$ & $0.5 \%$ \\
\hline - fabrication & $0.5 \%$ \\
\hline \multicolumn{2}{|l|}{ 4. Other data } \\
\hline Discount rate & $5 \%$ p.a. \\
\hline $\mathrm{U}$ and $\mathrm{Pu}$ credits & no credit \\
\hline
\end{tabular}

\footnotetext{
a. Discounted average.

b. At equilibrium.

c. Spent fuel will be stored at reactor for 10 years; costs are included in operation and maintenance costs.
} 
nitrate is shipped directly to the fuel element fabrication plant, thus avoiding additional conversion cost. The fabrication of unenriched uranium oxide fuels for CANDU reactors is considerably cheaper. This is attributed to the very high fuel throughput and the simple fuel assembly design. The lower fabrication cost of $\$ 65$ per $\mathrm{kg} \mathrm{U}$ (used as reference price) is partly counter-balanced by the relatively low burn-up achievable with unenriched fuel in the PHWR which means that more fuel has to be put through the reactor to achieve a given energy output.

The costs of encapsulation and disposal of spent CANDU fuel have been studied in Canada and estimated at \$73 per kg HM which are much lower than those for PWR spent fuel. The major reason for this difference is the low burn-up of CANDU fuel, thus the low concentration of fission products, which in turn means less heat production, less toxicity, less shielding requirements, etc. There is no criticality hazard with natural uranium fuel either, which simplifies handling. The repository design assumed in Canada is quite large, holding some 100 million $\mathrm{kg} \mathrm{HM}$, compared with those of other countries. Thus, there would be some benefits of scale in the disposal cost of CANDU spent fuel.

The lead and lag times assumed for the CANDU fuel cycle are also based on data presented by Canada. Spent fuel will be stored at the reactor site for 10 years and, according to present plans, disposed of without reprocessing. The allowances for material losses in the fuel cycle processes are also shown in Table 8.1.

For the reference calculations, a discount rate of 5 per cent per annum in real terms is assumed. No credits for uranium and plutonium have been taken into account.

Table 8.2. Material balance data for CANDU (881 MWe-net)

\begin{tabular}{|c|c|c|c|c|c|c|}
\hline $\begin{array}{c}\text { Time } \\
{\left[\mathrm{EFPY}^{(\mathbf{a})}\right]}\end{array}$ & $\begin{array}{c}\text { Interval } \\
\text { between } \\
\text { reload } \\
{\left[\text { EFPY }^{(a)}\right]} \\
\end{array}$ & $\begin{array}{c}\text { Total } \\
\text { uranium } \\
\text { (tonne) }\end{array}$ & $\begin{array}{l}{ }^{235} \mathrm{U} \\
(\%) \\
\end{array}$ & $\begin{array}{c}\text { Fissile } \\
\text { Pu } \\
(\mathbf{k g}) \\
\end{array}$ & $\begin{array}{c}\text { Total } \\
\text { Pu } \\
(\mathbf{k g}) \\
\end{array}$ & $\begin{array}{l}\text { Burn-up } \\
(\mathrm{MWd} / \mathrm{t})\end{array}$ \\
\hline \multicolumn{7}{|c|}{ 1. Initial fuel charge data } \\
\hline 0 & - & 118.6 & 0.711 & - & - & - \\
\hline \multicolumn{7}{|c|}{ 2. Equilibrium cycle charge data } \\
\hline 0.75 & $0.98^{(\mathrm{b})}$ & 119.0 & 0.711 & - & - & - \\
\hline \multicolumn{7}{|c|}{ 3. Equilibrium cycle discharge data } \\
\hline 1.73 & $0.98^{(\mathrm{b})}$ & 117.53 & 0.20 & 308 & 453 & 8330 \\
\hline \multicolumn{7}{|c|}{ 4. Equilibrium core discharge data } \\
\hline End of life & - & 117.71 & 0.36 & 250 & 308 & 8330 \\
\hline
\end{tabular}

a. EFPY = effective full-power year.

b. The time interval indicated was chosen to facilitate calculations; in reality CANDU reactors are refuelled on power "continuously" (i.e. on most operating days some fuel will be changed). 
Table 8.3 shows the typical fuel cycle cost for CANDU, which totals to $2.86 \mathrm{mills} / \mathrm{kWh}$.

Table 8.3. Levelised fuel cycle cost for CANDU

\begin{tabular}{||l|c|c||}
\hline Component & mills/kWh & per cent \\
\hline Fuel purchase $^{(a)}$ & 1.20 & 42.0 \\
Fuel fabrication & 1.03 & 36.0 \\
Subtotal for front-end & $\mathbf{2 . 2 3}$ & $\mathbf{7 8 . 0}$ \\
& & \\
Transportation of spent fuel & 0.10 & 3.5 \\
Spent fuel disposal & 0.53 & 18.5 \\
Subtotal for back-end & $\mathbf{0 . 6 3}$ & $\mathbf{2 2 . 0}$ \\
& & \\
Total & $\mathbf{2 . 8 6}$ & $\mathbf{1 0 0 . 0}$ \\
\hline
\end{tabular}

a. Including $\mathrm{U}_{3} \mathrm{O}_{8}$ purchase and conversion to $\mathrm{UO}_{2}$. 


\subsection{ATR}

\subsubsection{ATR fuel}

The Advanced Thermal Reactor (ATR) is a heavy water moderated, light water cooled reactor under development in Japan. The reactor uses mixed oxide fuel of natural uranium and plutonium. The substitution of plutonium for ${ }^{235} \mathrm{U}$ results in a large reduction of uranium ore requirements. The ATR does require, however, quantities of plutonium equivalent to the ${ }^{235} \mathrm{U}$ content, which have to be obtained by reprocessing conventional thermal reactor fuel.

Natural uranium oxide, similar to that used in the CANDU reactors or recovered uranium oxide is mixed with plutonium oxide which is obtained from reprocessing plants. Enriched uranium fuel could also be used instead of mixed oxide fuel, but this option is not considered here. Production of mixed oxide fuel requires additional mixing stages and careful quality control to ensure homogeneity of the fuel pellets which are put together in pins and fuel assemblies in the same way as pure uranium oxide fuels. Mixed oxide fuel fabrication requires appropriate shielding and the use of remote handling techniques in order to minimise the radiation exposure to the workers. These additional precautions lead to higher fabrication costs than those for conventional uranium fuel; the reference price is assumed to be $\$ 980$ per $\mathrm{kg} \mathrm{HM}$, in accordance with the Japanese data. This figure is only an indicative one and should not be directly compared with the reference PWR fabrication cost figure adopted for this study.

ATR spent fuel is initially held in cooling ponds at the reactor site, for a period similar to that for PWR spent fuel, and is then shipped in cooled and shielded transport flasks to the reprocessing plant. The ATR spent fuel reprocessing procedure and its lag time are essentially the same as those for conventional uranium oxide fuel. Figure 8.2 illustrates the material flow of the ATR fuel cycle.

\subsubsection{Basic assumptions}

The reference ATR plant, which is also assumed to be commissioned on 1st January 2000, has an electrical output of $1000 \mathrm{MWe}$ and will operate with a levelised load factor of 80 per cent for a lifetime period of 30 years. It is fuelled with plutonium and natural uranium oxide fuel. Tables 8.4 and 8.6 show the basic assumptions used in ATR fuel cycle cost calculations which are based on Japanese estimates. The discharged fuel has a burn-up of $48000 \mathrm{MWd} / \mathrm{t}$ at equilibrium. The fuel mass balance for the ATR is shown in Table 8.5.

Fuel cycle unit costs for the ATR are assumed to be the same with those adopted for the reference PWR with the exception of the MOX fuel fabrication cost which is assumed to be $\$ 980$ per $\mathrm{kg} \mathrm{HM}$. The US dollar of early 1991 has been taken as the constant monetary unit.

Lead and lag times are also based on Japanese data. The lag time for reprocessing is assumed to be 5 years including storage at the reactor site and the lag time for disposal of reprocessed waste is assumed to be 56 years, similar to the PWR case. Allowances for material losses in the fuel cycle processes are also shown in Table 8.4.

A discount rate of 5 per cent per annum is assumed. The price of plutonium and the plutonium credit value are assumed to be $\$ 5$ per gram of fissile plutonium, while no credit for uranium is taken into account. 


\subsubsection{Fuel cycle costs for the ATR}

Table 8.7 shows the typical fuel cycle costs for the ATR which total to 6.13 mills $/ \mathrm{kWh}$. Table 8.8 shows the effect of uranium prices on the total fuel cycle cost for the ATR. 
Table 8.4. Basic assumptions used in ATR fuel cycle cost calculations

\begin{tabular}{|c|c|}
\hline Item & Reference \\
\hline \multicolumn{2}{|l|}{ 1. Reactor and fuel data } \\
\hline Reactor type & HWR \\
\hline Thermal output & $3125 \mathrm{MWt}$ \\
\hline Electric output & $1000 \mathrm{MWe}$ \\
\hline Load factor $^{(a)}$ & $80 \%$ \\
\hline Commissioning year & 2000 \\
\hline Life of plant & 30 years \\
\hline Fuel burn-up ${ }^{(b)}$ & $48000 \mathrm{MWd} / \mathrm{t}$ \\
\hline Fuel mass balance & see Table 8.5 \\
\hline \multicolumn{2}{|l|}{ 2. Cost data } \\
\hline Base date of monetary unit & Early 1991 \\
\hline Monetary unit & front-end: US\$ \\
\hline & back-end: ECU \\
\hline Assumed exchange rate & $\mathrm{US} \$ 1=\mathrm{ECU} 1$ \\
\hline Unit costs for each component & see Table 8.6 \\
\hline Escalation factor & see Table 8.6 \\
\hline \multicolumn{2}{|l|}{ 3. Fuel cycle data } \\
\hline Tails asay for enrichment & $0.25 \%$ \\
\hline \multicolumn{2}{|l|}{ Lead/lag time for } \\
\hline - uranium purchase & 18 months $^{(\mathrm{c})}$ \\
\hline - conversion & 18 months $^{(\mathrm{c})}$ \\
\hline - fabrication & 6 months $^{(\mathrm{c})}$ \\
\hline - reprocessing & 6 years $^{(\mathrm{d})}$ \\
\hline - VHLW disposal & 56 years $^{(\mathrm{d})}$ \\
\hline \multicolumn{2}{|l|}{ Loss factor for } \\
\hline - fabrication & $2.0 \%$ \\
\hline - reprocessing & $1.0 \%$ \\
\hline - others & $0 \%$ \\
\hline \multicolumn{2}{|l|}{ 4. Other data } \\
\hline Discount rate & $5.0 \%$ \\
\hline U credit & no credit \\
\hline Pu credit & $\$ 5 / g$ Puf \\
\hline
\end{tabular}
a. Discounted average.
b. At equilibrium.
c. For initial fuel 6 months are added.
d. Including storage time at reactor. 
Table 8.5. Material balance (ATR, $48000 \mathrm{MWd} / \mathrm{t}$ )

\begin{tabular}{|c|c|c|c|c|c|c|}
\hline $\begin{array}{c}\text { Time } \\
\text { [EFPY] }\end{array}$ & $\begin{array}{c}\text { Interval } \\
\text { between } \\
\text { reload } \\
{[\text { EFPY] }}\end{array}$ & $\begin{array}{c}\text { Total } \\
\text { uranium } \\
\text { (tonne) } \\
\end{array}$ & $\begin{array}{l}{ }^{235} \mathrm{U} \\
(\%) \\
\end{array}$ & $\begin{array}{c}\text { Fissile } \\
\text { Pu } \\
(\mathbf{k g}) \\
\end{array}$ & $\begin{array}{c}\text { Total } \\
\text { Pu } \\
(\mathbf{k g}) \\
\end{array}$ & $\begin{array}{l}\text { Burn-up } \\
\text { (MWd/t) }\end{array}$ \\
\hline \multicolumn{7}{|c|}{ 1. Non-equilibrium cycle charge data } \\
\hline $\begin{array}{c}0 \\
1.25 \\
2.50 \\
3.75 \\
\end{array}$ & & $\begin{array}{c}119.40 \\
28.48 \\
28.48 \\
28.48 \\
\end{array}$ & $\begin{array}{l}0.711 \\
0.711 \\
0.711 \\
0.711 \\
\end{array}$ & $\begin{array}{r}1581 \\
889 \\
889 \\
889 \\
\end{array}$ & $\begin{array}{ll}2 & 196 \\
1 & 234 \\
1 & 234 \\
1 & 234 \\
\end{array}$ & \\
\hline \multicolumn{7}{|c|}{ 2. Equilibrium cycle charge data } \\
\hline 5.00 & & 28.48 & 0.711 & 889 & 1234 & \\
\hline \multicolumn{7}{|c|}{ 3. Non-equilibrium cycle discharge data } \\
\hline $\begin{array}{l}1.25 \\
2.50 \\
3.75 \\
5.00 \\
\end{array}$ & (average) & 28.54 & 0.154 & 160 & 388 & 30000 \\
\hline \multicolumn{7}{|c|}{ 4. Equilibrium cycle discharge data } \\
\hline 6.25 & & 27.50 & 0.100 & 211 & 659 & 48000 \\
\hline \multicolumn{7}{|c|}{ 5. Final core discharge data } \\
\hline & & 114.43 & 0.287 & 1578 & 3440 & 30000 \\
\hline
\end{tabular}

Note: $\mathrm{EFPY}=$ effective full-power year.

Table 8.6 ATR fuel cycle unit prices

\begin{tabular}{|c|c|c|}
\hline Component & Reference unit price & Sensitivity range \\
\hline $\begin{array}{l}\text { Uranium purchase } \\
\text { Plutonium purchase } \\
\text { Conversion } \\
\text { Fabrication (a) } \\
\text { Spent fuel transport } \\
\text { Reprocessing } \\
\text { (including buffer storage) } \\
\text { and vitrification } \\
\text { Waste disposal }\end{array}$ & $\begin{array}{c}\$ 50 / \mathrm{kg} \mathrm{U} \text { (in 1990) } \\
\left(\$ 19.2 / \mathrm{lb} \mathrm{U} 0_{8}\right) \\
\text { escalation 1.2\% p.a. } \\
\$ 5 / \mathrm{g} \mathrm{Puf} \\
\$ 8 / \mathrm{kg} \mathrm{U} \\
\$ 980 / \mathrm{kg} \mathrm{HM} \\
\text { ECU 50/kg HM } \\
\\
\text { ECU } 720 / \mathrm{kg} \mathrm{HM} \\
\text { ECU 90/kg HM }\end{array}$ & $\begin{array}{c}\text { \$40-\$90/kg U } \\
\text { escalation 0\% p.a. }\end{array}$ \\
\hline
\end{tabular}

a. Based on Japanese estimates. 
Table 8.7. Levelised fuel cycle cost for $\mathbf{A T R}^{(\mathbf{a})}$

\begin{tabular}{||l|c|c||}
\hline Component & mills/kWh & per cent \\
\hline Fuel purchase & & \\
- uranium ${ }^{(b)}$ & 0.26 & 4.2 \\
- plutonium & 0.49 & 8.0 \\
MOX fuel fabrication & 3.73 & 60.9 \\
Subtotal for front-end & $\mathbf{4 . 4 8}$ & $\mathbf{7 3 . 1}$ \\
& & \\
Spent fuel transport & 0.11 & 1.8 \\
Reprocessing & 1.59 & 25.9 \\
Waste disposal & 0.02 & 0.3 \\
Subtotal for back-end & $\mathbf{1 . 7 2}$ & $\mathbf{2 8 . 0}$ \\
& & -1.1 \\
Plutonium credit & -0.07 & $\mathbf{1 0 0 . 0}$ \\
Total cost & & \\
\hline
\end{tabular}

a. Sensitivities due to changes in plutonium, fabrication and reprocessing prices can be derived directly from this table.

b. Including $\mathrm{U}_{3} \mathrm{O}_{8}$ purchase and conversion to $\mathrm{UO}_{2}$.

Table 8.8 Effect of $\mathbf{U}_{3} \mathbf{O}_{\mathbf{8}}$ purchase price on levelised ATR fuel cycle cost

\begin{tabular}{||l|c|c||}
\hline Parameter & $\begin{array}{c}\text { Fuel cycle cost } \\
(\mathbf{m i l l s} / \mathbf{k W h})\end{array}$ & $\begin{array}{c}\text { Change from } \\
\text { reference }\end{array}$ \\
\hline Uranium price & & \\
- reference & 6.13 & \\
- \$40/kg U constant & 6.05 & $-1.3 \%$ \\
- \$90/kg U constant & 6.24 & $1.8 \%$ \\
\hline
\end{tabular}


Figure 8.1 Material flow of the CANDU fuel cycle

(the figure is an example and the numbers are approximate only)

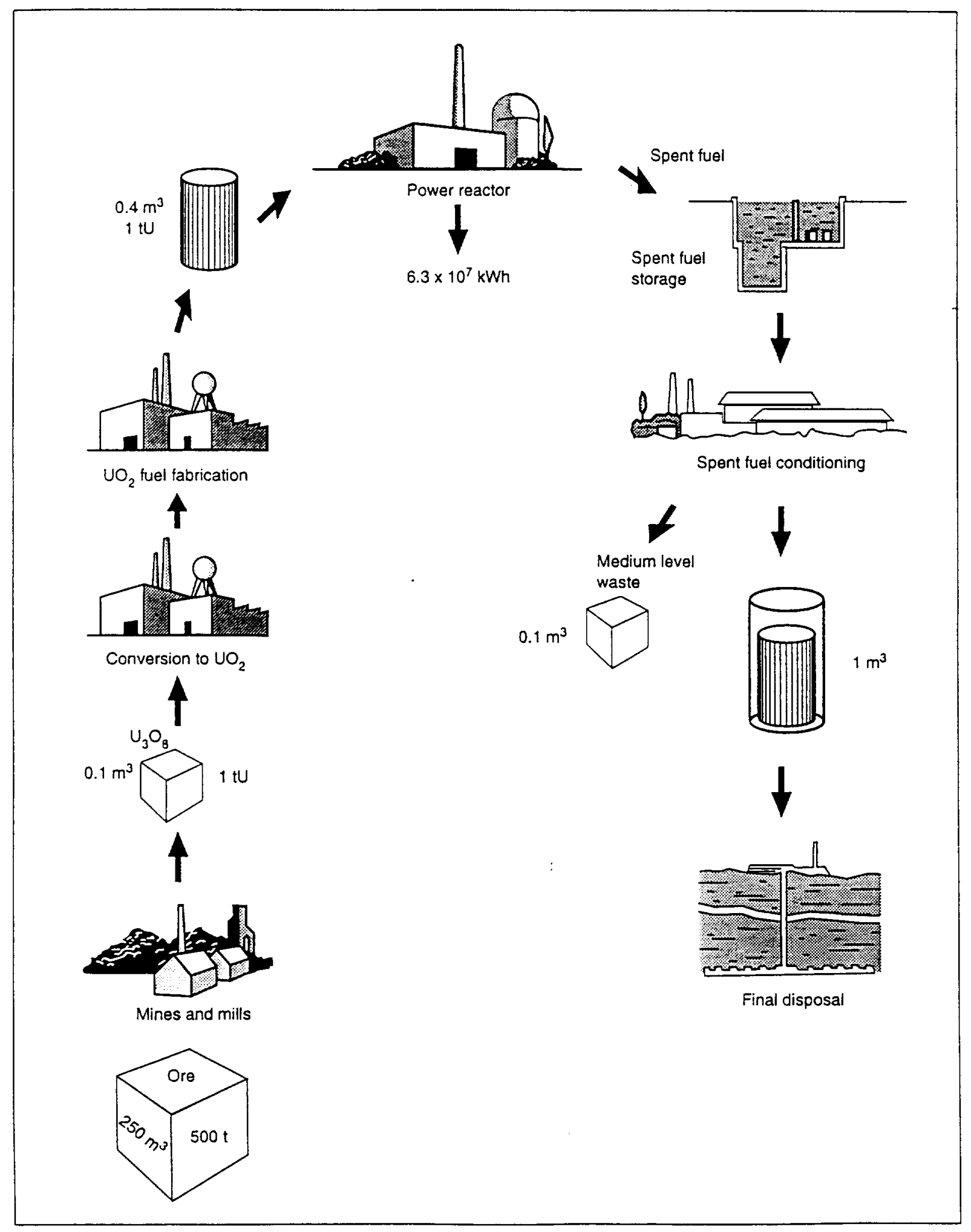


Figure 8.2 Material flow of the ATR fuel cycle

(the figure is an example and the numbers are approximate only)

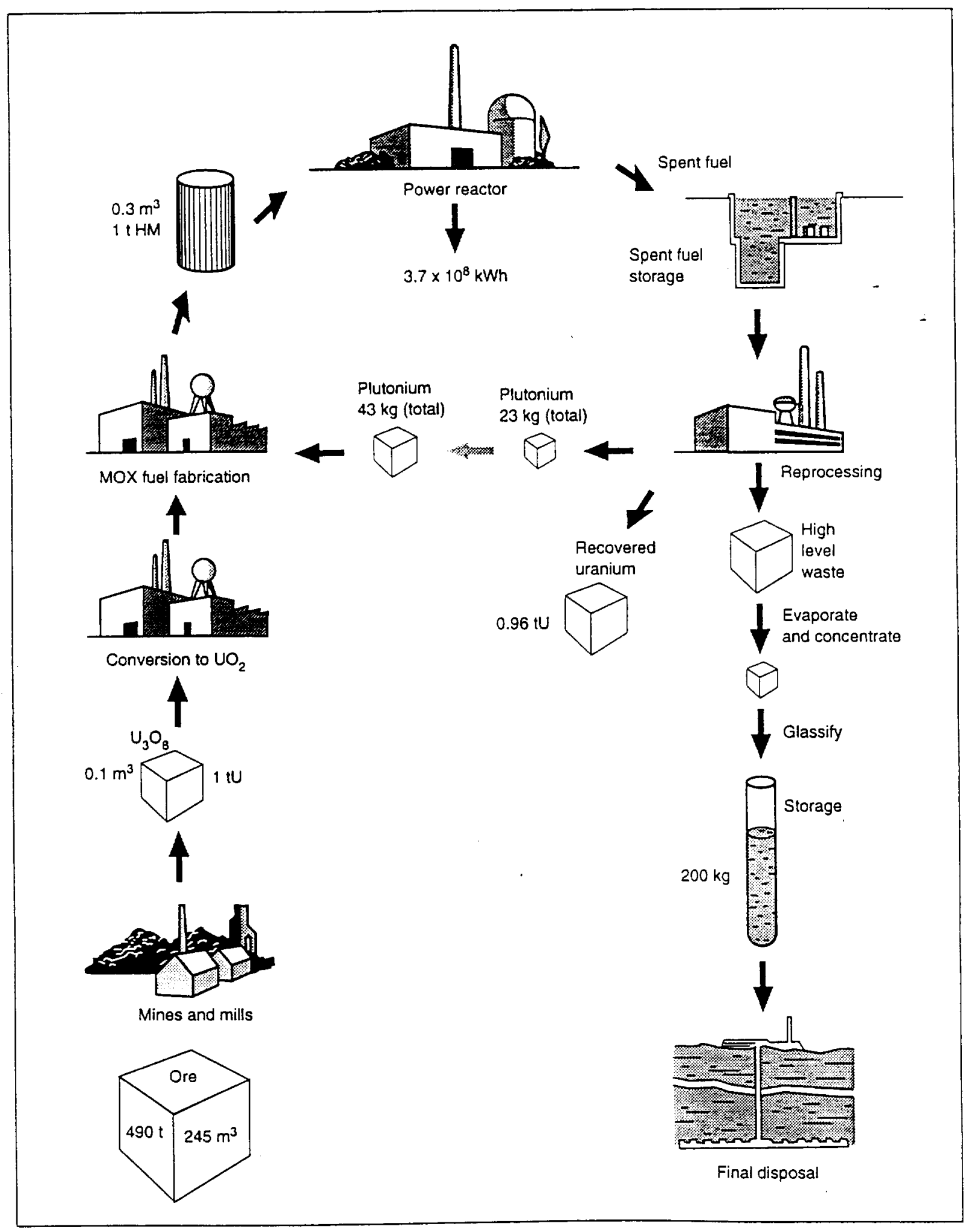




\section{CONCLUSIONS}

A 40 per cent reduction in levelised lifetime fuel cycle costs for a large PWR power station has occurred since the previous OECD/NEA study which was published in 1985. This reduction is due to improved fuel and reactor performance factors and reductions in the projected price of certain fuel cycle components. Improved fuel and reactor performance factors contributed a fifth of the reduction; the remaining four-fifths was due to major reductions in the price of uranium and enrichment services and reductions in the price for back-end fuel cycle services.

Based on the discounted cost methodology, using a 5 per cent per annum discount rate, the resulting lifetime fuel cycle costs are 6.23 mills $/ \mathrm{kWh}$ and $5.46 \mathrm{mills} / \mathrm{kWh}$ for the reprocessing and direct disposal options, respectively. Figures 7.1 and 7.2 of Chapter 7 give a breakdown and comparison of these costs with those of the 1985 study. The effects that the price and performance factors have had on the costs is indicated.

The front-end component of the fuel cycle contributes about 80 per cent of the total levelised lifetime cost. The front-end cost is the same regardless of the spent fuel management option chosen.

The magnitude of the back-end component of the fuel cycle cost depends on the option chosen for the management of the spent fuel. In this study two examples were selected, one based on a hypothetical new reprocessing plant based on the THORP design, the other based on the Swedish SKB development programme. The ratio of the reprocessing component, less credits, to the direct disposal component approaches a factor of two in absolute terms. However, in overall fuel cycle cost terms the direct disposal option remains at about 10 per cent lower than the reprocessing option based on the reference case studied.

Whilst reprocessing services are currently on offer from BNFL and COGEMA on a world market basis, the development of the direct disposal option is country specific. Noting the latter, in coming to a view on the appropriate sensitivity range to be used, recognition was given to the 5 per cent levelised prices obtained from cost estimates provided by other countries that are pursuing the direct disposal option. The German and US options were chosen to provide an indication of higher and lower prices for sensitivity study purposes. This leads to ranges of -75 to +25 per cent and -80 to +10 per cent round the reference prices for the transport/storage and encapsulation/disposal components, respectively. It should be noted that other countries may have costs which lie outside this range.

An analysis has been performed to determine the uncertainty that should be attached to the fuel cycle cost estimates based on best estimate data. The analysis shows that for either option the costs are likely to lie within a 20 per cent range at the 95 per cent confidence level.

The use of a 5 per cent per annum reference discount rate is still considered appropriate in reflecting the consensus of national practices. It enables a comparison to be made with the results of the 1985 study and is consistent with the methodology used to calculate the overall generation costs for new power stations be they nuclear or fossil-fuel powered. These costs are appropriate for investment appraisal. However, the discount rate appropriate to individual countries may differ from the 5 per cent per annum used and results 
have been quoted in this report over a wide range of discount rates from 0 to 15 per cent per annum in recognition.

Once an investment decision has been taken, utilities will be interested in financial appraisal of fuel cycle costs. This will involve matters of financial policy such as provisioning in the accounts and the selection of appropriate rates of interest. An annex in this report identifies the differences that occur in lifetime levelised costs when financial appraisal is undertaken as opposed to investment appraisal.

The reference levelised fuel cycle costs were based on a PWR power station. Experience shows that comparable fuel cycle costs would apply to a similarly sized BWR power station, commissioning and operating over similar time-scales. The fuel cycles for power stations based on the ATR and CANDU reactor types were also considered but no fuel cycle cost comparison has been made between these reactor types and the reference PWR used in this study, because the cost data for these two types are country specific.

A contemporary OECD/NEA-IEA study ${ }^{(4)}$ has been carried out on the projected costs of generating electricity from nuclear, coal and gas-fired power stations. That study shows that the proportion of the total generating cost taken up by the fuel component is, typically, 15 to 25 per cent, at 5 per cent real discount rate, for nuclear. Whereas in fossil-fuelled generation the fuel component is, typically, 40 to 60 per cent and in the case of gas it is, typically, 70 to 80 per cent of the total cost. Clearly, nuclear generation costs are far less sensitive to fuel price volatility compared with the fossil fuel alternatives.

In the light of the underlying cost uncertainties, the small cost difference between the prompt reprocessing and direct disposal options is considered to be insignificant and in any event represents a negligible difference in overall generating cost terms. It is likely that considerations of national energy strategy including reactor type, environmental impact, balance of payments and public acceptability will play a more important role in deciding a fuel cycle policy than the small economic difference identified. 


\section{REFERENCES}

1. The Costs of Generating Electricity in Nuclear and Coal-Fired Power Stations, OECD/NEA, 1983.

2. Projected Costs of Generating Electricity from Nuclear and Coal-Fired Power Stations for Commissioning in 1995, OECD/NEA, 1986.

3. Projected Costs of Generating Electricity from Power Stations for Commissioning in the Period 1995-2000, OECD/NEA-IEA, 1989.

4. Projected Electricity Generating Costs, Update 1992, OECD/NEA-IEA, 1993.

5. Plutonium Fuel - An Assessment, OECD/NEA, 1989.

6. The Cost of High-Level Waste Disposal in Geological Repositories An Analysis of Factors Affecting Cost Estimates, OECD/NEA, 1993.

7. The Economics of the Nuclear Fuel Cycle, OECD/NEA, 1985.

8. Uranium 1991: Resources, Production and Demand, ("Red Book"), OECD/NEA and IAEA, 1992.

9. I. Mikkola, Private communication, 1992.

10. Nuclear Energy and its Fuel Cycle - Prospects to 2025, ("Yellow Book"), OECD/NEA and IAEA, 1987.

11. Water Reactor Extended Burn-up Study (WREBUS), IAEA, 1993. 
Annex I

\section{METHOD OF CALCULATING A IEVELISED PRICE AND A FUEL CYCLE COST}

\section{Introduction}

The purpose of this annex is twofold: firstly, to explain the method of calculating the levelised price for the back-end services. Secondly, it illustrates how this ievelised price in conjunction with the front-end market prices are used to calculate the discounted fuel cycle cost per kilowatt hour ( $\mathrm{kWh}$ ) of electricity generated over the reactor lifetime, commonly known as the lifetime levelised fuel cycle cost.

\section{Levelising to a price}

All back-end services, such as reprocessing and waste disposal, can be defined in terms of plant cost estimates (see Annex 3). In order to charge the correct price the service provider must firstly decide the rate of retum on capital that is required.

Having chosen this rate of return, the net present value of the cash flows associated with construction, operation, maintenance and decommissioning of the plant are calculated at the chosen reference date [e.g. when the material deliveries commence (see Figure 1.1)]. The net present value associated with the processing of the material, based on the levelised price (as yet unquantified) and the thiroughput profile, is expressed to the same reference date. The levelised price is then calculated by setting the two net present values equal. This levelised price ensures the plant operator can meet all his costs and obtain the required rate of retum on the capital employed.

\section{Fuel cycle costs}

The cash oul-flow for fuel cycle material and services commences before the reactor starts to generate electricity and continues well after the reactor ceases operation. The exact timing of payments for uranium, fuel fabrication, reprocessing, etc., depend on the fuel cycle chosen and the associated lead and lag times for each of the fuel cycle components.

In order to calculate the overall fuel cycle cost, the magnitude of each component cost and the appropriate point in time that it occurs must be identified. The quantities of fuel are obtained from reactor neutronics calculations (see Table 5.6 in the main text). These quantities of material and services are adjusted to allow for process losses in the various component stages of the nuclear fucl cycle and then multiplied by the unit costs (or levelised prices for back-end services) to obtain the component costs. Table 1.1 lists the notation of all the parameters needed for the calculations. 


\section{General}

Discount rate

Time

Base date of monetary unit

Date of fucl loading

Fuel residence time

$$
\begin{aligned}
& r \\
& \mathfrak{t} \\
& \mathfrak{b}_{\mathrm{b}} \\
& \mathfrak{t}_{\mathrm{c}} \\
& \mathrm{T}_{\boldsymbol{f}}
\end{aligned}
$$

\section{Materials}

Mass of uranium feed $(\mathrm{kg})$

Mass of uranium charged in reactor $(\mathrm{kg})$

Mass of uranium in the tails $(\mathbf{k g})$

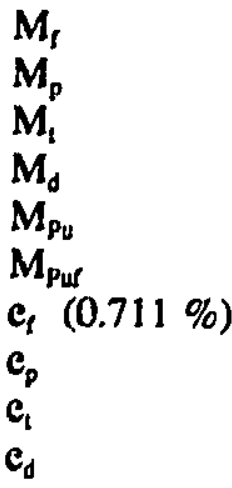

Conversion factor from $\mathrm{kg} \mathrm{U}$ to $\mathrm{lb}_{3} \mathrm{O}_{8}$ (a lts U,O, per kg U)

For cach component $i$ of the nuclear fucl cycle:

Total component cost

Unit cost

Escalation rate

Material losses

Total loss factor

Lead or lag time

where:

$\begin{array}{ll}i=1 & \text { Uranium purchase } \\ i=2 & \text { Conversion } \\ i=3 & \text { Enrichment } \\ i=4 & \text { Fabrication } \\ i=5 & \text { Transportation of spent fuel } \\ i=6 & \text { Reprocessing or Interim Storage } \\ i=7 & \text { Disposal of VHLW or Encapsulation/Disposal of spent fuel } \\ i=8 & \text { Uranium credit } \\ i=9 & \text { Plutonium credit }\end{array}$


and

$P_{1}=$ Monctary units per lb $U, O$,

$P_{2}=$ Monctary units per kg U

$P_{3}=$ Monetary units per SWU

$P_{1},=$ Monetary units per $\mathrm{kg} \mathrm{U}$

$P_{0}=$ Monetary units per $\mathrm{kg} U$ recovered

$\mathrm{P}_{\mathbf{v}}=$ Monetary units per $\mathrm{kg} \mathrm{Pu}$

For each component, the cost for a given fuel batch can be written as:

\section{Cost of uranium}

$$
F_{1}=M_{f} \cdot a \cdot f_{1} \cdot P_{1} \cdot\left(1+B_{1}\right)^{t-t_{b}}
$$

where:

$$
\begin{aligned}
& M_{t}=\frac{\left(\theta_{p}-\theta_{t}\right)}{\left(\theta_{t}-\theta_{t}\right)} \cdot M_{p} \\
& f_{1}=\left(1+I_{2}\right)\left(1+I_{3}\right)\left(1+1_{4}\right)
\end{aligned}
$$

From all front-end components: $t=t_{c}-t_{1}$

Cost of conversion

$$
F_{2}=M_{f} \cdot f_{2} \cdot P_{2} \cdot\left(1+B_{2}\right)^{t-t_{b}}
$$

where:

$$
f_{2}=\left(1+I_{2}\right)\left(1+I_{3}\right)\left(1+1_{4}\right)
$$

\section{Cost of enrichment}

$$
F_{3}=s \cdot f_{3} \cdot P_{3} \cdot\left(1+B_{3}\right)^{t-t_{b}}
$$

where:

$$
\begin{aligned}
S & =\text { Separative Work Units } \\
& =M_{p} V_{p}+M_{t} V_{t}-M_{t} V_{t} \\
M_{t} & =M_{t}-M_{D}
\end{aligned}
$$




$$
V_{x}=\left(2 \theta_{x}-1\right) \ln \frac{\theta_{x}}{1-\theta_{x}}
$$

and $x$ is subscripe for $f, p$ or $t$

$$
f_{3}=\left(1+I_{3}\right)\left(1+I_{4}\right)
$$

\section{Cost of fabrication}

$$
F_{4}=M_{p} \cdot f_{4} \cdot P_{4} \cdot\left(I+G_{4}\right)^{t-t_{b}}
$$

where :

$$
f_{4}=\left(1+I_{4}\right)
$$

\section{Cost of transportation}

$$
F_{5}=M_{p} \cdot P_{5} \cdot\left(1+S_{5}\right)^{t-t_{b}}
$$

for all the back-end components: $t=t_{c}+T_{r}+t_{1}$

\section{Cost of reprocessing or interim storage}

$$
F_{6}=M_{p} \cdot P_{6} \cdot\left(1+g_{6}\right)^{t-t_{b}}
$$

Cost of disposal of VHLW or Encapsulation/Disposal of spent fuel

$$
F_{7}=M_{p} \cdot P_{7} \cdot\left(1+s_{7}\right)^{t-t_{b}}
$$

\section{Uranium credit}

The value of recovered uranium $\left(C_{r e c}\right)$ is defined in detail in Annex 8:

$$
F_{8}=M_{d} \cdot P_{B} \cdot f_{B} \cdot\left(1+B_{8}\right)^{t-t_{b}}
$$

where:

$$
\begin{aligned}
& f_{0}=\left(1-I_{6}\right) \\
& p_{B}=C_{\text {rec }}
\end{aligned}
$$




\section{Plutonium credit}

$$
F_{q}=M_{P u_{f}} \cdot f_{0} \cdot P_{9} \cdot\left(1+s_{0}\right)^{t-t_{b}}
$$

The component costs above are given for a typical batch. Over the reactor lifetime, these costs are time dependent and should be written as $F_{i}(t)$.

\section{Discounting and levelising of fuel cycle costs}

All the component costs are discounted back to a selected base date and added together in order to arrive at a total fuel cost in present value terms.

The total discounted cost of the nuclear fuel cycle can be written as:

$$
\sum_{1} \sum_{t=t_{0}-T_{1}}^{t=t_{0}+L+T_{2}} \frac{F_{1}(t)}{(1+r)^{\left(t-t_{0}\right)}}
$$

where:

$t_{0}=$ reference date (commissioning date)

$L=$ reactor lifetime

$T_{1}=$ max. value of lead time (in front-end)

$T_{2}=$ max. value of lag time (in back-end)

If $\mathrm{C}$ is the constant levelised fuel cosi per unit of electricity sent out by a reactor, the total cost of fucl is also:

$$
\sum_{t=t_{0}}^{t_{0}+L} \frac{C \cdot E_{(t)}}{(1+r)^{t-t_{0}}}
$$

where:

$E_{(1)}=$ net clectrical output at time $t$

hence:

$$
\sum_{\text {stages }} \sum_{T \text { TImo }} \frac{F_{1}(t)}{(1+r)^{t-t_{0}}}=\sum_{r i m_{0}} \frac{C \cdot E(t)}{(1+r)^{t-t_{0}}}
$$


hence:

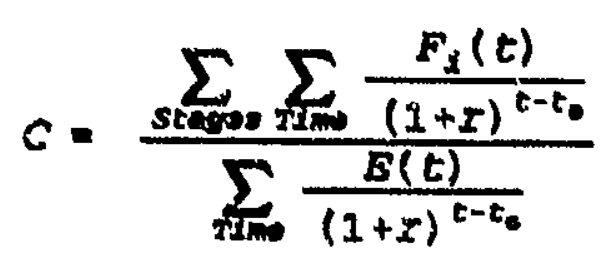

Because slectricity is generated more or less continuously during the reactor life, a continuous discounting method cun be employed. The discount rate $r$ is then repleced by $r^{\prime}=\ln (I+r)$, which is called the continurous discount rate, and the discount factor is replaced by the exponential form:

$$
\frac{1}{(1+r)^{t-t_{0}}}=\exp \left(-r^{\prime} t\right)
$$

The denominator of equation (4) is rewritten in the exponential form and the integration is made over the perios in which electricity is generated.

$$
\sum_{t=0} \frac{E(t)}{(1+r)^{t-t_{0}}}=\int_{t i m} \exp \left(-r^{\prime} t\right) \cdot E(t) d t
$$

If $E(t)$ is assumed to be constant over a period of time from 0 to $T$ and equal to $E$, the above integral then becomes:

$$
\begin{aligned}
E \int_{0}^{T} \exp \left(-r^{\prime} t\right) d t & =E \cdot \frac{1-\exp \left(-r^{\prime} T\right)}{r^{\prime}} \\
& =E \cdot r \cdot \frac{2-\exp \left(-r^{\prime} T\right)}{r^{\prime} T}
\end{aligned}
$$

When the lond factor of the plant varies from year to year or from cycle to cycle over the lifetime of reactor, $E$ has different values for exch operational year or cycle. In such a case, the above integral will be taken separately and will be added together in onder to arrive at the total discounted electricity output.

The procedures mentioned above can be laborious if economic and technical parameters vary with time. In the present study a PNC computer code was used for the calculation of the levelised fuel cycle cost over the lifetime of reactor. 


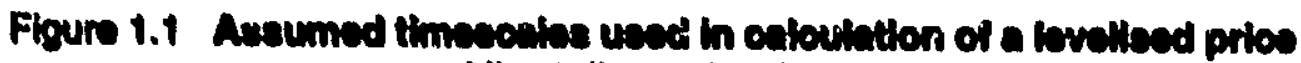
(direct diapoecal option)

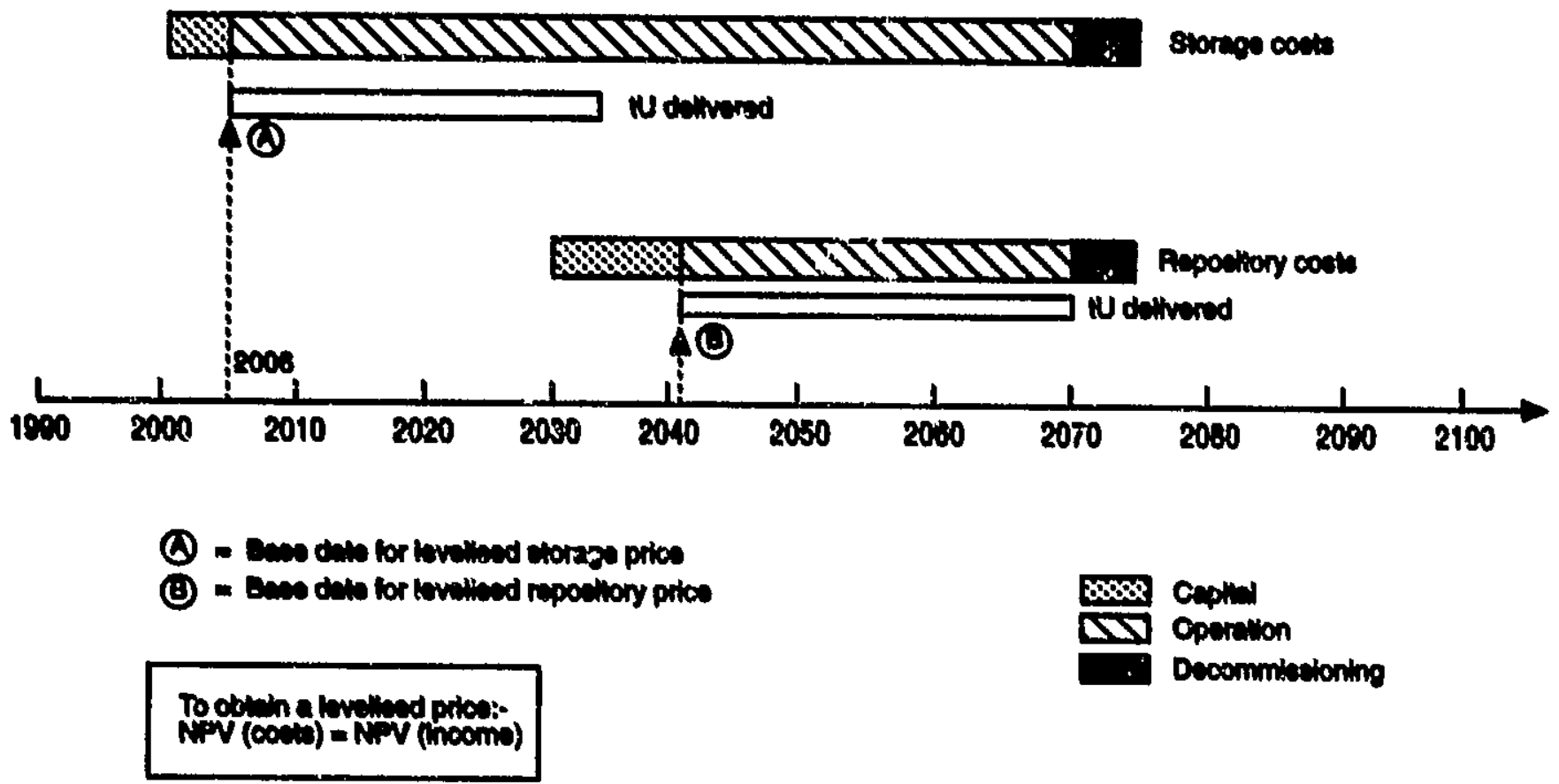


Annex 2

\section{COMPARISON BETWEEN INVESTMENT APPRAISAL AND FINANCIAL APPRAISAL}

\section{Introduction}

The evaluation of a fuel cycle cost is clearly sensitive to the methodology adopted. The aim of this annex is to describe the different methodologies required for investment appraisal and financial appraisal. From a utility's viewpoint, a "fixed price" is required from the service provider in order to carry out its appraisals. In this annex the reference prices from the main part of the report have been taken as the "fixed prices" to be used. This also allows the effect of using different discount rates to be clearly seen since discount rate is the only variable parameter in the examples shown. For convenience, these prices are shown in Table 2.1 below:

Table 2.1. Reference prices

\begin{tabular}{||l|c||}
\hline Component & $\begin{array}{c}\text { Reference unit price } \\
(\mathbf{1 9 9 1} \text { mv) }\end{array}$ \\
\hline Uranium purchase & $\begin{array}{c}\$ 50 / \mathrm{kg} \mathrm{U}(\mathrm{in} \mathrm{1990)} \\
(\$ 19.2 / \mathrm{lb}) \mathrm{U}_{3} \mathrm{O}_{8} \\
\text { escalation 1.2\% p.a. }\end{array}$ \\
\hline Conversion & $\$ 8 / \mathrm{kg} \mathrm{U}$ \\
\hline Enrichment & $\$ 110 / \mathrm{SWU}$ \\
\hline Fabrication & $\$ 275 / \mathrm{kg} \mathrm{U}$ \\
\hline Reprocessing option: & \\
- Spent fuel transport & ECU 50/kg U \\
- Reprocessing & ECU 720/kg U \\
- VHLW disposal & ECU 90/kg U \\
\hline Direct disposal option: & \\
- Spent fuel transport \& storage & ECU 230/kg U \\
- Encapsulation \& disposal & ECU 610/kg U \\
\hline
\end{tabular}

Note: A long-term exchange rate of ECU $1=\$ 1$ has been assumed.

These prices have been used consistently throughout the calculations in this annex. 


\section{Investment appraisal}

Investment appraisal requires the examination of all the costs through time of a particular project and involves discounting these costs to a base date. In the case of projects for the generation of electricity the levelised unit cost is determined by the method described in Annex 1. This methodology is appropriate when one is considering whether to make an investment in a particular type of power station, when a number of different options e.g. coal, oil, gas or nuclear are available. The discount rate used is set by the rate of return on capital employed that the investment is required to make. The scarcer the capital or the more risky the project, the higher the required return, and hence discount rate used.

As part of the investment appraisal for a nuclear power station, the fuel costs have to be treated in exactly the same way. This involves setting out the entire fuel cycle costs over time based on market price projections or prices derived from plant cost estimates (e.g. Annex 3). The entire fuel cycle cost stream in the form of cash flows for the reprocessing and direct disposal options are set out in Figures 2.1 and 2.2, respectively. From these cash flows, lifetime levelised fuel cycle costs can be obtained as described in Annex 1.

\section{Financial appraisal}

Once the type of power station to be built has been decided using investment appraisal, the utility will also be interested in financial appraisal because it has to make money available ahead of generation for the front-end components, and it has to put money aside to meet all back-end fuel cycle cash outflow as the electricity is generated. The electric utility has to account to its owners and/or its regulators on its financial performance on a regular basis. In doing this the company is obliged to recognise both costs that have been incurred and costs that will occur in the future due to the electricity generated during the period under review.

The expenditure on front-end costs occurs before the electricity is generated as the utility has to buy the uranium ore, enrich it, and then fabricate it into fuel assemblies, all of which can take a year or more. In financial and investment appraisal the front-end is treated in the same way, i.e. when the actual money was paid out for the material and services.

All back-end costs, i.e. storage, reprocessing, encapsulation and waste disposal, occur some time after the electricity has been produced and, therefore, a different approach has to be taken. The costs are treated as liabilities and are covered by making a financial provision in the accounts.

Provisioning is done because an electric utility must be certain that it has amassed sufficient funds during the operating lifetime of a reactor to be able to meet its future liabilities. It is usual practice for a sum of money to be levied on each unit of electricity produced and for that money to be invested, such that a financial return is secured at such a level that future liabilities will be met in full.

The rate of return assumed on this investment has to be risk free: this is done by adopting a prudent interest rate. In view of the long timescales involved, this is typically around a few percent per annum in real terms. This is consistent with historic returns seen in practice on investments over the past 50-100 years. The money thus put aside may be invested either for the utility's own projects or else external to the company.

A financial appraisal thus considers the annual charges being made in the profit and loss account of the utility, as the fuel is used in a reactor and defined on the basis of a prudent interest rate, lower than the discount rate used for investment appraisal. An illustration of the annual profit and loss accounting charges 
that would be made to cover costs associated with the reprocessing or direct disposal options are shown in Figures 2.3 and 2.4, respectively. Here, a real interest rate of 2 per cent per annum has been assumed.

If it is examined how the provisions fund balance changes with time for the reprocessing option (Figure 2.5) several distinct phases can be seen:

- During the first five years of station operation the fund grows at a fast rate since money is being set aside and interest accrued, but there is no expenditure for reprocessing services.

- During the next 25 years of station operation, income is received, money is still being set aside, interest is being accrued but transport and reprocessing expenses have to be met. Therefore the fund's growth rate is reduced and, when electricity generation ceases, income to the fund falls but expenditure continues until all the spent fuel has been reprocessed. The value of the fund falls particularly rapidly when the final core is reprocessed in 2033/34.

- Thereafter, whilst the high level waste is being stored prior to ultimate disposal, the balance of the fund grows slowly at an annual rate of 2 per cent less the annual storage charge.

- During the HLW disposal period, the balance of the fund falls as disposal expenses are met. The funds value falls to zero when payment is made for the disposal of the last batch of waste.

The direct disposal option has a different profile for the provisions fund balance with time (Figure 2.6). Here, early expenditure is for storage only and this is at a much lower level compared with the reprocessing option. Hence, the balance of the fund rises to a much greater value before the relatively larger expenses are incurred, later, for the encapsulation and disposal of spent fuel.

Based on experience in the United Kingdom, a long-term interest rate of 2 per cent per annum (real), the rate assumed in the illustrations given, would be consistent with short-term pre-tax rates of return in the range 6 per cent to 8 per cent per annum. If much higher short-term rates were experienced, then it is possible that a long-term rate higher than 2 per cent per annum may be more appropriate. However, no attempt has been made here to assess provision interest rates that might apply at these higher levels and the 2 per cent figure has been applied throughout merely for illustrative purposes.

\section{Front-end costs}

For both appraisal methods the cash outflow occurs ahead of generation and, hence, costs are compounded forward over the appropriate "lead time" at the discount rate used. The unit fuel cycle cost (mills/kWh) is the value which must be obtained for each unit of electricity generated, such that the net present value of the revenues is equal to the net present value of the costs.

The unit front-end fuel cost derived from either appraisal methods will be the same.

\section{Back-end costs}

For back-end unit fuel costs, the financial appraisal will usually give a higher unit cost compared with investment appraisal. This can be seen for both the reprocessing and direct disposal options in Figures 2.7 and 2.8 , respectively. 
Here the back-end unit cost depends on the rate of return assumed for the provision fund. The unit cost will be the same irrespective of the discount rate chosen. This is not the case in the investment appraisal case (see Figures 2.7 and 2.8).

Tables 2.2 to 2.6 bring together the total set of results and these are shown in Figures 2.7 and 2.8. Using only the reprocessing option for purposes of illustration, the effect of increasing the assumed rate of interest earned by the provisions fund from 2 per cent per annum to 5 per cent per annum is shown in Figure 2.9 and Table 2.4.

\section{Conclusions}

The value of the unit front-end cost will be the same regardless of whether financial or investment appraisal is used. The value will only depend on the discount rate selected.

The unit back-end cost, will depend on the type of appraisal performed, the assumed interest rate applicable to the provision fund and the discount rate selected.

Unit fuel cycle costs are a combination of front-end and back-end unit costs and therefore they too will be dependent on the type of appraisal carried out. The prudent use of low interest rates for provision funding results in financial appraisal producing generally higher unit fuel costs than investment appraisal. It is only when the discount rate is lower than the assumed interest rate that financial appraisal results in lower costs. Clearly, when the interest rate equals the discount rate, the same unit cost results whether financial or investment appraisal is used.

The magnitude of the difference between the unit cost derived by financial appraisal and that derived by investment appraisal increases as the difference between the assumed interest rate and the discount rate increases.

It is important to clearly identify the type of appraisal and the assumed interest rate/discount rate that has been used when presenting the results of unit fuel cycle cost calculations. 
Table 2.2. Fuel cycle levelised unit cost (reprocessing option); assumes back-end prices constant at 5 per cent reference values

\begin{tabular}{||l|c|c|c|c|c|c|c||}
\hline & \multicolumn{7}{|c||}{ Cost (mills/kWh) } \\
\hline Discount Rate & $\mathbf{0 \%}$ & $\mathbf{2 \%}$ & $\mathbf{5 \%}$ & $\mathbf{8 \%}$ & $\mathbf{1 0 \%}$ & $\mathbf{1 2 \%}$ & $\mathbf{1 5 \%}$ \\
\hline \hline Front-end & 4.15 & 4.35 & 4.70 & 5.08 & 5.36 & 5.66 & 6.14 \\
\hline Back-end & 2.73 & 2.23 & 1.79 & 1.50 & 1.34 & 1.20 & 1.04 \\
\hline Credit & -0.42 & -0.34 & -0.26 & -0.19 & -0.17 & -0.14 & -0.11 \\
\hline Total & $\mathbf{6 . 4 6}$ & $\mathbf{6 . 2 4}$ & $\mathbf{6 . 2 3}$ & $\mathbf{6 . 3 9}$ & $\mathbf{6 . 5 3}$ & $\mathbf{6 . 7 2}$ & $\mathbf{7 . 0 7}$ \\
\hline
\end{tabular}

Table 2.3. Fuel cycle levelised unit cost (reprocessing option) showing the effect of provisioning at 2 per cent p.a.

\begin{tabular}{||l|c|c|c|c|c|c|c||}
\hline & \multicolumn{7}{|c||}{ Cost (mills/kWh) } \\
\hline Discount Rate & $\mathbf{0 \%}$ & $\mathbf{2 \%}$ & $\mathbf{5 \%}$ & $\mathbf{8 \%}$ & $\mathbf{1 0 \%}$ & $\mathbf{1 2 \%}$ & $\mathbf{1 5 \%}$ \\
\hline \hline Front-end & 4.15 & 4.35 & 4.70 & 5.08 & 5.36 & 5.66 & 6.14 \\
\hline $\begin{array}{l}\text { Back-end } \\
\text { (Cash flow) }\end{array}$ & 2.73 & 2.23 & 1.79 & 1.50 & 1.34 & 1.20 & 1.04 \\
\hline Credits & -0.42 & -0.34 & -0.26 & -0.19 & -0.17 & -0.14 & -0.11 \\
\hline $\begin{array}{l}\text { Total } \\
\text { Cash flow) }\end{array}$ & $\mathbf{6 . 4 6}$ & $\mathbf{6 . 2 4}$ & $\mathbf{6 . 2 3}$ & $\mathbf{6 . 3 9}$ & $\mathbf{6 . 5 3}$ & $\mathbf{6 . 7 2}$ & $\mathbf{7 . 0 7}$ \\
\hline $\begin{array}{l}\text { Back-end } \\
\text { (Provisioned) }\end{array}$ & 2.23 & 2.23 & 2.23 & 2.23 & 2.23 & 2.23 & 2.23 \\
\hline $\begin{array}{l}\text { Total } \\
\text { Provisioned) }\end{array}$ & $\mathbf{5 . 9 6}$ & $\mathbf{6 . 2 4}$ & $\mathbf{6 . 6 7}$ & $\mathbf{7 . 1 2}$ & $\mathbf{7 . 4 2}$ & $\mathbf{7 . 7 5}$ & $\mathbf{8 . 2 6}$ \\
\hline \hline
\end{tabular}


Table 2.4. Fuel cycle levelised unit cost (reprocessing option) showing the effect of provisioning at 5 per cent p.a.

\begin{tabular}{||l|c|c|c|c|c|c|c||}
\hline & \multicolumn{7}{|c||}{ Cost (mills/kWh) } \\
\hline Discount Rate & $\mathbf{0 \%}$ & $\mathbf{2 \%}$ & $\mathbf{5 \%}$ & $\mathbf{8 \%}$ & $\mathbf{1 0 \%}$ & $\mathbf{1 2 \%}$ & $\mathbf{1 5 \%}$ \\
\hline \hline $\begin{array}{l}\text { Front-end+ } \\
\text { Credits }\end{array}$ & 3.73 & 4.01 & 4.44 & 4.89 & 5.19 & 5.52 & 6.03 \\
\hline $\begin{array}{l}\text { Back-end } \\
\text { Provisioned 5\%) }\end{array}$ & 1.79 & 1.79 & 1.79 & 1.79 & 1.79 & 1.79 & 1.79 \\
\hline Total & $\mathbf{5 . 5 2}$ & $\mathbf{5 . 8 0}$ & $\mathbf{6 . 2 3}$ & $\mathbf{6 . 6 8}$ & $\mathbf{6 . 9 8}$ & $\mathbf{7 . 3 1}$ & $\mathbf{7 . 8 2}$ \\
\hline
\end{tabular}

Table 2.5. Fuel cycle levelised unit cost (direct disposal option); assumes back-end prices constant at 5 per cent reference values

\begin{tabular}{||l|c|c|c|c|c|c|c||}
\hline & \multicolumn{7}{|c||}{ Cost (mills/kWh) } \\
\hline Discount rate & $\mathbf{0 \%}$ & $\mathbf{2 \%}$ & $\mathbf{5 \%}$ & $\mathbf{8 \%}$ & $\mathbf{1 0 \%}$ & $\mathbf{1 2 \%}$ & $\mathbf{1 5 \%}$ \\
\hline \hline Front-end & 4.15 & 4.35 & 4.70 & 5.08 & 5.36 & 5.66 & 6.14 \\
\hline Back-end & 2.63 & 1.46 & 0.76 & 0.51 & 0.43 & 0.37 & 0.31 \\
\hline Total & $\mathbf{6 . 7 8}$ & $\mathbf{5 . 8 1}$ & $\mathbf{5 . 4 6}$ & $\mathbf{5 . 5 9}$ & $\mathbf{5 . 7 9}$ & $\mathbf{6 . 0 3}$ & $\mathbf{6 . 4 5}$ \\
\hline
\end{tabular}

Table 2.6. Fuel cycle levelised unit cost (direct disposal option) showing the effect of provisioning at 2 per cent p.a.

\begin{tabular}{||l|c|c|c|c|c|c|c||}
\hline & \multicolumn{7}{|c||}{ Cost (mills/kWh) } \\
\hline Discount Rate & $\mathbf{0 \%}$ & $\mathbf{2 \%}$ & $\mathbf{5 \%}$ & $\mathbf{8 \%}$ & $\mathbf{1 0 \%}$ & $\mathbf{1 2 \%}$ & $\mathbf{1 5 \%}$ \\
\hline \hline Front-end & 4.15 & 4.35 & 4.70 & 5.08 & 5.36 & 5.66 & 6.14 \\
\hline $\begin{array}{l}\text { Back-end } \\
\text { (Cash flow) }\end{array}$ & 2.63 & 1.46 & 0.76 & 0.51 & 0.43 & 0.37 & 0.31 \\
\hline $\begin{array}{l}\text { Total } \\
\text { Cash flow) }\end{array}$ & $\mathbf{6 . 7 8}$ & $\mathbf{5 . 8 1}$ & $\mathbf{5 . 4 6}$ & $\mathbf{5 . 5 9}$ & $\mathbf{5 . 7 9}$ & $\mathbf{6 . 0 3}$ & $\mathbf{6 . 4 5}$ \\
\hline $\begin{array}{l}\text { Back-end } \\
\text { (Provisioned) }\end{array}$ & 1.46 & 1.46 & 1.46 & 1.46 & 1.46 & 1.46 & 1.46 \\
\hline $\begin{array}{l}\text { Total } \\
\text { (Provisioned) }\end{array}$ & $\mathbf{5 . 6 1}$ & $\mathbf{5 . 8 1}$ & $\mathbf{6 . 1 6}$ & $\mathbf{6 . 5 4}$ & $\mathbf{6 . 8 2}$ & $\mathbf{7 . 1 2}$ & $\mathbf{7 . 6 0}$ \\
\hline \hline
\end{tabular}


Figure 2.1 Indicative front and back-end cash flows for PWR

(1 $400 \mathrm{MWe}$ )

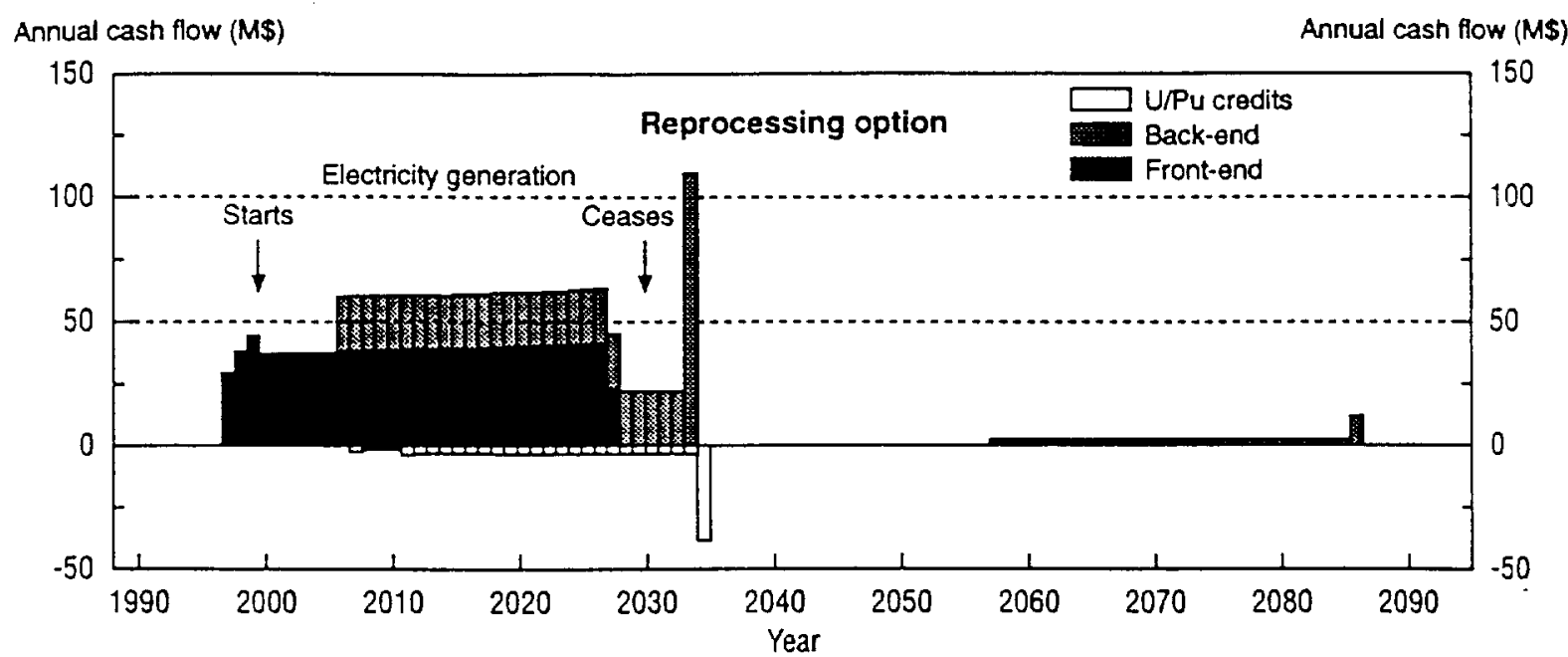

\begin{tabular}{|l|c|c|c|c|c|c|c|}
\hline Cost (mills/kWh) & $0 \%$ & $2 \%$ & $5 \%$ & $8 \%$ & $10 \%$ & $12 \%$ & $15 \%$ \\
\hline Front-end & 4.15 & 4.35 & 4.70 & 5.08 & 5.36 & 5.66 & 6.14 \\
\hline Back-end & 2.73 & 2.23 & 1.79 & 1.50 & 1.34 & 1.20 & 1.04 \\
\hline Credits & -0.42 & -0.34 & -0.26 & -0.19 & -0.17 & -0.14 & -0.11 \\
\hline Total & 6.46 & 6.24 & 6.23 & 6.39 & 6.53 & 6.72 & 7.07 \\
\hline
\end{tabular}

Figure 2.2 Indicative front and back-end cash flows for PWR (1 $400 \mathrm{MWe}$ )

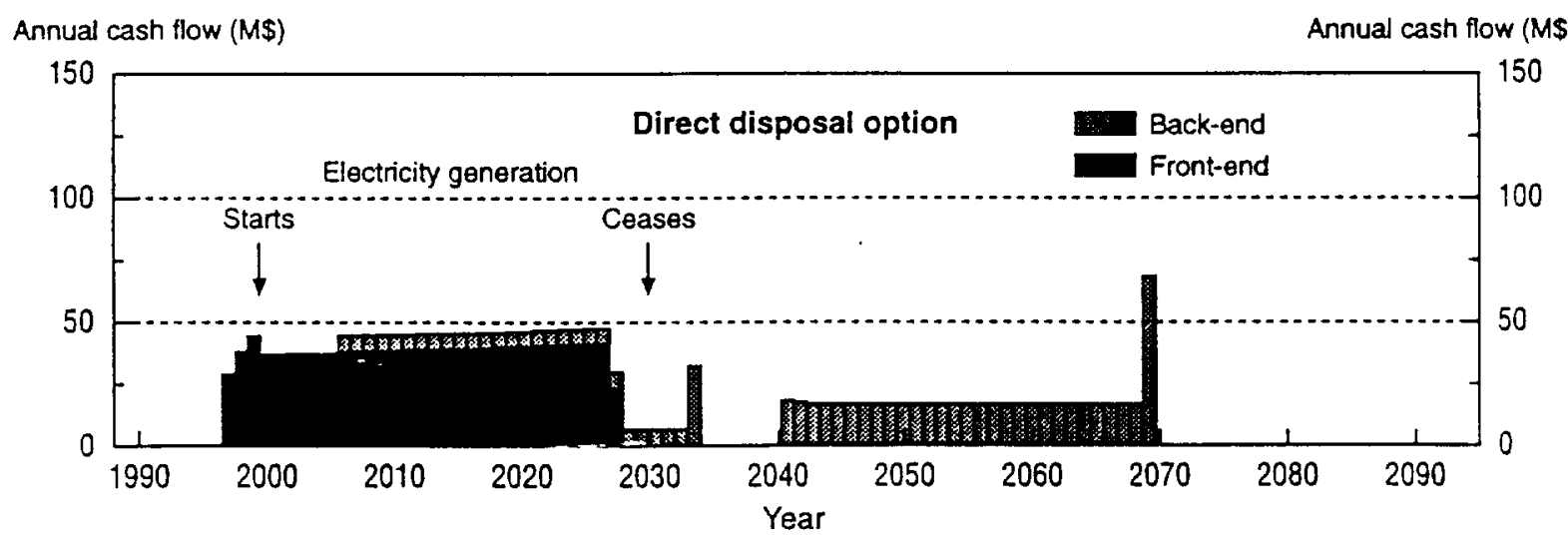

\begin{tabular}{|l|l|l|l|l|l|l|l|}
\hline Cost (mills/kWh) & $0 \%$ & $2 \%$ & $5 \%$ & $8 \%$ & $10 \%$ & $12 \%$ & $15 \%$ \\
\hline Front-end & 4.15 & 4.35 & 4.70 & 5.08 & 5.36 & 5.66 & 6.14 \\
\hline Back-end & 2.63 & 1.46 & 0.76 & 0.51 & 0.43 & 0.37 & 0.31 \\
\hline Total & 6.78 & 5.81 & 5.46 & 5.59 & 5.79 & 6.03 & 6.45 \\
\hline
\end{tabular}


Figure 2.3 Indicative front and back-end accounting charges for PWR (1 $400 \mathrm{MWe}$ )

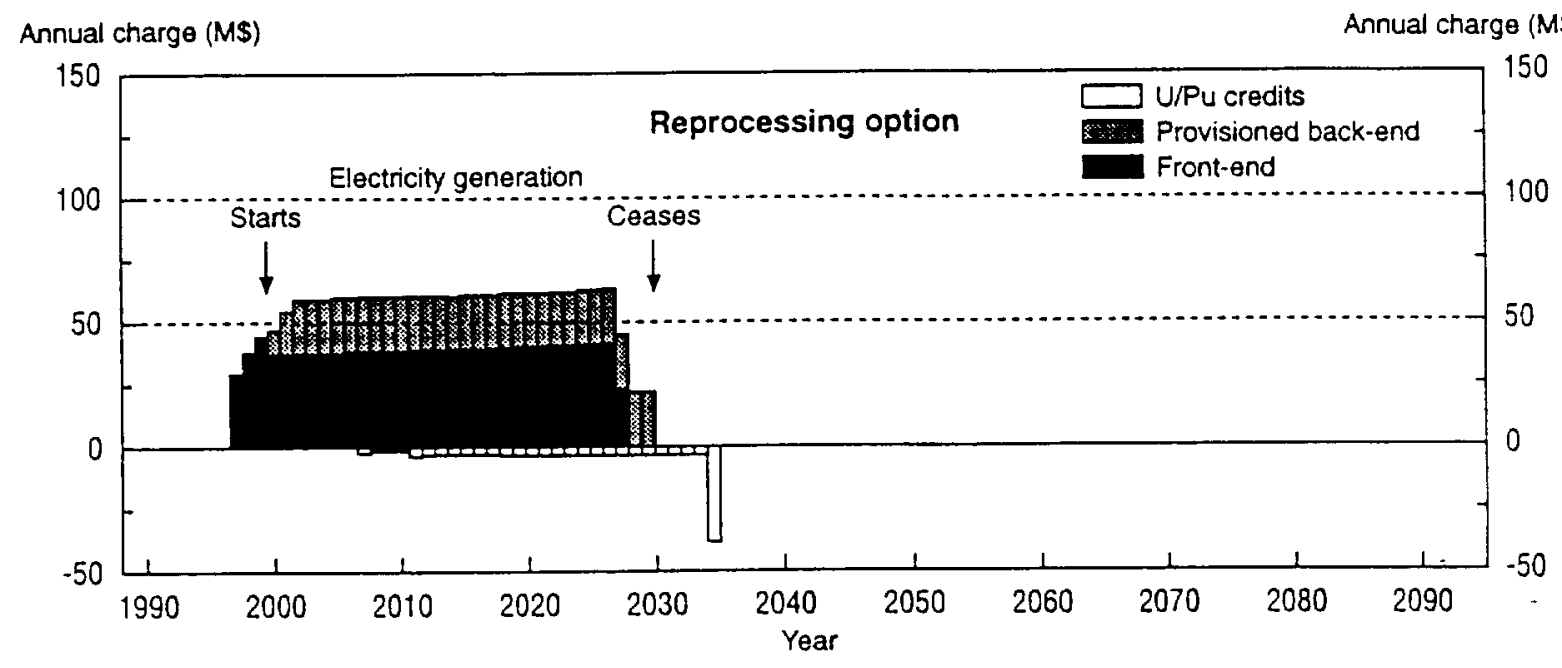

\begin{tabular}{|l|c|c|c|c|c|c|c|}
\hline Cost (mills/kWh) & $0 \%$ & $2 \%$ & $5 \%$ & $8 \%$ & $10 \%$ & $12 \%$ & $15 \%$ \\
\hline Front-end & 4.15 & 4.35 & 4.70 & 5.08 & 5.36 & 5.66 & 6.14 \\
\hline Back-end & 2.23 & 2.23 & 2.23 & 2.23 & 2.23 & 2.23 & 2.23 \\
\hline Credits & -0.42 & -0.34 & -0.26 & -0.19 & -0.17 & -0.14 & -0.11 \\
\hline Total & 5.96 & 6.24 & 6.67 & 7.12 & 7.42 & 7.75 & 8.26 \\
\hline
\end{tabular}

Figure 2.4 Indicative front and back-end accounting charges for PWR (1 $400 \mathrm{MWe}$ )

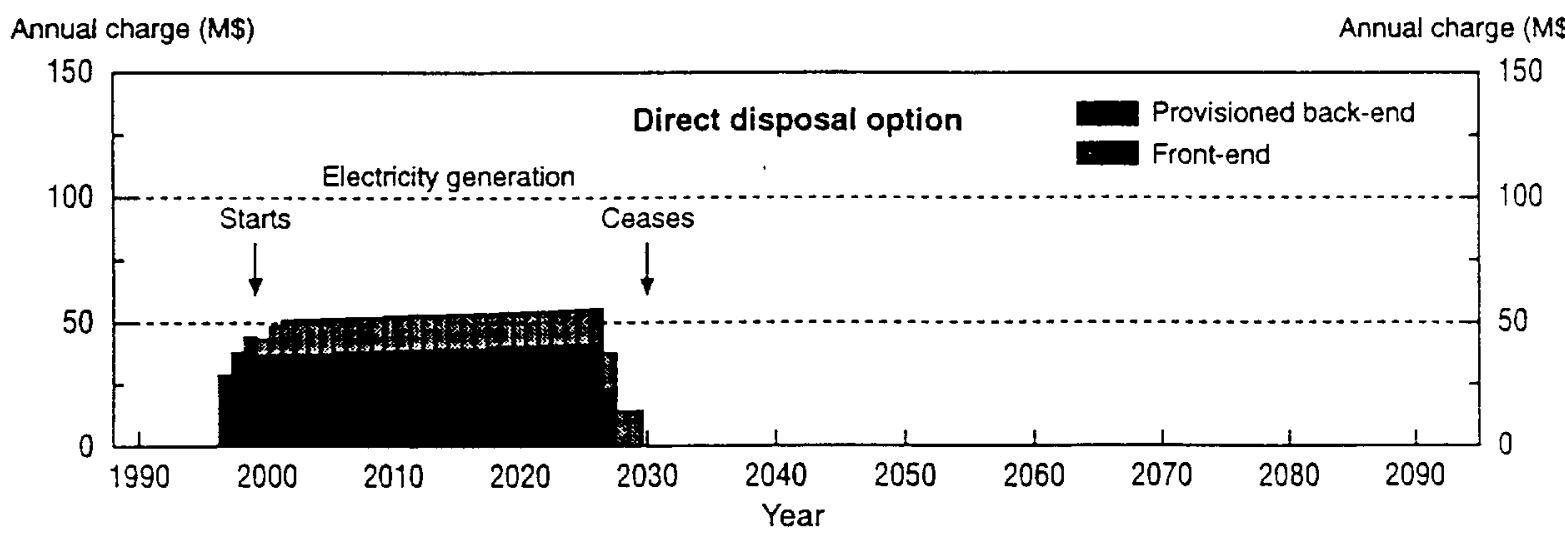

\begin{tabular}{|l|l|l|l|l|l|l|l|}
\hline Cost (mills/kWh) & $0 \%$ & $2 \%$ & $5 \%$ & $8 \%$ & $10 \%$ & $12 \%$ & $15 \%$ \\
\hline Front-end & 4.15 & 4.35 & 4.70 & 5.08 & 5.36 & 5.66 & 6.14 \\
\hline Back-end & 1.46 & 1.46 & 1.46 & 1.46 & 1.46 & 1.46 & 1.46 \\
\hline Total & 5.61 & 5.81 & 6.16 & 6.54 & 6.82 & 7.12 & 7.60 \\
\hline
\end{tabular}


Figure 2.5 Back-end provisions fund variations with time (reprocessing option)

Provisions fund balance (MS) (assuming $2 \%$ p.a. interest)

Provisions fund balance (M\$ (assuming 2\% p.a. interest)

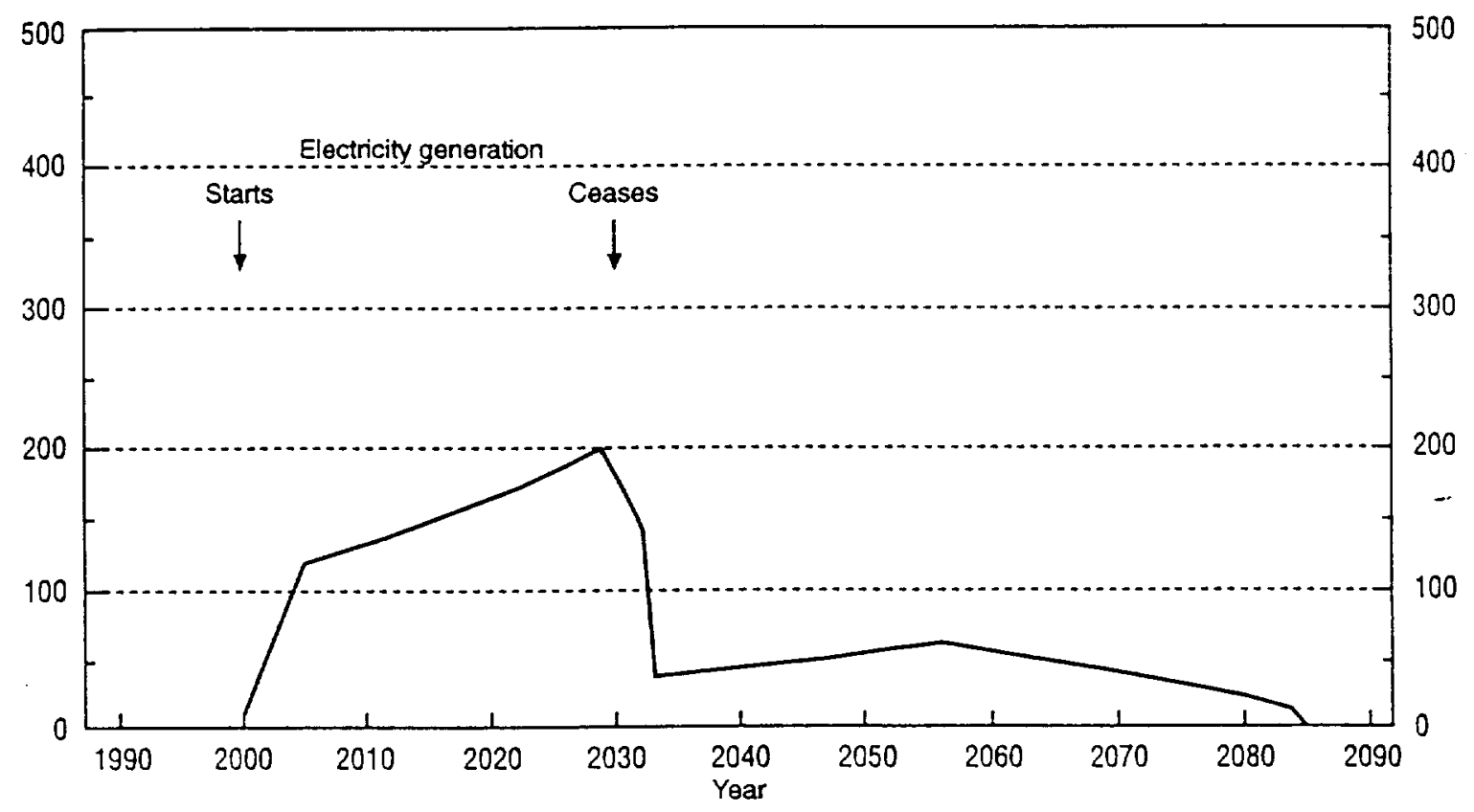

Figure 2.6 Back-end provisions fund variations with time (direct disposal option)

Provisions fund balance (M) (assuming $2 \%$ p.a. interest)

Provisions fund balance (M\$) (assuming $2 \%$ p.a. interest)

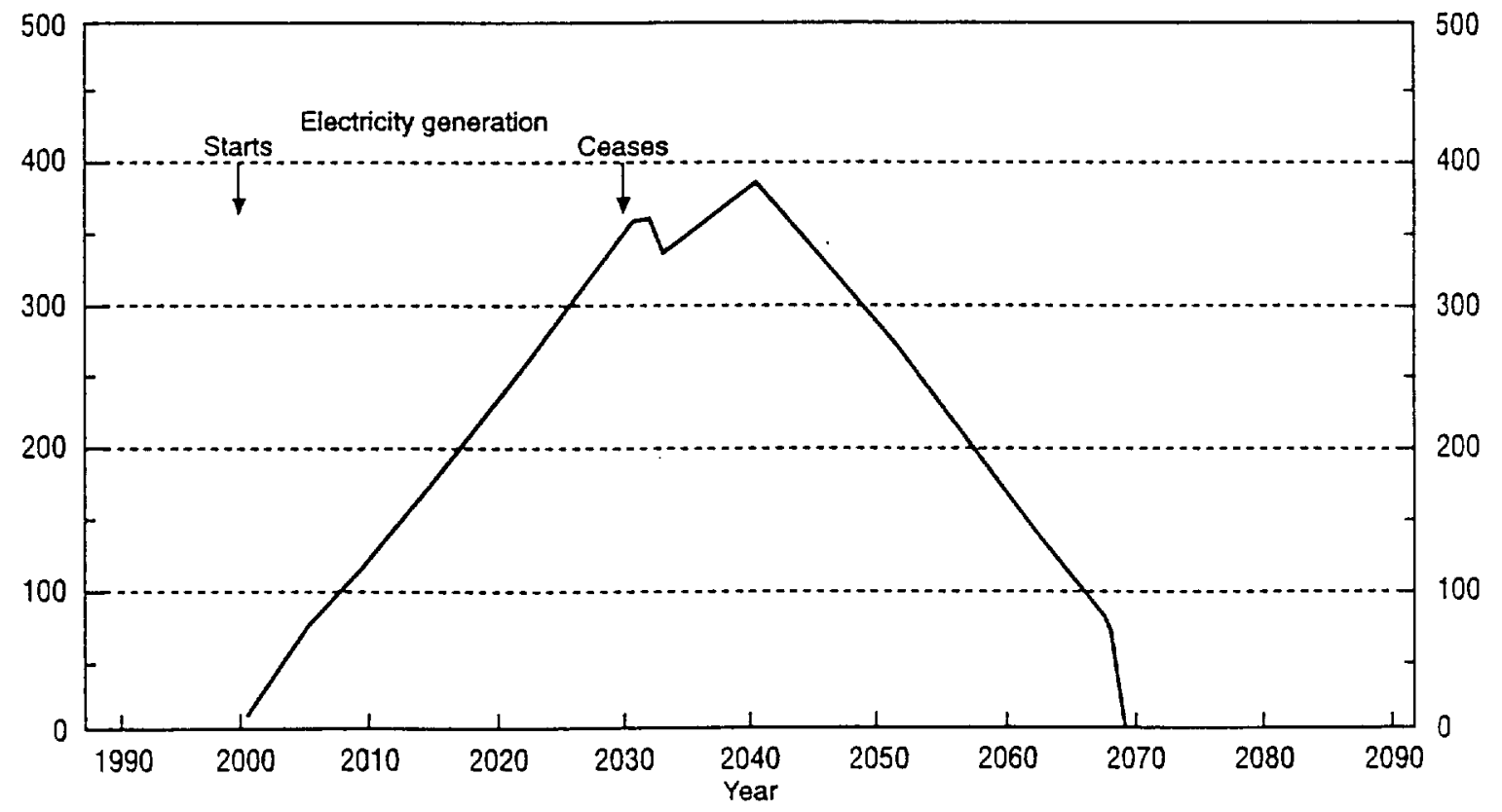




\section{Figure 2.7 Levelised fuel cycle cost appropriate}

to investment and financial appraisal

(reprocessing option)

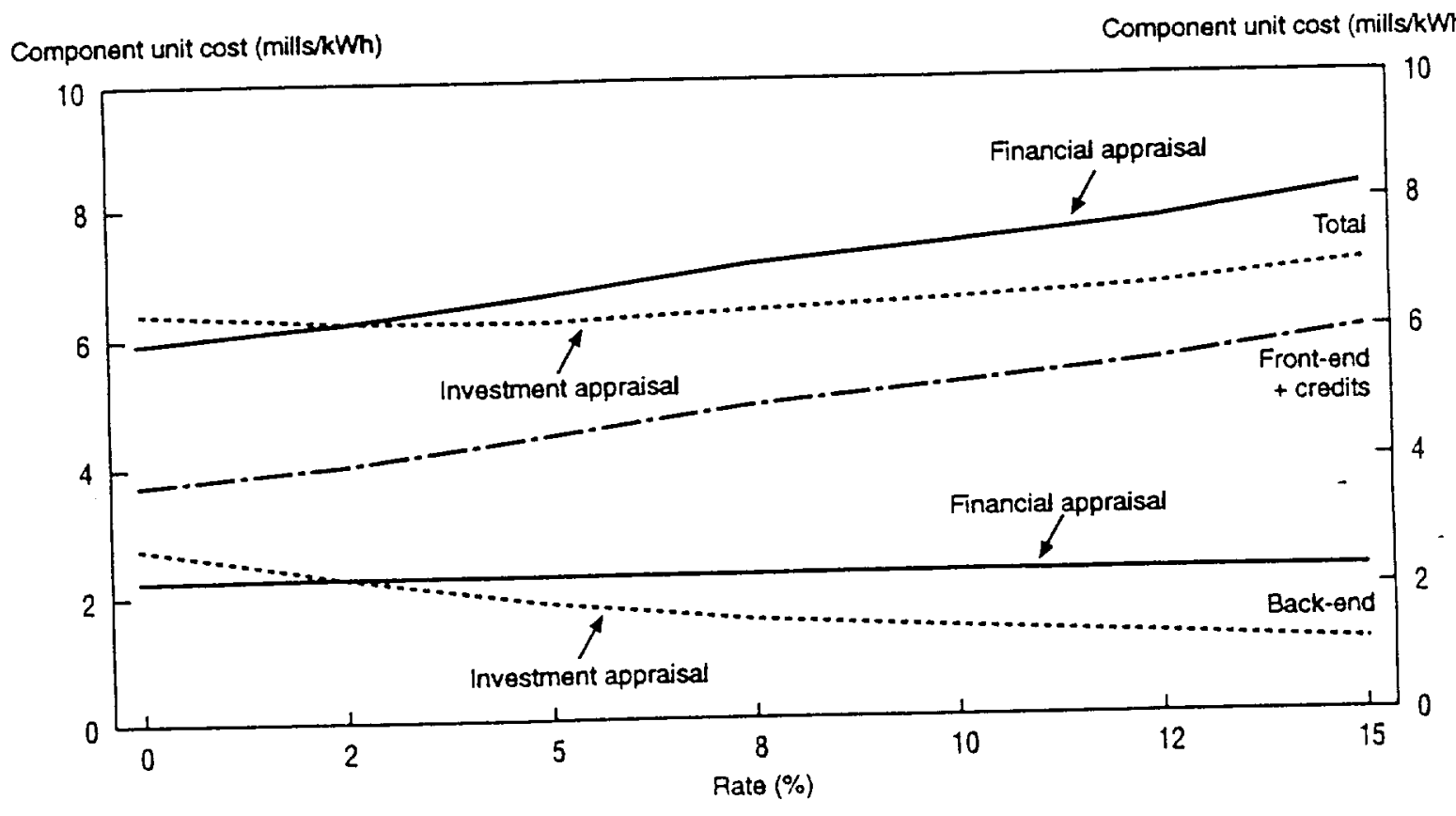

Figure 2.8 Levelised fuel cycle cost appropriate

to investment and financial appraisal

(direct disposal option)

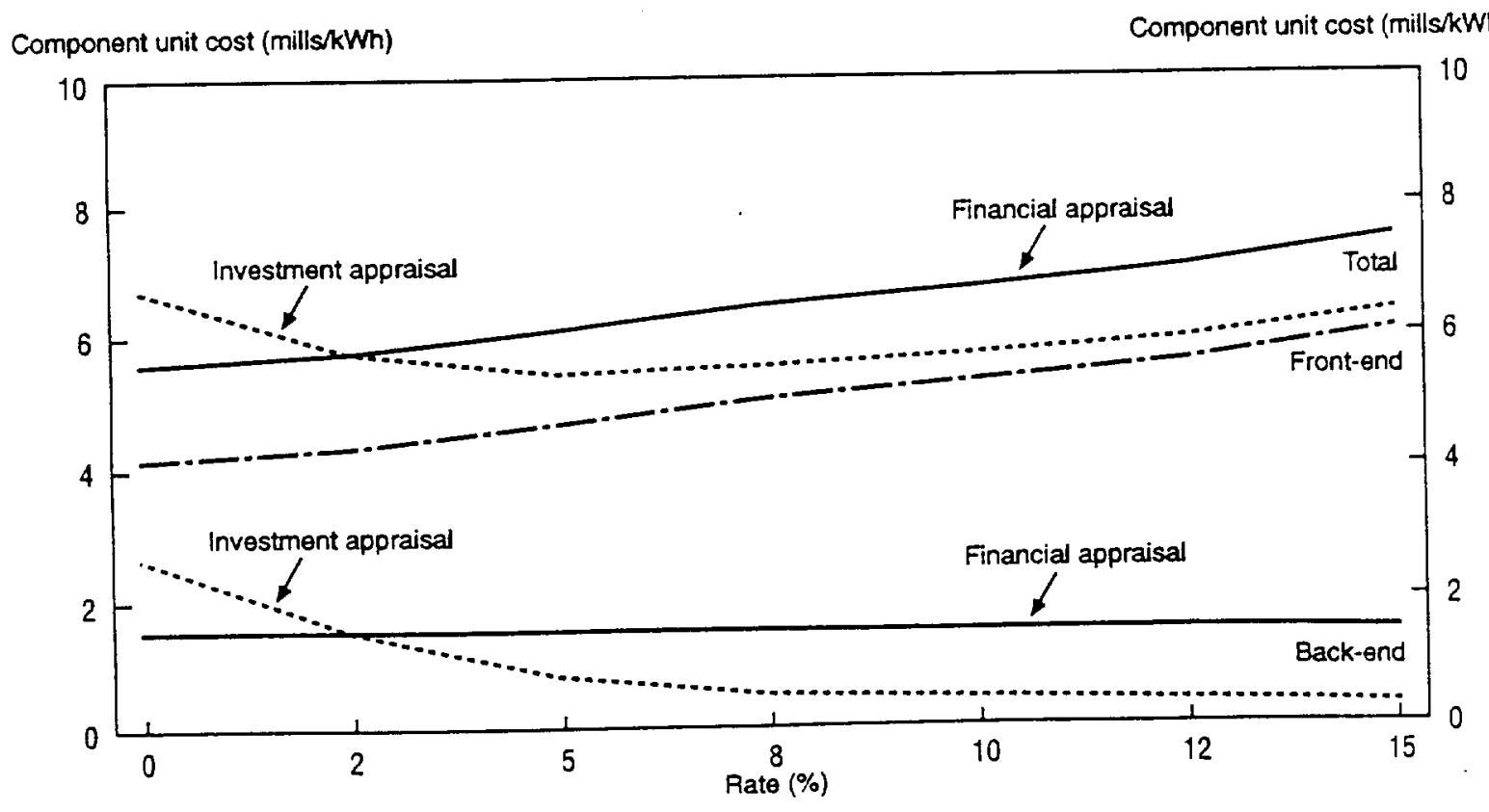


Figure 2.9 Levelised fuel cycle cost appropriate

to investment and financial appraisal

(reprocessing option)

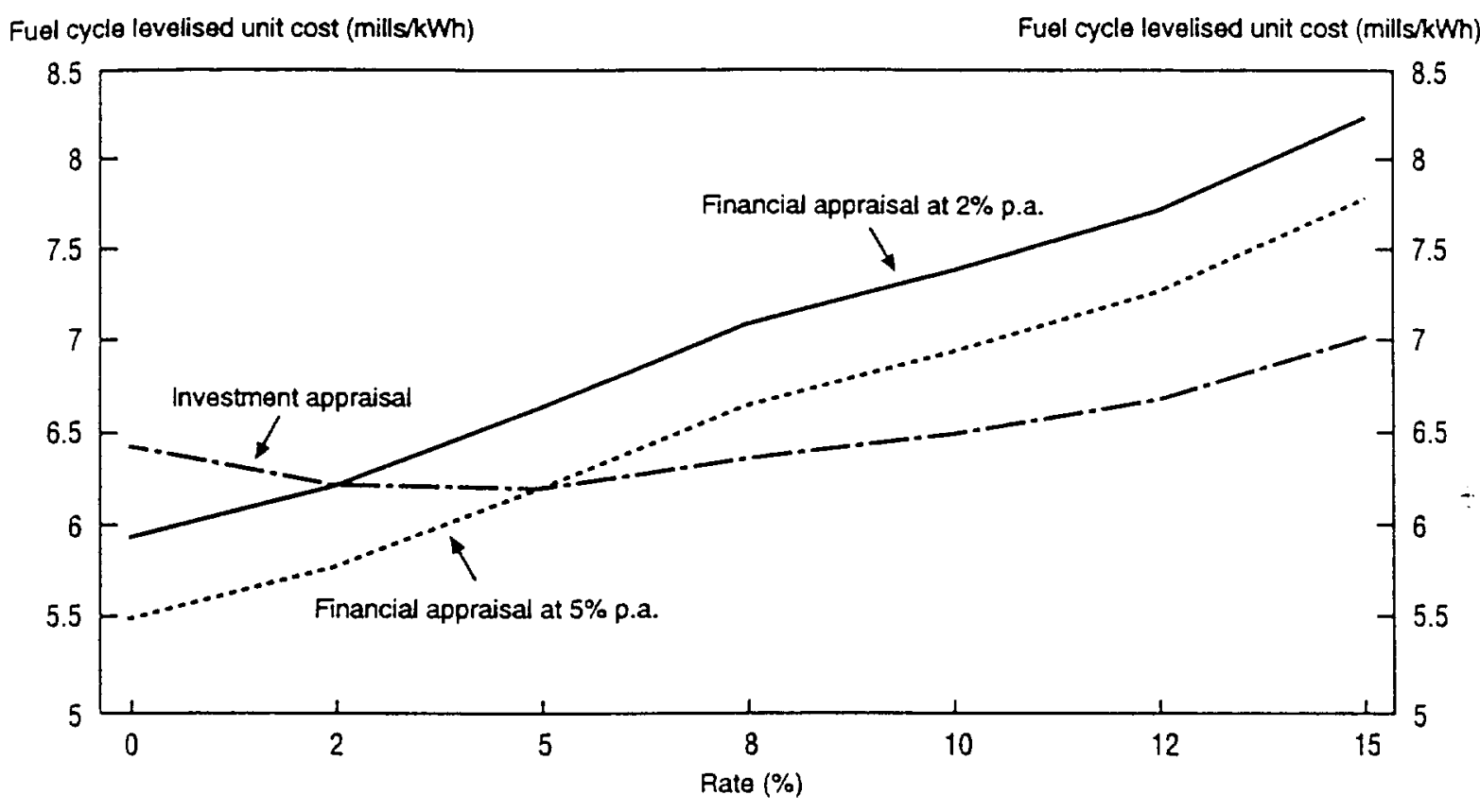



Annex 3

\section{REPROCESSING OPTION COST ESTIMATES AND FUTURE TRENDS}

\section{Introduction}

The basic cost estimates used in this study have, as in the 1985 NEA study, been provided by British Nuclear Fuels plc (BNFL). Further information relating to likely trends in future costs has been provided by COGEMA.

Reprocessing of spent nuclear fuel from civil reactors is now an established industry in France and the United Kingdom with a plant under construction in Japan and further civil facilities proposed elsewhere. It is also currently the only proven back-end route for closing the nuclear cycle and is recognised worldwide as a viable option. A significant number of countries with nuclear programmes have chosen to recover the energy resource which spent fuel represents, including Belgium, France, Germany, Japan, Switzerland, Russia and the United Kingdom.

The cost estimates provided by BNFL for the 1985 NEA study were based on evidence given to the Sizewell Inquiry and related to specific proposals for the UK programme. For the present study, prices have been based on a hypothetical plant based on the same technology, as illustrated in Figure 3.1, built and operated to coincide precisely with the requirements of the PWR power station under consideration. Although such timing and adoption of technology which would by then be obsolete would in practice be unlikely, this approach was adopted as providing a conservative estimate of reprocessing prices for the relevant period of operation. There is already an established world market in reprocessing (supplied by BNFL and COGEMA) and the price levels derived from the above assumptions are fully supported by firm prices currently available for future contracts.

\section{Outline programme and design assumptions}

It has been assumed that, after discharge, fuel is stored for 5 years in the reactor pond and then transported to a receipt and storage facility at the reprocessing plant where it is stored for a further year prior to reprocessing. The products of reprocessing are then available for use and are credited in accordance with previously published OECD/NEA methodology. High level wastes are assumed to be vitrified and stored for 50 years prior to final disposal. This programme is illustrated in Figure 3.2 which gives timescales for construction, operation and decommissioning of the required plant.

Recovery of plutonium and uranium products is very efficient (very close to 100 per cent) with $1 \mathrm{~kg}$ $\mathrm{HM}$ producing approximately $8 \mathrm{~g}$ plutonium, $960 \mathrm{~g}$ recovered uranium at about 0.8 per cent ${ }^{235} \mathrm{U}$ enrichment and $30 \mathrm{~g}$ of fission product wastes $(1 \mathrm{~g}$ of plutonium utilised in mixed oxide fuel is the heat equivalent of 1 tonne of oil). The value of these products is taken into account in the form of credits, as described in Annex 8. As a corollary, the radioactive wastes accompanying the plutonium and uranium are removed in a number of waste streams. Wastes arise both directly from the processed fuel 
(fission products, transuranics and hulls) and from other materials involved in the process (used equipment, degraded solvent and contaminated articles and refuse). Wastes from both sources are categorised according to level of radioactivity:

- high level waste (HLW) contains about 97 per cent of the total activity and is immobilised in glass inside 150 litre stainless steel containers giving a highly stable waste form for storage and disposal;

- intermediate level waste (ILW) is incorporated into bitumen or cement matrices in steel containers; and

- low level waste (LLW) is either handled in the same way as ILW or is sorted and compressed for disposal in steel containers.

For all these wastes there are clearly established management techniques which meet strict safety regulations. There are currently several major programmes aimed at reduction of waste levels and volumes as indicated below in the section on future improvements. These will have a positive impact on both economic and environmental aspects.

\section{Plant cost estimates}

The cost estimates for the various stages of the reprocessing option are given in Table 3.1. The experience and assumptions on which they are based are described below.

\section{i) Receipt and storage}

Pond storage costs are based on substantial experience of design and construction of this type of facility for different applications.

\section{ii) Reprocessing}

The costs for this plant are based on the outturn costs experienced in the construction of THORP including the associated research and development costs. More realistic assumptions on throughput have been used compared with the previous study (1 $200 \mathrm{tU}$ per year nominal throughput plant operating at $900 \mathrm{tU}$ per year rather than $600 \mathrm{tU}$ per year) and with an economic life of 28 years given appropriate refurbishment. It is assumed that the plant is fully utilised.

\section{iii) Waste treatment and storage}

The cost of storing and vitrifying HLW is based on experience of construction and operation at Sellafield of 21 tanks for HLW liquid storage and the Windscale vitrification plant. The costs for ILW treatment plants are again based on experience with currently operating plants where the ILW is embedded into a cement matrix held within steel containers. The costs also cover the storage facilities where the treated ILW is held for a short period prior to disposal. The cost estimates for the treatment and disposal of LLW are based on current practice using shallow land burial techniques at the Drigg site. 


\section{Table 3.1. Summary of basic data used by BNFL for calculating the cost of PWR spent fuel management}

\begin{tabular}{|c|c|c|c|c|c|}
\hline Plant & Size & $\begin{array}{c}\text { Capital } \\
\mathbf{M} £ \\
\end{array}$ & $\begin{array}{l}\text { Operating } \\
\text { M £ p.a. }\end{array}$ & $\begin{array}{c}\text { Refur- } \\
\text { bishment } \\
\text { M £ }\end{array}$ & $\begin{array}{c}\text { Decommis- } \\
\text { sioning } \\
\text { M } £\end{array}$ \\
\hline $\begin{array}{l}\text { Transport of spent fuel } \\
\text { to the reprocessing plant }\end{array}$ & & & & & \\
\hline 1. Flask maintenance & & 27 & 1 & 5 & 11 \\
\hline 2. Multi-element bottles & & 32 & 0 & 0 & 0 \\
\hline 3. MEB maintenance & & 27 & 1 & 5 & 11 \\
\hline Fuel receipt \& storage & $900 \mathrm{tU} / \mathrm{y}$ & 100 & 11 & 15 & 27 \\
\hline Reprocessing plant & $900 \mathrm{tU} / \mathrm{y}$ & 2300 & 145 & 465 & 690 \\
\hline HLW vitrification & $600 \mathrm{pks} / \mathrm{y}$ & 260 & 22 & 27 & 75 \\
\hline HLW interim storage & $16800 \mathrm{pks}$ & 70 & 2 & & 22 \\
\hline ILW encapsulation & $794 \mathrm{~m}^{3} / \mathrm{y}$ & 300 & 33 & 60 & 86 \\
\hline ILW interim storage & $2300 \mathrm{~m}^{3}$ & 38 & 1 & & 11 \\
\hline LLW disposal & $5295 \mathrm{~m}^{3} / \mathrm{y}$ & & 11 & & \\
\hline ILW disposal & $794 \mathrm{~m}^{3} / \mathrm{y}$ & & 5 & & \\
\hline Transport equipment & & 4.5 & & & \\
\hline $\begin{array}{l}\text { Transport, operating \& } \\
\text { packaging }\end{array}$ & & & 1.16 & & \\
\hline Disposal facility & $900 \mathrm{tU} / \mathrm{y}$ & 82 & 19 & & 6.1 \\
\hline
\end{tabular}

\footnotetext{
Notes: $\quad$ - Assumed exchange rate $£ 1=$ ECU 1.4.

- All costs based on a dedicated HLW repository, commencing 56 years post discharge of fuel.

- Based on total fuel quantity of $25000 \mathrm{tU}$ disposed over 28 years.
}

\section{iv) Waste disposal}

The costs for treated ILW disposal were based on indicative costs as provided by the UK Nuclear Industry Radioactive Waste Executive (NIREX) and have been included in the reprocessing price. The costs associated with the disposal of vitrified HLW are based on updated estimates and are consistent with a UK industry-wide study awaiting publication. ILW and HLW disposal costs are based on preliminary design estimates and a conceptual study, respectively. The costs should therefore be regarded as less certain when compared with the basis for most of the preceding costs. To cover this uncertainty, contingency allowances have been included in deriving the cost estimates used. 


\section{v) Operating costs}

The operating cost figures provided include the following components:

- direct labour, repair and maintenance;

- supply and process, rates and insurance;

- site services, depreciation, direct materials;

- works overheads and company overheads.

It has been assumed that the plant is built at an established nuclear site with no additional infrastructure costs.

\section{vi) Decommissioning}

BNFL has further developed its decommissioning policy which is now based on passive safe storage for 20 years post operation with decommissioning being completed over the following 7 years. Decommissioning costs for the reprocessing and associated service plants are assumed to be 30 per cent of the original capital cost (in constant money terms).

Cost cash flows of the reprocessing and waste disposal facilities are shown in Figure 3.3.

\section{Levelised price derivation}

Based on the cost estimates and timings given above, levelised unit prices have been calculated separately for reprocessing (including ILW disposal) and HLW disposal. The prices have been calculated using cost estimates that are based on out-turn costs for the reprocessing and its associated support plants and include a component for research and development. Other estimates for ILW and HLW disposal additionally contain a contingency allowance. Costs have been levelised in the case of reprocessing to the point of delivery at the reprocessing site and, in the case of HLW disposal, to the point of delivery to the disposal site. The levelisation is illustrated in Figure 3.4. The methodology is the same as that adopted for levelising the fuel cycle costs described in Annex 1.

Levelised prices are given in Table 3.2 for a range of discount rates. For the purposes of this study it has been agreed to adopt the 5 per cent discounted costs as an indicator of likely price. The resulting value for reprocessing, ECU 720 per $\mathrm{kg} \mathrm{U}$, is in line with current firm prices for reprocessing contracts for future business.

Table 3.2. Levelised unit prices (ECU/kg U) of reprocessing and disposal of vitrified waste for a range of discount rates

\begin{tabular}{||l|r|r|r|r|r|r|r||}
\hline Discount rate & $\mathbf{0 \%}$ & $\mathbf{2 \%}$ & $\mathbf{5 \%}$ & $\mathbf{8 \%}$ & $\mathbf{1 0 \%}$ & $\mathbf{1 2 \%}$ & $\mathbf{1 5 \%}$ \\
\hline Reprocessing & 620 & 640 & 720 & 840 & 930 & 1040 & 1220 \\
HLW disposal & 60 & 70 & 90 & 120 & 140 & 170 & 220 \\
\hline
\end{tabular}




\section{Basic design and future improvements}

\section{i) Basic design}

The environmental standards related to nuclear wastes are set in terms of the total return of radioactivity through the biosphere to man. This depends in turn on both the quantities of radionuclides in the wastes and the nature and integrity of the barriers between the wastes and man. These barriers may be physical e.g. cladding, containers, overpacks, and chemical/geological, e.g. bentonite clay, natural insolubility, absence of ground water, stable rock formations, etc.

Existing and planned reprocessing facilities are based on a technology that achieves a high level of purity in recovered uranium and plutonium products and ensures that only a small fraction of the uranium and plutonium appears in wastes and the bulk of this is concentrated in a solid form. The specification of all wastes disposed or released to the environment is set or approved by regulatory authorities with due regard to the protection of man. The achievement of the high levels of plutonium and uranium separation from the waste streams to which the industry currently works has a substantial effect on the overall cost of reprocessing.

It appears feasible, therefore, that even without any fundamental improvement in reprocessing technology, a different optimisation of product and waste stream specifications could lead to lower overall costs and hence low reprocessing prices for services provided by new facilities which could be constructed in the future*. Such an optimisation with a lower level of plutonium separation could have been assumed as the basis of the design of the reprocessing plant in this study. The extent to which cost advantage may be taken would be dependent on customer views since they ultimately have the responsibility for disposing the resulting high level waste products. Public and political attitudes would influence the regulatory position and would then also play a part.

\section{ii) Future improvements}

Reprocessing technology is well established, having been developed from a uranium metal based process to one capable of handling oxide fuels. COGEMA's latest plant UP3 has met or exceeded its design specification in its first year of operation. Although current reprocessing costs are in excess of those envisaged in the 1960s, there is firm evidence that the peak has been reached and that further industrial development and increased operating experience will bring continued economies.

In addition to scope for cost reduction in reprocessing plants there is clearly considerable potential for cost reduction in the area of waste management. There are a number of major programmes aimed at reducing the volume of wastes arising and COGEMA has set a target of 80 to 90 per cent reduction in ILW volumes by the year 2000, as indicated in Table 3.3. The key feature

of this programme is the goal of "zero bitumen" by 2000 which can be achieved through improvements in fluid recycling, evaporation etc. Already, very promising progress has been made towards these goals. The result by 2000 should be that, in terms of long-lived waste (for underground disposal), only about $0.5 \mathrm{~m}^{3}$ waste per tonne of uranium will arise from reprocessing as compared with $1.4 \mathrm{~m}^{3}$ today.

\section{Table 3.3. Volumes (1/tU) of long-lived wastes generated by the French}

\footnotetext{
* A COGEMA assessment has shown a cost advantage of about 25 per cent in overall reprocessing cost (excluding disposal cost considerations) for a plant design with a plutonium separation level of 99 per cent compared with the current 99.9 per cent.
} 
UP3 reprocessing plant, based on a throughput of $800 \mathrm{tU} / \mathrm{y}$

\begin{tabular}{||c|c|c||}
\hline \multirow{3}{*}{ Glass } & $\begin{array}{c}\text { Original } \\
\text { specification }\end{array}$ & $\begin{array}{c}\text { Expected } \\
\text { by 2000 }\end{array}$ \\
\cline { 2 - 3 } Other & 130 & 115 \\
Total & 2920 & $<350$ \\
\hline
\end{tabular}

To estimate the levels of likely future cost reduction, an assessment was made of the various factors which could contribute:

- Process improvements, the continuous improvement of current processes, such as improved decontamination factors and process materials recycling can make a significant impact in the shortto medium-term and were estimated to have a potential for 5 to 10 per cent reduction in costs.

- Industrial experience, via improved labour and overall productivity, more efficient maintenance programmes and reduced inventories was estimated to contribute a further 10 to 20 per cent reduction in costs over the 15 to 20 year period before reprocessing commences. Note that chemical industries typically achieve a 2 to 3 per cent annual improvement in productivity once at the top of their learning curve as is the case with reprocessing.

- Increased process throughput has a direct effect on unit costs as the majority of costs are fixed. This was estimated to contribute a further 10 to 20 per cent towards future cost reductions. This magnitude of improvement has already been achieved with the head-end unit at La Hague which currently achieves 550 tonnes per year compared with a design throughput of 400 tonnes per year.

- Increased plant life would also offer scope for cost reductions. For example, an increase from 28 to 40 years would, including the additional refurbishment, reduce costs by about 10 per cent.

A range of specific areas where improvements can be confidently predicted are listed in Table 3.4.

Taking a conservative combined estimate of these factors shows that the 25 per cent reduction adopted for the lower price range limit should be readily achievable.

These cost reductions from possible future developments do not take account of the possible reductions in the cost of a basic design adopting a lower level of plutonium separation, as described in sub-section 5 i) above. The combined effects of these factors would not necessarily be additive. 
Table 3.4. Developments in reprocessing

\begin{tabular}{||c||}
\hline \multicolumn{1}{|c||}{ Extraction cycle } \\
\hline - Process optimisation (in order to obtain the required \\
contamination factors with fewer extraction cycles) \\
- Novel process options for the purification cycle \\
e.g. centrifugal contactors \\
- Improved analytical methods \\
- Advanced monitoring methods \\
\hline \multicolumn{1}{c||}{ Solid and liquid wastes treatment } \\
\hline - Alternative processes for hulls and end pieces for \\
volume reduction \\
- Improved glass quality for vitrification \\
- Improved vitrification capacity (induction heating for \\
calcination, cold crucible technology for the melter) \\
- Co-precipitation process for LLW and ILW (supernate \\
clarification and additional decontamination) \\
- New management and conditioning processes for \\
LLW and ILW \\
- Increased alpha decontamination of technological wastes \\
\hline
\end{tabular}

\section{Sensitivity range}

There is continuing regulatory pressure on all aspects of the nuclear cycle. It is possible that further pressure could have an impact on costs in some areas. However, the strong likelihood of economies arising from technological developments and commercial pressure make any upward movement of reprocessing prices highly unlikely. Hence a sensitivity range of +0 to -25 per cent is adopted.

The use of no upside price risk can be supported in two ways:

- It is, at present, possible for any electricity utility to obtain a long-term reprocessing service at a firm contract price of about ECU 700 per $\mathrm{kg}$ U. Thus, even the smallest of utilities can benefit from the scale effect of a worldwide reprocessing market with any risk of capacity under-utilisation being borne entirely by the reprocessors.

- The conservative estimate for building a new reprocessing facility, as calculated for this study, arrives at a very similar figure, showing that the reprocessing market is in the healthy position of the current market price fully reflecting the development costs of new facilities.

The potential market for reprocessing remains large in terms of spent fuel arisings, so high capacity utilisation is expected.

The reference reprocessing case is for reprocessing after 6 years storage whereas the reference case for direct disposal assumes storage of fuel for 40 years before encapsulation and disposal. A calculation was undertaken in which it was assumed that reprocessing and spent fuel encapsulation 
were carried out on a similar deferred timescale, with the encapsulated spent fuel and the resulting conditioned wastes from reprocessing being disposed of immediately thereafter. This comparison showed that the cost advantage to direct disposal in the reference cost comparison became negligibly small. This result is insensitive to assumptions on credits for uranium and plutonium. 
Figure 3.1 BNFL back-end fuel cycle operations

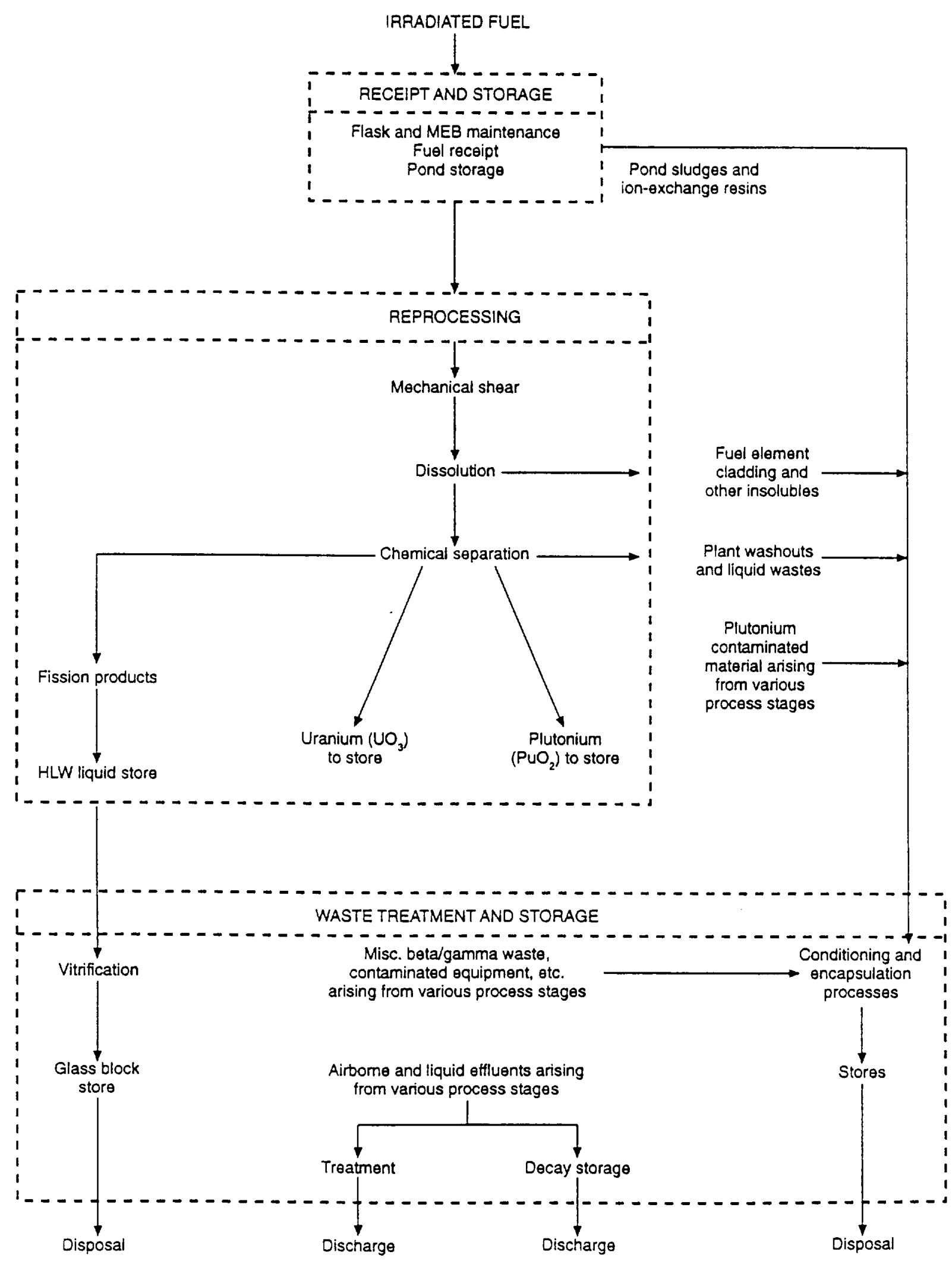


Figure 3.2 Programme of a $900 \mathrm{tU}$ per annum throughput plant operating over 28 years

POND 1

FLASK MAINTENANCE

MEB PUACHASE

MEB MAINTENANCE

REPROCESSING

VITAIFICATION PLANT

VITAIFIED PRODUCT STORE

ILW CONDITIONING PLANT

CONDITIONED PRODUCT STORE

HLW DISPOSAL
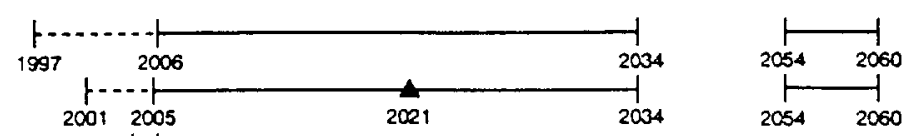

ILW DISPOSAL

LLW DISPOSAL

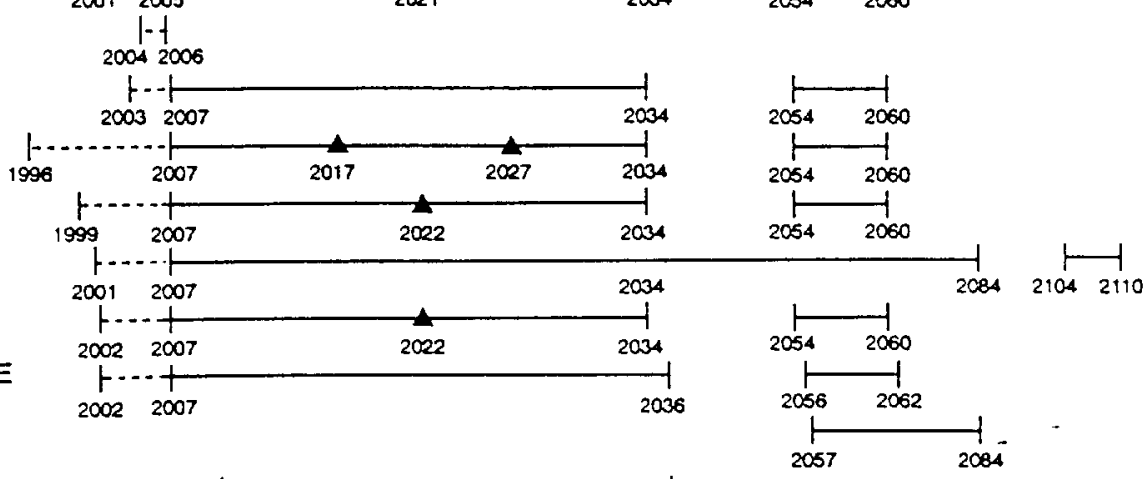

Figure 3.3 Cost cash flow of a 900 tU per annum reprocessing plant and associated facilities

KEY

Construction

Operations

Decommissioning

Refurbishment

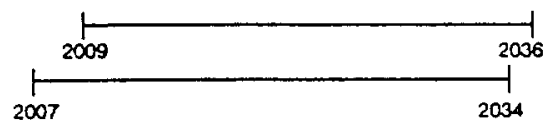


Figure 3.4 Levelisation of reprocessing and HLW disposal costs

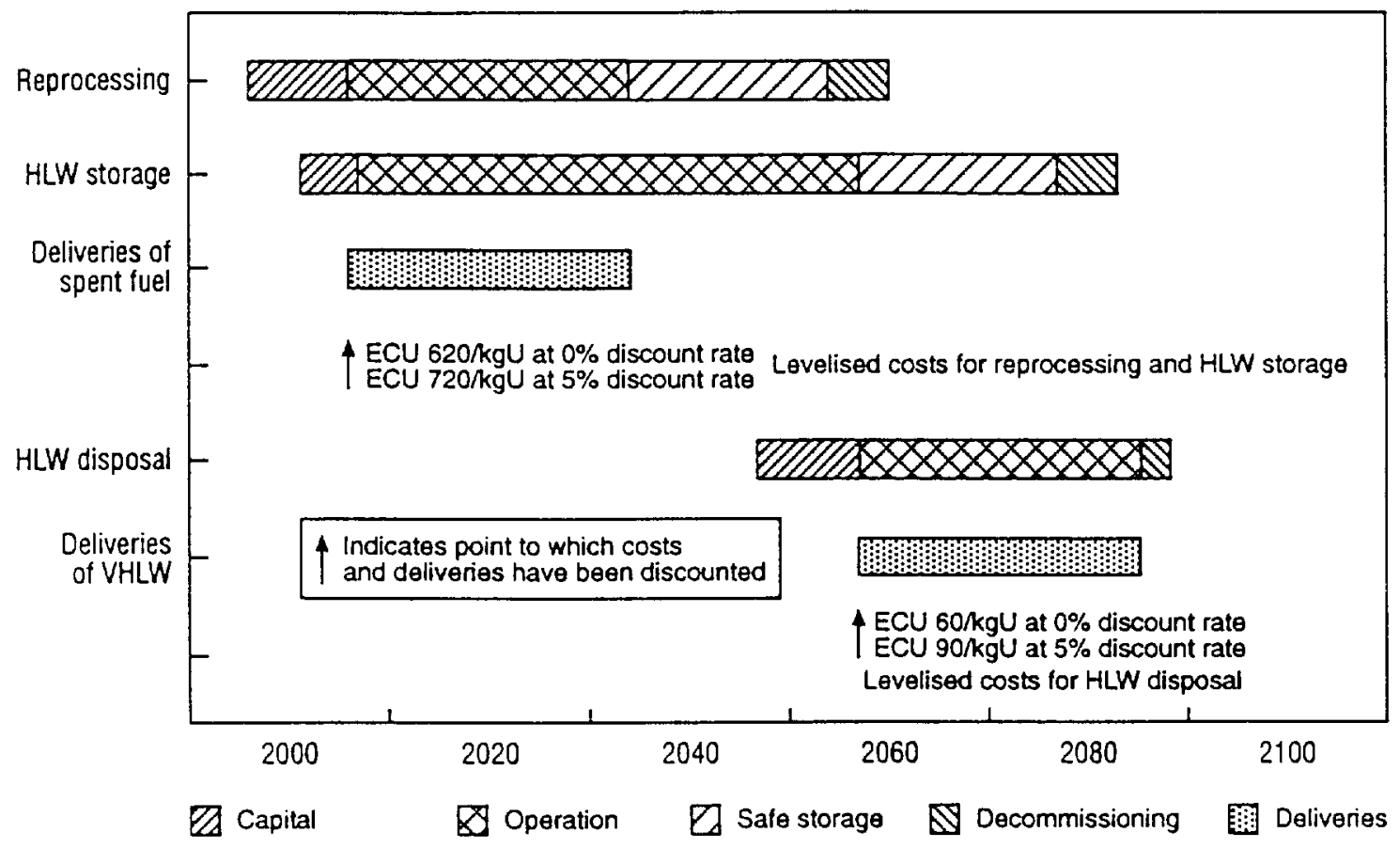





\section{Annex 4 \\ DIRECT DISPOSAL OPTION COST ESTIMATES AND FUTURE TRENDS: SWEDEN (REFERENCE)}

\section{Introduction}

The Swedish Nuclear Fuel and Waste Management Co., (SKB), a body which is responsible for carrying out nuclear waste management in Sweden, has provided cost information on its country's option. This study's reference direct disposal option replicates these costs on timescales which coincide with the needs of the hypothetical PWR.

A major change has occurred since the 1985 NEA study in that the Swedish Intermediate Storage Facility (CLAB) has now been in operation for 7 years. Experience gained from the construction and operation of this facility has been taken into consideration in deriving the basic cost estimates. Research efforts for the final disposal of spent fuel continue and, at present, the Äspö laboratory for rock research is being built. Yearly reports containing future cost calculations are being prepared and sent to the Swedish authorities.

\section{Outline of the programme}

Figure 4.1 shows the general programme and time schedule for construction, operation and decommissioning of the facilities for interim storage, encapsulation and final disposal of spent fuel, based on the SKB's achieved and planned timings.

It has been assumed, for the purpose of this study, that the spent fuel is stored at the reactor site for five years (or at least four years in the case of the final core) before being transported to the interim storage facility (CLAB). This is an underground water pond storage facility which also caters for the interim storage of some active core components and other reactor parts.

Prior to encapsulation and disposal, spent fuel will be stored for approximately 40 years, including the time at the reactor site. During this time period, both the radiation and the heat flux will have reduced by about 90 per cent.

The spent fuel will finally be disposed of in a 500 meter deep repository in granitic rock with an isolation based on a multiple barrier system. The first barrier is the spent fuel itself, which has very low solubility in ground water. The second barrier is a copper canister around the spent fuel which will be intact for 100000 years as copper does not corrode in ground water which does not contain dissolved oxygen. The third barrier is compacted bentonite clay around the canister and the fourth barrier is the granitic rock. Ground water flow in the rock will be very slow as large cracks are avoided when choosing the site, and the flow of radioactive substances is even slower.

There are certain costs associated with the site for final disposal; such costs are calculated separately from the costs for the actual disposal. 


\section{Plant cost estimates}

The cost estimates are based on a nuclear programme with a capacity of $10 \mathrm{GWe}$, producing $67 \mathrm{TWh}$ per year, which produces a total fuel quantity of 8000 tonnes over the plants' operating lives.

The cost estimates for the transport, storage, encapsulation and disposal of the spent fuel are summarised in Table 4.1. The experience and assumptions on which they are based are described below.

Table 4.1. Summary of basic data used by SKB for calculating the cost of PWR spent fuel management (million SKr, 1991 money values)

\begin{tabular}{|c|c|c|c|c|c|}
\hline Plant & Size & $\begin{array}{l}\text { Capital } \\
\text { M SKr } \\
\end{array}$ & $\begin{array}{l}\text { Operating } \\
\text { M SKr p.a. }\end{array}$ & $\begin{array}{c}\text { Refurbish- } \\
\text { ment } \\
\text { M SKr }\end{array}$ & $\begin{array}{c}\text { Decommis- } \\
\text { sioning } \\
\text { M SKr } \\
\end{array}$ \\
\hline $\begin{array}{l}\text { Transport of spent fuel } \\
\text { to interim storage } \\
\text { Interim store (CLAB) } \\
\text { Encapsulation (ES) } \\
\text { Repository site } \\
\text { services (d) } \\
\text { Spent fuel disposal } \\
\text { facility }\end{array}$ & $\begin{array}{c}\text { (a) } \\
8000 \mathrm{tU}^{(\mathrm{b})} \\
270 \mathrm{tU} / \mathrm{y}\end{array}$ & $\begin{array}{r}423 \\
3978 \\
2824 \\
3393 \\
4736 \\
\end{array}$ & $\begin{array}{c}21 \\
83^{(c)} \\
161 \\
\\
50 \\
\\
31 \\
\end{array}$ & $\begin{array}{c}516 \\
868 \\
123 \\
\\
208 \\
3160^{(\mathrm{e})} \\
\end{array}$ & $\begin{array}{c}- \\
358 \\
254 \\
\\
231 \\
\\
193 \\
\end{array}$ \\
\hline Assumed exchange rate & $\begin{array}{l}\operatorname{Kr} 7.45=E \\
\operatorname{Kr} 7.70=E\end{array}$ & $\begin{array}{l}1 \text { (long-t } \\
1 \text { (Janua }\end{array}$ & & & \\
\hline
\end{tabular}

a. One ship, 10 transportation casks, 5 land vehicles (SKr 400000 each).

b. Initial $3000 \mathrm{tU}, 5000 \mathrm{tU}$ achieved by compact racks, further caverns needed to give $8000 \mathrm{tU}$.

c. Includes small cost for the handling and disposal of LLW and ILW.

d. Improvement to harbour, $50 \mathrm{~km}$ rail, preparation and handling.

e. Includes sealing of the repository. 


\section{Transport}

Transport of the spent fuel from the nuclear power plants to the interim store and then to the final disposal takes place by special ship and railway. In order not to underestimate the cost shown in Table 4.1, a sea transport of $750 \mathrm{~km}$ and a railway transport of $200 \mathrm{~km}$ have been postulated.

\section{Interim storage}

The cost estimates for this plant draw on the experience gained from the construction of an interim storage facility (CLAB) and its operation for seven years. At present, CLAB has a $5000 \mathrm{tU}$ capacity. To enable CLAB to take the full amount of spent fuel from the Swedish system, further caverns have also been costed and these costs are reflected in the reinvestment cost shown in Table 4.1.

\section{Waste streams from interim storage}

A small amount of radioactive waste will occur on receipt of the spent fuel to the interim store from the cleaning water in the pools and from maintenance operations.

Practical experience from the last four years shows that there will be $30 \mathrm{~m}^{3}$ of treated and packed intermediate level waste (ILW) and $10 \mathrm{~m}^{3}$ of treated and packed low level waste (LLW) per year. The average cost for the final disposal of these wastes in the "Final Repository for Radioactive Operational Waste (SFR)" is ECU 2600 per $^{3}$. Thus, the total cost for disposal of these wastes is ECU 0.1 million p.a. These small costs are included in the operating cost for the interim store, see Table 4.1.

\section{Encapsulation}

The costs shown in Table 4.1 are based on encapsulation of the spent fuel into $100 \mathrm{~mm}$ thick copper canisters. It assumes a throughput of $270 \mathrm{tU}$ p.a. Currently, no waste streams are foreseen from this process apart from those from the decommissioning shown in Table 4.1.

\section{Decommissioning}

The decommissioning wastes from CLAB and the encapsulation facility (ES) come to a total of 7320 $\mathrm{m}^{3}$ in packed form. These wastes will be disposed finally in the tunnel system remaining after the disposal of the spent fuel has been completed. On completion of this operation the tunnels will be backfilled.

\section{Final disposal}

The system costed assumes final disposal of the spent fuel into a repository situated in a granitic rock substructure. The bentonite cost is included in the cost for refurbishment of the repository (Table 4.1).

\section{Contingencies and costs excluded}

In order not to underestimate this fee, the cost calculations are deliberately made in a very conservative way, for example, assumptions concerning locations and availability of infrastructure. The cost estimates include a contingency of 27 per cent to reflect the greater uncertainty associated with design and construction of the encapsulation plant. 
The following costs are not included in the calculations:

- research;

- costs for reprocessing contracts;

- decommissioning of nuclear power plants;

- disposal of low and intermediate active waste from nuclear power plants. 


\section{Levelised price derivation}

The capital, operating and decommissioning cost estimates used to calculate the levelised prices can be seen in Table 4.1. A simplified cash flow profile for the complete SKB plan is shown in Table 4.2 and diagrammatically in Figure 4.2.

Costs have been discounted to obtain levelised prices at the point of delivery to the respective sites (i.e. storage or disposal) in accordance with the methodology described in Annex 1. These are shown in Table 4.3 for various discount rates.

In Sweden, delivery to the interim storage facility (CLAB) commenced in 1985 and it is planned that the delivery to the encapsulation and disposal facility will commence in 2020 . The reference 5 per cent levelised prices for these operations are ECU 230 per $\mathrm{kg} \mathrm{U}$ and ECU 610 per kg U, respectively. As these prices are levelised, they can be applied to the timings assumed in the direct disposal reference case of this study.

Table 4.2. Undiscounted cash flows for direct disposal option

(million ECU, 1991 money values)

\begin{tabular}{||l|c|c|c|c||}
\hline Time period & Transport & $\begin{array}{c}\text { Interim } \\
\text { storage }\end{array}$ & $\begin{array}{c}\text { Final } \\
\text { disposal }\end{array}$ & Total \\
\hline $1980-1989$ & 107 & 490 & 0 & 597 \\
$1990-1999$ & 21 & 230 & 2 & 253 \\
$2000-2009$ & 39 & 145 & 24 & 208 \\
$2010-2019$ & 34 & 116 & 1117 & 1267 \\
$2020-2029$ & 57 & 150 & 626 & 833 \\
$2030-2039$ & 25 & 123 & 611 & 759 \\
$2040-2049$ & 22 & 106 & 555 & 683 \\
Total & $\mathbf{3 0 5}$ & $\mathbf{1 3 6 0}$ & $\mathbf{2 9 3 5}$ & $\mathbf{4 6 0 0}$ \\
\hline
\end{tabular}




\section{Potential improvements}

Continued research and development may improve the present technology for direct disposal of spent fuel. This might lower the total cost by 15 per cent. It should be noted that the aim is not to lower costs but to develop a safer method for disposal.

However, a new composite canister with a self-supporting steel body covered by a protective layer of copper, currently being developed in a common Finnish-Swedish project, may be both safer and have a lower cost of production compared to the reference canister of pure copper.

Improved knowledge of thermal behaviour and more accurate engineering may allow more fuel elements in each copper canister; this will lower the total cost.

In the SKB Project Alternative System Studies, PASS, the alternative VLH (Very Long Holes) with a composite canister with hemispherical ends should give a lower cost than the reference alternatives. However, the safety of these alternatives must be proved before they could be selected for use.

\section{Sensitivity range}

As shown in Table 4.3, the undiscounted total cost is ECU 570 per $\mathrm{kg} \mathrm{U}$ which has been deliberately calculated in a very conservative way, with a contingency of 27 per cent, in order to reflect the uncertainty associated with the design and construction of the encapsulation and disposal facilities.

There is a potential for further improvement in costs based on the alternatives mentioned above. If these could be developed, costs may be reduced by 15 per cent to ECU 485 per kg U.

Table 4.3. Back-end levelised unit prices (ECU/kg U) for the direct disposal option at various discount rates

\begin{tabular}{||l|c|c|c|c|c|c|c||}
\hline \hline Discount rate & $\mathbf{0 \%}$ & $\mathbf{2 \%}$ & $\mathbf{5 \%}$ & $\mathbf{8 \%}$ & $\mathbf{1 0 \%}$ & $\mathbf{1 2 \%}$ & $\mathbf{1 5 \%}$ \\
\hline $\begin{array}{l}\text { Transport/ } \\
\text { Storage } \\
\begin{array}{l}\text { Encapsulation/ } \\
\text { Disposal }\end{array}\end{array}$ & 210 & 200 & 230 & 280 & 340 & 400 & 500 \\
\hline
\end{tabular}

Note: The transport/storage costs are levelised to the point of delivery to the storage facility, i.e. commencing in 1985, whilst the encapsulation/disposal costs are levelised to the point of delivery to the disposal site, i.e. commencing in 2020, using the method indicated in Annex 1. These levelised prices are not additive. 
Figure 4.1 Facilities for the management of spent fuel

\section{Facilities}
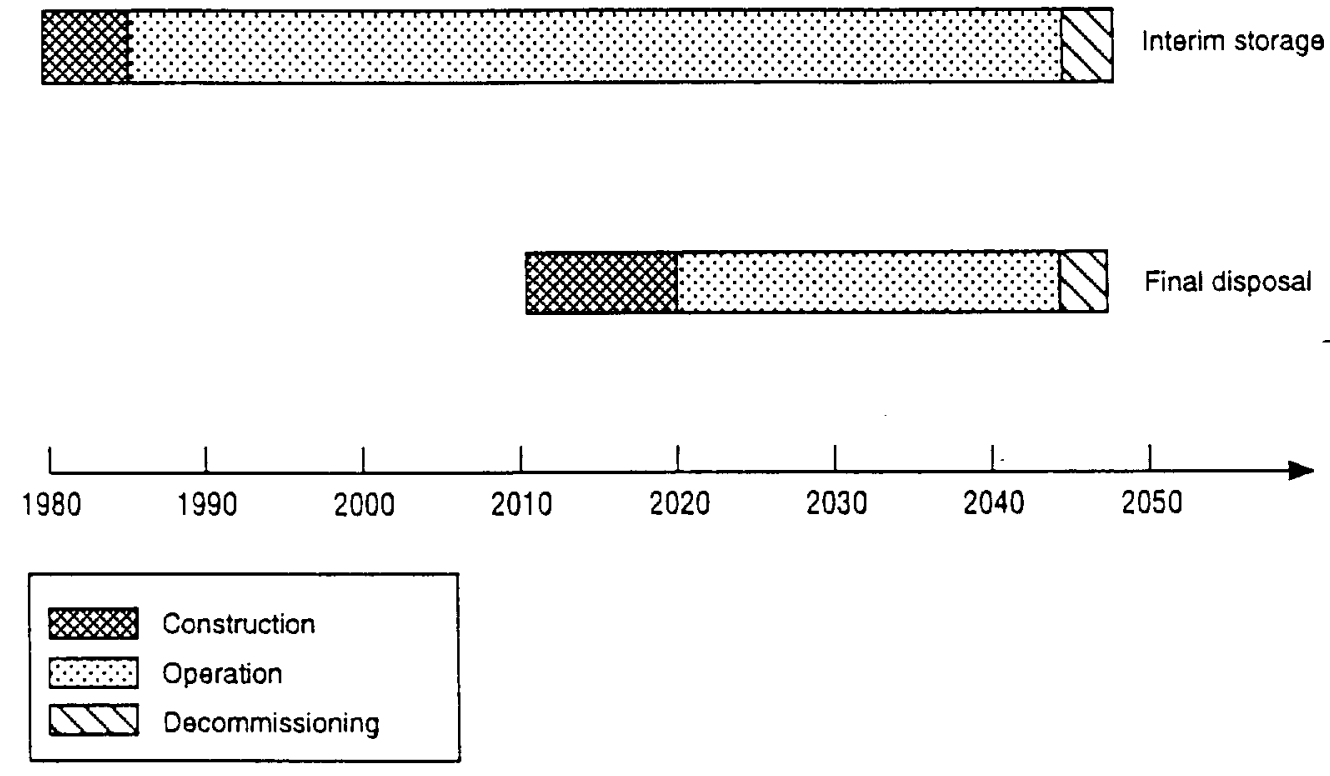

Figure 4.2 Annual future costs for spent fuel in M ECU

(1991 money value)

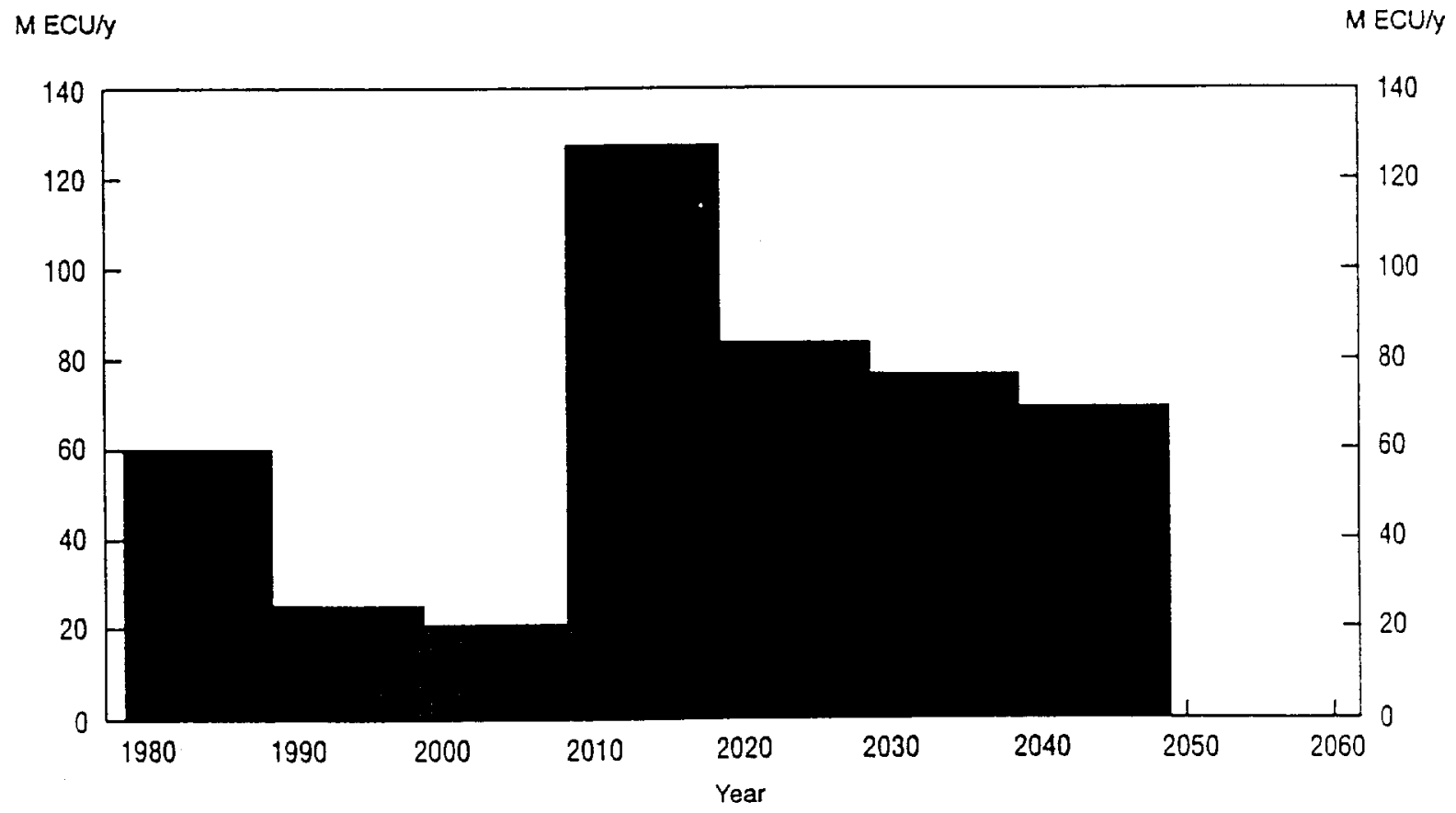


Annex 5

\section{DIRECT DISPOSAL OPTION COST ESTIMATES: UNITED STATES}

\section{Introduction}

The United States Department of Energy's (DOE) Office of Civilian Radioactive Waste Management (OCRWM) publishes total system life cycle cost (TSLCC) estimates for the nuclear waste disposal system. The most recent analysis is titled Preliminary Estimates of the Total-System Cost for the Restructured Programme: an Addendum to the 1989 Analysis of the Total-System Life Cycle Cost for the Civilian Radioactive Waste Management Programme, (DOE/RW-0295P) published in December 1990. TSLCC calculations are performed to aid in determining if the fees currently being charged to the civilian waste owners and generators will adequately cover programme costs. The TSLCC estimates represent "snapshots" in time which incorporate all available and appropriate information on programme activities up to a specific point in time in order to develop a comprehensive set of cost estimates for the system.

The cost estimates in this analysis assume a waste management system with a total volume of approximately 96300 metric tonnes of heavy metal (MTHM) which will be emplaced in a single deep geologic repository. The single repository would handle radioactive waste from three different sources:

a) $86800 \mathrm{MTHM}$ of spent nuclear fuel from 120 civilian reactors;

b) 8875 MTHM of defence high level waste (DHLW) from four sites;

c) 640 MTHM of civilian high level waste from the West Valley Demonstration Project (WVHLW).

Since 1985, a number of developments impacting the US waste management system occurred. They are:

! In 1985, President Reagan decided that separate facilities for utility spent fuel and government generated wastes were not to be pursued, but that each party must pay its full share of the total programme costs.

! In December 1987, Congress passed the Nuclear Waste Policy Amendments Act (NWPAA) and directed the DOE to stop all work on two of the candidate sites and to investigate only the Yucca Mountain, Nevada, site as a candidate for the first repository. The NWPAA also directed the DOE to stop all work on the second repository programme.

! In 1987, because the programme has been plagued by litigation at each step of the siting process, the DOE announced a delay in the schedule of the opening of the first repository from 1998 to 2003.

! On November 1989, the Secretary of Energy completed an extensive review of the programme and submitted to the Congress a report describing a restructuring of the programme. In the report, the Secretary announced a revised repository scheduled opening date of 2010. 


\section{Outline of the programme}

Figure 5.1 is a diagram of the assumed waste management system. After removal from the reactor core, spent nuclear fuel is stored at its place of origin, or other suitable short-term storage facilities. In 1998, spent nuclear fuel would be transported via rail and truck to the Monitored Retrievable Storage (MRS) facility for interim storage until the repository is operational. The MRS would receive approximately 3000 MTHM of spent nuclear fuel per year after an initial ramp-up period. The Nuclear Waste Policy Amendment Act limits the capacity of the MRS to 10000 MTHM until the start of repository emplacement operations; after that, the maximum capacity of the MRS is 15000 MTHM. All fuel must cool for at least a five year period after it is removed from the reactor prior to acceptance in the waste management system.

The repository is scheduled to begin receipt of spent nuclear fuel for permanent disposal in the year 2010 . After an initial ramp-up period, the repository would also receive approximately 3000 MTHM per year. Five years after emplacement of spent nuclear fuel commences, the DHLW would begin to arrive at the repository for emplacement. The annual amount of DHLW received is assumed to be 400 MTHM. The WVHLW is assumed to be emplaced in the repository after all DHLW is emplaced.

Emplacement of waste in the repository would occur from 2010 until 2042. Following the last year of emplacement, a caretaker (monitoring) phase would begin and last for 17 years until 2059. Decommissioning and closure activities would begin in 2060 and continue for 16 years until 2075 when site closure would be completed. Under this scenario, the last spent nuclear fuel discharge occurs in 2037, but the last emplacement occurs in 2042. The reason for this is to meet the required minimum five year cooling period for fuel once it has been removed from a reactor. During the emplacement phase, the average operating staff for the repository would be 1105 full-time equivalents, while the average staff at the MRS during operations would be 390 full-time equivalents.

Yucca Mountain in Nevada has been designated by law to be the site where scientific investigations will be conducted to determine if the site is suitable for the development of the first repository. Yucca Mountain is underlain by a sequence of silicic volcanic rocks from more than 3000 to about 10000 feet thick. The water table is about 2500 feet below the land surface. The underground repository would be constructed at a depth about 1000 feet below the eastern flank of Yucca Mountain. The primary rock-type at the repository location is welded tuff.

Containment of radioactivity is to be controlled through the use of a multiple barrier system. The geologic and geographic features of the site, combined with the heat output of the waste, metal lined boreholes, and the metal disposal containers make up the barrier system. Disposal containers are assumed to be fabricated from $304 \mathrm{~L}$ stainless steel.

\section{Plant cost estimates}

Table 5.1 presents a summary of the costs related to the transportation, storage and disposal of spent nuclear fuel for the US programme. All costs in Table 5.1 are in 1991 US dollars with no discounting. Table 5.1 provides a six category breakdown of the major cost components of the waste 
disposal system for each phase. The categories are:

! Engineering \& Construction - capital cost for construction of all components of the system.

! Operation - costs for operating the MRS (receiving, inspecting, handling, storing and monitoring) and repository facilities (receiving, inspecting, handling, containerising, purchasing waste disposal containers, emplacing and monitoring).

! Decommissioning - costs for closing, and decontaminating, if needed, the MRS and repository facilities.

! Shipping - costs for transporting the waste from the reactor to the MRS and from the MRS to the repository.

! Cask Capital \& Maintenance - costs for the purchase and maintenance of the transportation casks.

! Cask Maintenance Facility - costs for the construction and operation of a facility for maintaining the transportation casks.

TSLCC estimates also include costs for development and evaluation (D\&E), and benefit payments to the host State or Indian tribe for the repository and the MRS facility. However, these costs are not included in Table 5.1.

The financing system for the US waste management programme was established as part of the Nuclear Waste Policy Act (NWPA) which was signed into law on 7 January 1983. The NWPA authorised the Secretary of Energy (the Secretary) to enter into contracts with owners and generators of high level waste for the transportation and disposal of spent nuclear fuel. The fee of 1.0 mill $(\$ 0.001)$ per kilowatt hour $(\mathrm{kWh})$ of electricity generated and sold after 7 April 1983 was established. The interpretation of "electricity generated" has changed twice since 1983 . The 1.0 mill per $\mathrm{kWh}$ is now based on net electricity generated and sold, deducting transmission and distribution losses. A separate one-time fee for spent nuclear fuel generated before 7 April 1983 was also levied. The utilities were given several options for payment of the one-time fee. The NWPA also required that if the defence waste used the same repository as the civilian, DOE would pay its fair share of waste disposal costs for the defence waste.

A separate fund in the Treasury of the United States was established, known as the Nuclear Waste Fund (NWF), for the collection of fees. The Secretary is required to annually assess whether the collection of the fee will provide sufficient revenues to cover the costs of the programme. In the event that the Secretary determines that either insufficient or excess revenues are being collected, the Secretary will immediately notify the Congress with a proposed appropriate alteration to the fee.

As of 30 September 1991, approximately $\$ 5.2$ billion (year of expenditure dollars) had been paid by the utilities into the NWF. From the inception of the programme in 1983 approximately $\$ 3.0$ billion had been spent from the NWF.

Six assessments of the adequacy of the fee have been performed by DOE to date. Each determined that the collection of 1.0 mill per $\mathrm{kWh}$ fee will produce revenues sufficient to cover the costs of the programme.

\section{Levelised price derivation}

Table 5.2 provides the undiscounted waste disposal costs over time from 1993 to 2075. Table 5.3 provides the same information as Table 5.2, except that all costs are discounted 5 per cent to the point of delivery into the system (1998 for MRS and 2010 for Repository). The undiscounted total cost is \$14 888 million 1991 dollars, while the discounted total cost is \$5 322 million 1991 dollars. 
With a total quantity of spent nuclear fuel and high level waste (both defence and West Valley) of 96 $272000 \mathrm{~kg}$ (undiscounted), and $32824000 \mathrm{~kg}$ (discounted), the total disposal cost for $1 \mathrm{~kg}$ of waste would be:

- $\$ 14888$ million/96 $272000 \mathrm{~kg}=\$ 155$ per $\mathrm{kg}$ (undiscounted);

- $\$ 5322$ million/32 $824000 \mathrm{~kg}=\$ 162$ per $\mathrm{kg}$ (discounted 5 per cent to point of delivery).

Figure 5.2 shows a comparison of the MRS, repository and total system unit costs for 5 per cent, 10 per cent and 15 per cent. It is important to note that the total does not equal the sum of MRS and repository costs. This is because the MRS and total costs are levelised to 1998 (delivery date into the system), while the repository costs are levelised to 2010 (start of emplacement operations). Figure 5.3 is a graphical depiction of the levelisation periods, as well as a comparison of the unit costs for both no ( 0 per cent) levelisation and 5 per cent levelisation to the point of delivery.

Table 5.4 presents a breakout of the costs into civilian and defence portions. The costs are shown for both the undiscounted and discounted (5 per cent to point of delivery at the MRS in 1998). Defence costs are determined using previously accepted 1990 TSLCC Addendum methodologies.

With total production of electricity equal to $23004 \mathrm{TWh}$ (for civilian electricity generation only) the total civilian cost (minus D\&E and benefits) for the production of $1 \mathrm{TWh}$ of electricity will be:

- $\$ 12700$ million/23004 TWh $=\$ 0.5521$ million per TWh (undiscounted);

- $\$ 4584$ million/23004 TWh = \$0.1993 million per TWh (discounted).

\section{Potential improvements}

The waste management system described in this report is based on the reference designs currently under DOE consideration. Investigations are ongoing to design the most efficient and effective waste management system that is consistent with the provisions of the NWPA, as amended. As the results of these investigations become available, stringent reviews, both internally and externally, will be conducted to determine the applicability of these results to the reference design of the waste management system.

\section{Sensitivity range}

Two additional scenarios previously investigated are presented here. These scenarios involve increased amounts of spent nuclear fuel wastes with the defence high level waste remaining constant. Therefore, two additional scenarios are presented assuming a waste management system with two repositories to dispose of the greater volumes of waste. For a system with two repositories, the costs extend until 2094, when closure and decommissioning of the second repository is completed.

The first scenario assumes that there will be no new orders of nuclear power plants; however, approximately 70 per cent of the existing plants will operate for 20 years beyond their existing 40 year life. This is known as the Plant Life Extension scenario. Under this scenario, approximately 110000 MTHM of spent fuel is assumed to be discharged over the life of the reactors. For this scenario, a typical reactor is assumed to discharge approximately 1500 MTHM over its operating life. Table 5.5 provides a breakdown by decade of the disposal cost, by phase, for the plant life extension scenario. 
With a total quantity of spent nuclear fuel $(110000000 \mathrm{~kg})$ and high level waste (both defence and West Valley: $9515000 \mathrm{~kg}$ ) of $119515000 \mathrm{~kg}$, the total disposal cost for $1 \mathrm{~kg}$ of waste would be:

- $\$ 22852$ million/119515000 kg = \$191 per kg (undiscounted).

The second scenario assumes a substantial growth in the electricity generated from nuclear power in the United States. It is assumed that the electricity generated will be produced from a combination of existing LWRs, plant life extension, and new advanced and evolutionary LWRs. This is known as the National Energy scenario. Under this scenario, approximately 112000 MTHM of spent fuel is assumed to be discharged through the year 2030. The NES scenario assumes an "open-ended" system (i.e. there is no end date for the forecast of electricity generation). The selection of 2030 as a cut-off date is arbitrary, and used only for costing purposes. Wastes would continue to be produced beyond 2030. For this scenario, a typical reactor is assumed to be of the new design and will produce spent fuel similar to the spent fuel produced by existing reactors. A typical reactor will have an operating life of about 45 years and will discharge approximately 1 125 MTHM. Table 5.6 provides a breakdown of the disposal cost, by phase, for the NES scenario.

With a total quantity of spent nuclear fuel $(112000000 \mathrm{~kg})$ and high level waste (both defence and West Valley: $9515000 \mathrm{~kg}$ ) of $121515000 \mathrm{~kg}$, the total disposal cost for $1 \mathrm{~kg}$ of waste would be:

- $\$ 22407$ million/121 $515000 \mathrm{~kg}=\$ 184$ per kg (undiscounted). 
Table 5.1. Summary of selected cost results for US spent nuclear fuel and high level waste disposal (millions of 1991 dollars)

\begin{tabular}{|c|c|c|c|c|c|c|c|}
\hline \multirow[b]{3}{*}{$\begin{array}{l}\text { Engineering \& } \\
\text { construction }\end{array}$} & \multirow[b]{2}{*}{ Transportation } & \multirow[b]{2}{*}{$\begin{array}{c}\text { Monitored }^{(\mathbf{a})} \\
\text { retrievable } \\
\text { storage } \\
\text { facility }\end{array}$} & \multicolumn{5}{|c|}{ Repository $^{(b)}$} \\
\hline & & & $\begin{array}{c}\text { Management } \\
\text { integration } \\
\& \\
\text { engineering }\end{array}$ & $\begin{array}{c}\text { Site } \\
\text { preparation }\end{array}$ & $\begin{array}{l}\text { Surface } \\
\text { facilities }\end{array}$ & $\begin{array}{c}\text { Under- } \\
\text { ground } \\
\text { repository }\end{array}$ & Total \\
\hline & 0 & 393 & 305 & 198 & 591 & 212 & 1700 \\
\hline Operation & 0 & 1648 & 57 & 149 & 4728 & 2911 & 9493 \\
\hline Decommissioning & & & & & & & \\
\hline \& closure & 0 & 27 & 26 & 44 & 94 & 389 & 580 \\
\hline Shipping costs & 1432 & 0 & 0 & 0 & 0 & 0 & 1432 \\
\hline $\begin{array}{c}\text { Cask capital \& } \\
\text { maintenance }\end{array}$ & 1028 & 0 & 0 & 0 & 0 & 0 & 1028 \\
\hline $\begin{array}{l}\text { Cask maintenance } \\
\text { facility }\end{array}$ & 654 & 0 & 0 & 0 & 0 & 0 & 654 \\
\hline Total $^{(\mathrm{c})}$ & 3114 & 2068 & 388 & 391 & 5413 & 3512 & 14886 \\
\hline
\end{tabular}

a. Interim storage.

b. Disposal.

c. Columns or rows may not add to totals due to independent rounding. 
Table 5.2. Summary of selected cost results

for US spent nuclear fuel and highlevel waste disposal (millions of 1991 dollars)

Undiscounted

\begin{tabular}{|c|c|c|c|c|c|c|c|c|c|}
\hline \multirow[b]{2}{*}{ Year } & \multirow[b]{2}{*}{$\begin{array}{c}\text { MRS } \\
\text { Facility }^{(a)}\end{array}$} & \multirow[b]{2}{*}{$\begin{array}{l}\text { MRS } \\
\text { Trans. }\end{array}$} & \multirow[b]{2}{*}{$\begin{array}{l}\text { MRS } \\
\text { Total }\end{array}$} & \multicolumn{3}{|c|}{ Repository $^{(\mathbf{b})}$} & \multirow[b]{2}{*}{$\begin{array}{c}\text { REP } \\
\text { Trans. }\end{array}$} & \multirow[b]{2}{*}{$\begin{array}{l}\text { REP } \\
\text { Total }\end{array}$} & \multirow[b]{2}{*}{$\begin{array}{l}\text { Total } \\
\text { Cost }\end{array}$} \\
\hline & & & & $\begin{array}{c}\text { Engr. \& } \\
\text { Const. }\end{array}$ & OPNS & $C \& D$ & & & \\
\hline 1993-1999 & 425 & 283 & 709 & 96 & 0 & 0 & 25 & 121 & 830 \\
\hline 2000-2009 & 461 & 201 & 662 & 1145 & 0 & 0 & 50 & 1195 & 1858 \\
\hline 2010-2019 & 414 & 342 & 756 & 66 & 2034 & 0 & 418 & 2517 & 3274 \\
\hline $2020-2029$ & 334 & 384 & 719 & 0 & 2504 & 0 & 403 & 2907 & 3627 \\
\hline $2030-2039$ & 323 & 393 & 716 & 0 & 2385 & 0 & 471 & 2855 & 3571 \\
\hline $2040-2049$ & 110 & 57 & 167 & 0 & 700 & 0 & 84 & 784 & 951 \\
\hline $2050-2059$ & 0 & 0 & 0 & 0 & 224 & 0 & 0 & 224 & 224 \\
\hline $2060-2069$ & 0 & 0 & 0 & 0 & 0 & 405 & 0 & 405 & 405 \\
\hline $2070-2075$ & 0 & 0 & 0 & 0 & 0 & 147 & 0 & 147 & 147 \\
\hline Total $^{(\mathrm{c})}$ & 2068 & 1661 & 3729 & 1307 & 7847 & 552 & 1451 & 11157 & 14888 \\
\hline
\end{tabular}

\footnotetext{
a. Interim storage

b. Disposal

c. Columns may not add to totals due to independent rounding
} 
Table 5.3. Summary of selected cost results for US spent nuclear fuel and high level waste disposal (millions of 1991 dollars)

Discounted 5 per cent (to the point of delivery)

\begin{tabular}{|c|c|c|c|c|c|c|c|c|c|}
\hline \multirow[b]{2}{*}{ Year } & \multirow[b]{2}{*}{$\begin{array}{c}\text { MRS } \\
\text { Facility }^{(a)}\end{array}$} & \multirow[b]{2}{*}{$\begin{array}{c}\text { MRS } \\
\text { Trans. }\end{array}$} & \multirow[b]{2}{*}{$\begin{array}{l}\text { MRS } \\
\text { Total }\end{array}$} & \multicolumn{3}{|c|}{ Repository $^{(\mathbf{b})}$} & \multirow[b]{2}{*}{$\begin{array}{c}\text { REP } \\
\text { Trans. }\end{array}$} & \multirow[b]{2}{*}{$\begin{array}{l}\text { REP } \\
\text { Total }\end{array}$} & \multirow[b]{2}{*}{$\begin{array}{l}\text { Total } \\
\text { Cost }\end{array}$} \\
\hline & & & & $\begin{array}{c}\text { Engr. \& } \\
\text { Const. }\end{array}$ & OPNS & $C \& D$ & & & \\
\hline 1993-1999 & 431 & 279 & 709 & 171 & 0 & 0 & 45 & 216 & 831 \\
\hline 2000-2009 & 341 & 152 & 493 & 1354 & 0 & 0 & 67 & 1421 & 1285 \\
\hline 2010-2019 & 192 & 153 & 345 & 42 & 1600 & 0 & 323 & 1965 & 1439 \\
\hline $2030-2039$ & 55 & 68 & 123 & 0 & 734 & 0 & 146 & 880 & 613 \\
\hline 2040-2049 & 13 & 7 & 20 & 0 & 147 & 0 & 19 & 166 & 113 \\
\hline $2050-2059$ & 0 & 0 & 0 & 0 & 26 & 0 & 0 & 26 & 14 \\
\hline $2060-2069$ & 0 & 0 & 0 & 0 & 0 & 29 & 0 & 29 & 16 \\
\hline $2070-2075$ & 0 & 0 & 0 & 0 & 0 & 7 & 0 & 7 & 4 \\
\hline
\end{tabular}

a. Interim storage.

b. Disposal.

c. Columns may not add to totals due to independent rounding. 
Table 5.4. Summary of selected cost results for civilian and defence waste disposal costs

(millions of 1991 dollars)

\begin{tabular}{||c|r|r|r|r|r|r||}
\hline \multirow{2}{*}{ Year } & \multicolumn{3}{|c|}{} & \multicolumn{3}{c||}{$\begin{array}{c}\text { Discounted 5\% } \\
\text { (Point of delivery) }\end{array}$} \\
\cline { 2 - 7 } & Total & Civilian & Defence & Total & Civilian & Defence \\
\hline $1993-1999$ & 830 & 806 & 24 & 831 & 806 & 24 \\
$2000-2009$ & 1858 & 1635 & 223 & 1285 & 1137 & 148 \\
$2010-2019$ & 3274 & 2611 & 663 & 1439 & 1146 & 293 \\
$2020-2029$ & 3627 & 3007 & 620 & 1007 & 835 & 173 \\
$2030-2039$ & 3571 & 3053 & 519 & 613 & 522 & 92 \\
$2040-2049$ & 951 & 914 & 37 & 113 & 109 & 4 \\
$2050-2059$ & 224 & 191 & 33 & 14 & 12 & 2 \\
$2060-2069$ & 405 & 355 & 50 & 16 & 14 & 2 \\
$2070-2075$ & 147 & 129 & 18 & 4 & 3 & 0 \\
\hline Total $^{\text {(a) }}$ & $\mathbf{1 4 ~ 8 8 8}$ & $\mathbf{1 2 ~ 7 0 0}$ & $\mathbf{2 ~ 1 8 8}$ & $\mathbf{5 3 2 2}$ & $\mathbf{4 ~ 5 8 4}$ & $\mathbf{7 3 8}$ \\
\hline \hline
\end{tabular}

a. Columns may not add to totals due to independent rounding. 
Table 5.5. Summary of selected cost results for US spent nuclear fuel and high level waste disposal

Plant life extension scenario

(millions of 1991 dollars)

Undiscounted

\begin{tabular}{|c|c|c|c|c|c|c|}
\hline \multirow[b]{2}{*}{ Year } & \multirow[b]{2}{*}{ Trans. } & \multirow[b]{2}{*}{$\begin{array}{c}\text { MRS } \\
\text { Facility }^{(a)}\end{array}$} & \multicolumn{3}{|c|}{ Repositories $^{(\mathbf{b})}$} & \multirow[b]{2}{*}{ Total } \\
\hline & & & $\begin{array}{c}\text { Engr. \& } \\
\text { Const. } \\
\end{array}$ & OPNS & $C \& D$ & \\
\hline 1993-1999 & 90 & 425 & 89 & 0 & 0 & 604 \\
\hline 2000-2009 & 228 & 461 & 1152 & 0 & 0 & 1841 \\
\hline $2010-2019$ & 789 & 411 & 0 & 2046 & 0 & 3246 \\
\hline $2020-2029$ & 768 & 334 & 206 & 2384 & 0 & 3691 \\
\hline 2030-2039 & 320 & 187 & 2286 & 1405 & 0 & 4198 \\
\hline 2040-2049 & 643 & 0 & 0 & 3752 & 0 & 4396 \\
\hline 2050-2059 & 315 & 0 & 0 & 2067 & 0 & 2383 \\
\hline 2060-2069 & 164 & 0 & 0 & 875 & 384 & 1424 \\
\hline 2070-2079 & 4 & 0 & 0 & 299 & 83 & 387 \\
\hline 2080-2089 & 0 & 0 & 0 & 269 & 58 & 327 \\
\hline 2090-2094 & 0 & 0 & 0 & 0 & 357 & 357 \\
\hline Total $^{(\mathrm{c})}$ & 3321 & 1818 & 3732 & 13098 & 882 & 22852 \\
\hline
\end{tabular}

\footnotetext{
a. Interim storage.

b. Disposal in two repositories.

c. Columns may not add to totals due to independent rounding.
} 
Table 5.6. Summary of cost results for US spent nuclear fuel and high level waste disposal

National energy strategy scenario

(millions of 1991 dollars)

Undiscounted

\begin{tabular}{|c|c|c|c|c|c|c|}
\hline \multirow[b]{2}{*}{ Year } & \multirow[b]{2}{*}{ Trans. } & \multirow[b]{2}{*}{$\begin{array}{c}\text { MRS } \\
\text { Facility }^{(\mathrm{a})}\end{array}$} & \multicolumn{3}{|c|}{ Repositories $^{(\mathbf{b})}$} & \multirow[b]{2}{*}{ Total } \\
\hline & & & $\begin{array}{c}\text { Engr. \& } \\
\text { Const. } \\
\end{array}$ & OPNS & $C \& D$ & \\
\hline 1993-1999 & 90 & 425 & 89 & 0 & 0 & 604 \\
\hline 2000-2009 & 227 & 461 & 1152 & 0 & 0 & 1840 \\
\hline $2010-2019$ & 790 & 411 & 0 & 2046 & 0 & 3247 \\
\hline 2020-2029 & 768 & 334 & 206 & 2378 & 0 & 3686 \\
\hline 2030-2039 & 320 & 187 & 2286 & 1455 & 0 & 4248 \\
\hline 2040-2049 & 640 & 0 & 0 & 3839 & 0 & 4479 \\
\hline 2050-2059 & 271 & 0 & 0 & 2285 & 0 & 2556 \\
\hline $2060-2069$ & 0 & 0 & 0 & 299 & 384 & 683 \\
\hline 2070-2079 & 0 & 0 & 0 & 299 & 83 & 382 \\
\hline 2080-2089 & 0 & 0 & 0 & 269 & 58 & 327 \\
\hline 2090-2094 & 0 & 0 & 0 & 0 & 357 & 357 \\
\hline Total $^{(\mathrm{c})}$ & 3105 & 1818 & 3732 & 12870 & 882 & 22407 \\
\hline
\end{tabular}

\footnotetext{
a. Interim storage.

b. Disposal in two repositories.

c. Columns may not add to totals due to independent rounding.
} 
Figure 5.1 US waste management system

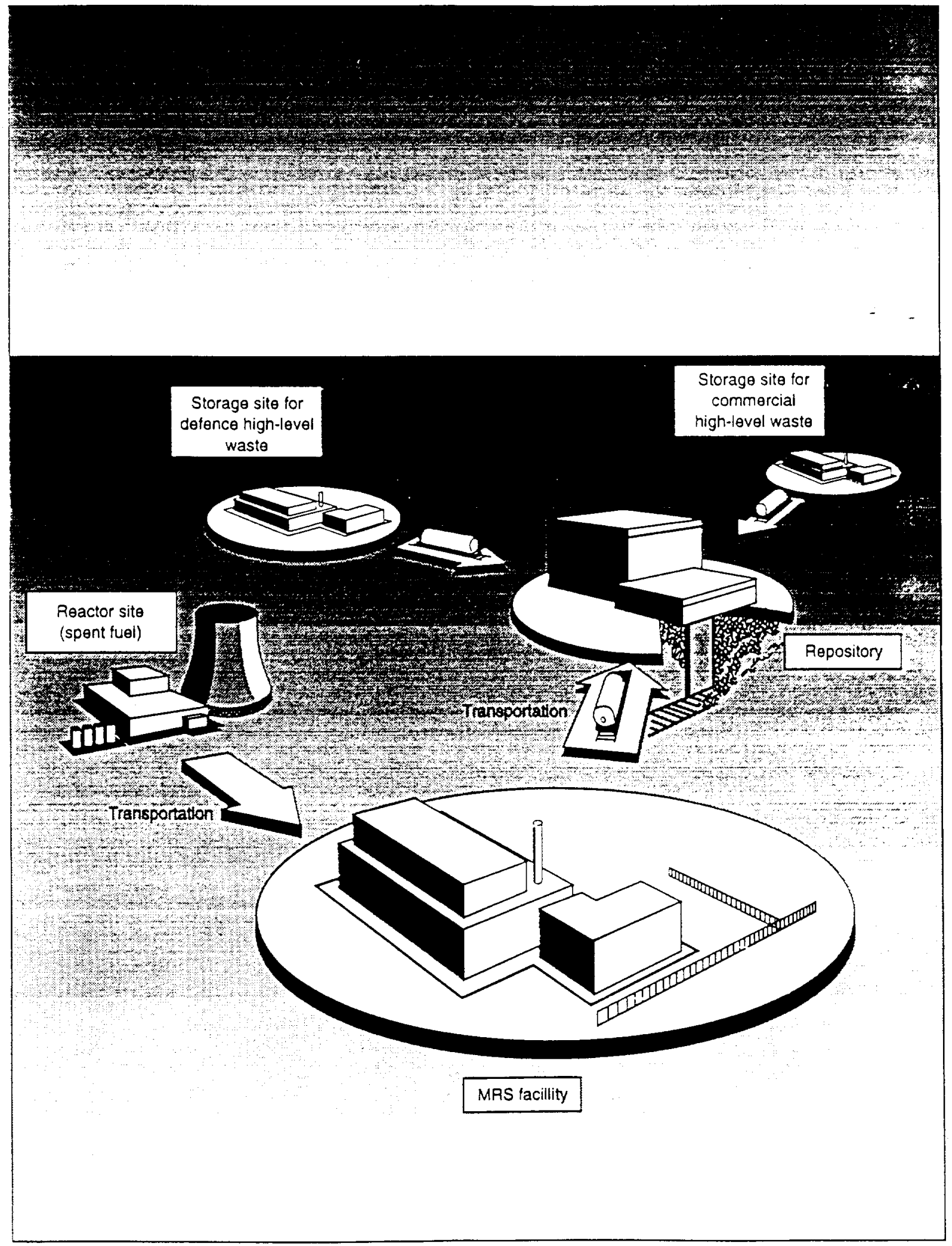


Figure 5.2 Comparison of unit prices

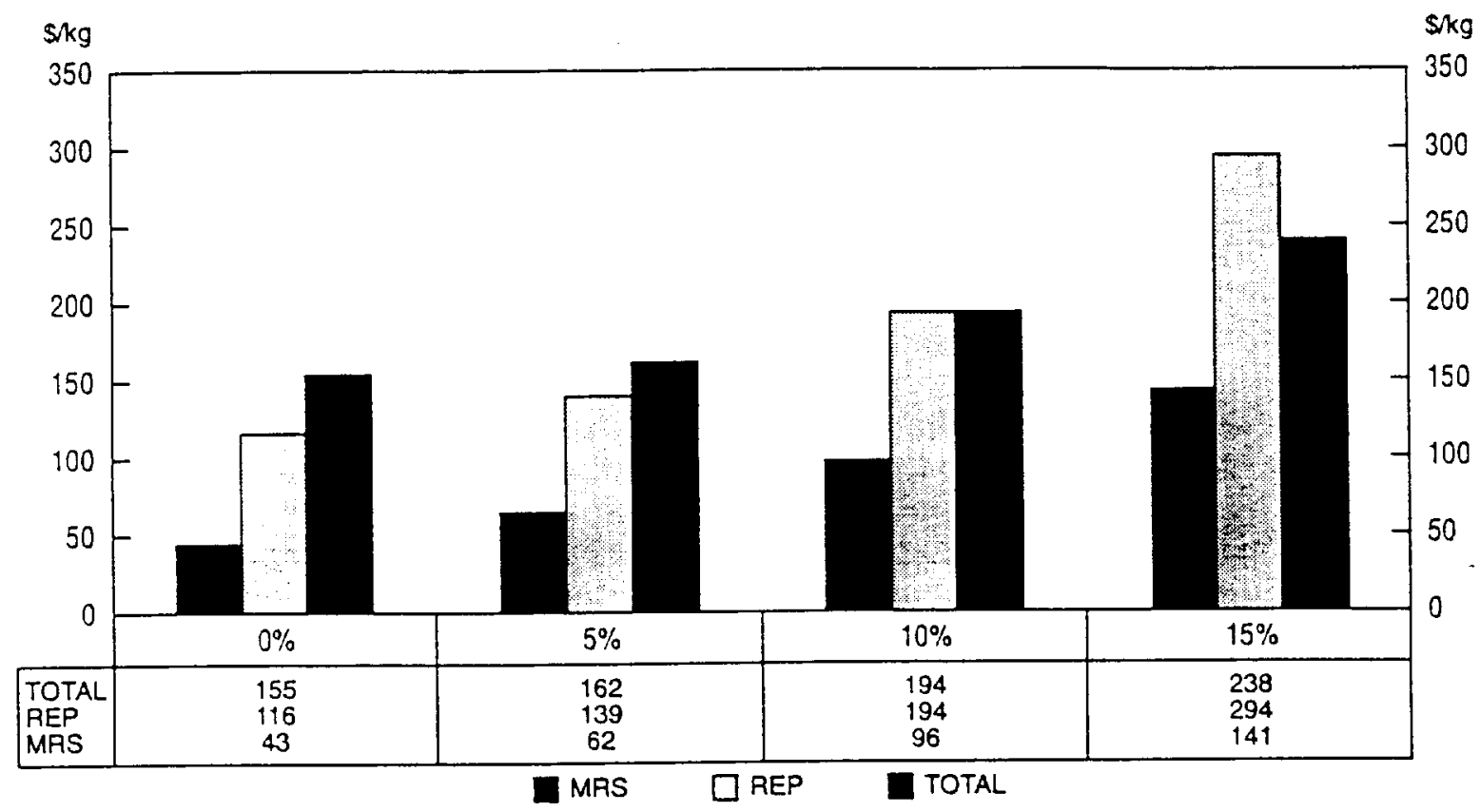

Note: These do not add since the levelised unit prices have been discounted to different delivery dates.

Figure 5.3 Levelised unit costs to point of delivery

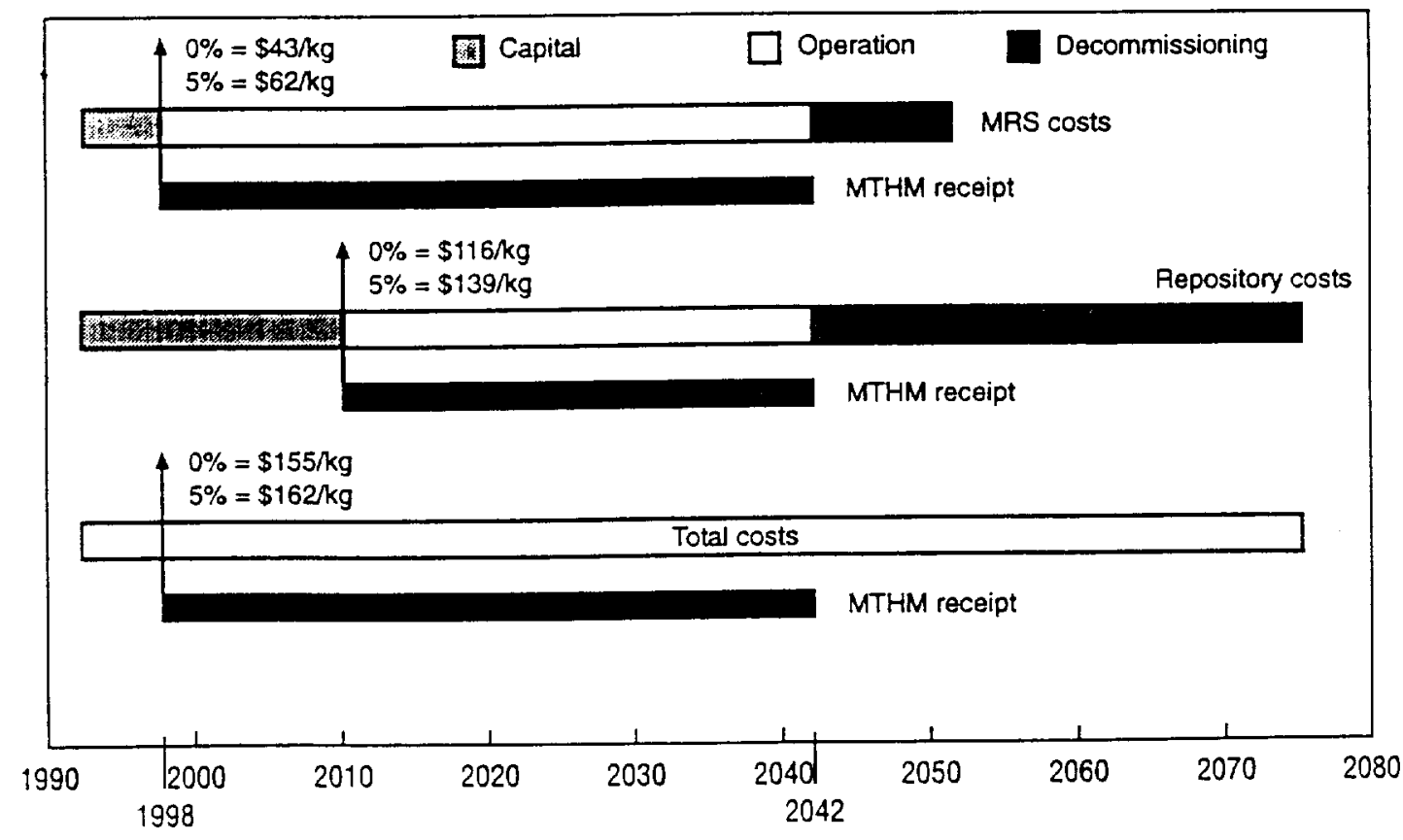


Annex 6

\section{DIRECT DISPOSAL OPTION COST ESTIMATES: GERMANY}

\section{Introduction}

In Germany about 32 per cent of electricity is generated from nuclear power stations comprising 21 reactors with an installed capacity of $23.6 \mathrm{GWe}$. According to the German Nuclear Energy Act, recycling of uranium and plutonium after reprocessing has first priority for the treatment of spent fuel. The German utilities are interested in having the direct disposal option accepted by the authorities. This Annex concentrates on the direct disposal option; the costs presented have been derived from a German paper entitled Systemanalyse Mischkonzept (SAM) which was published in 1989.

\section{Outline of the programme}

The radioactive waste management system considered is shown schematically in Figure 6.1. Studies carried out in Germany within SAM consider the combined final storage of both radioactive waste from reprocessing and encapsulated spent fuel assemblies.

The total quantity of spent fuel assumed for costing purposes is $35000 \mathrm{tU}$ (accruing within 50 years) of which about 30 per cent will be in the form of encapsulated spent fuel and the remainder in the form of vitrified high level waste (VHLW) from reprocessing. In practice, it is likely that less than this quantity will need disposal since reductions in fuel quantities will occur with improved fuel utilisation (for example, by fuel burn-up increases).

At present, the German intermediate storage facilities Gorleben and Ahaus, can hold up to 1500 tonnes of fuel each. The spent fuel will be stored in transport and storage casks of the CASTOR type will be used for the intermediate storage period of about 30 years. Prior to encapsulation, the spent fuel will be unloaded from the CASTOR casks and it will then be encapsulated at the conditioning and encapsulation plant and put into an overpack (for example, POLLUX casks) before being placed in the final repository (Gorleben Salt Dome).

It should be noted that transport and storage casks with higher payloads are still in the development and licensing stages. This development may result in certain technical and economical benefits. The present cost analysis has not taken into account these potential advantages.

The POLLUX cask is cylindrical in shape, about five meters long and one meter in diameter. Depending on the type of POLLUX cask, it can hold up to 24 BWR or 8 PWR fuel assemblies, about 4 tU equivalent. Current development programmes provide for the inclusion of activities with higher payloads. An illustration of a POLLUX cask is shown in Figure 6.2.

Current plans indicate that the repository at Gorleben will operate for approximately 50 years, commencing in 2010, and will receive all the VHLW and spent fuel from the existing German nuclear power 
stations. LLW and ILW (which is non-heat generating waste) will be disposed of at the Konrad and Morsleben facilities.

The repository at Gorleben will be situated in a depth of about 900 meters. Two shafts are required for the mining and disposal activities. A schematic layout of the repository is shown in Figure 6.3.

\section{Levelised price derivation}

The breakdown of the levelised prices to be charged at the time of delivery to the storage or disposal sites is detailed in Table 6.1. The prices are in constant money values. They do not include financing charges, but do include material and labour charges. Although the prices have been levelised using a 4.3 per cent discount rate, this is sufficiently close to the 5 per cent reference discount rate used in this study. There is no significant difference for sensitivity purposes.

Table 6.1. Back-end prices for the direct disposal option in Germany

\begin{tabular}{||l|c|r|c|r||}
\hline \multirow{5}{*}{} & \multicolumn{2}{|c|}{ Prices (DM/kg) } & \multicolumn{2}{c||}{ Prices (ECU/kg) } \\
\cline { 2 - 5 } & \multicolumn{2}{|c|}{ Discount rate } & \multicolumn{2}{c|}{ Discount rate } \\
\cline { 2 - 5 } Transport & $\mathbf{0 \%}$ & $\mathbf{4 . 3 \%}$ & $\mathbf{0 \%}$ & $\mathbf{4 . 3 \%}$ \\
\cline { 2 - 5 } Intermediate storage & 110 & 110 & 60 & 60 \\
Total transport/storage & 390 & 390 & 230 & 230 \\
Encapsulation & $\mathbf{5 0 0}$ & $\mathbf{5 0 0}$ & $\mathbf{2 9 0}$ & $\mathbf{2 9 0}$ \\
Final disposal & 600 & 700 & 340 & 400 \\
Total encapsulation/disposal & 270 & 470 & 160 & 270 \\
\hline
\end{tabular}

Note: $\quad$ Prices are given in money values of 1991 and have been suitably rounded. The prices quoted were calculated in DM and US\$; they were converted to ECU under the study's assumption that $\$ 1=$ ECU 1 .

Reference: $\quad$ Systemanalyse Mischkonzept, PAE, SAM 10/89. 
Figure 6.1 Main system for management of radioactive waste in Germany

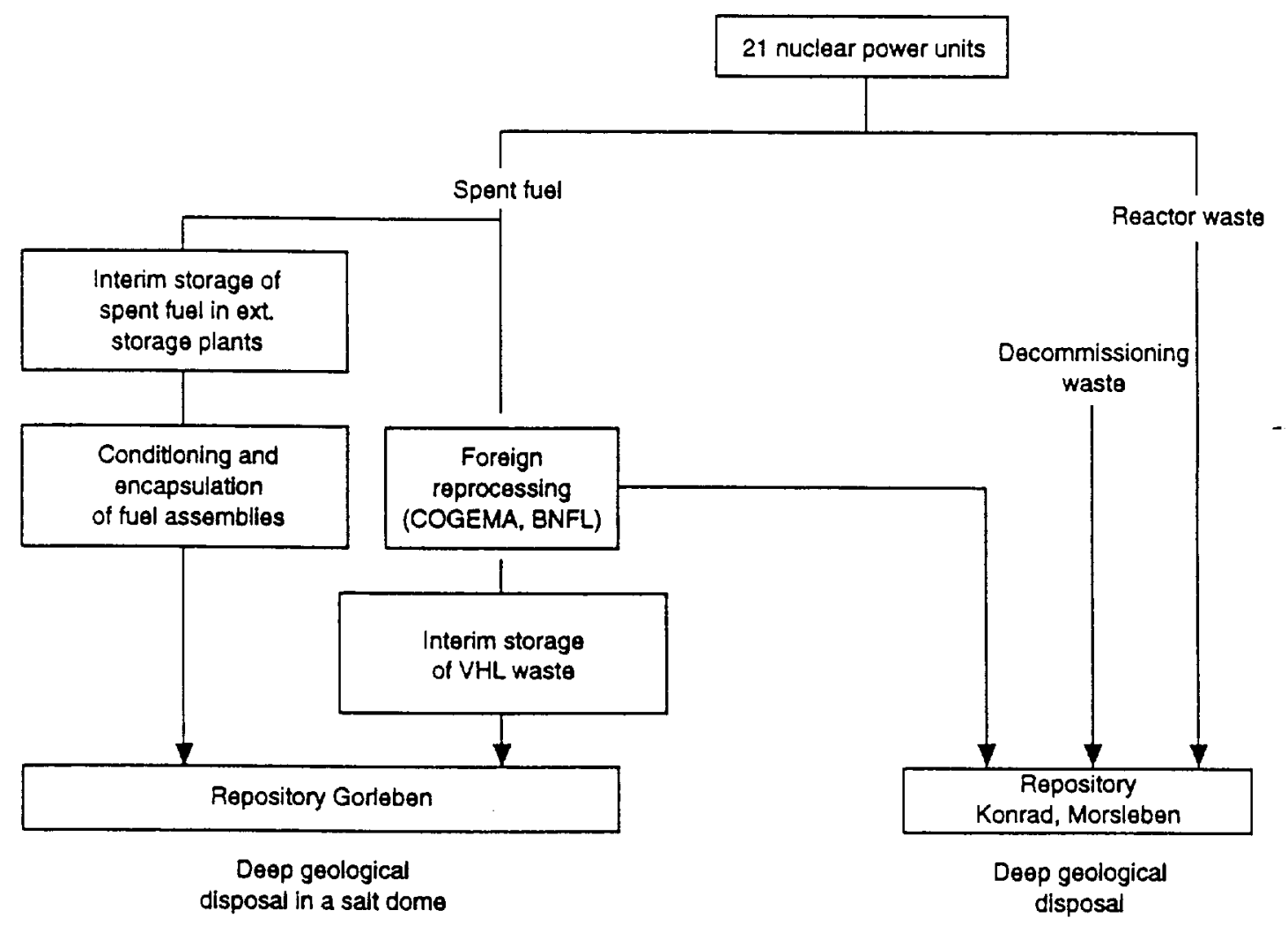


Figure 6.2 Pollux spent fuel disposal package

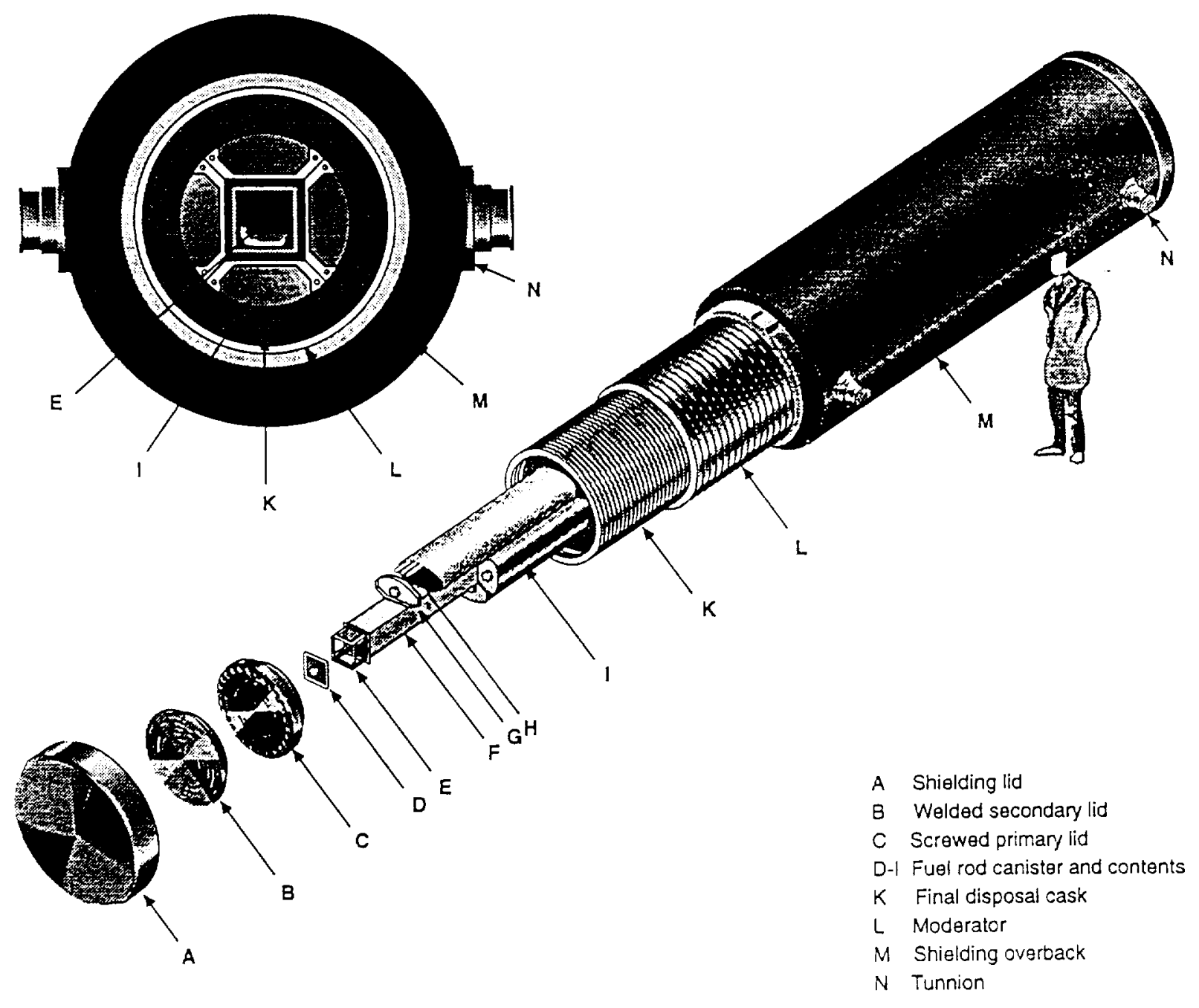


Figure 6.3 Schematic layout of the repository for borehole and drift emplacement

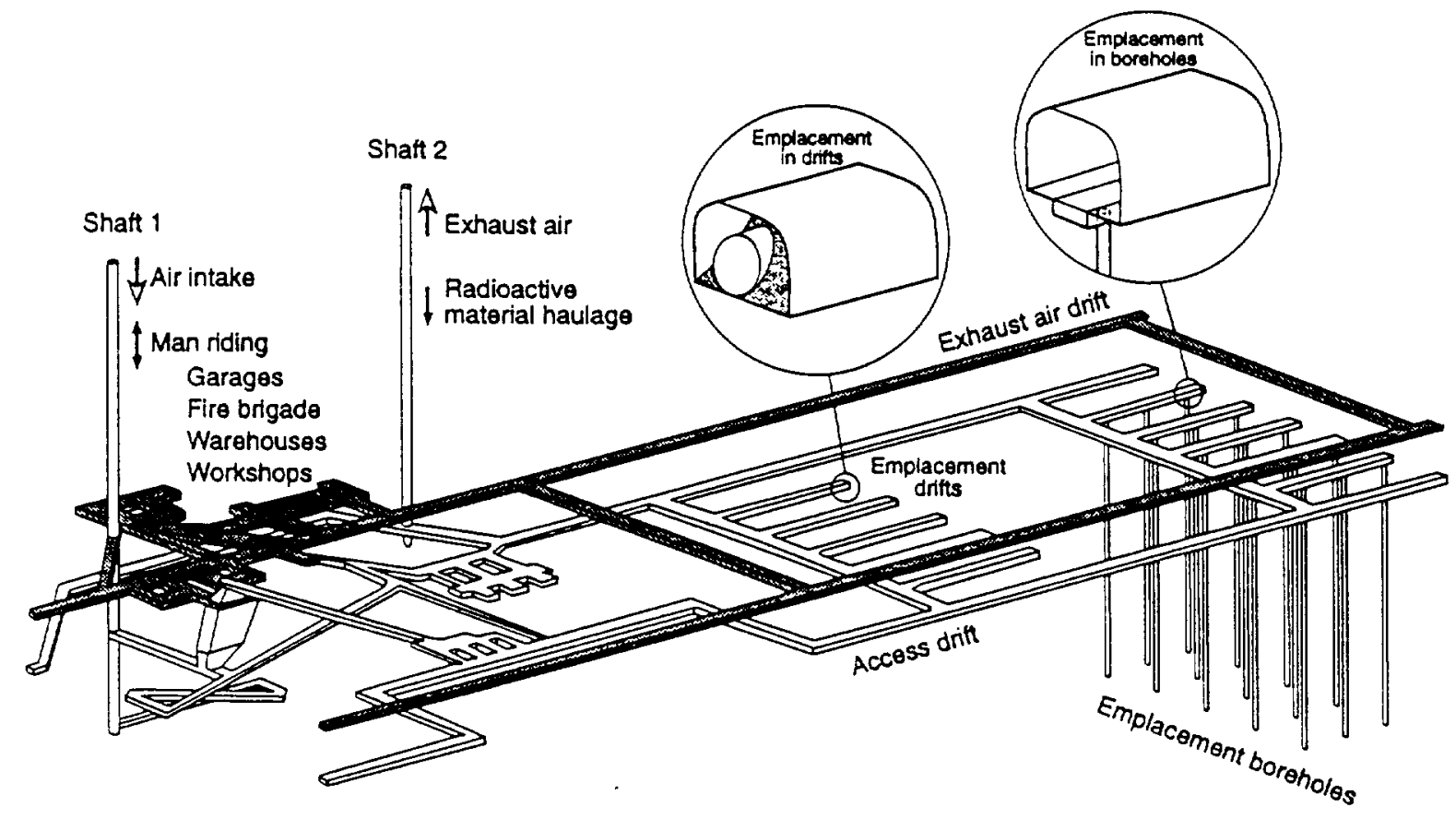


Annex 7

\section{COMPARISON OF WASTE DISPOSAL COSTS}

\section{Introduction}

An OECD/NEA Expert Group on Geological Disposal Costs ${ }^{(6)}$ has been studying the costs of disposing encapsulated spent fuel and vitrified high level waste (VHLW) to deep geological repositories. This annex compares disposal cost data from the work of the above-mentioned group with those used by this study. It is shown that the reference costs for this study, which are based on two country-specific examples are representative and close to the average of a range of international views. For sensitivity purposes, this range of views has also been used.

Although the data have been split into reprocessing and direct disposal sets, several countries envisage repositories where the disposal of one type of waste form will predominate but which will nevertheless take a small proportion of the other type. The estimates of disposal costs are very country-specific and are strongly influenced by national regulatory and licensing requirements, the engineering and design approaches and nature of the geology considered for the disposal.

\section{Costs for direct disposal of spent fuel}

Table 7.1 shows country specific total cost estimates for the direct disposal of fuel as derived by the Expert Group on Geological Disposal Costs. All costs in this table include the cost of encapsulating the spent fuel prior to disposal. Table 7.2 shows the average unit costs calculated from Table 7.1. The results show the effect of scale (based on volume of waste to be disposed) on the unit cost; the overall average is also displayed. The Canadian data are excluded from Table 7.2 because the CANDU reactor system gives rise to a large quantity of low irradiation fuel (average burn-up $8 \mathrm{GWd} / \mathrm{tU}$ ) with an associated low unit disposal cost. This is not typical of the light water reactor systems (PWR and BWR) that predominate around the world and form the focus of this study.

\section{Costs for vitrified high level waste (VHLW) disposal}

Table 7.3 shows country-specific total cost estimates for the disposal of VHLW from reprocessing, again taken from the Geological Disposal Costs study. The German data presented in that study classified the fuel as VHLW and are, therefore, not comparable to the German entry to this study which classifies it as spent fuel. To avoid misinterpretation, the German data have been excluded from Table 7.3. Table 7.4 shows the average unit costs as calculated from Table 7.3. In this case, the UK data are excluded from the calculation due to their Magnox fuel content. Magnox fuel (which has an average burn-up of $5.5 \mathrm{GWd} / \mathrm{tU}$ ) gives rise to relatively small quantities of VHLW per tonne of uranium and higher than average quantities per unit of electricity generated; its inclusion would unfairly distort the costs applicable to LWR fuel. 
Table 7.1. Undiscounted cost estimates for encapsulation and direct disposal of fuel

\begin{tabular}{||l|c|c|c||}
\hline Country & $\begin{array}{c}\text { Total costs } \\
(\mathbf{M} \mathbf{~})\end{array}$ & $\begin{array}{c}\text { Quantity of fuel } \\
(\mathbf{t U )}\end{array}$ & $\begin{array}{c}\text { Unit cost } \\
\text { (\$/kg U) }\end{array}$ \\
\hline Finland & 760 & 1840 & 413 \\
Spain (salt) & 2300 & 5300 & 430 \\
Spain (granite) & 1900 & 5300 & 358 \\
Sweden & 3214 & 7840 & 410 \\
US & 10000 & 96300 & 104 \\
Canada & 8700 & 191000 & 46 \\
\hline
\end{tabular}

Note: $\quad$ Values taken from the OECD/NEA study on Geological Disposal Costs ${ }^{(6)}$; all the above costs include encapsulation.

Table 7.2. Total costs of small/large scale operations and the weighted undiscounted average unit cost for encapsulation and direct disposal

\begin{tabular}{||l|c|c|c|}
\hline Scale of operation & $\begin{array}{c}\text { Sum of costs } \\
(\mathbf{M} \mathbf{\$})\end{array}$ & $\begin{array}{c}\text { Sum of fuel } \\
\text { (ktU) }\end{array}$ & $\begin{array}{c}\text { wt. average } \\
\text { unit cost (\$/kg U) }\end{array}$ \\
\hline Small & 6060 & 14.94 & 406 \\
Large & 10000 & 96.30 & 104 \\
Total & $\mathbf{1 6 0 6 0}$ & $\mathbf{1 1 1 . 2 4}$ & $\mathbf{1 4 4}$ \\
\hline
\end{tabular}

Notes: - Canada is excluded from this table.

- An average value of $\$ 396 / \mathrm{kg} U$ was taken from Table 7.1 and used as the average cost of waste disposal for Spain.

- US data represent the "large" case.

Table 7.3. Undiscounted unit cost estimates for disposal of VHLW

\begin{tabular}{|c|c|c|c|}
\hline Country & $\begin{array}{c}\text { Total costs } \\
(\mathrm{M} \$) \\
\end{array}$ & $\begin{array}{c}\text { Quantity of fuel } \\
(\mathbf{t U})\end{array}$ & $\begin{array}{l}\text { Unit cost } \\
(\$ / k g ~ U) \\
\end{array}$ \\
\hline France & 6300 & 100000 & 63 \\
\hline Belgium & 800 & 3530 & 227 \\
\hline Netherlands & 460 & 2000 & 230 \\
\hline Switzerland & 1400 & 4000 & 350 \\
\hline UK & 1700 & 70000 & 24 \\
\hline
\end{tabular}

Note: Values taken from the OECD/NEA study on Geological Disposal Costs ${ }^{(6)}$; all the above costs exclude vitrification. 
Table 7.4. Total costs of small/large scale operations and the weighted undiscounted average unit cost for VHLW disposal

\begin{tabular}{||l|c|c|c|}
\hline Scale of operation & $\begin{array}{c}\text { Sum of costs } \\
(\mathbf{M} \$)\end{array}$ & $\begin{array}{c}\text { Sum of fuel } \\
\text { (ktU) }\end{array}$ & $\begin{array}{c}\text { wt. average } \\
\text { unit cost (\$/kg U) }\end{array}$ \\
\hline Small & 2660 & 9.53 & 279 \\
Large & 6300 & 100.00 & 63 \\
Total & $\mathbf{8 9 6 0}$ & $\mathbf{1 0 9 . 5 3}$ & $\mathbf{8 2}$ \\
\hline
\end{tabular}

Notes: - UK data are excluded from this table.

- French data represent the "large" case. 


\section{Comparison of geological disposal data with data used in this study}

The comparison of costs in this annex refers to 1991 money values and although they are related to different months they can be taken to be broadly comparable for the purposes of this annex which are not to look at the fine detail effect on the costs of monthly variations in money values.

\section{Direct disposal}

In this study, the reference case (Sweden) gives a total undiscounted disposal cost, including encapsulation, of ECU 2878 million (SKr 22.1 billion) for $7800 \mathrm{tU}$ in January 1991 money values. The equivalent value from the Geological Disposal group is ECU 2885 million ( $\mathrm{SKr} 22.2$ billion), again for 7 $800 \mathrm{tU}$. In this study, this quantity of fuel was rounded up to $8000 \mathrm{tU}$ and the cost was escalated pro rata to the fuel quantity to become ECU 2935 million ( $\mathrm{SKr} 22.5$ billion). The exchange rate between the US dollar and the ECU adopted for the purposes of this study assumes parity in the longer term. As a result, the costs in the two Swedish cases are derived from the same base and are equivalent to $\$ 360$ per $\mathrm{kg} \mathrm{U}$.

In the Geological Disposal Costs study, the undiscounted costs of encapsulation and directly disposing fuel (including the Swedish estimate) ranged from $\$ 104$ to $\$ 430$ per $\mathrm{kg}$ U. It can, therefore, be concluded that the undiscounted cost of this study lies within the range (towards the upper end) shown by the Geological Disposal Costs study.

\section{VHLW}

This study requires disposal costs without vitrification since the latter is covered in the reprocessing price. Data in Table 7.4 are, therefore, directly applicable to this study which uses an undiscounted unit cost of ECU 60 per kg U. This cost is at the lower bound of the range shown by the Geological Disposal Costs study and is consistent with the unit cost of the large scale option.

\section{Levelised prices}

Repository projects all have similar spend profiles since they all have capital, operating and closure costs spread over varying time periods. Individual schemes (design, quantity throughputs, geologies, timings, etc.) can be compared by the calculation of levelised price. The price is calculated by taking net present values of the cost and income streams (based on throughput) to the same point and setting them equal (Annex 1).

Levelised prices are required in this study for two reasons, the first is to allow a comparison to be made between separate options. The second and most important reason is to ensure the price that the plant operator (the disposer) charges for the service is sufficient to enable all future costs and financial targets to be met. A range of discount rates ( 0 to 15 per cent p.a.) is used to calculate the levelised price to allow the calculation of fuel costs for discount rates (rates of return) other than the reference 5 per cent p.a. rate assumed here. All the costs supplied by the Geological Disposal Expert Group are undiscounted and unlevelised and, hence, cannot be directly compared to the prices of this study at rates greater than zero.

Although the costs resulting from the two studies cannot be compared at rates greater than zero, the undiscounted reference prices used in this study lie within the Geological Disposal Costs study's range. There is no reason to believe that this would change at higher discount rates. 
The reference case of this study assumes a 5 per cent rate of return. The levelised unit price for disposal is ECU 90 per $\mathrm{kg} \mathrm{U}$ and ECU 610 per $\mathrm{kg} \mathrm{U}$ for the reprocessing and direct disposal options, respectively.

Although the reference VHLW disposal price is at the lower bound of the range, this fuel cycle component makes a very small contribution to the overall, levelised fuel cost and hence any distortion this introduces is negligibly small. A similar comment is applicable to the direct disposal option where the reference disposal price was towards the upper bound of the range.

\section{Conclusion}

Although country-specific, the reference disposal prices used in this study for VHLW and encapsulated spent fuel lie within the range of costs identified by the NEA Expert Group on Geological Disposal Costs and are, therefore, judged to be appropriate for fuel costing purposes. 
Annex 8

\section{PLUTONIUM AND RECOVERED URANIUM CREDITS}

\section{Introduction}

Plutonium and uranium, recovered by reprocessing LWR spent fuel, can be used as fresh fuel. But in using recovered plutonium and uranium, it is necessary to consider the effect of their isotopic composition.

The main isotopes of plutonium recovered by reprocessing are ${ }^{239} \mathrm{Pu},{ }^{210} \mathrm{Pu},{ }^{241} \mathrm{Pu}$ and ${ }^{242} \mathrm{Pu}$. Of these isotopes, only ${ }^{239} \mathrm{Pu}$ and ${ }^{241} \mathrm{Pu}$ are fissionable and ${ }^{241} \mathrm{Pu}$ decays to ${ }^{241} \mathrm{Am}$ with a half-life of 14.4 years. Thus, in utilising plutonium, it is necessary to consider the fraction of plutonium fissile materials. This fraction depends on the fuel bum-up and the period after the discharge from the reactor core.

In utilising of recovered uranium, it should be noted that the isotopic fraction of ${ }^{236} \mathrm{U}$ in the recovered uranium depends on the bum-up of speni fuel. $A s^{236} \mathrm{U}$ is a thermal neutron absorber, more separative work is needed than that for fresh natural uranium in order to compensate for this absorption effect.

\section{The plutonium value estimation}

In the Annex 15 of the 1985 NEA study on The Economics of the Nuclear Fuel Cycle(7), the plutonium value was estimated by the indifference method. By using that method, the plutonium value is settled as the economic break-even point of the MOX fucls to the fresh enriched uranium fuels.

On the cther hand, the concept of "free plutonium" was proposed in the 1989 NEA study Plutonium Fuel - An Assessment(5). This concept is useful to estimate the economic advantage of using plutonium for the substitution of enriched uranium.

In the present study the indifference method has been adopted as in the 1985 study for calculating the plutonium credit.

The plutonium enrichment for MOX fuel fabrication depends on the isotopic composition and bum-up required in the core. Figure 8.1 shows the Puf weight required for $1 \mathrm{~kg} \mathrm{HM}$ of PWR MOX fuel, using plutonium obtained from the spent fuel with bum-up of $33 \mathrm{GWd} / \mathrm{h}$ and $43 \mathrm{GWd} / \mathrm{t}$, respectively. This figure was obrained from the data given in Table 12 (a) \& (b) in the NEA Plutonium Fuel - An Assessment study(s).

In this study, the fucl bum-up specification for an $\mathrm{N} 4$ plant of $42.5 \mathrm{GWd} / \mathrm{t}$ has been adopted. From Figure 8.1, it is estimated that the Puf weight required for $1 \mathrm{~kg} \mathrm{HM}$ of MOX fuel is about $44 \mathrm{~g}$. Assuming the same back-end costs for $\mathrm{UO}_{2}$ fucl and $\mathrm{MOX}$ fuel, the plutonium value is obtained from the difference of front-ends costs. Table $\mathbf{8 . 1}$ shows the results obtained by using reference values for 
Table 8.1. Plutonium value (reference case)

\begin{tabular}{|l|c|c|}
\hline & $\begin{array}{c}\text { UO }{ }_{2} \text { fuel } \\
(1 \mathrm{~kg})\end{array}$ & $\begin{array}{c}\text { MOX fuel } \\
(1 \mathrm{~kg})\end{array}$ \\
\hline Uranium purchase & $\$ 509$ & $\$ 65$ \\
Conversion & $(\$ 70.1 \times 7.267 \mathrm{~kg})$ & $(\$ 70.1 \times 0.933 \mathrm{~kg})$ \\
& $\$ 58$ & $\$ 7$ \\
Enrichment & $(\$ 8 \times 7.267 \mathrm{~kg})$ & $(\$ 8 \times 0.933 \mathrm{~kg})$ \\
& $\$ 552$ & - \\
Fabrication & $(\$ 110 \times 5.014 \mathrm{SWU})$ & $\$ 275$ \\
& $(\$ 275 \times 1 \mathrm{~kg})$ & $\$ 1100$ \\
Total & $\$ 1394$ & $(\$ 1100 \times 1 \mathrm{~kg})$ \\
Saving & - & $\$ 1172$ \\
Plutonium value & - & $\$ 222$ \\
\hline
\end{tabular}

fuel cycle unit prices. The value of $\$ 70.1$ per $\mathrm{kg} \mathrm{U}$ for uranium purchase price was adopted in this plutonium credit calculation. This value is the levelised price over 29 years piutonium recovered period (i.c. for the reference PWR, the first plutonium will not be separated until 2007 and will last until 2035). Based on these reference unit prices, the cost of an enriched uranium fuel element for PWR (3.6 per cent enrichment) is $\$ 1394$ per $\mathrm{kg}$. On the other hand, the cost of an equivalent mixed oxide made from $933 \mathrm{~g}$ of natural uranium and $44 \mathrm{~g}$ of fissile plutonium will be $\$ 1172$ per $\mathrm{kg}$ made up of $\$ 65$ for uranium purchase, $\$ 7$ for conversion and $\$ 1100$ for fabrication. The value of $\$ 1100$ per kg HM for MOX fuel fabrication is consistent with the Plutonium Fuel - An Assessment study, where the $\mathrm{MOX} / \mathrm{NO}_{2}$ fabrication cost ratio used was four.

The $44 \mathrm{~g}$ of fissile plutonium thus save a net sum of $\$ 222$ per $\mathrm{kg}$ of PWR fuel and the plutonium credit is therefore $\$ 5.0$ per $\mathrm{g}$ plutonium fissile.

Figures 8.2 and 8.3 show how this plutonium value varies with uranium price, enrichment cost and mixed oxide fuel fabrication cost. These back-up data are shown in Tables 8.2 and 8.3 , respectively.

Figure 8.2 shows the plutonium indifference value for three MOX fuel fabrications costs which are 3,4 and 5 times the reference $\mathrm{UO}_{2}$ fuel fabrication cosi of $\$ 275 \mathrm{per} \mathrm{kg} U$. The ratios of 3 and 5 are settled as a lower and upper bound for the sensitivity analysis. This corresponds to the case where the MOX fuel fabrication technology will not be matured at the level of four times of $\mathrm{UO}_{2}$ fuel fabrication cost in future.

Figure 8.3 shows the plutonium indifference value for three MOX fucl fabrication costs which are all four times the $\mathrm{UO}_{2}$ fuel fabrication cost, but using differem $\mathrm{UO}_{2}$ fuel fabrication cost (i.e. $\$ 200$, $\$ 275$ and $\$ 350$ per $\mathrm{kg} U$ ). This sensitivity analysis was performed in order to estimate the influence 
of changes of the $\mathrm{UO}_{2}$ fucl fabrication cost on the plutonium indifference value, assuming a fixed MOXNOO, fabrication cost ratio of 4 to reflect the maturity of the MOX fucl fabrication technology.

As a resulh, both cases give a nearly identical range and the variation of the piutonium indifference values shows the same iendency in either case.

Table 8.2. Sensitivity of plutonium indifference value (\$/g Puf) to enrichment and MOX fuel fabrication prices

\begin{tabular}{|c|c|c|c|}
\hline \multicolumn{4}{|c|}{ MOX fuel fabrication price: $\$ 825 / \mathrm{kg} \mathrm{HM}\left(\mathrm{UO}_{2} \$ 275 \times 3\right)$} \\
\hline \multirow{2}{*}{$\begin{array}{l}\text { Uranium price } \\
\text { (\$/kg U) }\end{array}$} & \multicolumn{3}{|c|}{ Enrichment price (\$/SWU) } \\
\hline & 80 & 110 & 130 \\
\hline $\begin{array}{l}40 \\
70.1 \\
90\end{array}$ & $\begin{array}{r}3.53 \\
7.87 \\
10.73 \\
\end{array}$ & $\begin{array}{r}6.95 \\
11.29 \\
14.15 \\
\end{array}$ & $\begin{array}{r}9.23 \\
13.56 \\
16.43\end{array}$ \\
\hline \multicolumn{4}{|c|}{ MOX fuel fabrication price: $\$ 1100 / \mathbf{k g ~ H M}\left(\mathrm{UO}_{2} \$ 275 \times 4\right)$} \\
\hline \multirow{2}{*}{$\begin{array}{c}\text { Uranium price } \\
(\$ / k g \text { U) }\end{array}$} & \multicolumn{3}{|c|}{ Enrichment price (\$/SWU) } \\
\hline & 80 & 110 & 130 \\
\hline $\begin{array}{l}40 \\
70.1 \\
90\end{array}$ & $\begin{array}{c}-2.72 \\
1.62 \\
4.48\end{array}$ & $\begin{array}{c}0.70 \\
5.04(\text { reference) } \\
7.90\end{array}$ & $\begin{array}{r}2.98 \\
7.31 \\
10.18 \\
\end{array}$ \\
\hline \multicolumn{4}{|c|}{ MOX fuel fabrication price: $\$ 1375 / \mathrm{kg} H M\left(\mathrm{UO}_{2} \$ 275 \times 5\right)$} \\
\hline \multirow{2}{*}{$\begin{array}{l}\text { Uranium price } \\
(\$ / k g ~ U)\end{array}$} & \multicolumn{3}{|c|}{ Enrichment price (\$/SWU) } \\
\hline & 80 & 110 & 130 \\
\hline $\begin{array}{l}40 \\
70.1 \\
90\end{array}$ & $\begin{array}{l}-8.97 \\
-4.63 \\
-1.77\end{array}$ & $\begin{array}{r}-5.55 \\
-1.22 \\
1.65\end{array}$ & $\begin{array}{r}-3.27 \\
1.06 \\
3.93\end{array}$ \\
\hline
\end{tabular}


Table 8.3. Sensitivity of plutonium indifference value (\$/g Pun to enrichment and MOX fuel fabrication prices

\begin{tabular}{|c|c|c|c|}
\hline \multicolumn{4}{|c|}{ MOX fuel fabrication price: $\$ 800 / k g$ HM $\left(\mathrm{UO}_{2} \$ 200 \times 4\right)$} \\
\hline \multirow{2}{*}{$\begin{array}{l}\text { Uranium price } \\
\text { (S/kg U) }\end{array}$} & \multicolumn{3}{|c|}{ Enrichment price (\$/SWU) } \\
\hline & 80 & 110 & 130 \\
\hline $\begin{array}{l}40 \\
70.1 \\
90\end{array}$ & $\begin{array}{r}4.10 \\
8.43 \\
11.30 \\
\end{array}$ & $\begin{array}{r}7.52 \\
11.85 \\
14.72\end{array}$ & $\begin{array}{r}9.80 \\
14.13 \\
17.00\end{array}$ \\
\hline \multicolumn{4}{|c|}{ MOX fuel fabrication price: $\$ 1$ 100/kg HM $\left(\mathrm{UO}_{2} \$ 275 \times 4\right)$} \\
\hline \multirow{2}{*}{$\begin{array}{l}\text { Uranium price } \\
(\text { (S/kg U) }\end{array}$} & \multicolumn{3}{|c|}{ Enrichment price (\$/SWU) } \\
\hline & 80 & 110 & 130 \\
\hline $\begin{array}{l}40 \\
70.1 \\
90\end{array}$ & $\begin{array}{r}-2.72 \\
1.62 \\
4.48\end{array}$ & $\begin{array}{c}0.70 \\
5.04 \text { (reference) } \\
7.90\end{array}$ & $\begin{array}{r}2.98 \\
7.31 \\
10.18\end{array}$ \\
\hline \multicolumn{4}{|c|}{ MOX fuel fabrication price: $\$ 1400 / \mathrm{kg} H M\left(\mathrm{UO}_{2} \$ 350 \times 4\right)$} \\
\hline \multirow{2}{*}{$\begin{array}{l}\text { Uranium price } \\
\text { (\$/kg U) }\end{array}$} & \multicolumn{3}{|c|}{ Enrichment price (\$/SWU) } \\
\hline & 80 & 110 & 130 \\
\hline $\begin{array}{l}40 \\
70.1 \\
90\end{array}$ & $\begin{array}{l}-9.54 \\
-5.20 \\
-2.34\end{array}$ & $\begin{array}{r}-6.12 \\
-1.78 \\
1.08\end{array}$ & $\begin{array}{r}-3.84 \\
0.50 \\
3.36\end{array}$ \\
\hline
\end{tabular}

3. The eatimation of the recovered uranium value

As described in the introduction, the recovered uranium value must be estimated taking the presence of the strong neutron absorber ${ }^{236} U$ into consideration. In addition, there are ${ }^{232} U$ and ${ }^{234} U$ in the recovered uranium; the daughter products of these isotopes are strong gamma emitters. Therefore, shielding to protect from gamma rays during the fuel fabrication process should also be considered.

The recovered uranium value is calculated with reference to the relevant annex of the NEA Plutonium Fuel - An Assessment study(3). 
The value of the necovered uranium in the form of UF 6 is obtained by the following formula:

$$
\begin{aligned}
& C_{z x c}=C_{v s q} \cdot F_{m v} / F_{z v}+C_{v r_{i}} \cdot F_{m v} / F_{z v}+C_{g w v}\left(S_{w v}-S_{z v}\right) / F_{z v} \\
& -\Delta C_{v F_{f}} / F_{n u}-\Delta C_{s w v} S_{z u} / F_{q u}-\Delta C_{v q_{2}} / F_{z v}
\end{aligned}
$$

where:

$$
\begin{aligned}
& C_{u_{5} a} \text { levelised natural uranium price for reference case (570.1/kg U); } \\
& C_{\text {U., }} \quad \text { price of } \mathrm{UF}_{6} \text { conversion }(\$ 8 / \mathrm{kg}) \text {; } \\
& C_{\text {swo }} \quad \text { price of enrichment (\$110/SWU); } \\
& \Delta C_{\text {swv }} \text { premium for enrichment of recovered uranium (\$10/SWU); } \\
& \mathrm{C}_{\mathrm{wO}_{2}} \quad \text { price of } \mathrm{UO}_{2} \text { fuel fabrication }(\$ 275 / \mathrm{kg}) \text {; } \\
& \Delta C_{U r_{6}} \quad \text { premium for conversion of recovered uranium; } \\
& \Delta C_{v q_{2}} \text { premium for } \mathrm{UO}_{2} \text { fuel fabrication }(\$ 30 / \mathrm{kg}) \text {; } \\
& F_{M v} \quad \text { natural uranium requirement for } 1 \mathrm{~kg} \text { of enriched uranium }(7.267 \mathrm{~kg}) \text {; } \\
& F_{z U} \quad \text { recovered uranium requirement for } 1 \mathrm{~kg} \text { of enriched uranium; } \\
& S_{M U} \quad \text { separative work for } 1 \mathrm{~kg} \text { of enriched uranium from natural uranium; } \\
& s_{\boldsymbol{z}} \quad \text { separative work for } 1 \mathrm{~kg} \text { of enriched uranium from recovered uranium. }
\end{aligned}
$$

The natural uranium requirement is calculated using the data for the N4 plant material balance, 3.6 per cent ${ }^{235} \mathrm{U}$ enrichment for the equilibrium cycle charge. In this calculation the tail ${ }^{235} \mathrm{U}$ concentration of the enrichment process is 0.25 per cent. The ${ }^{235} \mathrm{U}$ concentration of recovered uranium is 0.81 per cent as shown in the data for the $\mathrm{N} 4$ plant material balance.

In this study, the uranium credit has been calculated on the basis that the recovered uranium comes from a THORP type plant in the form $\mathrm{UO}_{3}$ and only a relatively small premium is involved in converting it to $\mathrm{UF}_{6}$ when it is recycled. If the uranium was recovered in another chemical form, such as UHN, higher conversion costs would be incurred with a potentially higher premium. This would have the effect of reducing the credit worth of the recovered uranium.

The premium for enrichment and $\mathrm{UO}_{2}$ fuel fabrication of recovered uranium is assumed to have the same value as in the NEA Plutonium Fuel - An Assessment study ${ }^{(3)}$. The premium for enrichment is expressed per SWU, but may encompass costs associated with the processing of feed and/or tail materials. 
The recovered uranium requirement for $1 \mathrm{~kg}$ of enriched uranium is calculated to be $5.982 \mathrm{~kg}$ in the case of no allowance for ${ }^{236} \mathrm{U}$. Because of the ${ }^{236} \mathrm{U}$ negative reactivity effect, additional ${ }^{233} \mathrm{U}$ enrichment required is obtained by the following equations and the data given in the 1987 NEA/AEA "Yellow Book"(10).

$$
\begin{aligned}
x_{e} / x_{x u} & =0.75\left(a_{e}+c_{e}\right) / a^{\prime} \\
c_{e} & =0.28 x_{e}
\end{aligned}
$$

\begin{tabular}{|c|c|}
\hline$x_{\varepsilon}$ & ${ }^{236} \mathrm{U}$ concentration in re-enriched fucl; \\
\hline$x_{n v}$ & ${ }^{236} \mathrm{U}$ concentration in recovered uranium; \\
\hline & ${ }^{235} \mathrm{U}$ concentration in fresh fuel without ${ }^{236} \mathrm{U}$; \\
\hline$e$ & additional concentration of ${ }^{235} \mathrm{U}$ required to allow for ${ }^{236} \mathrm{U}$; \\
\hline
\end{tabular}

where:

From Figure 10.1 in the annex of the 1987 NEA/IAEA "Yellow Book", the ${ }^{236} U$ concentration in the recovered uranium corresponding to fuel bum-up of $42500 \mathrm{MWd} / \mathrm{t}$, is about 0.45 per cent. The calculation results show that $X_{c}$ and $c_{z}$ are 1.70 per cent and 0.48 per cent, respectively. Uranium and separative work requirements are shown in Table 8.4.

When the effects of the ${ }^{236} \mathrm{U}$ content and of fabrication and enrichment premiums are neglected, the formula giving the recovered uranium value is:

$$
C_{x u c}=F_{(0)} \cdot C_{v, \rho_{8}}+F_{(0)} \cdot C_{u r_{6}}+S_{(6)} \cdot C_{s w v}
$$

where:

$F\left(e_{U}\right)=F_{N V} / F_{R U}$ and $S\left(e_{0}\right)=\left(S_{N U}-S_{R U}\right) / F_{R U}$ are, respectively, the natural uranium and separative work required to produce $1 \mathrm{~kg}$ of uranium with an enrichment equal to the discharged ${ }^{235} U$ content $\left(e_{1}\right)$.

The resulting recovered uranium value for the reference natural uranium, conversion and enrichment prices (see Table 8.1) is shown in Table 8.5, together with the effects of ${ }^{236} \mathrm{U}$ and processing premiums, both in absolute and in relative terms.

When only the deieterious effect of ${ }^{23} \mathrm{U}$ is taken into account, the value of the recovered uranium drops to 74 per cent of the base value. It is further reduced to 70 per cent when a fabrication premium of $\$ 30$ per $\mathrm{kg}$ is considered and to 62 per cent when an enrichment premium of $\$ 10$ per SWU is, in addition, taken into account.

For the fucl cycle cost calculations, a simple mean value of 70 per cent of the value of new uranium at the same enrichment has been used. 
Sensitivity analyses for uranium credit were performed in order to examine how the uranium credit value changes under the influence of the variation of each front-end fucl cycle price. In these sensitivity analyses, calculations for two extreme cases were performed, namely all the "lower" values for front-end fuel cycie prices were taken in the low case and all the "higher" values were taken in the high case. The results of low and high cases are shown in Table 8.6. The low case for uranium credit gives a value range of 52 to 71 per cent of equivalent new uranium and enrichment and the high case gives a value range of 66 to 75 per cent.

Table 8.4. Uranium and separative work requirements

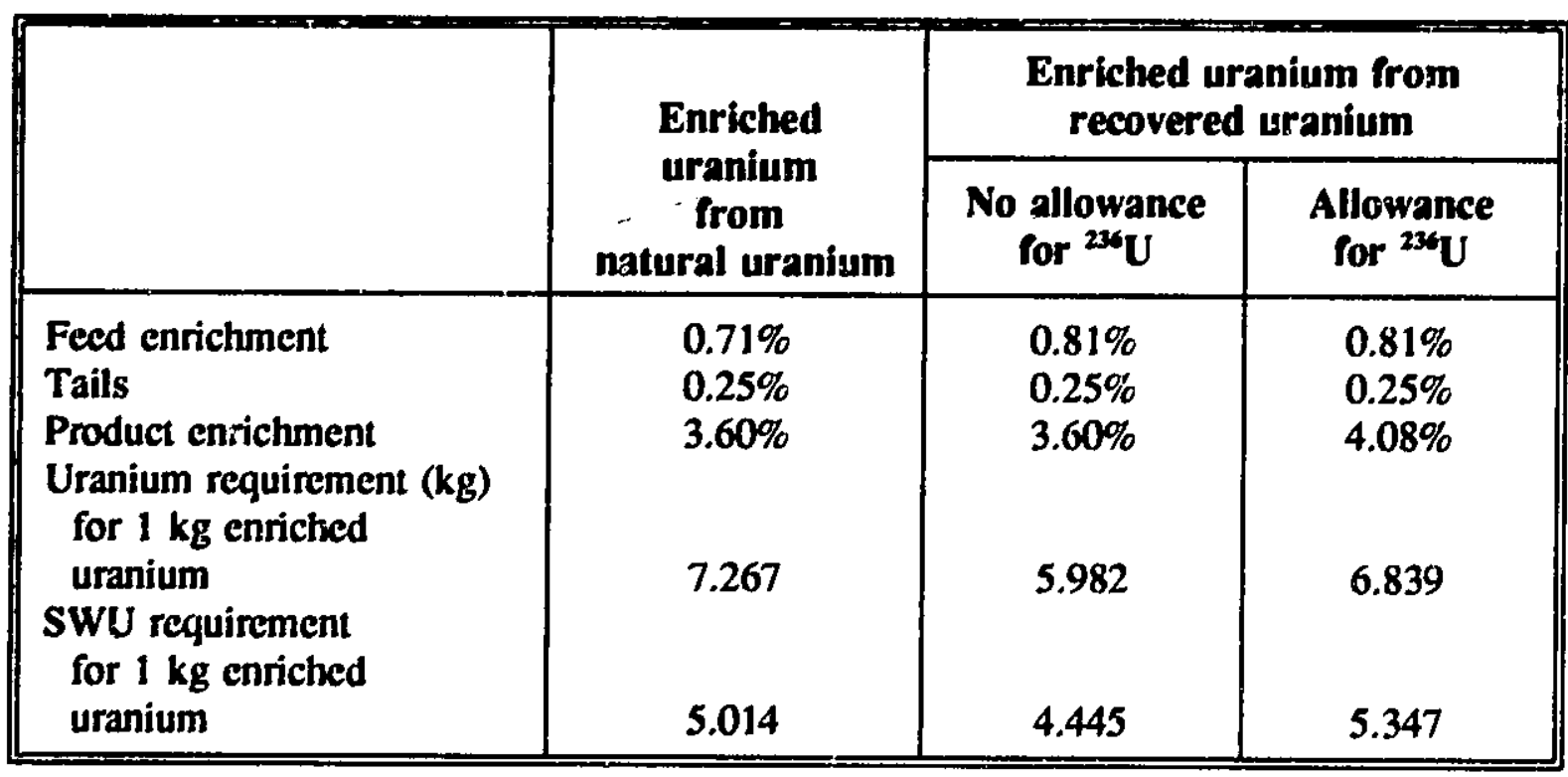

Table 8.5. Recovered uranium value (reference case)

\begin{tabular}{||c|c|c|}
\hline $\begin{array}{c}\text { No allowance for }{ }^{236} \mathrm{U} \text { and } \\
\text { no premium for fabrication }\end{array}$ & $\begin{array}{c}\text { Value of recovered } \\
\text { uranium }\end{array}$ & Ratio \\
\hline $\begin{array}{c}\text { With allowance for }{ }^{236} \mathrm{U} \text { and } \\
\text { no premium for fabrication } \\
\begin{array}{c}\text { With allowance for }{ }^{236} \mathrm{U} \text { and } \\
\text { premium for fabrication }\end{array}\end{array}$ & $\$ 105 / \mathrm{kg} \mathrm{U}$ & $100 \%$ \\
$\begin{array}{c}\text { With allowance for }{ }^{236} \mathrm{U} \text { and } \\
\text { premium for fabrication and } \\
\text { cnrichment }\end{array}$ & $\$ 78 / \mathrm{kg} \mathrm{U}$ & $74 \%$ \\
\hline
\end{tabular}


Table 8.6. Recovered uranium value (paramatric cases)

\begin{tabular}{|l|c|c|c|c|}
\hline & \multicolumn{2}{|c|}{ Low case } & \multicolumn{2}{c|}{ High case } \\
\cline { 2 - 5 } & $\begin{array}{c}\text { Value of } \\
\text { recovered } \\
\text { uranium }\end{array}$ & Ratio & $\begin{array}{c}\text { Value of } \\
\text { recovered } \\
\text { uranium }\end{array}$ & Ratio \\
\hline $\begin{array}{c}\text { No allowance for }{ }^{236} \mathrm{U} \text { and } \\
\text { no premium for fabrication } \\
\text { and enrichment }\end{array}$ & $\$ 63 / \mathrm{kg} \mathrm{U}$ & $100 \%$ & $\$ 135 / \mathrm{kg} \mathrm{U}$ & $100 \%$ \\
$\begin{array}{c}\text { With allowance for }{ }^{236} \mathrm{U} \text { and } \\
\text { no premium for fabrication } \\
\text { and enrichment }\end{array}$ & $\$ 45 / \mathrm{kg} \mathrm{U}$ & $71 \%$ & $\$ 101 / \mathrm{kg} \mathrm{U}$ & $75 \%$ \\
$\begin{array}{c}\text { With allowance for }{ }^{236} \mathrm{U} \text { and } \\
\text { premium for fabrication }\end{array}$ & $\$ 41 / \mathrm{kg} \mathrm{U}$ & $65 \%$ & $\$ 97 / \mathrm{kg} \mathrm{U}$ & $72 \%$ \\
$\begin{array}{c}\text { With allowance for }{ }^{236} \mathrm{U} \text { and } \\
\text { premium for fabrication } \\
\text { and enrichment }\end{array}$ & $\$ 33 / \mathrm{kg} \mathrm{U}$ & $52 \%$ & $\$ 89 / \mathrm{kg} \mathrm{U}$ & $66 \%$ \\
\hline
\end{tabular}

Nole: Calculated by using the lower and higher data, i.e. $\$ 40$ and $\$ 90$ per $\mathrm{kg} U$ for natural unanium price, $\mathbf{S 6}$ and $\$ 11$ per $\mathrm{kg} U$ for conversion price, $\$ 80$ and $\$ 130$ per $\mathbf{S W U}$ for enrichment price, and $\$ 200$ and $\$ 350$ per $\mathrm{kg} U$ for fabrication price.

Figure 8.1 Mases de plutonium fiegle requise pour obtenir $1 \mathrm{~kg}$ do $\mathrm{ML}$ dectins eu combustiblo MOX dos AEP

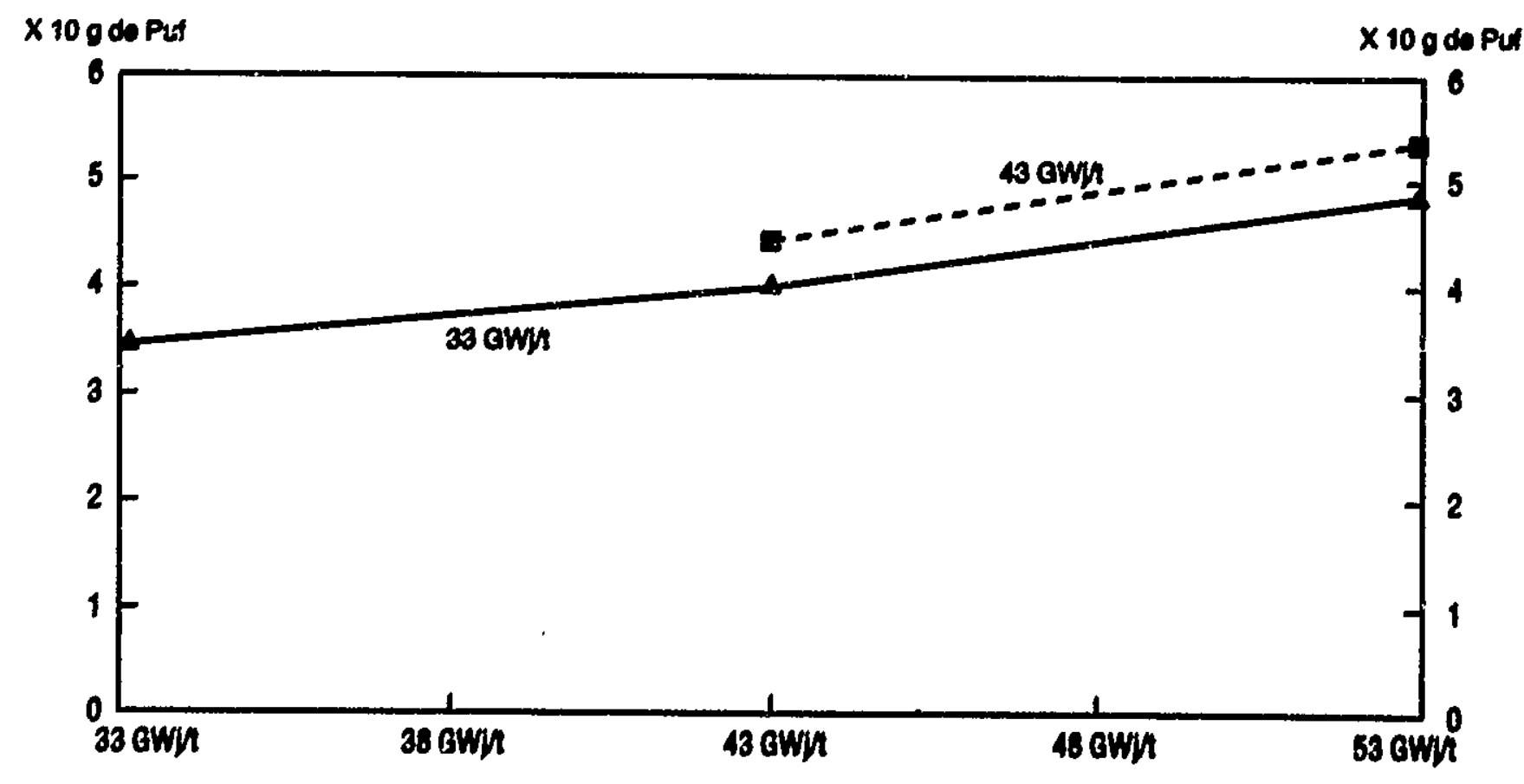


Figure 8.2 senaltivity of phitonkum indifterence value to enrichment price and MOX firel febrication price

Pu velus (\$/g Pu)

Pu valuo (Eg Puil)

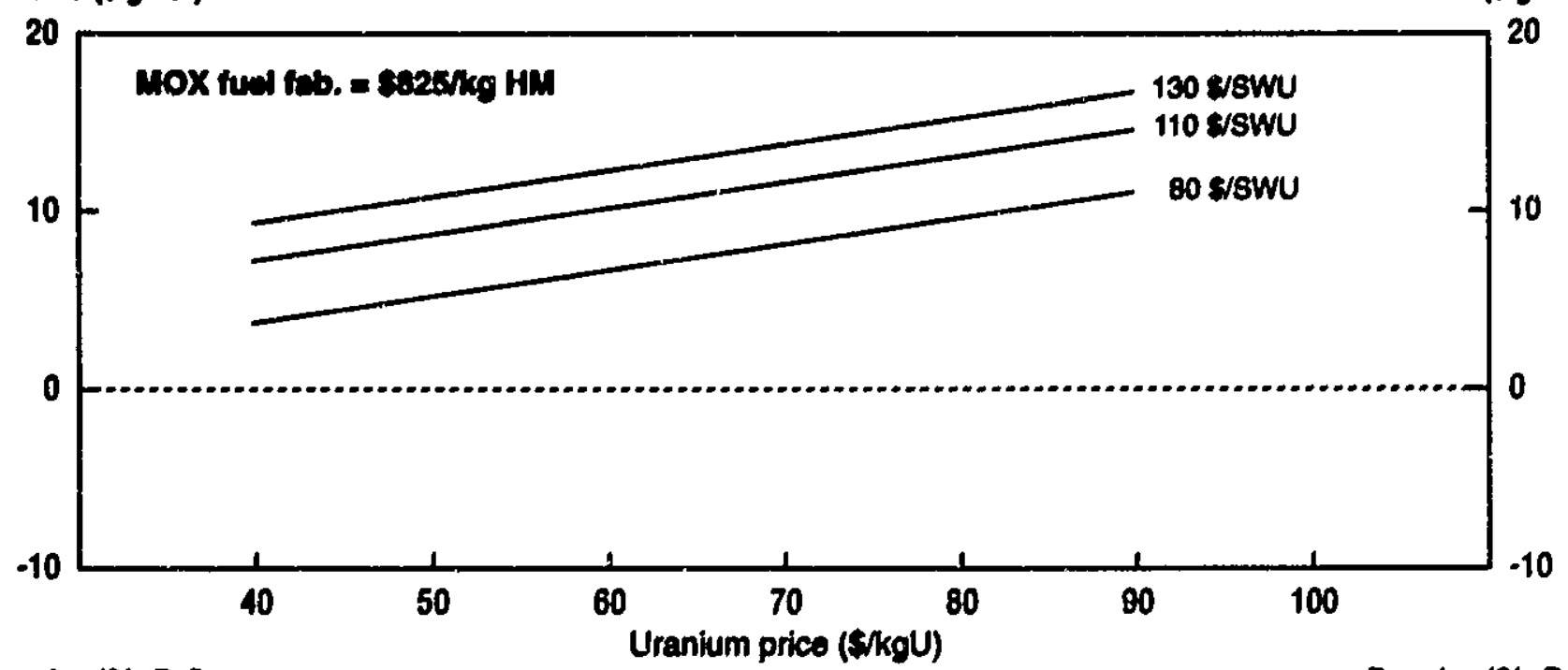

Pu valuo (E/g PUI)

Puvalue ( $(E / g$ Puf)

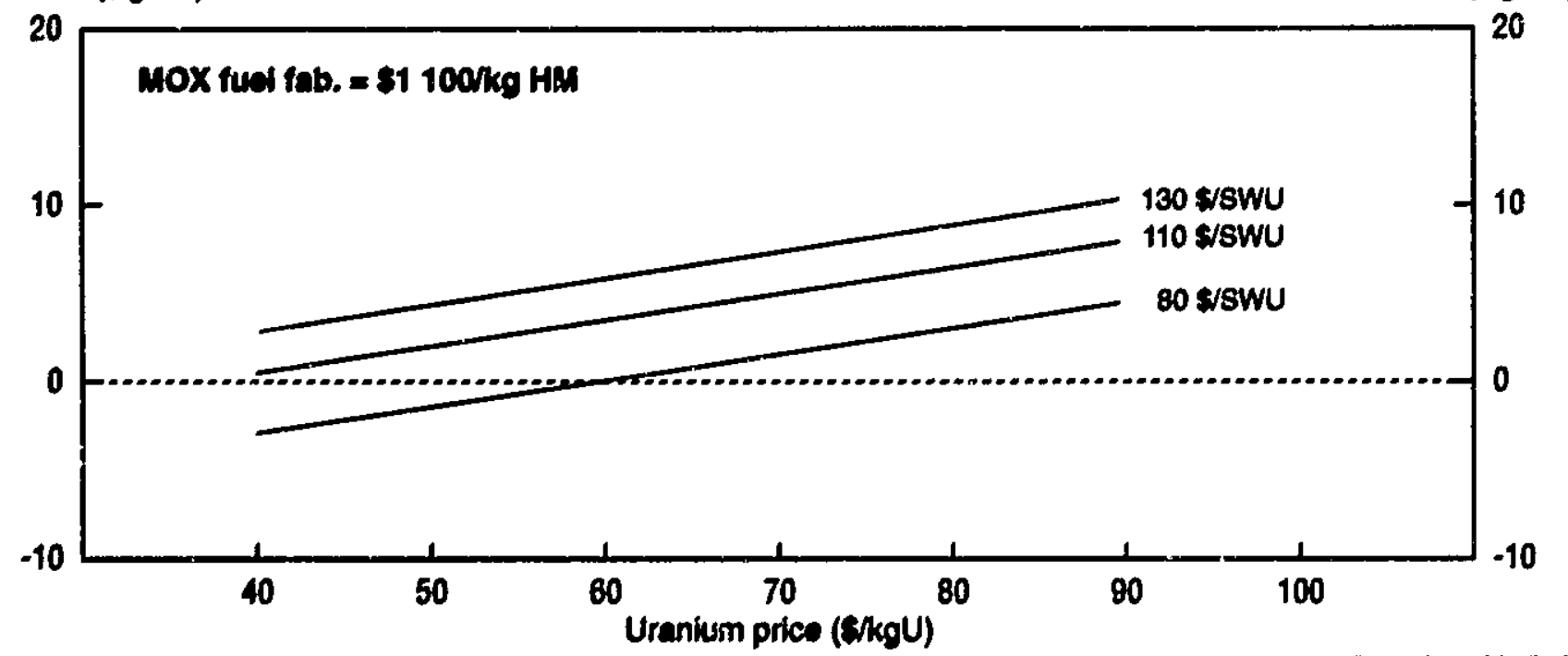

Pu velue (E/g PuA)

Pu valuo (\$/g Puf)

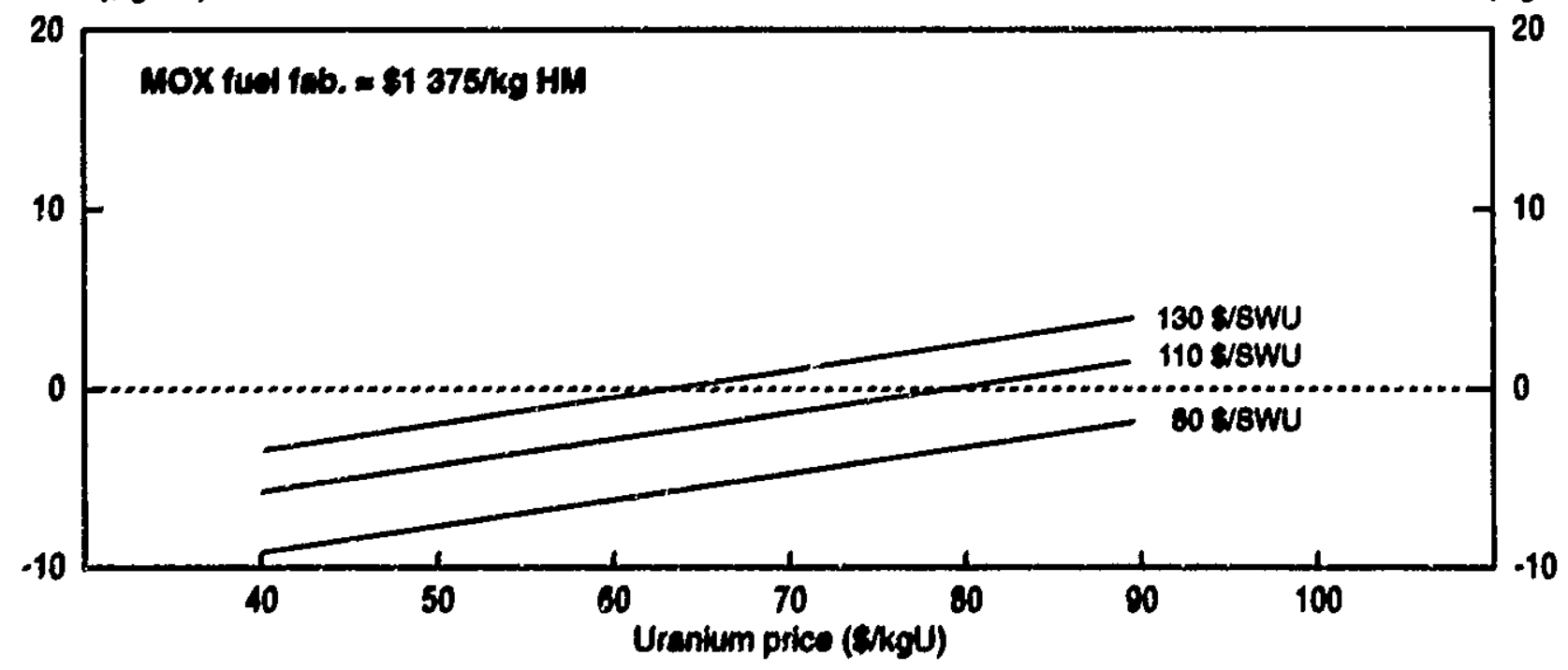


Figure 8.3 8enaltuity of plutonkum indifterence valus to enriahment price and MOX fuel febrication prioe

Pu valus (S/g Pu)

Pu valus (\$V Pun)

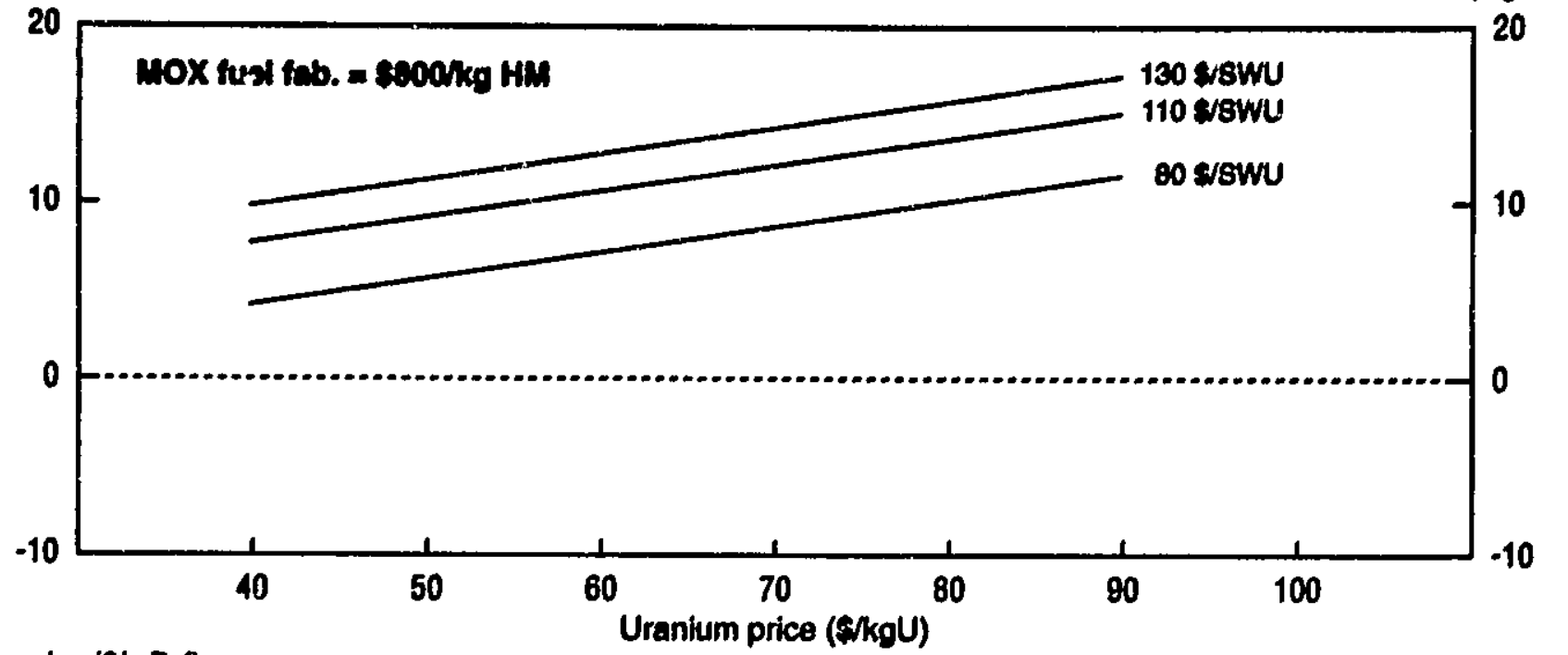

Pu value (\$/g PuH)

Pu valua (E/g Puf)

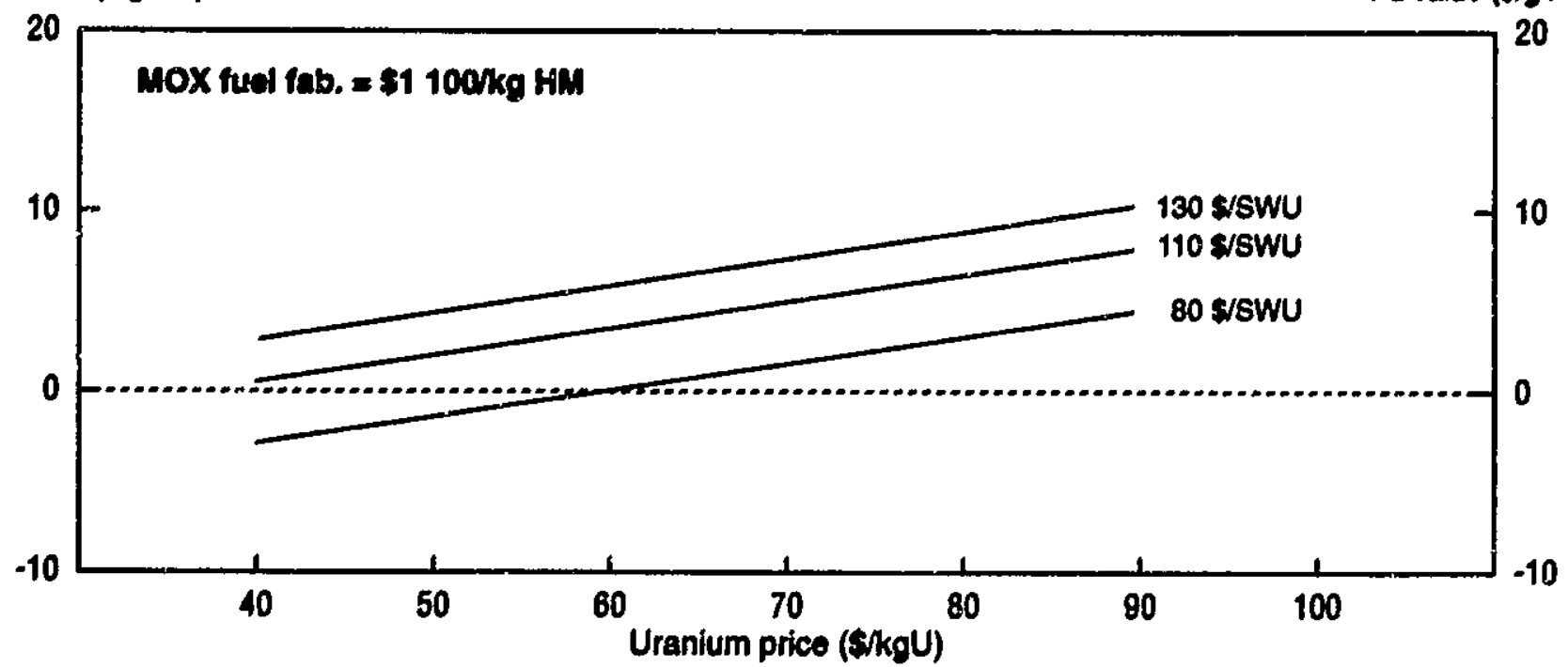

Pu value (E/g Pul)

Pu valuo (\$g Puf)

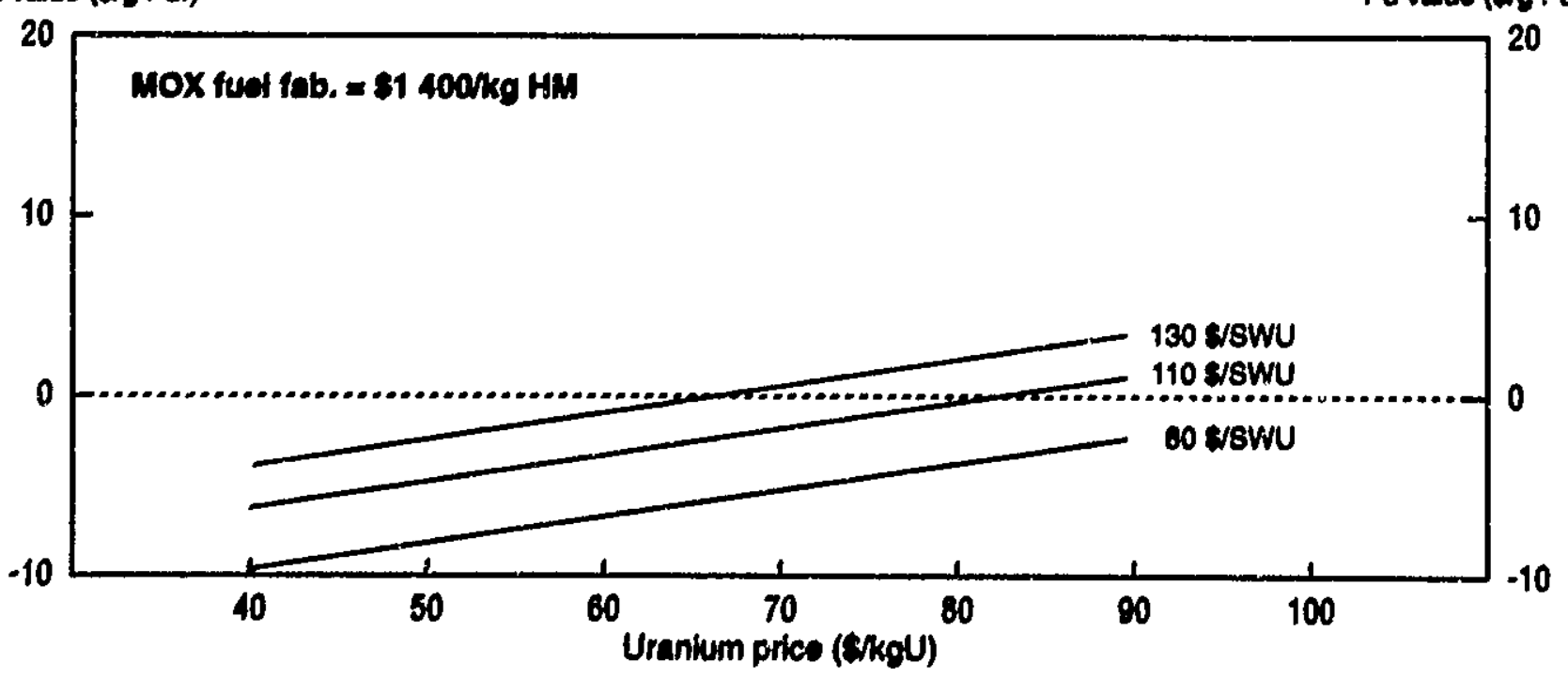


Annex 9

\section{NUCLEAR FUEL CYCLE COSTS VERSUS BURN-UP}

\section{Introduction}

Over the past decade the discharge irradiation level (burn-up) of PWR and BWR fuel has increased steadily. This development is mainly attributable to the increased economic benefit that is associated with higher fuel burn-up. This benefit comes from the reduced throughput of fuel that results from higher burn-up. This is particularly noticeable in the costs for fuel fabrication and back-end services where the price paid relates to a unit mass of fuel. As a result the adoption of higher burn-up has resulted in substantial savings in fuel cycle costs. The question of the economic potential of moving to even higher burn-ups beyond the present range is of great interest.

\section{Base estimates and input data}

The economic evaluation of increasing the burn-up of uranium fuel was addressed by an IAEA multinational study called Water Reactor Extended Burn-up Study (WREBUS) ${ }^{(11)}$ which was performed in 1990-91. Eight countries (Belgium, France, Czechoslovakia, USSR, Germany, Korea, UK and US) provided contributions. In this study, a broad range of technical boundary conditions, i.e. reactor type (PWR, BWR), power output (440 MWe to $1300 \mathrm{MWe}$ ) and cycle length (12 to 24 months cycles), was considered.

All the WREBUS fuel cycle cost calculations were carried out in 1991 money values and related to the unit cost of a reload once the equilibrium fuel cycle had been obtained. The fuel cycle was based on reprocessing as the spent fuel management option but credits for the recovered plutonium and uranium were not considered for reasons of simplicity.

The burn-up range of interest was from $40 \mathrm{MWd}$ per $\mathrm{kg} \mathrm{U}$ up to $60 \mathrm{MWd}$ per $\mathrm{kg} \mathrm{U}$. This was considered to cover a set of values which should be technically attainable although no detailed technical cases were in existence to support the upper end of the range. Undoubtedly, research and development work would be needed and the costs of this would need to be taken into account in practice.

\section{Comparative fuel costs}

In this annex, the economic effect of increased burn-up has been evaluated by using the reference prices from this present study (see Table 9.1) and applying them to the technical spectrum of cases (with the exception of VVER reactors) that were used in the WREBUS study. This resulted in the range of fuel cycle costs which is shown in Figure 9.1. For comparison, the fuel cycle cost for the reprocessing reference case from the current study is shown within the range derived using the WREBUS technical data. 
Table 9.1. Economic input data

(reference)

\begin{tabular}{||l|c||}
\hline Uranium purchase & $\begin{array}{c}\$ 50 / \mathrm{kg} \mathrm{U} \text { (in 1990) } \\
\text { escalation 1.2\% p.a. }\end{array}$ \\
Conversion & $\$ 8 / \mathrm{kg} \mathrm{U}$ \\
Enrichment & $\$ 110 / \mathrm{SWU}$ \\
Fabrication & $\$ 275 / \mathrm{kg} \mathrm{U}$ \\
S.F. transport & ECU 50/kg U \\
Reprocessing & ECU 720/kg U \\
VHLW disposal & ECU 90/kg U \\
Discount rate & $5 \%$ p.a. \\
Tails assay & $0.25 \%$ \\
\hline
\end{tabular}

Figure 9.1 shows that, for the whole spectrum of reactor types and operating conditions considered, no minimum fuel cycle cost was found within the burn-up range considered, i.e. within this burn-up range, it appears desirable to go to the highest technically possible burn-up.

\section{Variation of economic input data}

The results of the calculations are sensitive to the variation of the economic input data. The parameters having the greatest influence are the prices for back-end services and the discount rate, the former being the more important.

Increasing the burn-up of the fuel leads to a reduction in the quantity of fuel used for a given amount of electricity produced. Regardless of whether the reprocessing or direct disposal option is chosen, the effect on the unit fuel cost of any increase in the price for back-end services can be reduced by increasing the fuel burn-up. The effect may not be so great for the direct disposal option where storage, encapsulation and disposal prices will be geared to the overall fuel quantity to be managed. This is not the case with reprocessing where a competitive market exists and prices are quoted per unit mass of fuel to be reprocessed.

\section{The economic effect of cycle length}

Comparisons of the economics of different cycle lengths depend on a number of factors which are not specifically related to nuclear fuel cycle costs (less shut-down time, fewer refuelings, replacement power costs, etc.). Nevertheless, it can be deduced, from a rather complex comparison which was made for the WREBUS study, that longer cycles tend to shift the economic optimum to higher burn-up values.

\section{MOX fuel}

As discussed above, for uranium fuel, disposal costs related to the amount of heavy metal to be disposed can strongly influence fuel cycle costs as a function of the discharge burn-up. Therefore, the resulting reduction in the fuel cycle costs is more distinct with higher values of specific disposal costs. 
In a similar way, fuel fabrication costs can influence fuel cycle costs. As a result, high specific fabrication costs, leading to fuel cycle costs with a high share of cost components which are strongly influenced by the energy worth of the fuel, as is the case with MOX fuel, cause significant decreases of fuel cycle costs when the burn-up is extended. This relationship is qualitatively shown in Figure 9.2 which compares uranium and MOX fuel cycle costs assuming constant fabrication costs for each type of fuel.

Taking into consideration the dependence of fuel fabrication costs on the fuel burn-up or the initial fuel enrichment (e.g. additional shielding required for MOX fuel fabrication), according to current information, the economic effects which are shown in Figure 9.2 would not significantly change.

\section{Conclusions}

Based on the above discussion, the following can be derived:

- Given the reference set of economic input data (as shown in Table 9.1) no minimum fuel cycle cost was found for burn-up values up to $60 \mathrm{MWd} / \mathrm{kg} \mathrm{U}$. It is to be noticed that even small improvements in fuel cycle costs can result in considerable yearly savings for nuclear power plants (for example, 0.1 mills/kWh equals to approximately 1 million dollars per year for a $1300 \mathrm{MWe}$ plant).

- The most important parameters contributing to fuel cycle cost benefits from burn-up extensions are the back-end costs and the discount rate, with back-end costs being much more important than the discount rate.

- The sensitivity of the results, and in particular the derivation of a minimum value of fuel cycle costs, is due to the interaction between back-end costs and the range of variation of the other economic input parameters which are primarily affecting fuel cycle costs. Thus, for example, the discount rate may have a significant effect on deriving the minimum value of the fuel cycle costs as a function of burn-up if back-end costs are related to the generated electricity rather than to the quantity of fuel.

- With regard to MOX fuel, an additional economic incentive for burn-up extensions results from the considerably higher share of fuel fabrication costs to the total fuel cycle costs. The quantitative impact of this economic effect on the total fuel cycle costs depends partially on the percentage of MOX fuel assemblies of the reload.

- In PWR plants, especially those operating at high coolant outlet temperatures and utilising zircaloy fuel cladding, water corrosion has been a limiting problem. Recent developments of new cladding materials (e.g. duplex cladding) enables a shifting of the cladding corrosion limit to substantially higher burn-ups in the future. 
Figure 9.1 Fuel cycle cost results for reference economic input data and a range of technical characteristics

(WREBUS study)

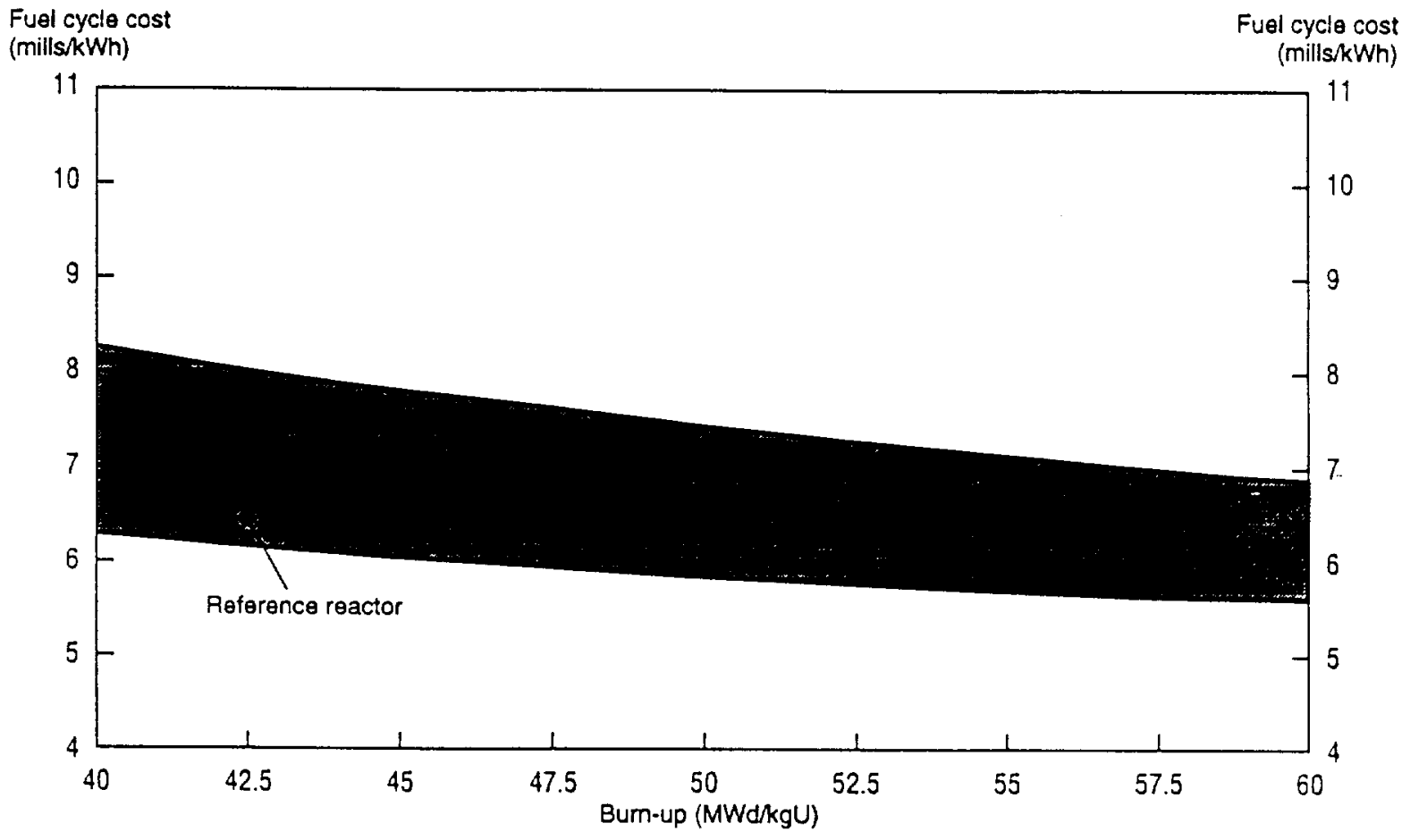

Figure 9.2 Comparison of $U$ and MOX fuel assemblies

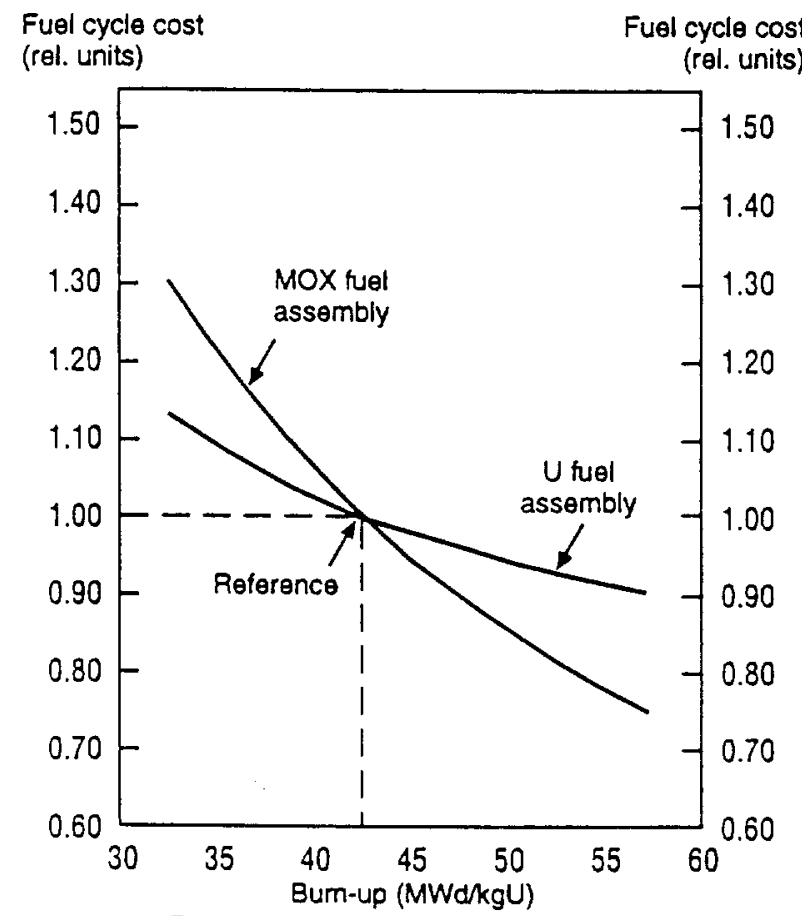

Fuel cycle costs as a function of bum-up

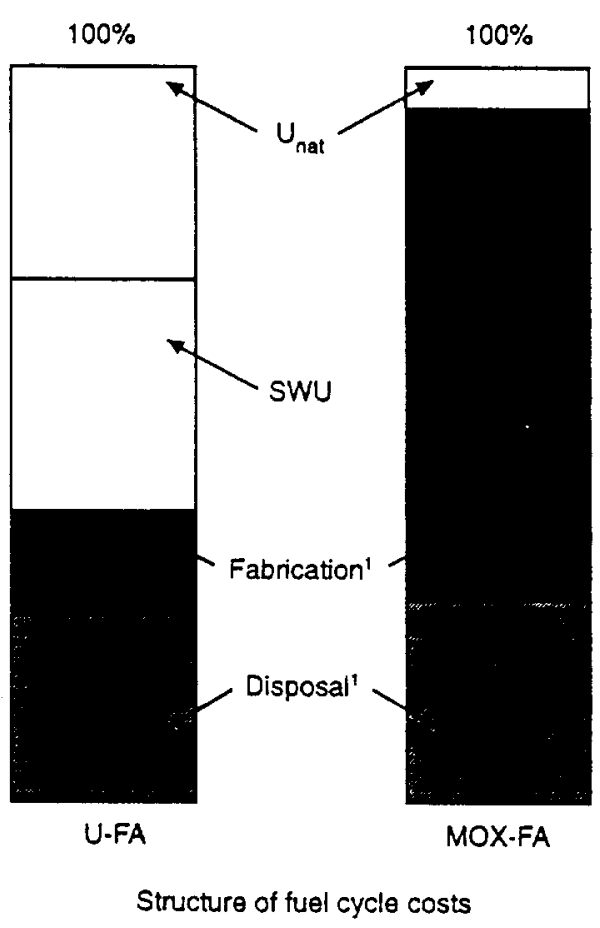

1. Cost components strongly influenced by energy production. 
Annex 10

\section{SENSITIVITY ANALYSIS ON ESTIMATED FUEL CYCLE COST}

Parametric calculations have been carried out for fuel cycle cost components in order to estimate the effect of probable price changes. These calculations were performed, for reasons of simplicity, for the reference cases of each option assuming that costs of the main components vary from -50 per cent to +100 per cent. The following main components have been identified as the influential factors of total fuel cycle costs: uranium purchase, enrichment, fabrication and reprocessing for the reprocessing option and uranium purchase, enrichment, fabrication, spent fuel transport/storage and spent fuel encapsulation/disposal for the direct disposal option.

The effects of varying the main unit costs for the reprocessing and direct disposal options are shown in Figures 10.1 and 10.2, respectively. It is clear that the enrichment cost is the most sensitive component for both options. Varying the enrichment unit cost from -50 per cent to +100 per cent (corresponding to varying costs from $\$ 55$ per SWU to $\$ 220$ per SWU) leads to total fuel cycle costs deviations from the reference values from -15 per cent to +29 per cent for the reprocessing option and from -17 per cent to +34 per cent for the direct disposal option. Nearly equal importance on the reprocessing option total cost has also the reprocessing unit cost.

The fabrication unit cost for the reprocessing option and the spent fuel encapsulation/disposal unit cost for the direct disposal option are the less sensitive unit components of total fuel cycle costs. 
Figure 10.1 Effect of parameter on reprocessing fuel cycle costs

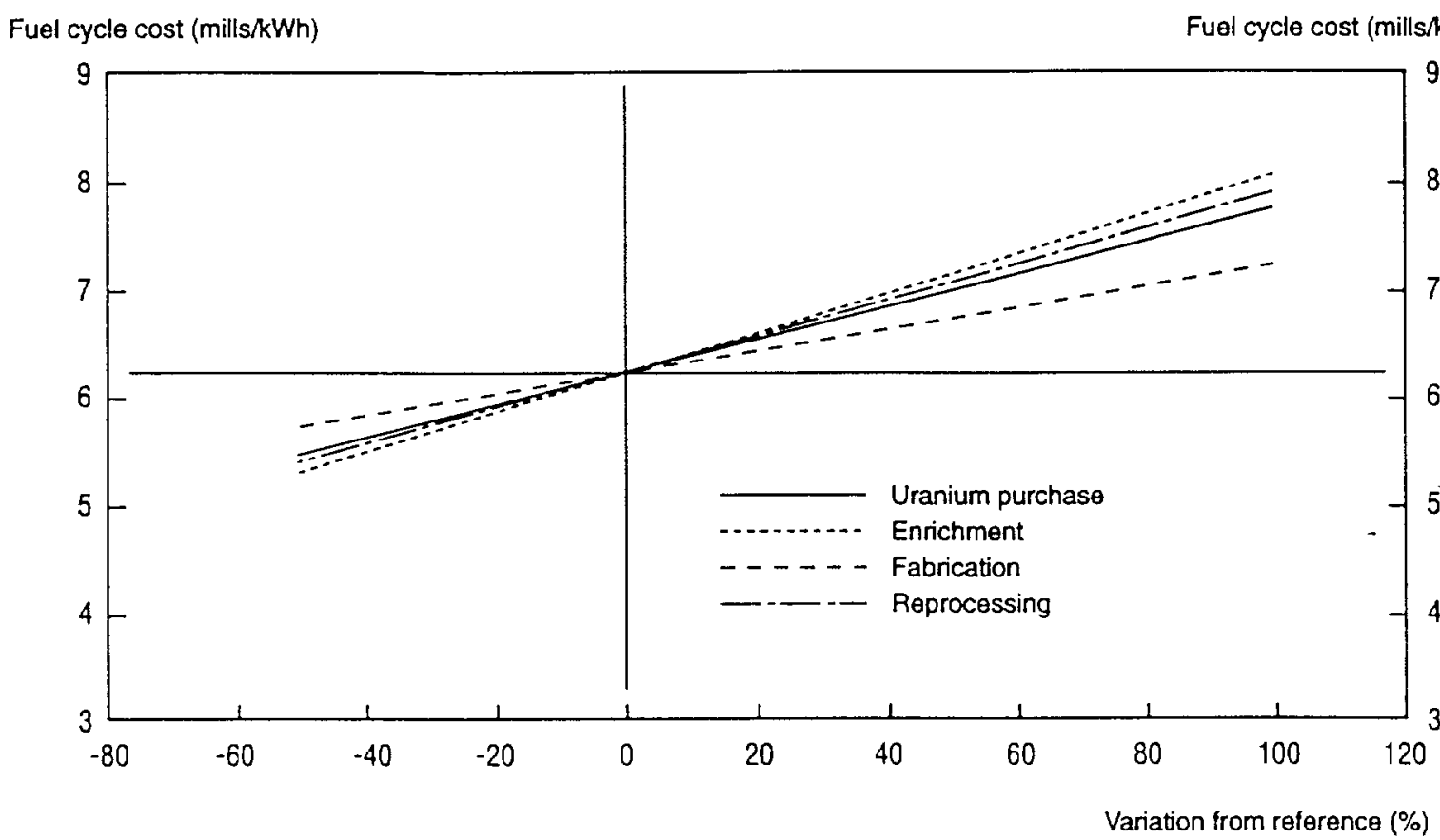

Figure 10.2 Effect of parameter on direct disposal fuel cycle costs

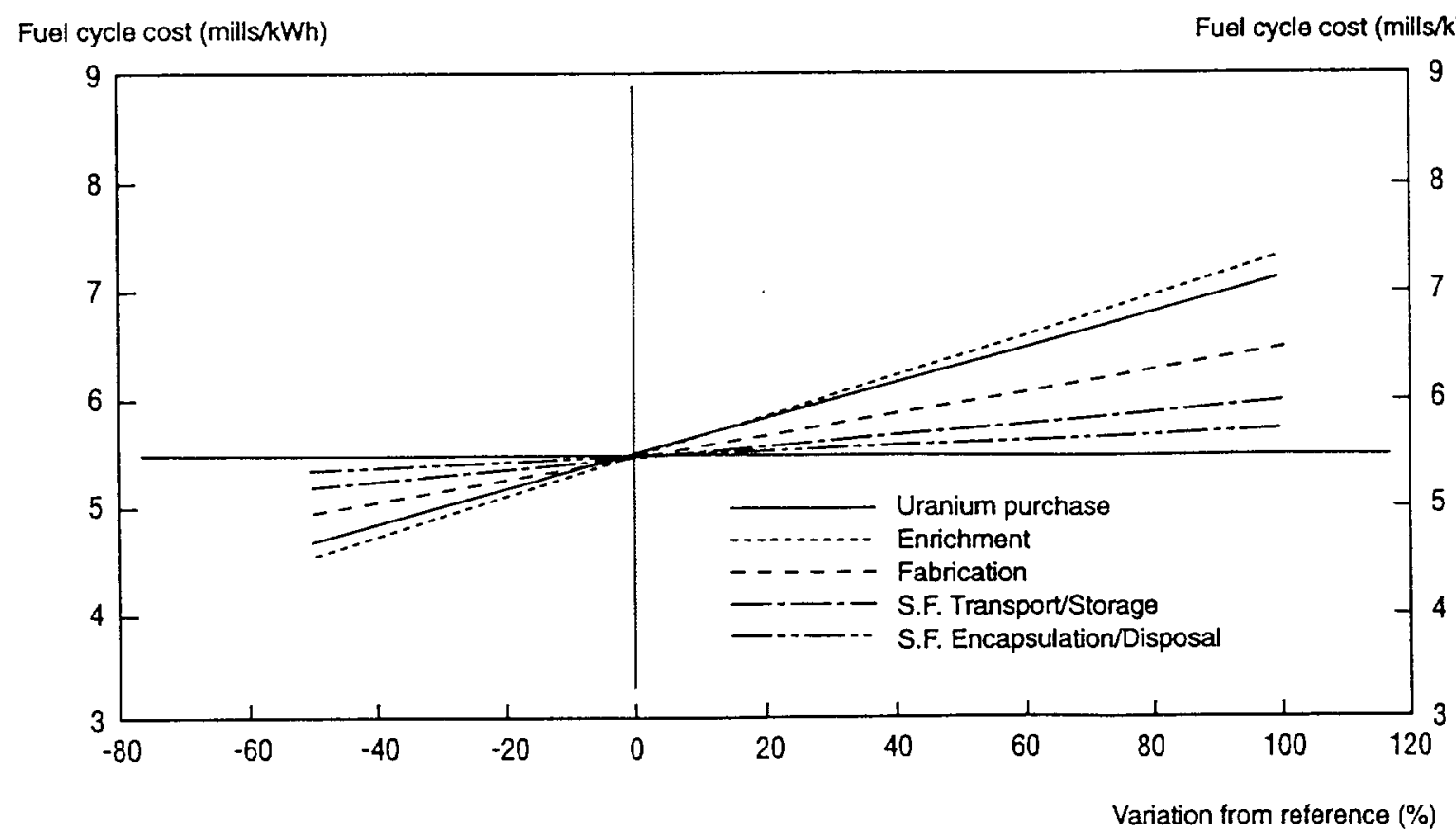


Annex 11

\section{LIST OF ABBREVIATIONS, UNITS AND GLOSSARY OF TERMS}

\section{AGR}

British Advanced Gas-Cooled Reactor.

ATR

Japanese Advanced Thermal Reactor.

\section{Back-end (of the fuel cycle)}

Those nuclear fuel cycle processes and activities concerned with the treatment of spent fuel discharged from reactors including disposal of radioactive wastes.

BNFL

British Nuclear Fuels plc.

\section{Burn-up}

The total energy released per unit mass of a nuclear fuel; it is commonly expressed in mega- or gigawatt-days per tonne (MWd/t or $\mathrm{GWd} / \mathrm{t})$.

\section{BWR}

Boiling Water Reactor.

\section{CANDU}

Canadian Deuterium Uranium Reactor; a type of heavy water reactor.

\section{CLAB}

Swedish Intermediate Storage Facility.

\section{Cladding}

An external layer of material applied directly to nuclear fuel or other material that provides protection from a chemically reactive environment and containment of radioactive products produced during the irradiation of the composite. It may also provide structural support.

\section{COGEMA}

Compagnie Générale des Matières Nucléaires (France).

\section{Conversion}

The operation of altering the chemical form of a nuclear material to a form suitable for its end use.

\section{Decommissioning}

The work required for the planned permanent retirement of a plant from active service.

\section{Direct disposal}


Fuel cycle in which fuel goes through the reactor once; no spent fuel reprocessing is foreseen.

\section{DM}

German Mark.

DOE

US Department of Energy.

\section{Discounting}

A procedure used to convert the value of money earned or spent in the future to a present value.

\section{ECU}

European Currency Unit.

\section{Encapsulation}

Processes associated with preparation of spent fuel for disposal.

\section{Enrichment}

i) The fraction of atoms of a specified isotope in a mixture of isotopes of the same element when this fraction exceeds that in the naturally occurring mixture;

ii) Any process by which the content of a specified isotope (uranium-235, etc.) in an element is increased.

\section{Fabrication}

The process of preparing nuclear fuel pellets, and cladding them to make fuel elements and the incorporation of elements into assemblies ready for the reactor.

\section{Fission}

The physical process whereby the nucleus of a heavy atom is split into two (or, rarely, more) nuclei with masses of equal order of magnitude whose total mass is less than that of the original nucleus.

\section{Fission products}

Nuclides produced either by fission or by the subsequent radioactive decay of the nuclides thus formed.

\section{Front-end (of the fuel cycle)}

Those nuclear fuel cycle processes and activities concerned with the production of fuel for a reactor.

\section{Fuel (nuclear)}

Material containing fissile nuclides which, when placed in a reactor, enables a self-sustaining nuclear chain to be achieved. 


\section{Fuel cycle}

The sequence of processing, manufacturing and transportation steps involved in producing fuel for a reactor, and in processing fuel discharged from the reactor including disposal of radioactive wastes.

g

Gram.

\section{GWe}

Gigawatt electric.

\section{Half-life (radioactive)}

For a single radioactive decay process, the time required for the activity to decrease to half its value by that process.

\section{HLW}

High Level Waste.

HM

Heavy Metal (uranium, plutonium and other actinides in spent fuel).

\section{IAEA}

International Atomic Energy Agency.

\section{IEA}

International Energy Agency.

\section{ILW}

Intermediate Level Waste.

\section{Indifference value (of plutonium)}

This is the value that plutonium would have in order to produce MOX fuel and equivalent uranium oxide fuel at equal cost.

\section{Isotopes}

Nuclides having the same atomic number (i.e. identical chemical element) but different mass numbers.

kg

Kilogram.

\section{kWh}

Kilowatt hour.

I

Litre.

lb

Pound. 


\section{Levelised cost}

Levelised cost spreads total fuel cycle cost over total output to arrive at a figure which, if charged for each $\mathrm{kWh}$, would exactly balance costs and income.

\section{LLW}

Low Level Waste.

\section{Load factor}

A ratio of the energy that is produced by a facility during the period considered to the energy that it could have produced at maximum capacity under continuous operation during the whole of that period.

\section{LWR}

Light Water Reactor.

m

Meter.

M

Million.

\section{MOX fuel}

Mixed Oxide (uranium dioxide and plutonium dioxide) fuel.

mv

Money value.

\section{$\mathbf{M W d} / \mathbf{t}$}

Megawatt-day per tonne.

MWe

Megawatt electric.

MWt

Megawatt thermal.

NEA

OECD Nuclear Energy Agency.

NEA/NDC

Committee for Technical and Economic Studies on Nuclear Energy Development and the Fuel Cycle of the Nuclear Energy Agency.

\section{OECD}

Organisation for Economic Co-Operation and Development.

p.a.

Per annum. 
PNC

Power Reactor and Nuclear Fuel Development Corporation (Japan).

Pu

Plutonium.

Puf

Plutonium fissile.

$\operatorname{Pu}(\mathbf{t})$

All isotopes of plutonium, not only fissile.

PWR

Pressurised Water Reactor.

$\mathbf{R} \& \mathbf{D}$

Research and Development.

Reprocessing

A generic term for the chemical and mechanical processes applied to fuel elements discharged from a nuclear reactor. The purpose is to remove fission products and recover fissile (e.g. uranium-235, plutonium-239), fertile (e.g. uranium-238) and other valuable material.

\section{SKr}

Swedish Krone.

S.F.

Spent Fuel.

SKB

Swedish Nuclear Fuel and Waste Management Company.

Spent fuel

Nuclear fuel removed from a reactor following irradiation.

SWU

Separative Work Units, a measure of the effort required to enrich a material in a given isotope.

$\mathbf{t}$

Tonne.

THORP

Thermal Oxide Reprocessing Plant (UK).

$\mathbf{U}$

Uranium. 


\section{Waste management}

All activities that are involved in the handling, treatment, conditioning, transportation, storage and disposal of waste.

\section{WREBUS}

Water Reactor Extended Burn-up Study (IAEA).

\section{US mill}

A unit of currency. One tenth of a US cent (US\$0.001).

\section{VHLW}

Vitrified High Level Waste.

\section{Waste repository}

Prepared geological site suitable for permanent disposal of radioactive waste.

$\mathbf{y}$

$$
\text { Year. }
$$


Annex 12

\section{LIST OF MEMBERS OF THE EXPERT GROUP}

AUSTRALIA

Dr. G. DURANCE

Mr. B. JONES

\section{BELGIUM}

Mr. P. HAUBERT

\section{CANADA}

Mr. A. YU

FINLAND

Mr. I. MIKKOLA

\section{FRANCE}

Mr. J-M. CAPRON

Mr. J-G. DEVEZEAUX DE LAVERGNE

Mr. E. MIGNOT

Mr. B. SICARD

\section{GERMANY}

Mr. H. KEESE

NUKEM GmbH

Mr. W. SCHRICKER

\section{ITALY}

Mr. O. COMELLINI

l'Energia e l'Ambiente

\section{JAPAN}

Mr. K. ARATANI

Mr. H. MORI

Mr. I. TAKEGURO

Mr. K. USAMI

\section{NETHERLANDS}

Mr. P. J. VAN DER HULST

Ir. G.C. VAN UITERT

SPAIN

Mr. E. DELGADO
Australian High Commission, London

Australian Delegation to the OECD

\section{SYNATOM}

Atomic Energy of Canada Ltd.

Teollisuuden Voima Power Co.

Commissariat à l'Energie Atomique COGEMA

Electricité de France

Commissariat à l'Energie Atomique

Ente per le Nuove Tecnologie,

Power Reactor \& Nuclear Fuel Development Corp. Power Reactor \& NUclear Fuel Development Corp.

Tokyo Electric Power Company

Tokyo Electric Power Company

GKN Dodewaard

Ministry of Economic Affairs

Empresa Nacional del Uranio, S.A. 
Mr. L. GONZALEZ GOMEZ

Mr.

Empresa Nacional del Uranio, S.A.

\section{SWEDEN}

Mr. I. LINDHOLM

SWITZERLAND

Mr. R. STAPPER

Dr. P. ZUEHLKE

UNITED KINGDOM

Miss T. BRYDON

Mr. D.J. GROOM (Chairman)

Mr. M. HYLAND

Mr. R. KING

Mr. J. SHEPHERD

Mr. D.I. THOMAS

UNITED STATES

Dr. J.C. BRESEE

Dr. C.E. WEBER

IAEA

Mrs. E. BERTEL

Dr. N. OI

Mr. J.L. ROJAS

Mr. G. WOITE

IEA

Mr. S. FOSTER

EC

Dr. A. DECRESSIN

OECD/NEA

Mr. G.H. STEVENS

Mr. K. TODANI (Scientific Secretary)

Dr. N. ZARIMPAS (Scientific Secretary)
Empresa Nacional de Residuos Radiactivos, S.A. R . J I M I N E Z - S H A W

Swedish Nuclear Fuel \& Waste Management Co.

Elektrizitätsgesellschaft Laufenburg AG

Schweizerische Vereinigung für Atomenergie

Nuclear Electric plc.

Nuclear Electric plc.

UK Atomic Energy Authority

UK Atomic Energy Authority

UK Atomic Energy Authority

British Nuclear Fuels plc.

Department of Energy

Department of Energy

Nuclear Power Division

Nuclear Fuel Cycle \& Waste Management Division

Nuclear Fuel Cycle \& Waste Management Division

Nuclear Power Division

Alternative Energy Sources Division

Directorate General XVII

Head, Nuclear Development Division

Nuclear Development Division

Nuclear Development Division 


\section{LIST OF MEMBERS OF THE EDITORIAL REVIEW GROUP}

The final draft of this report was reviewed by an editorial group. The members of this group were:

Mr. K. ARATANI (Japan)

Dr. J.C. BRESEE (United States)

Miss T. BRYDON (United Kingdom)

Mr. J-G. DEVEZEAUX DE LAVERGNE (France)

Mr. R. DODDS (BNFL, United Kingdom)

Mr. D.J. GROOM (United Kingdom) (Chairman)

Mr. I. LINDHOLM (Sweden)

Mr. F. YONEDA (PNC, Japan)

Dr. N. ZARIMPAS (Scientific Secretary) 